Mario Luiz Marques Conti

\title{
Tratamento endovascular das malformações arteriovenosas raquimedulares : resultados clínicos e angiográficos
}

Tese apresentada à Faculdade de Medicina da Universidade de São Paulo para obtenção do título de Doutor em Ciências

Área de concentração: Radiologia

Orientador: Dr. José Guilherme Mendes Pereira Caldas

São Paulo

2005 


\section{FICHA CATALOGRÁFICA}

Preparada pela Biblioteca da

Faculdade de Medicina da Universidade de São Paulo

Creprodução autorizada pelo autor

\section{Conti, Mario Luiz Marques}

Tratamento endovascular das malformações arteriovenosas raquimedulares : resultados clínicos e angiográficos / Mario Luiz Marques Conti. -- São Paulo, 2005.

Tese(doutorado)--Faculdade de Medicina da Universidade de São Paulo. Departamento de Radiologia.

Área de concentração: Radiologia.

Orientador: José Guilherme Mendes Pereira Caldas.

Descritores: 1.DOENÇAS VASCULARES DA MEDULA ESPINHAL 2.MALFORMAČ̃OES ARTERIOVENOSAS 3.MALFORMAÇÕES VASCULARES DO SISTEMA NERVOSO CENTRAL 4.EMBOLIZAÇÃO TERAPÊUTICA 5.RADIOLOGIA INTERVENCIONISTA 
DEDICATÓRIA 
Aos meus pais, Mario e Eneida, que através da sua esmerada educação me tornaram capaz de enfrentar e superar as dificuldades que a vida nos impõe diariamente

À minha esposa, Cristina, que desde quando nos conhecemos sempre me apoiou, incentivou e confortou

Às minhas filhas, Luiza e Carolina, que com sua alegria me estimulam mesmo nos momentos mais difíceis 
AGRADECIMENTOS 
Ao meu orientador, Prof. Dr. José Guilherme Mendes Pereira Caldas, que, através do seu exemplo de dedicação ao estudo e ensino da Neurorradiologia Intervencionista, estimula o aprimoramento contínuo daqueles que o cercam.

Ao Prof. Dr. José Carlos Esteves Veiga, chefe do Serviço de Neurocirurgia da Santa Casa de São Paulo, pela minha formação em Neurocirurgia e incentivo no aprimoramento acadêmico.

Ao Prof. Dr. Rui Raul Dahas de Carvalho, pelos ensinamentos médicos, éticos e morais transmitidos ao longo da Residência Médica e no início da minha vida profissional.

Ao Dr. Antero Costa Filho, pelos ensinamentos durante minha formação neurocirúrgica e pelas fotos de sua Dissertação de Mestrado cedidas para a ilustração deste trabalho.

Aos meus colegas trabalho, Dárcio Roberto Nalli, Michel Eli Frudit, Paulo Puglia Júnior e Francisco Ramos Júnior, que auxiliaram no tratamento dos pacientes deste estudo.

Ao Dr. Jefferson Walter Daniel, pela dedicação na minha formação neurocirúrgica e pela colaboração na realização do resumo na língua inglesa.

Aos estagiários e ex-estágiarios de Neurorradiologia Intervencionista dos Institutos do Coração e de Radiologia da Faculdade de Medicina da Universidade de São Paulo, que colaboraram direta ou indiretamente no seguimento dos pacientes deste estudo.

Aos Drs. Nelson Saade e Bechara Mattar Neto, com quem desde a Residência Médica convivo diariamente de maneira fraterna e amistosa, tanto no exercício profissional como nas horas de folga. 
Aos Assistentes do Serviço de Neurocirurgia da Santa Casa de São Paulo, que me substituíram e assumiram responsabilidades para que eu me dedicasse à realização deste estudo.

Aos funcionários das Bibliotecas das Faculdades de Medicina da Universidade de São Paulo, Ciências Médicas da Santa Casa de São Paulo e BIREME, que sempre se mostraram atenciosos e prestativos.

A Irony Therezinha Pires, pelas magníficas ilustrações criadas para tornar mais claro este trabalho.

A Laís de Almeida Cardoso, pela atenção conferida á revisão ortográfica e gramatical do texto final desse trabalho.

A Creuza Dal Bó, pela presteza na análise estatística do material de estudo.

A Sandra Pacheco de Barros, secretária da Pós-Graduação do Instituto de Radiologia da Universidade de São Paulo, pelo apoio na realização deste trabalho. 
Esta tese está de acordo com:

Referências: adaptado de International Committee of Medical Journals Editors (Vancouver)

Universidade de São Paulo. Faculdade de Medicina. Serviço de Biblioteca e Documentação. Guia de apresentação de dissertações, teses e monografias. Elaborado por Anneliese Carneiro da Cunha, Maria Julia de A. L. Freddi, Maria F. Crestana, Marinalva de Souza Aragão, Suely Campos Cardoso, Valéria Vilhena. São Paulo: Serviço de Biblioteca e Documentação; 2004.

Abreviaturas dos títulos dos periódicos de acordo com List of Journals Indexed in Index Medicus. 


\section{Sumário}

Lista de Abreviaturas .........................................................................

Lista de Tabelas.......................................................................

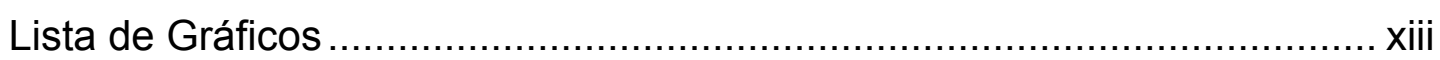

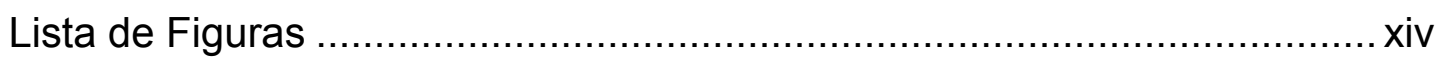

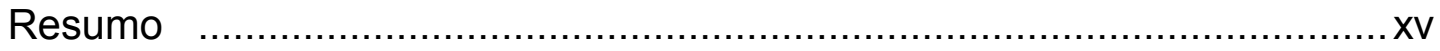

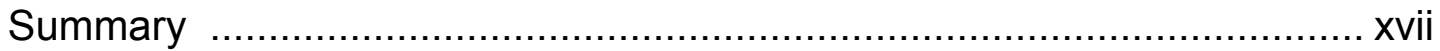

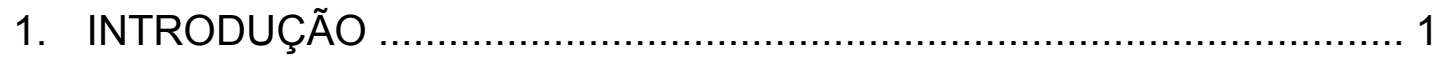

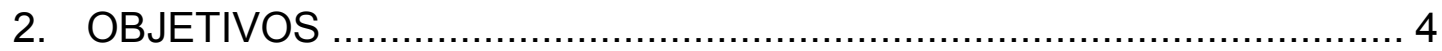

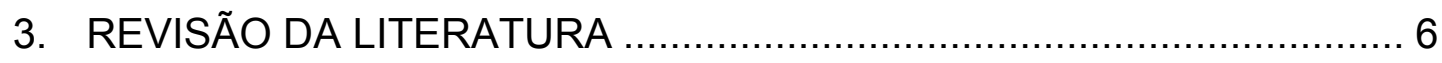

3.1 Histórico............................................................................ 7

3.2 Anatomia Vascular Raquimedular .................................. 11

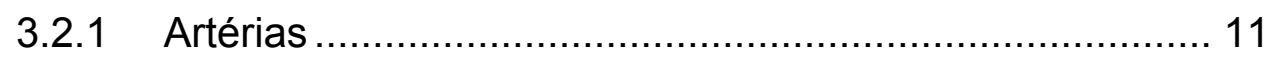

3.2.2 Veias ............................................................... 20

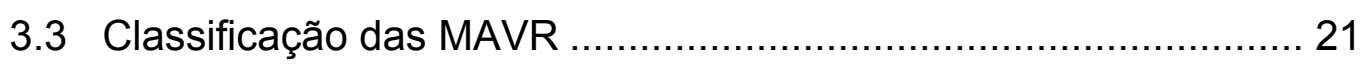

3.4 MAVR tipo I ..................................................................... 27

3.4.1 Aspectos Anatômicos .............................................. 27

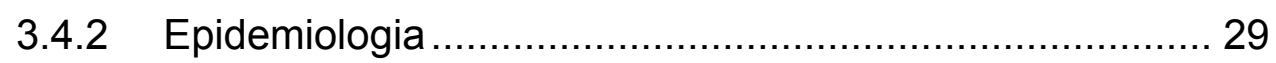

3.4.3 Fisiopatologia ................................................. 30

3.4.4 Anatomia Patológica............................................. 31

3.4 .5 Sintomatologia ............................................... 32

3.4.6 História Natural................................................... 35

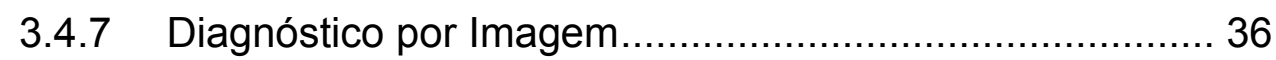

3.4.8 Tratamento ............................................................. 41

3.5 MAVR tipo II ................................................................... 46

3.5.1 Aspectos Anatômicos ............................................. 46

3.5.2 Epidemiologia .................................................... 46

3.5.3 Fisiopatologia ................................................... 47

3.5.4 Anatomia Patológica............................................ 49

3.5 .5 Sintomatologia .................................................. 49

3.5.6 História Natural..................................................... 49

3.5.7 Diagnóstico por Imagem......................................... 51

3.5.8 Tratamento ......................................................... 53 


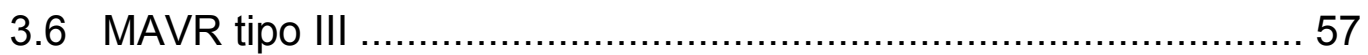

3.6.1 Aspectos Anatômicos ............................................ 57

3.6.2 Epidemiologia ................................................ 58

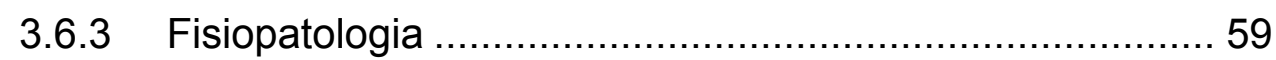

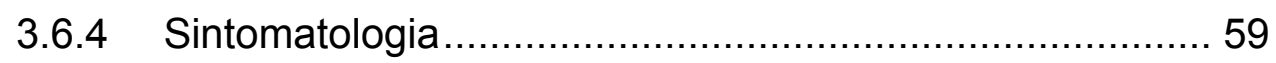

3.6.5 História Natural ................................................. 60

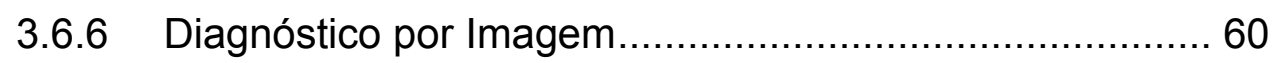

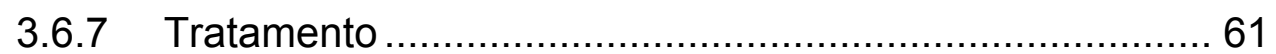

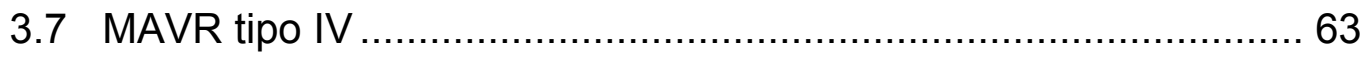

3.7.1 Aspectos Anatômicos .................................................. 63

3.7.2 Epidemiologia ................................................. 64

3.7.3 Fisiopatologia ................................................. 65

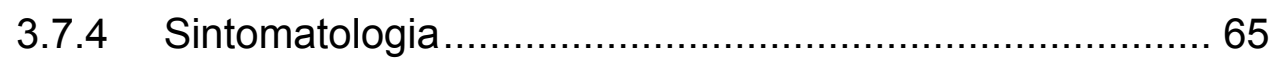

3.7.5 História Natural.................................................... 66

3.7.6 Diagnóstico por Imagem........................................ 66

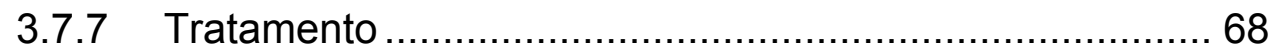

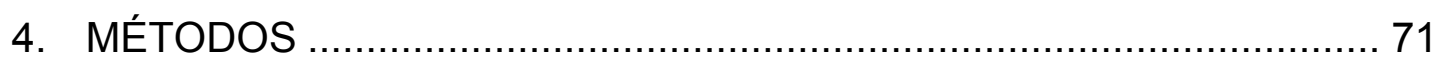

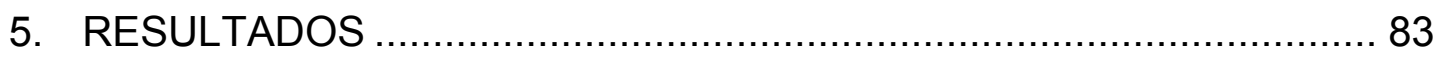

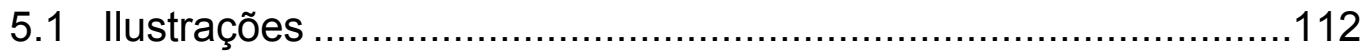

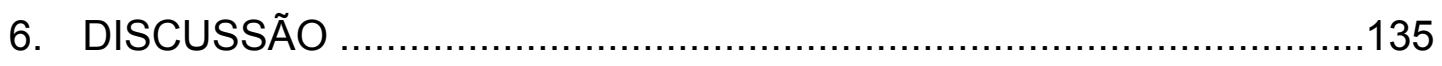

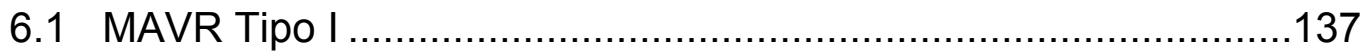

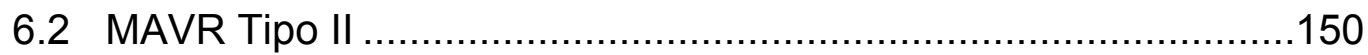

6.3 MAVR Tipo III .................................................................. 159

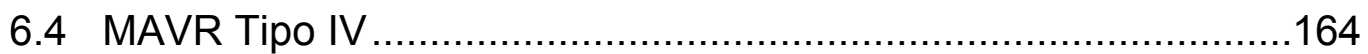

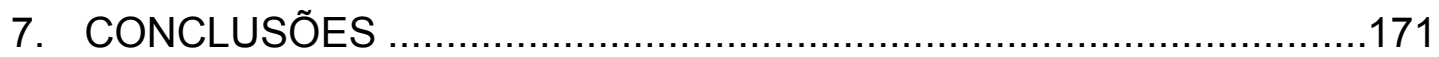

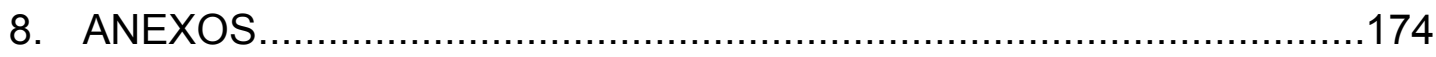

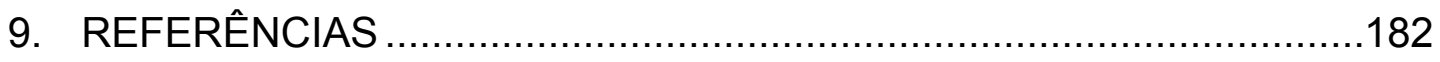

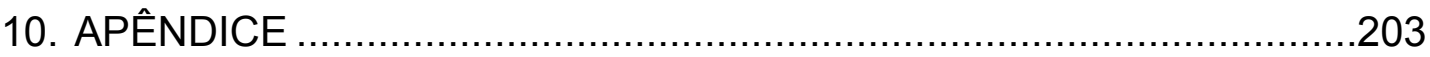




\section{Lista de Abreviaturas}

\begin{tabular}{|c|c|}
\hline $\mathrm{F}$ & French \\
\hline FAD & Fístula Arteriovenosa Dural \\
\hline FAD-A & Fístula Arteriovenosa Dural subtipo A \\
\hline FAD-B & Fístula Arteriovenosa Dural subtipo B \\
\hline FAVP & Fístula Arteriovenosa Perimedular \\
\hline FAVP-A & Fístula Arteriovenosa Perimedular subtipo A \\
\hline FAVP-B & Fístula Arteriovenosa Perimedular subtipo B \\
\hline FAVP-C & Fístula Arteriovenosa Perimedular subtipo C \\
\hline FMUSP & Faculdade de Medicina da Universidade de São Paulo \\
\hline IBCA & Isobutil-2-Cianoacrilato \\
\hline InCor & Instituto do Coração \\
\hline INRAD & Instituto de Radiologia \\
\hline MAI & Malformação Arteriovenosa Intramedular \\
\hline MAVM & Malformação Arteriovenosa Metamérica \\
\hline MAVR & Malformação Arteriovenosa Raquimedular \\
\hline NBCA & N-Butil Cianoacrilato \\
\hline PA & Póstero-anterior \\
\hline PVA & Polivinil Álcool \\
\hline RM & Ressonância Magnética \\
\hline TC & Tomografia Computadorizada \\
\hline
\end{tabular}




\section{Lista de Tabelas}

Tabela 1: Distribuição das MAVR segundo a classificação de Anson e Spetzler (1992)................................................... 84

Tabela 2: $\quad$ Distribuição por idade dos pacientes com MAVR............... 85

Tabela 3: $\quad$ Distribuição por faixa etária das FAD.............................. 86

Tabela 4: $\quad$ Distribuição dos sintomas iniciais nas FAD..................... 87

Tabela 5: $\quad$ Distribuição dos sintomas pré-embolização nas FAD........ 88

Tabela 6: $\quad$ Distribuição da marcha pré-embolização nas FAD.............. 88

Tabela 7: $\quad$ Distribuição dos sintomas pós-embolização nas FAD......... 90

Tabela 8: Distribuição da marcha pós-embolização nas FAD............ 91

Tabela 9: Distribuição dos resultados do tratamento nas FAD considerando os diferentes métodos e o sucesso obtido.... 94

Tabela 10: Distribuição por faixa etária das MAl............................... 95

Tabela 11: Distribuição dos sintomas iniciais nas MAI....................... 95

Tabela 12: Distribuição dos sintomas pré-embolização nas MAl.......... 96

Tabela 13: Distribuição da marcha pré-embolização nas MAI............. 96

Tabela 14: Distribuição dos sintomas pós-embolização nas MAI......... 98

Tabela 15: Distribuição da marcha pós-embolização nas MAI.............. 99

Tabela 16: Distribuição dos resultados do tratamento nas MAI considerando os diferentes métodos e o sucesso obtido.... 101

Tabela 17: Distribuição por faixa etária das FAVP......................... 104

Tabela 18: Distribuição dos sintomas iniciais nas FAVP.................... 105

Tabela 19 Distribuição dos sintomas pré-embolização nas FAVP....... 106

Tabela 20: Distribuição das alterações na marcha pré-embolização nas FAVP........................................................ 106

Tabela 21: Distribuição dos sintomas pós-embolização nas FAVP...... 107

Tabela 22: Distribuição das alterações na marcha pós-embolização nas FAVP

Tabela 23: Distribuição dos resultados do tratamento nas FAVP considerando os diferentes métodos e o sucesso obtido.... 


\section{Lista de Gráficos}

Gráfico 1: Distribuição quanto ao sexo das FAD ................................. 86

Gráfico 2: Distribuição das alterações na marcha pré-embolização nas FAD.

Gráfico 3: Distribuição das alterações na marcha pós-embolização nas FAD.

Gráfico 4: Distribuição quanto ao sexo das MAI.

Gráfico 5: Distribuição das alterações na marcha pré-embolização nas MAl

Gráfico 6: Distribuição das alterações na marcha pós-embolização nas MAl

Gráfico 7: Distribuição quanto ao sexo das FAVP

Gráfico 8: Distribuição das alterações na marcha pré-embolização nas FAVP

Gráfico 9: Distribuição das alterações na marcha pós-embolização nas FAVP 


\section{Lista de Figuras}

Figura 1: Esquema das artérias radiculares e vias longitudinais......... 12

Figura 2: Foto de detalhe do suprimento sangüíneo no segmento cérvico-torácico em cadáver.

Figura 3: Foto de detalhe do suprimento sangüíneo no segmento torácico-médio em cadáver.

Figura 4: Foto de detalhe do suprimento sangüíneo no segmento tóraco-lombo-sacro em cadáver.

Figura 5: Esquema das artérias perimedulares e intramedulares....... 19

Figura 6: MAVR tipo I-A, nutrida por somente uma artéria radicular... 23

Figura 7: MAVR tipo II, com nidus intramedular................................. 24

Figura 8: MAVR tipo III, com comprometimento intra e extradural...... 25

Figura 9: MAVR tipo IV-A, mostrando a conexão entre a artéria espinhal anterior e veia perimedular ectasiada

Figura 10: Mielografia de um paciente com MAVR, em que se observa imagem serpiginosa intra-raquiana, sugestiva de engurgitamento venoso.

Figura 11: FAD-A que se opacifica pela artéria intercostal de T10 direita.

Figura 12: FAD-B que se opacifica pela artéria intercostal de T5 e T6 esquerdas.

Figura 13: MAl que se opacifica por artéria radículo-medular, ramo da artéria vertebral esquerda.

Figura 14: MAI que se opacifica pela artéria intercostal de T9 esquerda.

Figura 15: MAVM que se opacifica pelas artérias brônquica, intercostal de T8 e T11 esquerdas.

Figura 16: FAVP-A cervical com "aneurisma venoso" associado.

Figura 17: FAVP-C que se opacifica pelas artérias radicular de T10 direita e lombar de L2 direita. 
RESUMO 
Conti, M L M. Tratamento endovascular das malformações arteriovenosas raquimedulares : resultados clínicos e angiográficos [tese]. São Paulo: Faculdade de Medicina da Universidade de São Paulo; 2005, 202p.

Trinta e cinco pacientes com malformações arteriovenosas raquimedulares (MAVR) foram tratados por via endovascular. Foram analisados os tipos de MAVR, bem como os aspectos clínicos e angiográficos pré e pós-tratamento endovascular. As MAVR mais freqüentes foram as fístulas arteriovenosas durais (FAD), com 17 pacientes, seguidas das malformações arteriovenosas intramedulares (MAI), fístulas arteriovenosas perimedulares (FAVP) e malformações arteriovenosas metaméricas (MAVM). A avaliação do resultado do tratamento foi dividida em sucesso técnico e clínico, sendo que o primeiro foi subdividido em sucesso técnico do procedimento e do tratamento. O sucesso técnico do procedimento foi caracterizado como oclusão total da MAVR ao final de um procedimento endovascular. O sucesso técnico do tratamento foi caracterizado pela oclusão definitiva da MAVR, independentemente do número de procedimentos. A recidiva foi definida como o reaparecimento da MAVR, identificada na angiografia durante 0 seguimento dos pacientes, independentemente do quadro clínico apresentado. A recidiva implicava em insucesso do procedimento, mas não necessariamente do tratamento. O sucesso clínico do tratamento foi considerado como a melhora parcial ou total dos sintomas após um período mínimo de acompanhamento de 6 meses. Nas FAD, houve predomínio do sexo masculino e da faixa etária acima dos 36 anos. O tratamento endovascular das FAD mostrou sucesso do procedimento na maioria dos casos, porém com recidiva da lesão em $56,7 \%$ dos mesmos. Quando usadas partículas, observou-se recidiva em $73,3 \%$ dos procedimentos, porém com sucesso do tratamento em 66,7 dos pacientes. Quando utilizado o adesivo tissular ("cola"), houve recidiva em $11,1 \%$ dos procedimentos e sucesso do tratamento em $88,9 \%$ dos pacientes. A melhora clínica foi obtida em $64,7 \%$ dos pacientes. Dos 10 pacientes tratados com MAI, a faixa etária mais freqüente foi dos 19 aos 35 anos de idade e predomínio do sexo masculino. O tratamento endovascular das MAl mostrou sucesso do procedimento em $53,3 \%$ e recidiva da lesão em $6,7 \%$ dos pacientes. O sucesso do procedimento também foi superior quando usada cola, atingindo $63,6 \%$ dos procedimentos e apenas $25,0 \%$ com partículas. O sucesso do tratamento foi de $80,0 \%$ e a melhora clínica foi observada em $40,0 \%$ dos pacientes. Somente 1 paciente com MAVM foi tratado. O tratamento objetivou a embolização parcial da lesão para alívio dos sintomas, resultado que foi obtido com sucesso. Nas FAVP houve predomínio do sexo masculino e a faixa etária mais acometida foi dos 19 aos 35 anos. O tratamento endovascular das FAVP mostrou sucesso do procedimento em $75,0 \%$ dos pacientes e ausência de recidiva. O sucesso do tratamento foi de $85,7 \%$, com melhora clínica em todos os pacientes. O nosso estudo mostrou que as MAVR podem ser tratadas de maneira eficiente e segura através da embolização. O seguimento dos pacientes tratados com cola mostrou menor índice de recidiva do que aqueles tratados com partículas. Após a embolização, houve melhora significativa no padrão da marcha nos pacientes com FAD e MAI.

Descritores: doenças vasculares da medula espinhal, malformações arteriovenosas, malformações vasculares do sistema nervoso central, embolização terapêutica, radiologia intervencionista. 
SUMMARY 
Conti, M L M. Endovascular treatment for spinal cord arteriovenous malformations : clinical and angiographic results [thesis]. São Paulo: Faculdade de Medicina da Universidade de São Paulo: 2005, 202p.

Endovascular treatment was used in 35 patients with spinal cord arteriovenous malformations (SCAVM). SCAVM types, along with clinical and angiographic features of pre-op and post-op endovascular treatments were analyzed. Seventeen patients had dural arteriovenous fístulas (DAVF), being this type the most frequent SCAVM, followed by intramedullary arteriovenous malformations (IAVM), perimedullary arteriovenous fístulas (PAVF) and metameric arteriovenous malformations (MAVM). Evaluation of treatment results was divided into technical and clinical success, being the first subdivided into technical success of the procedure and treatment. The procedural's technical success was characterized by total SCAVM occlusion at the end of an endovascular procedure. Technical success of the treatment was characterized by definitive occlusion of the SCAVM, independent of the number of procedures. Recurrence was defined as reappearance of SCAVM, identified on angiograms during patient follow up, independent of the observed clinical situation. Recurrence implied in an unsuccessful procedure but not necessarily in treatment failure. Treatment's clinical success was considered partial or total symptom improvement after a minimum 6 month period follow up. Male and age over 36 years was preponderate in DAVF. Endovascular treatment in DAVF had procedural success in most cases, but with lesion recurrence in $56,7 \%$ of these patients. When particulate embolic agents were used, recurrence occurred in $73,3 \%$ of the procedures but with treatment success in $66,7 \%$ of these patients. When liquid tissue adhesive was used, there was $11,1 \%$ of recurrence and $88,9 \%$ in treatment success in these patients. Clinical improvement occurred in $64,7 \%$ of these patients. Male predominance and age between 19 to 35 years was more frequent in the 10 treated patients with IAVM. IAVM endovascular treatment was a procedural success in $53,3 \%$ and lesion recurrence in $6,7 \%$ of these patients. Procedural success was also superior when liquid tissue adhesive was used, up to $63,6 \%$ of these procedures and, only $25,0 \%$ with particulate embolic agents. Treatment success occurred in $80,0 \%$ and clinical improvement seen in $40,0 \%$ of these patients. Only 1 patient with MAVM was treated. Aim in treatment was partial lesion embolization to mitigate symptoms, which was successfully achieved. Male predominance and age between 19 to 35 years occurred in PAVF. PAVF endovascular treatment had procedural success in $75,0 \%$ and no recurrences in these patients. Treatment success occurred in $85,7 \%$ and clinical improvement in all patients. This study demonstrates that SCAVM can be treated efficiently and safely with endovascular embolization. Patient follow up revealed fewer recurrences in those treated with liquid tissue adhesive than in those with particulate embolic agents. After DAVF and IAVM embolization, patients had significant improvement in their gait.

Descriptors: spinal cord diseases, arteriovenous malformations, central nervous system vascular malformations, therapeutic embolization, interventional radiology. 
1. INTRODUÇÃO 
As lesões vasculares raquimedulares são um grupo de doenças heterogêneas que se desenvolvem de maneiras distintas. Podem ser congênitas ou adquiridas e resultam clinicamente em comprometimento da função da medula espinhal. Sua fisiopatologia, história natural e tratamento são bastante variados. Foram primeiramente reconhecidas no século XIX, inicialmente como relatos de casos e também em achados pós-cirúrgicos ou autópsias. Por isso, o nosso conhecimento sobre essas lesões era pequeno, até o final da primeira metade do século XX. Foi a partir da década de 60 , com o desenvolvimento da angiografia com cateterismo seletivo, que se começou a mapear o sistema vascular da medula de uma forma dinâmica. Com isso, os principais aspectos anatômicos, clínicos e radiológicos passaram a ser estabelecidos, gerando um grande avanço na compreensão dessas lesões. Esse aprendizado se deu graças ao esforço cooperativo de neurorradiologistas e neurocirurgiões em diversos centros, principalmente na França, Inglaterra e Estados Unidos da América. A partir da década de 70, com o surgimento do microscópio cirúrgico e o aprimoramento da técnica cirúrgica, observou-se a melhora no resultado dos pacientes tratados por esse método. Concomitantemente, tem início a terapia endovascular. O resultado disso foi um aprimoramento no tratamento dos pacientes com malformações arteriovenosas raquimedulares (MAVR). 
No entanto, ainda existe controvérsia quanto à melhor abordagem terapêutica das MAVR. Para que o tratamento seja eficaz, é necessário ter conhecimento anatômico, estudo radiológico completo, classificar corretamente a lesão e estabelecer critérios para escolher o tipo de tratamento adequado para cada paciente. 
2. OBJETIVOS 
1. Identificar qual a freqüência dos diferentes tipos de MAVR.

2. Estabelecer qual a técnica preferencial para o tratamento endovascular das MAVR.

3. Determinar se o tratamento endovascular das MAVR é seguro.

4. Avaliar qual o resultado clínico do tratamento endovascular das MAVR. 
3. REVISÃO DA LITERATURA 


\subsection{Histórico}

As MAVR são lesões pouco freqüentes da medula espinhal. Estima-se que correspondam a cerca de $3 \%$ de todas anomalias da medula espinhal (Toole, 2002).

A primeira descrição anatômica e classificação das lesões vasculares do sistema nervoso central foi feita por Virchow, em 1863, mas muitas outras surgiram introduzindo uma extensa nomenclatura e refletindo o desconhecimento da fisiopatologia e da angioarquitetura das MAVR (Virchow, 1863 apud Jellinger, 1978*; Wyburn-Mason, 1943 apud Barrow, 1999**; McCormick, 1966; Anson e Spetzler, 1992).

Foram inicialmente descritas em relatos de autópsia, por Hebold em 1885 e Gaupp em 1888, como hemorróidas da pia-máter espinhal (Hebold, 1885 apud Marsh 1999**; Gaupp, 1888 apud Grote, $1996^{* * * *}$ ).

Fedor Krause, em 1910, foi o primeiro cirurgião a abordar cirurgicamente essas lesões. Realizou uma laminectomia entre a sexta e a

\footnotetext{
*Virchow R. Die krankhaften Geschwülste. Berlin: Hirschfield; 1863.

** Wyburn-Mason R. The vascular abnormalities and tumors of the spinal cord and its membranes. London: $\mathrm{H}$ Klimpton; 1943.

${ }^{* * *}$ Hebold O. Aneurysmen der kleinsten ruckenmarksgefasse. Arch Psychiat Nervenkr. 1885; 16: 813-23.

${ }^{* * * *}$ Gaupp J. Hämorrhoiden der pia mater spinalis in gebiet des lendenmarks. Beitr Pathol Anat. 1888; 2: 516-8.
} 
décima segunda vértebras torácicas num paciente com suspeita de tumor raquimedular, revelando um aglomerado de vasos sangüíneos que foram ligados, mas não ressecados (Krause, 1910 apud Marsh, 1999*). O primeiro relato cirúrgico com sucesso é atribuído a Charles Elsberg, em 1914, que removeu vasos anormalmente dilatados adjacentes à dura-máter da nona raiz torácica (Elsberg, 1916 apud Thompson, 2004**).

Até 1927, muitos pacientes com MAVR foram operados com a hipótese diagnóstica de tumor raquimedular. Eram submetidos à mielografia, que mostrava uma imagem de bloqueio, sugestiva de tumor, a partir da qual era indicada a cirurgia. Em 1927, Perthes reconheceu a imagem de uma lesão vascular numa mielografia e extirpou-a cirurgicamente (Perthes, 1927 apud Marsh, $\left.1999^{* * *}\right)$.

As primeiras análises das MAVR foram baseadas em estudos histológicos após autópsia. Sargent, em 1925, revisou 21 casos previamente relatados e concluiu que 19 deles eram "angiomas venosos" (Sargent, 1925). Em 1943, Wyburn-Mason revisou 110 casos e classificou as MAVR do ponto de vista histológico em 2 grupos, angiomas arteriovenosos e angiomas venosos, sendo que o último tipo era responsável por dois terços dos casos (Wyburn-Mason, 1943 apud Barrow, 1999****).

\footnotetext{
* Krause F. Surgery of the brain and spinal cord. New York: Rebman Company; 1912. v.3, p.1129-30.

${ }^{* *}$ Elsberg CA. Diagnosis and treatment of surgical diseases of the spinal cord and its membranes. Philadelphia: Saunders; 1916.

*** Perthes G. Über des Rankenangiom der weichen häute des gehirns und rückenmarks. Dtsch Z Chir. 1927; 203/204: 93-103.

**** Wyburn-Mason R. The vascular abnormalities and tumors of the spinal cord and its membranes. London: $\mathrm{H}$ Klimpton; 1943.
} 
Em 1926, Foix e Alajouanine descreveram uma síndrome denominada mielopatia subaguda necrotizante, com paraplegia de caráter progressivo resultando em óbito (Foix e Alajouanine, 1926). Entretanto Lhermitte et al., em 1931, reconheceram a associação dessa síndrome com a presença de MAVR (Lhermitte, 1931). Wirth, em 1970, desencorajou intervenções cirúrgicas nesses pacientes, considerando ser o estágio final de um processo irreversível, não havendo perspectiva de melhora neurológica (Wirth, 1970). Criscuolo et al. sugeriram que essa síndrome seria causada por congestão venosa e não necessariamente por trombose e, por isso, potencialmente reversível se tratada precocemente (Criscuolo, 1989).

A partir da década de 50, o surgimento da angiografia estabeleceu uma nova fase na avaliação dessas lesões. Em 1956, Henson e Croft relataram a opacificação de um angioma raquimedular através da injeção de contraste na artéria vertebral (Henson e Croft, 1956). A investigação das MAVR através da aortografia foi relatada posteriormente por vários autores, iniciando uma nova etapa na compreensão das MAVR (Djindjian R, 1962; Doppman, 1965; Baker, 1967; Djindjian R, 1967). O desenvolvimento das técnicas de cateterização seletiva permitiu a visibilização in vivo de vasos sangüíneos anormais de maneira mais precisa. O estudo angiográfico seletivo foi desenvolvido pioneiramente por Di Chiro et al., em 1967, permitindo o estudo sistemático dos vasos sangüíneos raquimedulares através da cateterização seletiva dos ramos cervicais, intercostais e lombares (Di Chiro, 1967). 
O tratamento cirúrgico foi por muito tempo baseado nas ligaduras arteriais (Houdart, 1966; Baker, 1967; Bailey, 1969). Um avanço importante ocorreu em 1969, com a publicação de Krayenbühl e Yaşargil, relatando sua experiência na ressecção de MAVR com o uso do microscópio cirúrgico, da coagulação com bipolar e de instrumental microcirúrgico (Krayenbühl, 1969).

Simultaneamente, teve início a era da terapia endovascular, quando Doppman et al. relataram em 1968 a embolização seletiva de artérias nutridoras de uma MAVR com esferas de aço inoxidável de $3 \mathrm{~mm}$ (Doppman, 1968). Posteriormente o desenvolvimento dos materiais de embolização — cateteres cada vez menores e mais flexíveis, e diversos agentes oclusivos propiciou um grande impulso nesta modalidade terapêutica.

Em 1977, Kendall e Logue relataram pela primeira vez uma MAVR constituída por um único vaso espiralado, na verdade, uma fístula dural raquimedular (Kendall, 1977). Nesse relato, descreveram nove casos de pacientes com fístula dural na região das raízes espinhais, que foram identificados angiograficamente. Foram submetidos à interrupção cirúrgica dessa fístula e evoluíram com melhora ou estabilização do quadro neurológico.

Em 1977, Djindjian M et al. descreveram pela primeira vez uma fístula arteriovenosa perimedular (Djindjian M, 1977). Essas lesões foram posteriormente subdivididas e reclassificadas baseadas no calibre, comprimento e número de vasos, visando facilitar a escolha da abordagem terapêutica adequada para cada uma delas (Heros, 1986; Gueguen, 1987). 


\subsection{Anatomia Vascular Raquimedular}

A circulação sangüínea raquimedular é formada por múltiplas e variáveis artérias e veias. Mesmo as maiores artérias variam quanto à origem, configuração e importância de paciente para paciente, tornando sua compreensão uma tarefa difícil. No entanto não deve ser menosprezada, pois é fundamental para o diagnóstico e tratamento dessas lesões.

\subsubsection{Artérias}

O suprimento arterial raquimedular depende das artérias radiculares (ou sistema extramedular), dos três eixos arteriais longitudinais (ou sistema perimedular) e da microcirculação (ou sistema intramedular) (Lazorthes, 1978).

\section{Sistema Extramedular}

No sentido transversal de cada segmento vertebral, a artéria radicular entra pelo forame intervertebral e penetra a dura-máter de uma raiz, podendo terminar em artéria radículo-medular anterior ou posterior. É incomum a presença de ambas num mesmo segmento vertebral. A artéria radicular irriga predominantemente a dura-máter e a raiz adjacente, e a radículo-medular emite a artéria espinhal anterior ou a posterior. A artéria radículo-pial não se anastomosa às vias longitudinais, mas participa da rede perimedular. Apesar de embriologicamente existirem 62 artérias radiculares, a maioria delas involui durante o desenvolvimento e no adulto somente 6 a 8 
contribuem funcionalmente suprindo a artéria espinhal anterior, e de 10 a 23 suprindo as artérias espinhais posteriores. A artéria radículo-medular bifurcase em ramos superior e inferior imediatamente antes da anastomose com a artéria espinhal (Figura 1) (Djindjian R, 1970).

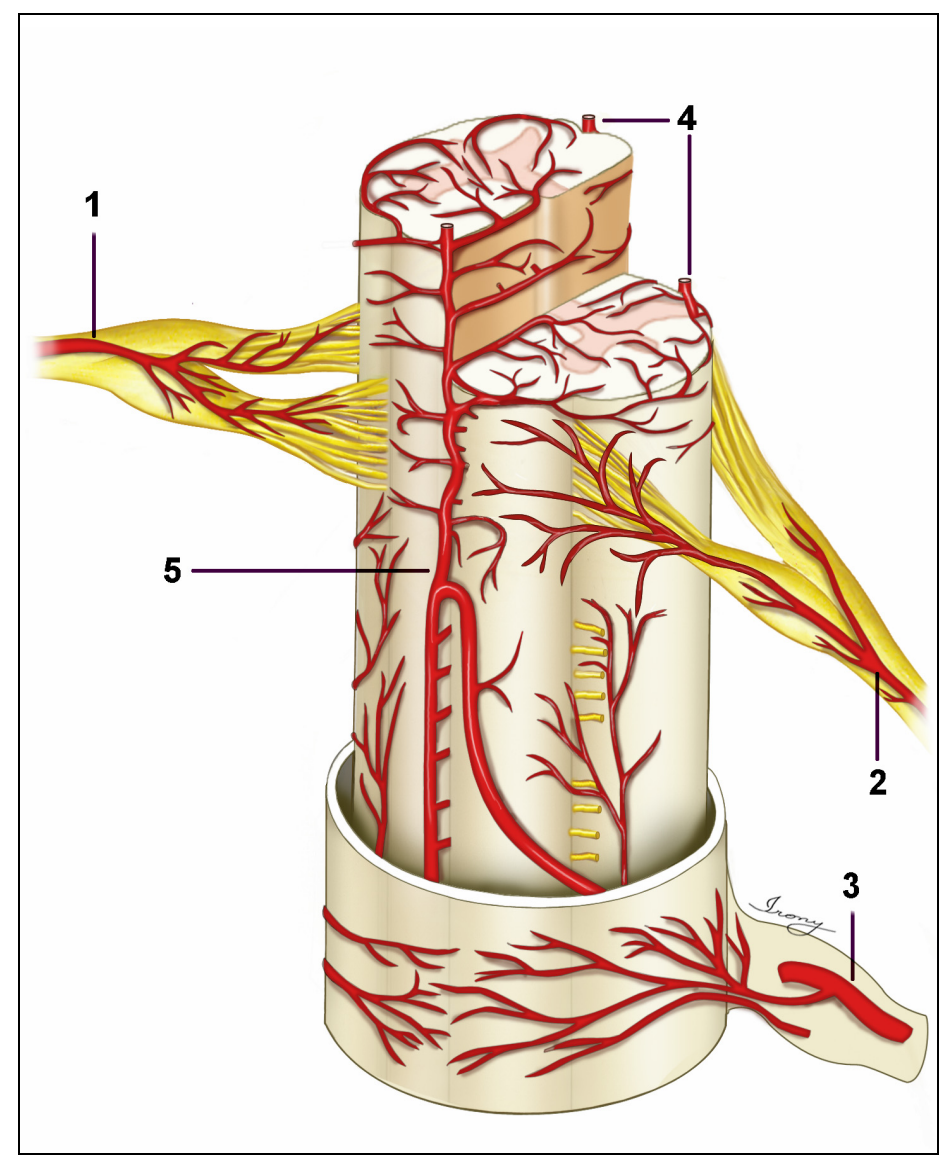

Figura 1: Esquema das artérias radiculares e vias longitudinais: 1- artéria radicular, 2- artéria radículo-pial, 3- artéria radículo-medular, 4- vias espinhais posteriores e 5- via espinhal anterior (ilustração realizada por Irony Therezinha Pires) 
Devido à complexidade do suprimento sangüíneo raquimedular e suas diferenças regionais, Lazorthes, em 1958, propôs a divisão dos territórios arteriais em cérvico-torácico, torácico-médio e tóraco-lombo-sacro, facilitando sua compreensão (Lazorthes, 1958).

O segmento cérvico-torácico estende-se da primeira vértebra cervical até a segunda vértebra torácica. Nos quatro primeiros segmentos cervicais (C1-C4), geralmente não há suprimento sangüíneo pelas artérias radiculares. Ele é determinado basicamente pela artéria espinhal anterior, que se origina diretamente das artérias vertebrais. Os quatro últimos segmentos cervicais e os dois primeiros torácicos (C4-T2) constituem a unidade funcional dos membros superiores (intumescência cervical) e possuem suprimento sangüíneo independente. Geralmente, é nutrido por duas a quatro artérias radiculares, que podem originar-se das artérias vertebral, cervical ascendente e/ou cervical profunda (Figura 2). A mais inferior costuma acompanhar a sétima ou oitava raiz cervical, e é denominada artéria da intumescência cervical, ou de Lazorthes (Lazorthes, 1958). 


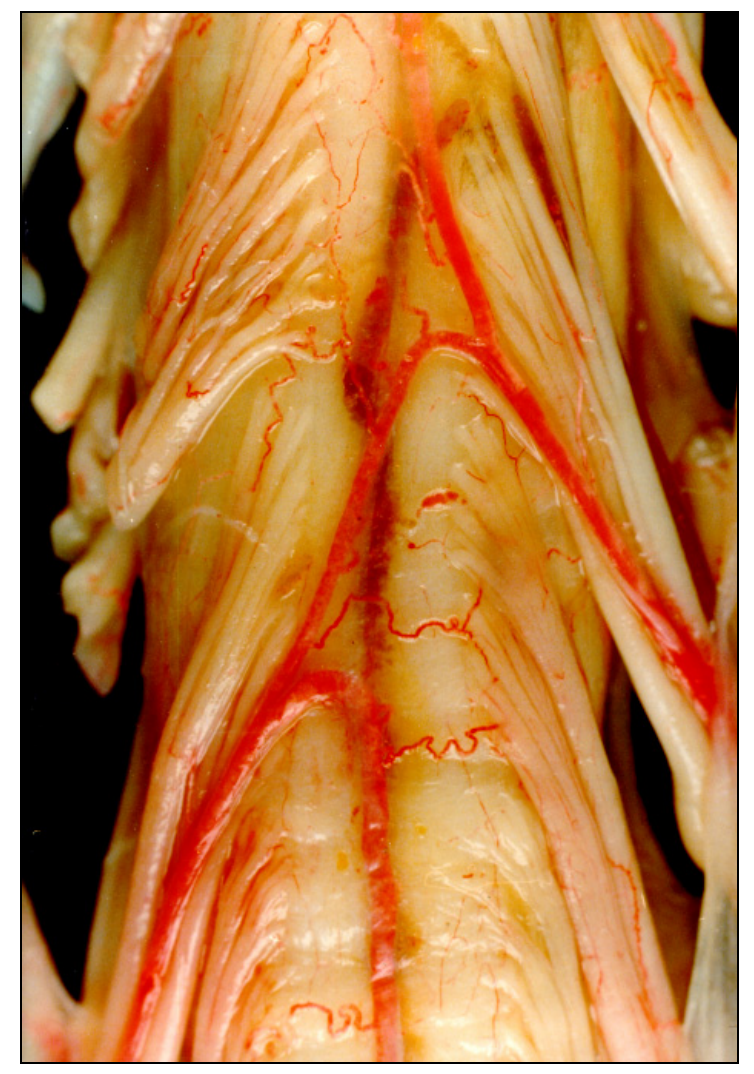

Figura 2: Foto de detalhe do suprimento sangüíneo no segmento cérvico-torácico anterior em cadáver, mostrando duas artérias radiculares em segmentos adjacentes, uma à direita e outra à esquerda, dando origem a artérias radículo-medulares anteriores e terminando na via espinhal anterior (Antero Costa Filho, com permissão) 
O segmento torácico-médio estende-se da terceira até a sétima vértebra torácica (T3-T7) e em geral recebe aporte sangüíneo de somente uma artéria. É chamada de artéria intercostal, mais freqüente do lado esquerdo e costuma acompanhar a quarta ou quinta raiz torácica (Djindjian, 1970). Esse território costuma ter um suprimento tênue, sendo mais susceptível a lesões (Figura 3).

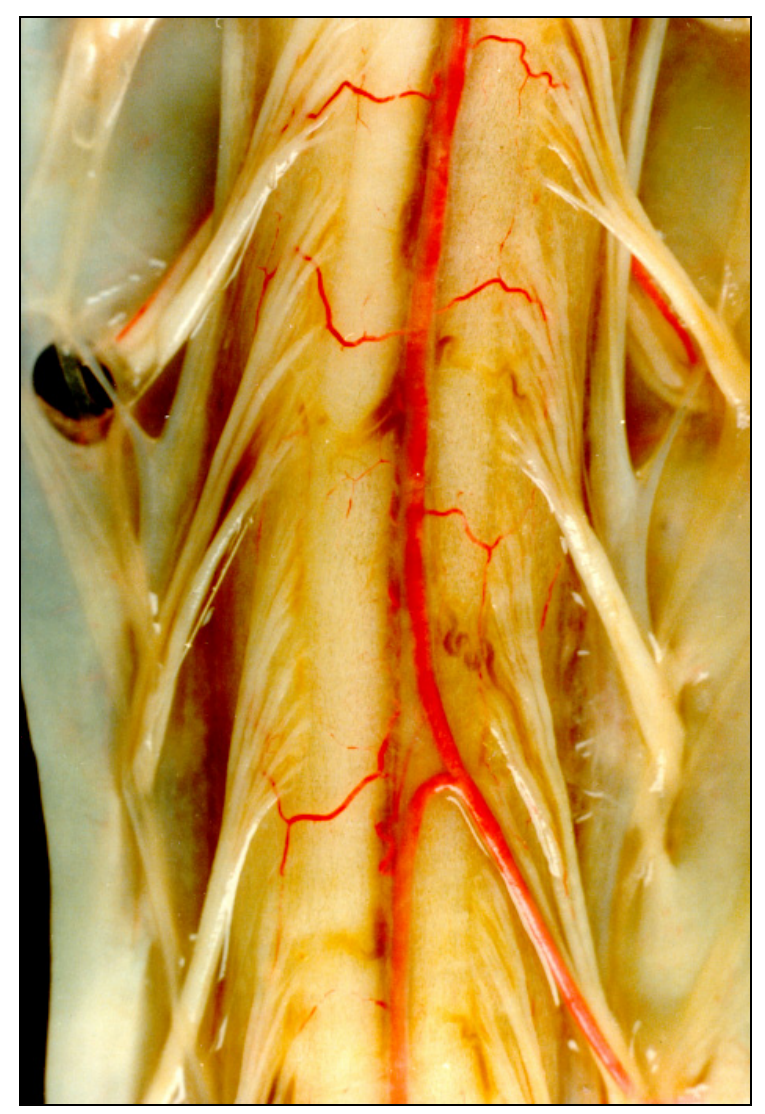

Figura 3: Foto de detalhe do suprimento sangüíneo no segmento torácico-médio anterior em cadáver, mostrando uma artéria radicular, ramo da artéria intercostal esquerda, terminando na via espinhal anterior. Nota-se que esta artéria radicular está suprindo vários segmentos medulares (Antero Costa Filho, com permissão) 
O segmento tóraco-lombo-sacro estende-se da oitava vértebra torácica até o final do cone medular. É nutrido basicamente pela artéria da intumescência lombar, ou de Adamkiewicz (Adamkiewicz, 1881 apud Marsh, 1999*). Em 80\% dos casos, essa artéria alcança a medula com uma raiz entre T9 e L2, e em 75\% dos casos do lado esquerdo (Costa Filho, 1984). Geralmente divide-se em um ramo ascendente, fino e um descendente, mais calibroso e tortuoso, que formará uma rede anastomótica com as artérias espinhais posteriores, marcando o cone medular (Figura 4).

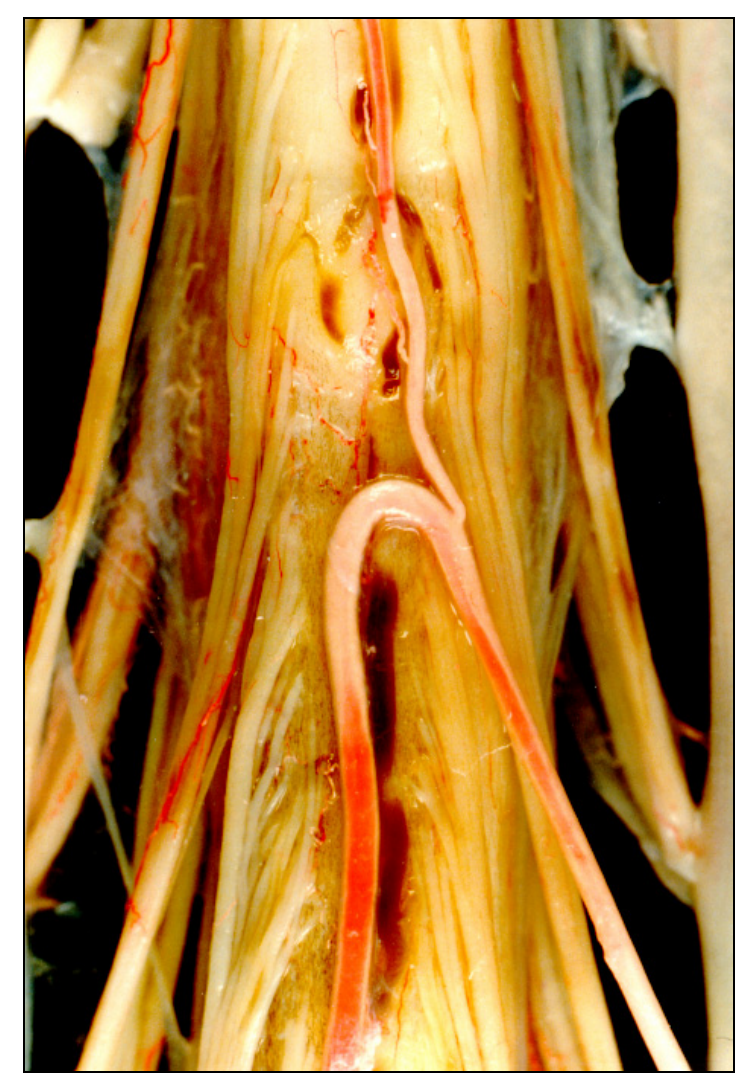

Figura 4: Foto de detalhe do suprimento sangüíneo no segmento tóraco-lombo-sacro anterior em cadáver, mostrando uma artéria radicular à esquerda (artéria de Adamkiewicz), emitindo um ramo ascendente fino e um descendente mais calibroso, formando a via espinhal anterior (Antero Costa Filho, com permissão)

\footnotetext{
* Adamkiewicz A. Die blutegefässe des menschlichen rückenmarkes: Die geffässe der rückenmarksubstanz. $S$ Ber Akad Wiss (Wien). 1881; 85.
} 


\section{Sistema Perimedular}

No sentido longitudinal, três eixos arteriais percorrem a superfície da medula: uma artéria espinhal anterior e duas artérias espinhais posteriores. Essas artérias muito freqüentemente apresentam irregularidades e descontinuidades, dificultando sua identificação tanto pelos métodos de diagnóstico por imagem, como no intra-operatório e costumam ser denominadas via ou eixo espinhal anterior e vias ou eixos espinhais posteriores (Costa Filho, 1984).

A artéria espinhal anterior inicia-se na região inferior do bulbo, da junção de duas artérias espinhais anteriores ventrais, ramos das artérias vertebrais. Percorre a fissura mediana anterior da medula com eventuais tortuosidades, principalmente nas intumescências cervical e lombar. É importante o conceito de segmentação da artéria espinhal anterior. Em toda sua extensão, é formada por diversos segmentos, determinados pela inserção das artérias radículo-medulares anteriores, que determinam a direção do fluxo sangüíneo. É mais calibrosa quando recebe a artéria radículo-medular anterior e mais estreita onde se anastomosa com a do segmento superior ou inferior. Na região torácica média, seu calibre é menor e muitas vezes torna-se descontínua. Termina na parte inferior da medula, próxima ao final do cone medular, onde apresenta uma rede anastomótica com as artérias espinhais posteriores (Krauss, 1999).

As artérias espinhais posteriores localizam-se na região póstero-lateral da medula, adjacente a zona de entrada da raiz dorsal. Formam-se a partir da anastomose do ramo espinhal posterior da artéria vertebral, e do segundo ramo 
ascendente da artéria radículo-medular posterior. Durante toda sua extensão, recebe ramos das artérias radículo-medulares posteriores. Sua anatomia é mais variável e seu calibre menor quando comparado com a artéria espinhal anterior. São mais evidentes nas intumescências cervical e lombar, e ocasionalmente descontínuas na região torácica. Terminam em anastomose com a artéria espinhal anterior no cone medular (Rosenwasser, 1999).

\section{Sistema Intramedular}

Distal às artérias espinhais, a circulação medular é feita através de um sistema centrífugo e centrípeto (Krauss, 1999).

O centrífugo (ou central) é determinado pela artéria espinhal anterior. Os ramos terminais da artéria espinhal anterior são as artérias comissurais (ou centrais). Atravessam a fissura mediana anterior, penetrando na medula e passando posteriormente até a comissura anterior, onde podem dirigir-se para direita ou esquerda, suprindo uma hemimedula. São artérias pouco calibrosas, com diâmetro médio inferior a $0,25 \mathrm{~mm}(250 \mu)$. Geralmente existem de 5 a 12 artérias por centímetro na região lombar, de 2 a 6 na torácica e de 3 a 8 na cervical. A artéria comissural nutre a substância cinzenta central e a substância branca adjacente. Isso inclui a comissura anterior, a coluna anterior, a base da coluna posterior, a coluna de Clarke, os funículos anterior e lateral, compreendendo tratos córtico-espinhais, tratos espino-talâmicos e a parte ventral dos fascículos grácil e cuneiforme. Esse sistema é responsável pelo suprimento de grande parte da medula e seu comprometimento pode ocasionar dano neurológico grave. 
O sistema centrípeto (ou periférico) depende do plexo coronal perimedular, que conecta através de ramos transversos e oblíquos as artérias espinhais em todos os segmentos medulares. Pequenos ramos desse plexo penetram pela pia-máter, ao redor de toda a circunferência da medula, nutrindo principalmente sua periferia (Figura 5). Nutrem a parte dorsal da coluna posterior e o funículo posterior, e a periferia da substância branca. Isso inclui os fascículos grácil e cuneiforme, os tratos espinocerebelares, a parte lateral dos tratos córtico-espinhais laterais e a zona de Lissauer.

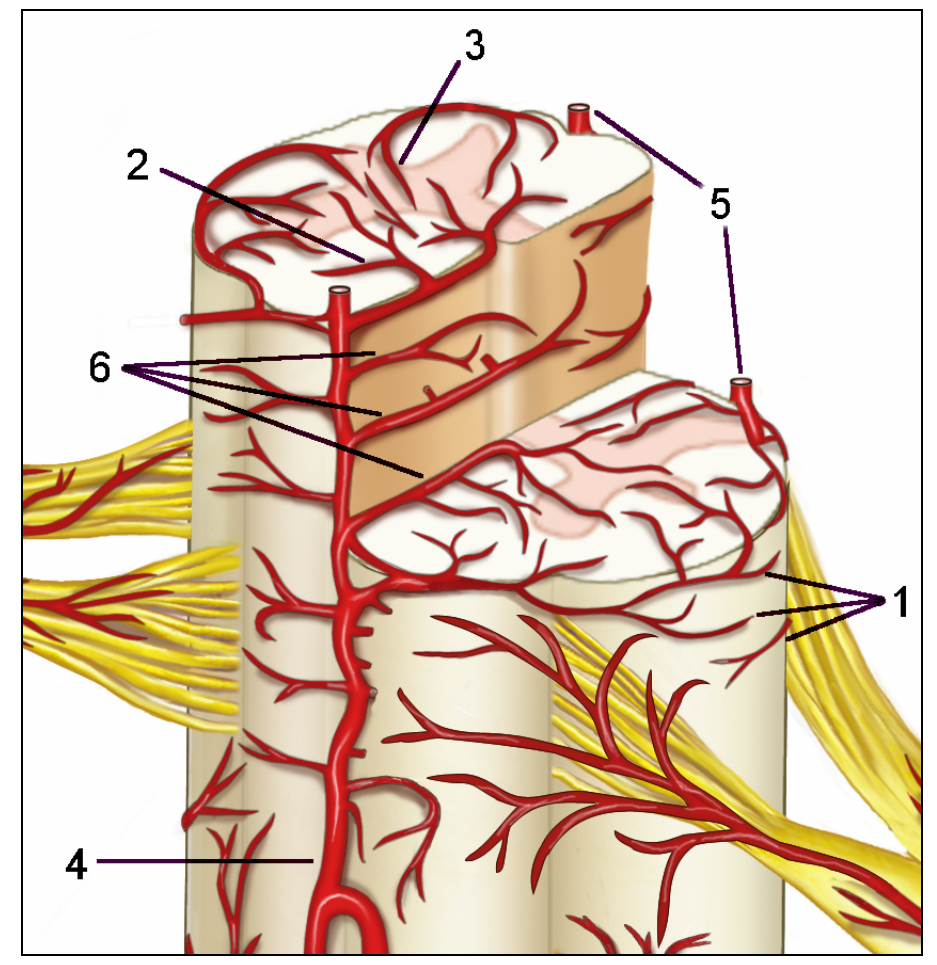

Figura 5: Esquema das artérias perimedulares e intramedulares: 1- rede arterial perimedular, 2- sistema central, 3- sistema periférico, 4- via espinhal anterior, 5- vias espinhais posteriores, 6- artérias comissurais (ilustração realizada por Irony Therezinha Pires) 


\subsubsection{Veias}

A anatomia venosa raquimedular tem mais variações do que a arterial, tornando mais difícil sua compreensão. Ausências e duplicações dos vasos são a regra, e não exceção. Do leito capilar, o sangue drena através de veias intramedulares em veias perimedulares. Estas drenam em veias radiculares, que se comunicam com o plexo perivertebral de Batson, levando o sangue para grandes veias (Rosenwasser, 1999).

As veias intramedulares podem drenar por veia central, tributária da veia espinhal anterior ou por veias tributárias do plexo coronal.

A mais constante veia perimedular é a espinhal anterior, que geralmente encontra-se na fissura mediana anterior e muitas vezes é dupla na região cervical e torácica alta. A veia espinhal posterior é muitas vezes mais calibrosa que a anterior e situa-se no sulco mediano posterior. Existe um numero variável e irregular de veias ântero-laterais e póstero-laterais na superfície medular (Gillilan, 1970).

As veias perimedulares formam veias medulares, que são tributárias das veias radiculares. Freqüentemente existem 14 veias radiculares: 7 anteriores e 7 posteriores. Sua posição é relativamente constante: uma em C3 e uma em C5, uma na região torácica superior e na torácica média, duas na região torácica inferior, e finalmente uma na região lombar (Djindjian, 1970).

As veias radiculares então saem do compartimento intradural, juntamente com as raízes, e costumam apresentar uma válvula 
proximal antes da drenagem para o plexo perivertebral. Este é formado por veias radiculares, epidurais e vertebrais, e não possui válvulas (Rosenwasser, 1999).

O plexo perivertebral finalmente então drena para seios cranianos, veias ázigos, hemiázigos, cava e ilíacas (Krauss, 1999).

\subsection{Classificação das MAVR}

Desde 1863, quando Virchow fez a primeira descrição anatômica e classificou as lesões vasculares encontradas no sistema nervoso central, uma extensa nomenclatura foi introduzida na literatura para definição das MAVR (Virchow, 1863 apud Jellinger, 1978*). As lesões eram divididas em angioma cavernosum e angioma racemosum, sendo este último subdividido em capilar, venoso, arterial e arteriovenoso. Após essa classificação, várias outras foram descritas, sempre considerando aspectos anatomopatológicos (Cushing e Bayley, 1928; Turner e Kernohan, 1941; Wyburn e Mason, 1943 apud Barrow, 1999**; McCormick, 1966; Zülch, 1986; Russel e Rubinstein, 1989).

Djindjian M, em sua Tese em Medicina apresentada em 1976, utilizou uma classificação baseada no suprimento arterial das lesões, dividindo as MAVR em retromedulares, intramedulares e extramedulares (Djindjian M, 1976). As retromedulares eram supridas pelas artérias espinhais posteriores

\footnotetext{
*Virchow R. Die krankhaften Geschwülste. Berlin: Hirschfield; 1863.

** Wyburn-Mason R. The vascular abnormalities and tumors of the spinal cord and its membranes. London: $\mathrm{H}$ Klimpton; 1943.
} 
enquanto as intramedulares e extramedulares tinham suprimento pela artéria espinhal anterior ou mista.

Gueguen e Merland, em 1987, propuseram uma classificação baseada na história natural, nos aspectos anatômico e angiográfico (Gueguen e Merland, 1987). Dessa maneira são classificadas em fístulas arteriovenosas durais, malformações vasculares intramedulares e fístulas arteriovenosas perimedulares. Estas últimas foram subdivididas em tipos 1, 2 e 3, de acordo com o calibre, comprimento, número de vasos suprindo e drenando a fístula e também relacionadas com o aspecto hemodinâmico da fístula.

Mais recentemente, Anson e Spetzler classificaram as MAVR em 4 tipos, numa tentativa de uniformizar a terminologia, correlacionado com os diferentes aspectos clínicos, angiográficos e tentando de maneira ambiciosa estabelecer as opções terapêuticas (Anson e Spetzler, 1992). Essa classificação é a que utilizamos, na qual as MAVR são divididas em: 
- Tipo I: Também chamada de fístula arteriovenosa dural, ou MAVR dorsal. Formada a partir de uma fístula localizada entre um ramo meníngeo, originário de um ramo espinhal da artéria radicular e uma drenagem venosa anômala intradural. Podem ser subdivididas em:

Subtipo I-A: Nutridas por um único ramo arterial (Figura 6).

Subtipo I-B: Nutridas por múltiplos ramos arteriais.

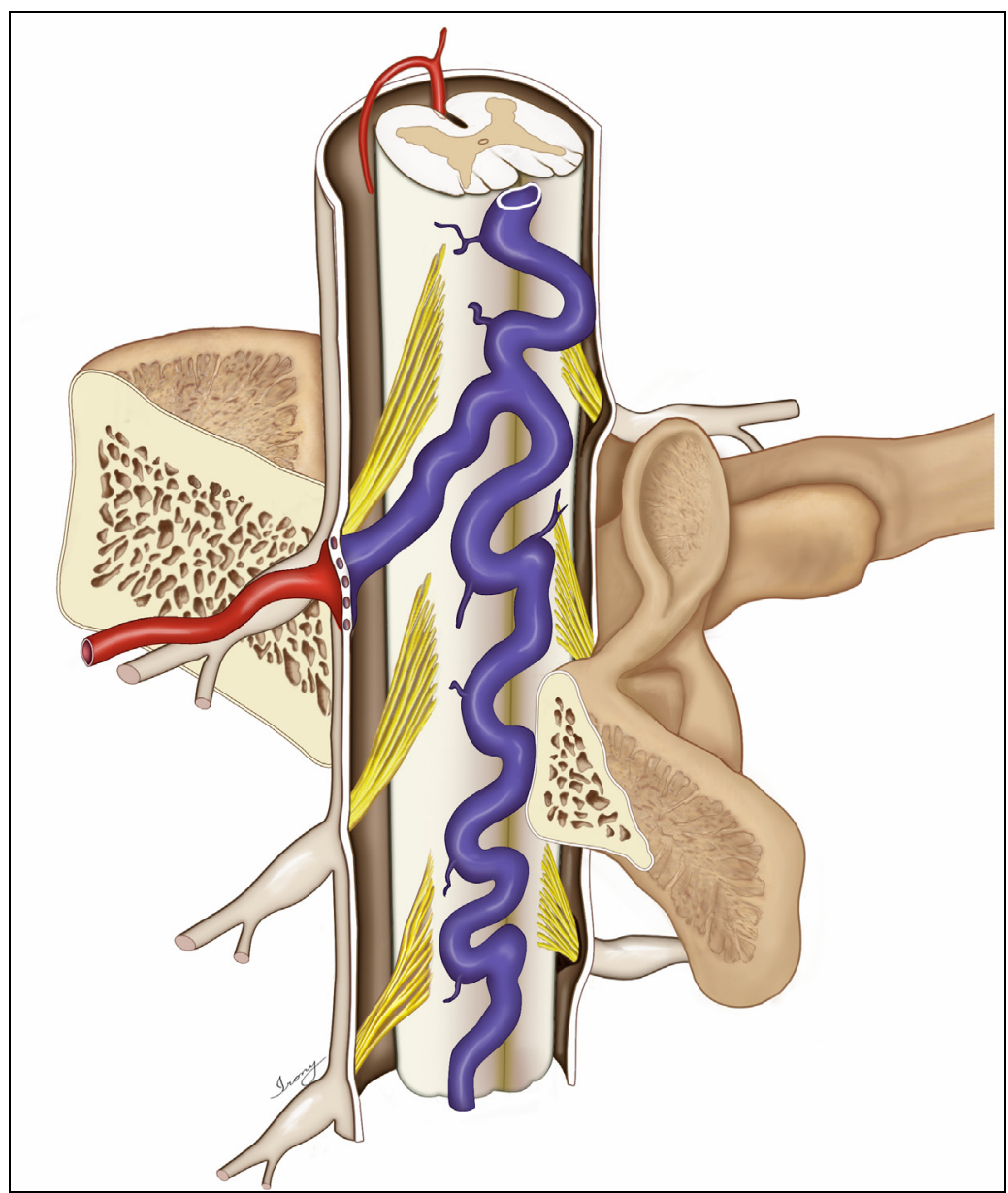

Figura 6: MAVR tipo I-A, nutrida por somente uma artéria radicular (ilustração realizada por Irony Therezinha Pires) 
- Tipo II: É a malformação arteriovenosa intramedular clássica, ou angioma arteriovenoso, geralmente com um aglomerado de vasos sangüíneos (nidus) intramedular. Pode ser nutrida pelas artérias espinhal anterior e/ou posteriores, e a drenagem é para o plexo coronal (Figura 7).

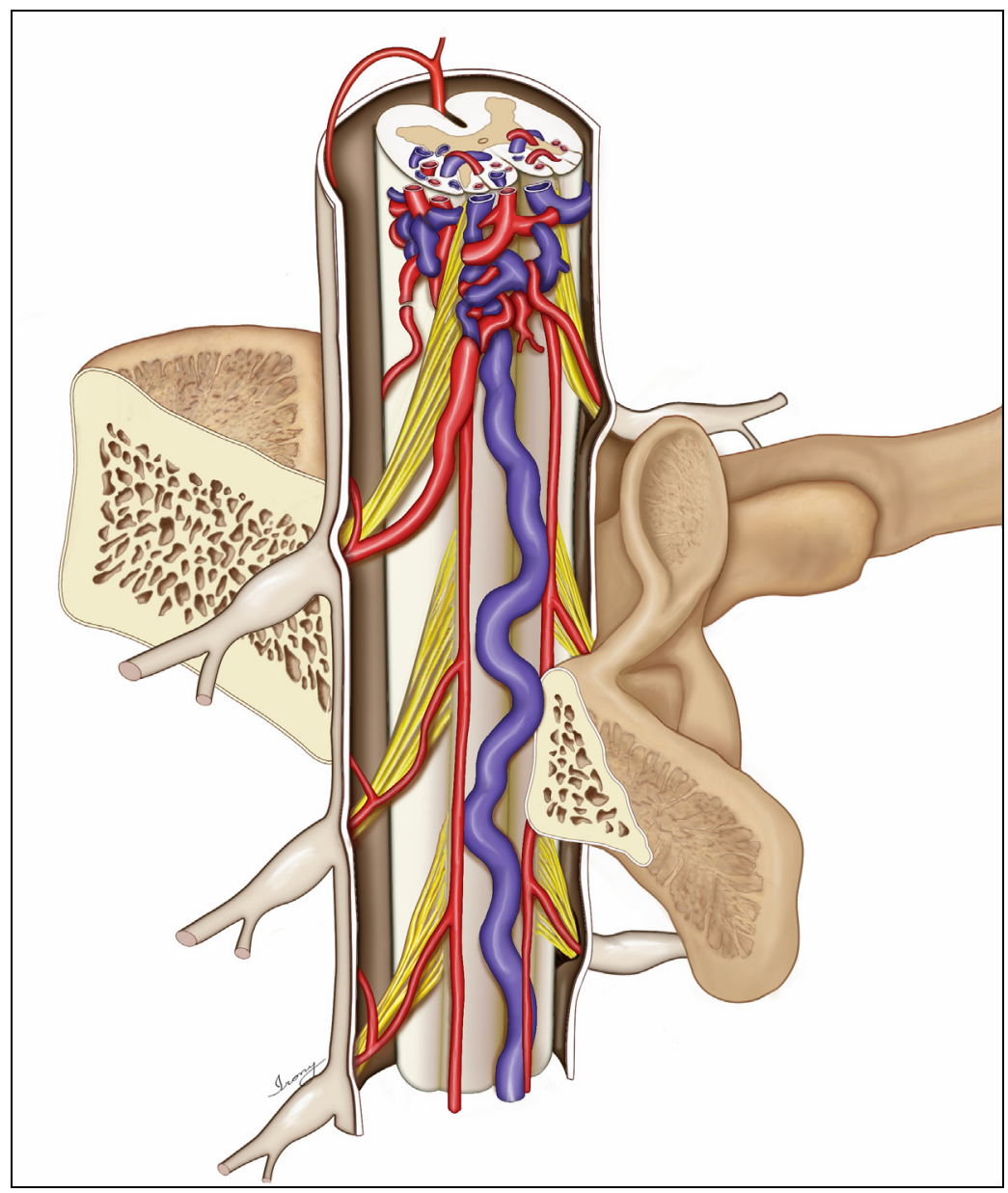

Figura 7: MAVR tipo II, com nidus intramedular (ilustração realizada por Irony Therezinha Pires) 
- Tipo III: Também chamadas de MAVR juvenil ou metamérica. Extensa malformação arteriovenosa com componentes intramedular, extradural e extra-raquiano, comprometendo inclusive corpos vertebrais e tecidos paravertebrais (Figura 8).

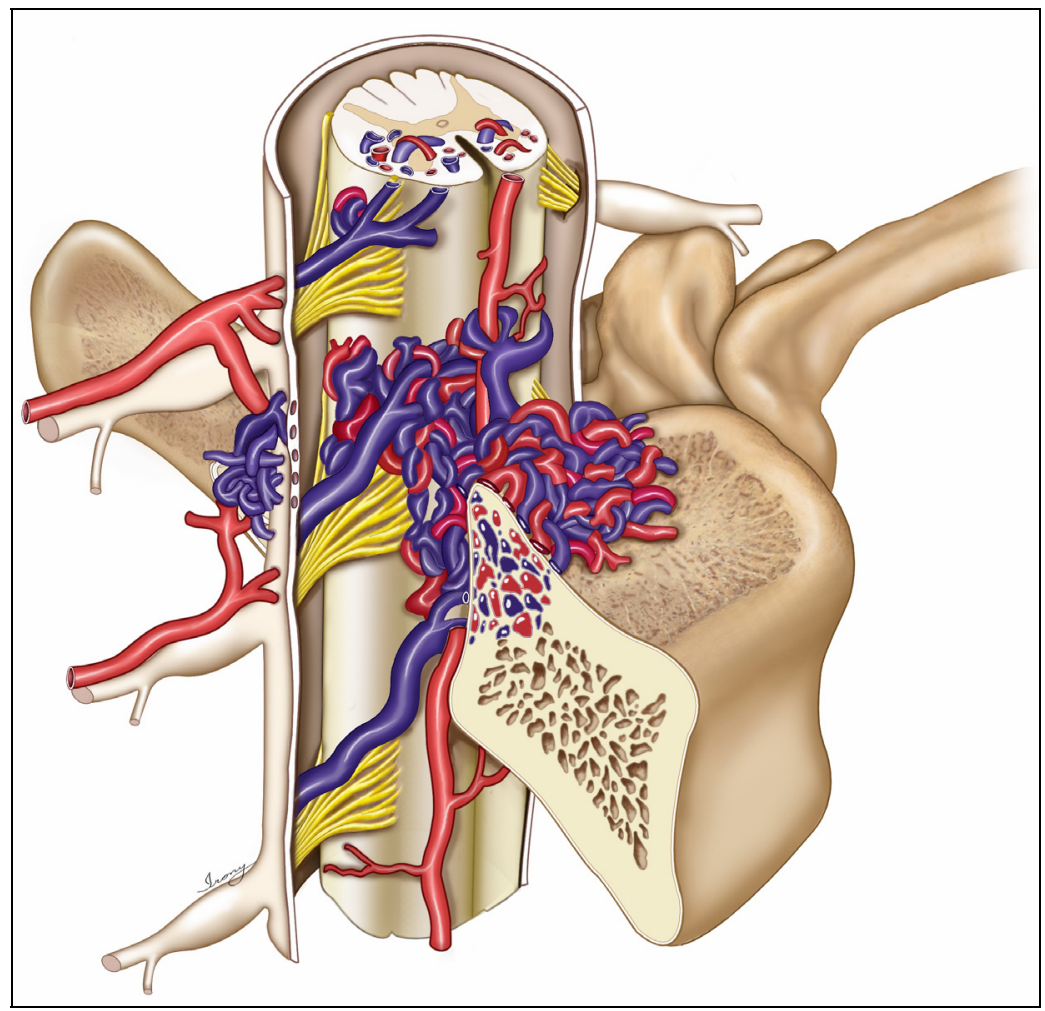

Figura 8: MAVR tipo III, com comprometimento intra e extradural (ilustração realizada por Irony Therezinha Pires) 
- Tipo IV: É a fístula perimedular, ou fístula arteriovenosa intradural localizada na superfície pial. Geralmente ventral ou lateral, e nutrida pelas artérias espinhais anteriores ou posteriores e pode ser subdividida em 3 subtipos:

Subtipo IV-A: Fístula perimedular de tamanho pequeno, nutrida por um único ramo arterial e pouca hipertensão venosa (Figura 9).

Subtipo IV-B: Fístula perimedular de tamanho intermediário, nutrida por múltiplos ramos arteriais.

Subtipo IV-C: Fístula perimedular grande, nutrida geralmente por ramos arteriais gigantes e com sistema venoso muito ectasiado.

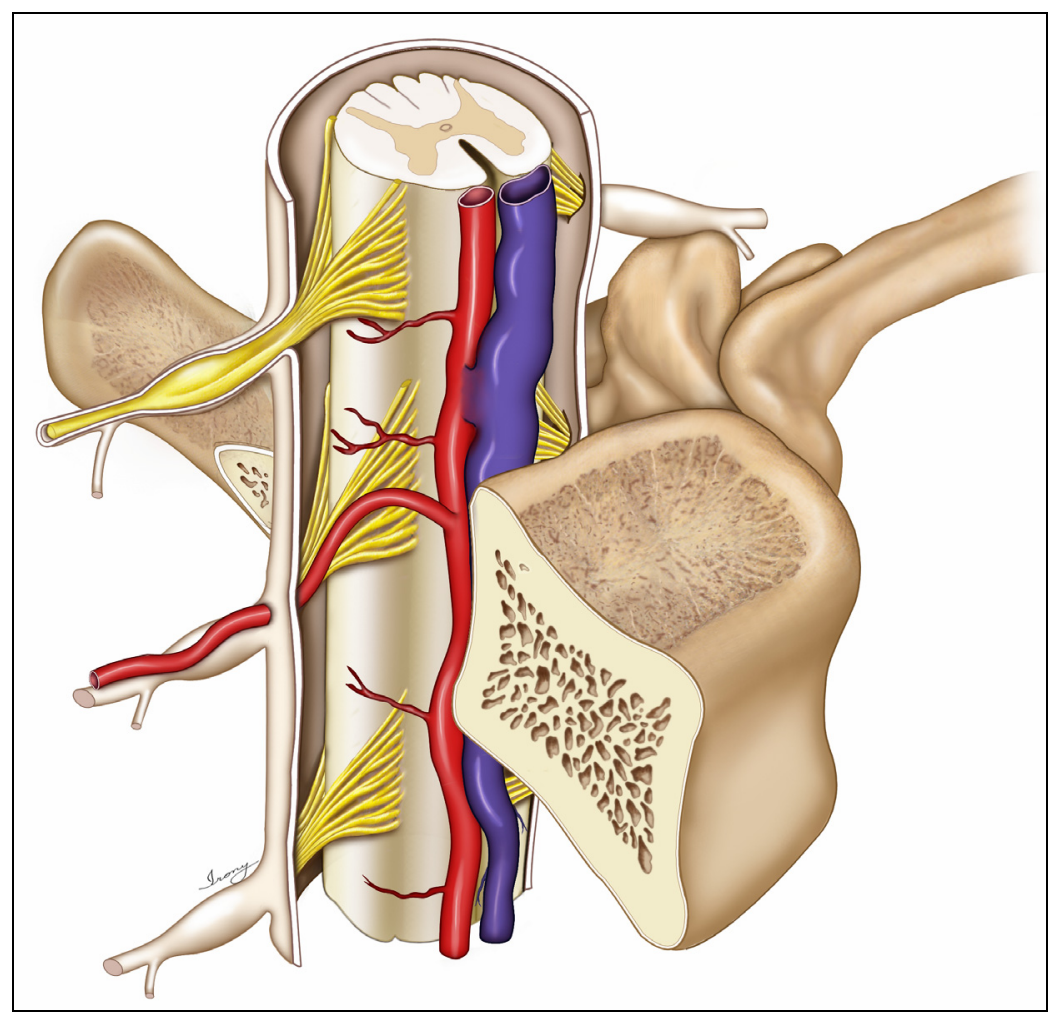

Figura 9: MAVR tipo IV-A, mostrando a conexão entre a artéria espinhal anterior e a veia perimedular ectasiada (ilustração realizada por Irony Therezinha Pires) 
No entanto, ainda existe muita controvérsia na classificação dessas lesões (Marsh, 1999). Spetzler et al., em 2002, reclassificaram essas lesões, incluindo aneurismas e neoplasias, e descreveram um novo tipo de lesão denominada malformação arteriovenosa do cone medular (Spetzler, 2002). Rodesch et al., também em 2002, propuseram outra classificação levando em consideração o seu número (única ou múltipla), arquitetura (nidus ou fístula), localização (medula, cauda eqüina ou raiz) e sua possível ligação a lesões metaméricas (Rodesch, 2002).

Cada tipo de MAVR tem apresentação distinta, do ponto de vista clínico, radiológico e terapêutico, devendo ser discutido separadamente.

\subsection{MAVR tipo I}

\subsubsection{Aspectos Anatômicos}

Também chamadas de fístulas arteriovenosas durais (FAD), essas lesões foram inicialmente descritas por Kendal e Logue, em 1977, que identificaram que o nidus dessa malformação estava distante da medula espinhal (Kendal e Logue, 1977). A comunicação arteriovenosa é transdural, com a drenagem venosa intradural (Benhaiem, 1983).

A maioria das FAD localizam-se na região torácica e lombar e é suprida por ramos das artérias intercostais e lombares. Fístulas sacrais podem ser nutridas por ramos das artérias ilíacas internas, enquanto as cervicais e 
torácicas altas podem receber aporte sangüíneo das artérias carótida externa, vertebral, tronco tirocervical e costocervical (Larsen, 1995). As artérias intercostais e lombares, além de originarem as artérias radiculares anteriores e posteriores, emitem ramos espinhais e dorsais. Esses ramos podem irrigar a dura-máter da coluna vertebral e conseqüentemente suprir a FAD. A fístula está localizada geralmente adjacente ao pedículo vertebral (Stiver, 1999). Quando existe somente uma nutrição arterial, é classificada em subtipo I-A (FAD-A), e quando existem múltiplas nutridoras, em subtipo IB (FAV-B). Neste último, as fístulas podem se localizar em uma única artéria radicular, ou comprometer múltiplas artérias (em múltiplos níveis), e podem ser uni ou bilaterais (Anson e Spetzler, 1992).

A drenagem venosa da $F A D$ é feita retrogradamente para veias medulares, que se comunicam com o plexo coronal. Isso ocorre porque o sistema venoso intradural é desprovido de válvulas, ocasionando transmissão da hipertensão venosa para todo o compartimento venoso intradural. Por isso há competição da drenagem venosa da fístula e da medula espinhal, ocasionando comprometimento da drenagem venosa da medula espinhal. Raramente a drenagem venosa pode ser realizada exclusivamente para o plexo epidural (Willinsky, 1993).

O fluxo retrógrado ocasiona engurgitamento e tortuosidade nas veias de drenagem da FAD, que se apresentam "arterializadas" na superfície da medula espinhal. A veia "arterializada" se estende em média por quatro ou cinco níveis vertebrais, mas ocasionalmente pode atravessar toda a superfície da medula espinhal torácica e a da cauda eqüina (Oldfield, 1983). 
Em cerca de $15 \%$ dos casos, uma veia dilatada também pode estar situada na superfície anterior da medula espinhal (Rosenblum, 1987).

\subsubsection{Epidemiologia}

A FAD é o tipo mais freqüente, totalizando 30 a $80 \%$ das MAVR (Symon 1984, Rosenblum, 1987; Koenig, 1989; Berenstein e Lasjaunias, 1992). No entanto, Bao et al., em 1997, encontraram essas lesões em somente $10 \%$ dos pacientes com MAVR (Bao, 1997). Ocorrem predominantemente na coluna torácica inferior e no cone medular (Rosenblum, 1987). Apresentam-se com maior freqüência entre a quinta e a sexta décadas de vida (Rosenblum, 1987; Morgan, 1989; Van Dijk, 2002). A idade média de apresentação dos pacientes é de 60 a 65 anos (Morgan, 1989; Song, 2001). Raros exemplos de FAD na infância foram relatados (Cahan, 1987; Glasser, 1993). Acomete preferencialmente o sexo masculino (80 a 90\%) (Berenstein e Lasjaunias, 1992; Watson, 1999; Van Dijk, 2002; Jellema, 2003; Steinmetz, 2004; Jellema, 2004). Aproximadamente 60\% das lesões são espontâneas e 40\% associadas a traumas (Osborn, 1999). Stiver, em 1999, questionou se essas lesões, tal como as fístulas durais intracranianas, se desenvolveriam a partir de uma trombose venosa (Stiver, 1999). Outros fatores que poderiam estar relacionados com o desenvolvimento dessas lesões são os repetidos traumas nos discos intervertebrais, osteófitos e estenose foraminal localizados na transição tóraco-lombar (Cahan, 1987). Essa hipótese baseou-se na observação que esses achados eram freqüentes nos pacientes com FAD. 


\subsubsection{Fisiopatologia}

A FAD consiste na comunicação de artérias durais com veias medulares. Essa comunicação é constituída de um nidus plexiforme localizado no folheto dural de uma raiz espinhal (Cahan, 1987; McCutheon, 1996; Wong, 1999). Essa conexão anormal entre artéria e veia ocasiona dilatação e "arterialização" das veias medulares. Normalmente, as veias medulares recebem aporte sangüíneo do plexo venoso coronal e drenam para o plexo epidural. Como o sistema venoso espinhal é desprovido de válvulas, na presença de FAD há inversão no fluxo sangüíneo, que se transmite para o plexo coronal ocasionando hipertensão venosa e congestão medular (Kaynar, 1999).

Aminoff et al., em 1974, propuseram a hipótese de que a hipertensão venosa era o mecanismo que ocasiona a disfunção neurológica nos pacientes com FAD e retrogradamente seria transmitida para veias medulares, perimedulares e plexo coronal. Isso ocasionaria diminuição no gradiente pressórico arteriovenoso na medula espinhal, levando à diminuição da perfusão tecidual e à hipóxia isquêmica do tecido neural, cuja manifestação seria a disfunção neurológica (Aminoff, 1974a). Também poderia causar hipofluxo sangüíneo adjacente à lesão. Clinicamente, isso ocasionaria mielopatia lentamente progressiva. Esse quadro é potencialmente reversível se diagnosticado e tratado prontamente (Kataoka, 2001). 
Hassler et al. realizaram um interessante estudo analisando aspectos hemodinâmicos das FAD (Hassler, 1989). Num período de 5 anos, foi medida a pressão na veia proximal, antes e após a desconexão cirúrgica da fístula em 25 pacientes. Antes da ligadura, a pressão era de aproximadamente 60 a $88 \%$ da pressão arterial média sistêmica. Após a desconexão, a pressão diminuía para 16 a $64 \%$ do valor inicial. Antes da ligadura, a pressão venosa oscilava simultaneamente com a pressão arterial média sistêmica, fato que não se observava após a ligadura. Esse achado talvez esteja relacionado com a piora dos sintomas quando o paciente realiza esforço físico.

Outros mecanismos foram sugeridos, como compressão da medula espinhal por vasos dilatados (Krayenbühl, 1969) e aracnoidite (Criscuolo, 1989), porém nenhum teve embasamento suficiente para ser aceito.

\subsubsection{Anatomia Patológica}

Relatos do aspecto histológico das FAD são escassos. Aminoff et al. descreveram que havia uma proliferação dos capilares nas faces ânterolateral e posterior da medula espinhal, correspondendo à região drenada pelo plexo coronal e sugestiva de hipóxia crônica (Aminoff, 1974a). McCutcheon et al. constataram que a fístula era constituída de uma ou mais artérias durais e uma veia de drenagem (McCutcheon, 1996). Hurst et al. demonstraram a presença de hialinização e arterialização das veias, além da presença de eventuais calcificações. Evidências de trombose recente e 
organizada foram observadas, tanto nos vasos intramedulares como nos piais. Constatou-se a presença de necrose na substância branca e cinzenta, e evidência de perda neuronal (Hurst, 1995).

\subsubsection{Sintomatologia}

Uma história de sintomas intermitentes, recorrentes com exercícios e aliviada com repouso não é incomum (Aminoff e Logue, 1974b; Oldfield, 1988). A dor é o sintoma inicial mais freqüente. Dor tóraco-lombar ou radicular é um sintoma inicial em 35 a 42\% dos pacientes (Aminoff e Logue, 1974b; Symon, 1984). Um pequeno número de casos, cerca de 15\%, apresenta dor radicular isolada (Rosenblum, 1987). A dor decorrente da mielopatia pode ser muito intensa e é ocasionada pela desorganização parcial ou total da arquitetura nervosa no local da lesão. Isso provoca desorganização no processamento e na transferência de informações na medula espinhal, justificando a ocorrência de dor mielopática (Rogano, 2001). Na ocasião do diagnóstico, a dor pode estar presente em cerca de $55 \%$ dos pacientes e ser o sintoma mais valorizado por eles (Aminoff e Logue, 1974b).

A fraqueza nos membros inferiores também é um sintoma inicial muito freqüente. Aminoff e Logue, em 1974, observaram que esse foi o sintoma inicial em 32\% dos pacientes (Aminoff e Logue, 1974b). Na ocasião do diagnóstico, esse sintoma foi o mais observado, sendo encontrado em cerca de $95 \%$ dos casos (Aminoff e Logue, 1974b). Os pacientes com FAD podem 
se apresentar com um padrão de comprometimento do neurônio motor inferior, com paraparesia flácida, ou com comprometimento do neurônio motor superior, com paraparesia espástica e sinais de liberação piramidal. Sinais de comprometimento do neurônio motor inferior foram encontrados em $56 \%$ dos pacientes e fasciculações em 13\% daqueles com FAD (Symon, 1984). Koenig et al., analisando uma série de 20 pacientes com FAD, verificaram que 19 apresentavam comprometimento no neurônio motor inferior (Koenig, 1989). Em cinco dos pacientes, o exame neurológico inicial mostrava uma transição de paraparesia espástica para flácida, sendo esses achados atribuídos ao comprometimento das células do corno anterior da medula espinhal, que são mais sensíveis à anóxia (Koenig, 1989).

A constatação de nível sensitivo no exame neurológico é freqüentemente observada e reflete o nível da fístula (Rosenblum, 1987). Aminoff e Logue, em 1974, observaram que essa alteração foi o sintoma inicial em $33 \%$ dos pacientes e na ocasião do diagnóstico estava presente em $87 \%$ dos pacientes (Aminoff e Logue, 1974b).

O comprometimento esfincteriano é freqüente na ocasião do diagnóstico. Aminoff e Logue, numa série de 60 pacientes, encontraram comprometimento vesical em 56 pacientes (93\%), classificando essas alterações em discreta, moderada ou severa (Aminoff e Logue, 1974c). A discreta foi caracterizada como excitação, urgência, ou aumento na freqüência; a moderada como ocasional incontinência ou retenção; e a severa como total incontinência ou retenção. Dos 56 pacientes seguidos, em $18(32 \%)$ o comprometimento foi discreto, 12 (21\%) moderado e em 26 
(46\%) acentuado. A obstipação foi observada na ocasião do diagnóstico em $65-86 \%$ dos pacientes (Aminoff e Logue, 1974b). Sintomas vesicais e intestinais são raramente encontrados inicialmente. Criscuolo et al., numa série de 55 pacientes, encontraram somente 4 pacientes em que o sintoma inicial apresentado era de comprometimento de esfíncteres (Criscuolo, 1989). Entretanto, é um sintoma muito freqüente na ocasião do diagnóstico, com até $90 \%$ dos pacientes apresentando fraqueza muscular, parestesia e disfunção vesical (Symon, 1984).

Larsen e Hallbach, em 1999, relataram os resultados do tratamento de 34 pacientes com FAD (Larsen e Hallbach, 1999). Os sintomas iniciais encontrados foram paresia em membros inferiores (41\%), dor tóraco-lombar (17\%), distúrbios na marcha $(15 \%)$, alterações na sensibilidade $(15 \%)$, dor radicular $(9 \%)$, e alterações vesicais (3\%). Na ocasião do diagnóstico, as alterações foram as seguintes: distúrbios sensitivos (100\%), paresia em membros inferiores (94\%), distúrbios intestinais (86\%), distúrbios vesicais (83\%), dor tóraco-lombar (49\%), distúrbios na marcha (46\%), impotência (44\%) e dor radicular (34\%).

A maioria dos pacientes apresenta uma história de sintomas com desenvolvimento lentamente progressivo (Aminoff e Logue, 1974c). Cerca de 10 a $15 \%$ dos pacientes têm apresentação aguda ou subaguda (até 4 semanas) dos sintomas (Criscuolo, 1989). Sintomas relacionados a hemorragia não foram observados em grandes séries (Symon, 1984; Criscuolo, 1989), porém um caso de hematoma subdural já foi relatado (Han, 1999). 
Vários fatores foram associados à piora da hipertensão venosa e/ou dos sintomas. Exercícios físicos e certas posturas estão relacionadas ao agravamento dos sintomas em $70 \%$ dos pacientes (Rosenblum, 1987). Outros fatores como trauma (Symon, 1984), cirurgia (Criscuolo, 1989), punção liquórica lombar (Awad, 1990), gestação (Rosenblum, 1987) e menstruação (Kim, 1991) foram descritos como desencadeantes da piora dos sintomas. Aminoff e Logue, em 1974, relataram que, em uma série de 60 pacientes, em 19 havia claudicação intermitente associada ao exercício físico, que melhorava após o repouso (Aminoff e Logue, 1974c).

A deterioração clínica rapidamente progressiva na ausência de hemorragia é sugestiva de síndrome de Foix-Alajouanine, que deriva da congestão venosa levando a estase e trombose (Criscuolo, 1989).

O diagnóstico diferencial das FAD inclui espondilose lombar, doenças desmielinizantes e tumores raquimedulares (Kaynar, 1999).

\subsubsection{História Natural}

Aminoff e Logue, em 1974, relataram com detalhes a história natural das FAD baseados no acompanhamento de 60 pacientes (Aminoff e Logue, 1974c). Em 25 pacientes (42\%), dor tóraco-lombar ou radicular precedia outros sintomas. Cerca de $56 \%$ dos pacientes não apresentavam restrições nas suas atividades após 6 meses de instalação dos sintomas. No entanto, após 3 anos, cerca de $91 \%$ dos pacientes já apresentavam limitações nas atividades cotidianas. Cerca de $20 \%$ dos pacientes já se apresentavam 
severamente debilitados após 6 meses do início dos sintomas. Cerca de $50 \%$ dos pacientes apresentaram comprometimento motor severo após 3 anos de evolução dos sintomas e $90 \%$ após 5 anos. Nove pacientes evoluíram para óbito, como resultado de complicações da paraparesia ou paraplegia. Raros casos de resolução espontânea das FAD após trombose foram relatados (Renowden, 1993; Meder, 1995).

\subsubsection{Diagnóstico por Imagem}

\section{Mielografia}

A mielografia foi o primeiro exame por imagem a estabelecer 0 diagnóstico pré-operatório de MAVR (Perthes, 1927 apud Marsh, 1999*). Sua sensibilidade é próxima de 100\% (Djindjian, 1978a). No entanto, deixa a desejar em diversos aspectos: é um método invasivo, além de não fornecer dados sobre nutrição, drenagem, localização, velocidade do fluxo e avaliação do parenquima medular. A imagem serpiginosa perimedular é bastante sugestiva de FAD, traduzindo uma veia dilatada (Figura 10). Essa imagem também pode estar presente em tumores que levem a engurgitamento venoso. Pode-se observar imagens de bloqueio parcial ou total, principalmente quando há hemorragia ou aracnoidite (Agnoli, 1978). Entretanto, a mielografia pode ser normal. Rosenblum et al., numa série de 27 pacientes com FAD, encontraram 3 pacientes com mielografia normal (Rosenblum, 1987). Após o advento da Ressonância Magnética (RM), este 
método caiu em desuso, sendo indicado somente naqueles casos em que RM é inconclusiva, negativa ou contra-indicada. A colheita do líquido cefalorraquidiano pode mostrar elevação da taxa de proteína (Aminoff e Logue, 1974b).

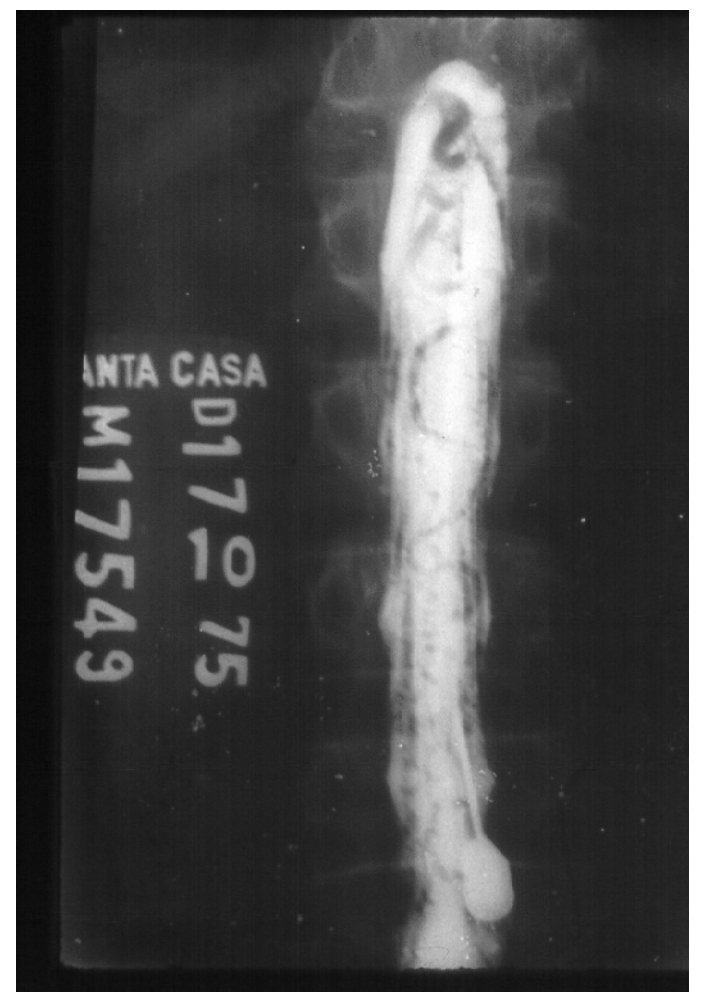

Figura 10: Mielografia de um paciente com MAVR, em que se observa imagem serpiginosa intra-raquiana, sugestiva de engurgitamento venoso

\section{Tomografia Computadorizada}

A tomografia computadorizada (TC) também é pouco utilizada, pois se trata de um método seccional e a medula é extensa, tornando-se pouco sensível, além da exposição excessiva à radiação. O osso da coluna vertebral também ocasiona artefatos que prejudicam a visibilização da lesão. 
Com a administração de contraste podem ser realçadas imagens serpiginosas extramedulares compatíveis com FAD. A mielotomografia não traz novos elementos em relação à mielografia.

\section{Ressonância Magnética}

Quando existe suspeita de MAVR, o primeiro exame que deve ser feito é a RM (Conti, 2004). A RM é um exame sensível para o diagnóstico, no qual porém é difícil a avaliação da extensão do nidus, da nutrição e da drenagem venosa. Na RM observa-se freqüentemente uma imagem serpiginosa com ausência de sinal ("flow void") na superfície da medula espinhal, relatada em $82 \%$ dos pacientes, e melhor visibilizada na seqüência em densidade de prótons, ponderada em T2, ou após injeção de gadolínio (Willinsky, 1995). Outro aspecto observado na RM é a expansão focal da medula espinhal, fato presumidamente atribuído ao edema. Recentemente, Gilbertson et al. relataram os resultados da análise retrospectiva das imagens de RM em 66 pacientes com FAD (Gilbertson, 1995). Descreveram que a imagem de hipersinal na medula espinhal visibilizada na seqüência ponderada em T2 foi observada em todos pacientes com FAD. As fístulas estão localizadas na dura-máter e não podem ser identificadas por esse método diagnóstico, observando-se apenas a ectasia venosa. O fato de a RM não evidenciar a FAD não exclui este diagnóstico (Gariépy, 1999). Bowen et al., em 1995, relataram 8 pacientes com diagnóstico de FAD submetidos à angioressonância seguida de angiografia digital (Bowen, 1995). Todos os pacientes apresentavam vasos tortuosos e dilatados na 
superfície da medula espinhal, que correspondiam a veias, quando correlacionadas a angiografia digital. Lee et al., em 1998, relataram que a angioressonância pode mostrar vasos dilatados e tortuosos na superfície medular, contíguos a um vaso dilatado, estendendo-se até um forame. Esse aspecto foi observado em 9 pacientes, e em todos foram realizados angiografia e cirurgia, que comprovaram o diagnóstico e a localização da lesão (Lee, 1998).

\section{Angiografia}

Após o processo de triagem com determinação do nível a ser estudado, deve ser realizada a angiografia medular, que é o exame chave para avaliar precisamente a FAD e determinar o tipo de tratamento a ser realizado (Caragine, 2002). Raramente pode haver casos de falso negativo (Alleyne Jr, 1999). A ocorrência de complicações neurológicas durante esse exame é rara (Moseley, 1977). Permite demonstrar a angioarquitetura da MAVR e a vascularização da medula normal, inclusive das artérias espinhais anterior e posteriores (Kunk, 1969; Djindjian R, 1978a). O protocolo para estudo das FAD deve seguir um padrão, que foi desenvolvido para o diagnóstico de qualquer MAVR. Rotineiramente é feita sob anestesia geral, pois os movimentos respiratórios podem causar artefatos que dificultam a análise completa da lesão (Houdart, 1966; Rosenwasser, 1999; Scroop, 2003). Quando a presença de gases no intestino causa artefatos na imagem, dificultando a análise do exame, podem ser administradas drogas que reduzem peristaltismo, ajudando a controlar esse problema (Rosenwasser, 
1999). A subtração da imagem é importante, pois a eliminação das estruturas ósseas permite melhor definição da MAVR (Doppman, 1965). O estudo angiográfico seletivo foi desenvolvido pioneiramente por Di Chiro et al., em 1967, permitindo o estudo sistemático dos vasos sangüíneos raquimedulares (Di Chiro, 1967). Na região cervical, investigam-se as artérias vertebrais, cervicais profunda e ascendente bilateralmente e a intercostal suprema. Por vezes há a necessidade de estudar todas as aferências vasculares para a dura-máter dessa região, bem como todas as possibilidades de anastomoses com os eixos espinhais anterior e posterior, pois estes podem participar da MAVR. Deve-se estudar então a artéria carótida externa, pois as artérias faríngeas ascendentes e occipitais emitem ramos neuromeníngeos, que podem contribuir na nutrição da MAVR. A artéria carótida interna também deve ser estudada, devido à possibilidade de participação de ramos do troncos meningo-hipofisário e ínfero-lateral. Nas lesões torácicas são cateterizadas seletivamente as artérias intercostais que nutrem a MAVR, no mínimo em dois níveis acima e abaixo da lesão, bilateralmente. Nas lesões torácicas baixas e lombares, é recomendado o estudo das artérias lombares, e eventualmente das sacrais laterais e mediana, pois pode haver nutrição retrógrada pela artéria do filamento terminal. A cateterização de artérias lombares e sacrais pode ser difícil, requerendo manobras complementares com o cateter (Chiras, 1978). A fístula pode ser única ou múltipla. A drenagem venosa das MAVR pode ser rostral, caudal, ou ambas e pode mudar com o tempo (Niimi, 1999). A velocidade do fluxo sangüíneo também é importante, pois existem FAD em 
que o fluxo é tão lento que a lesão só é evidenciada em aquisições tardias, por vezes chegando a 20-60 segundos (Oldfield, 1983; Berenstein e Lasjaunias, 1992). A drenagem venosa pode ser bastante extensa, podendo alcançar até os seios cranianos. É extremamente importante a identificação do eixo espinhal anterior acima e abaixo da lesão, pois isso será importante no planejamento cirúrgico ou endovascular. Em cerca de $15 \%$ dos pacientes, a $F A D$ e a medula espinhal compartilham do mesmo suprimento arterial (Rosenblum, 1987). Biondi et al., em 1992 estudaram 72 pacientes com FAD e não encontraram qualquer paciente com formação aneurismática, o que é compatível com o fluxo lento dessa lesão (Biondi, 1992a).

\subsubsection{Tratamento}

O objetivo do tratamento é a completa obliteração da fístula no início da veia, pois a ligadura arterial proximal promove revascularização por anastomoses e conseqüentemente a recorrência dos sintomas. Isso pode ser conseguido através de tratamento endovascular ou cirúrgico. Em 1977, Kendall e Logue relataram a primeira descrição das FAD e mostraram o resultado satisfatório da desconexão cirúrgica e exérese de uma veia "arterializada" intradural (Kendall e Logue, 1977). Em algumas instituições, o tratamento inicial é o endovascular. O tratamento cirúrgico estaria indicado naqueles pacientes em que o suprimento da medula espinhal fosse o mesmo da FAD, ou naqueles em que o tratamento endovascular não conseguisse tratar a lesão (Stiver, 1999). Outras instituições indicam 
também o tratamento cirúrgico se a artéria de Adamkiewicz, ou espinhal anterior, e a FAD se opacificam pelo mesmo pedículo vascular (Djindjian R, 1978b). No entanto, alguns autores indicam sempre o tratamento cirúrgico, por considerarem o resultado deste procedimento como definitivo (Detwiler, 1999). Alleyne Jr et al., em 1999, relataram três casos da FAD angiograficamente oculta que foram tratados através de laminectomia exploradora. Nesses pacientes, o quadro clínico e outros exames de imagem (RM ou mielografia) sugeriam FAD (Alleyne Jr, 1999).

\section{Tratamento Cirúrgico}

O tratamento cirúrgico consiste na desconexão da comunicação entre a artéria ou artérias que suprem a fístula e a veia de drenagem. No início, a laminectomia descompressiva foi realizada, mas mostrou-se ineficaz para o tratamento dessas lesões (Symon, 1984; Figueirêdo, 1999). Posteriormente, propôs-se que o tratamento cirúrgico deveria promover a exérese dos vasos tortuosos e dilatados, situados na superfície dorsal da medula espinhal (Krayenbühl, 1969; Luessenhop, 1969; Yaşargil, 1976). Com isso, muitas vezes as veias perimedulares e do plexo coronal eram retiradas, mas não a veia principal de drenagem, o que ocasionava persistência da lesão e, eventualmente, agravamento da hipertensão venosa na medula espinhal. Somente mais tarde demonstrou-se que a interrupção ou desconexão da veia de drenagem, sem a necessidade da retirada do nidus, mostrou ser um método cirúrgico eficaz para o tratamento das FAD (Logue, 1979; Afshar, 1995). 
Para a abordagem dessas lesões pode ser feita laminectomia, ou hemilaminectomia e, se necessário, foramenotomia. Após a abertura da duramáter é possível identificar-se uma veia dilatada próxima a esta, que recobre uma raiz, além do plexo venoso coronal igualmente congesto na face dorsal da medula. Em geral, a simples coagulação e secção da veia de drenagem junto ao ponto fistular é o suficiente para tratamento dessa malformação. A exérese da dura-máter comprometida, se por um lado evita a reabertura da fístula por outras vias, não evidentes na cirurgia ou angiografia, por outro adiciona riscos, como fístula liquórica e lesão radicular (Watson, 1999). Também pode ocasionar dano neurológico caso a artéria de Adamkiewicz seja originária da mesma artéria radicular que supre a FAD (Rosenblum, 1987).

Logue, em 1979, relatou o resultado cirúrgico de 24 pacientes com FAD (Logue, 1979). Na ocasião do diagnóstico, 12 pacientes (50\%) apresentavam comprometimento acentuado da marcha. Após o tratamento, observou que 15 pacientes (62,5\%) tiveram algum grau de melhora. A dor, que estava presente em 12 pacientes, apresentou remissão em 8 pacientes. A melhora dos sintomas urinários foi mais discreta, ocorrendo em somente 5 (22\%) dos 22 pacientes com esse comprometimento. Symon et al., em 1984, relataram os resultados do tratamento cirúrgico em 55 pacientes (Symon, 1984). Em 85\% dos pacientes houve estabilização da progressão da alteração na marcha, enquanto 20 dos 31 pacientes com comprometimento acentuado e 12 dos 15 pacientes com comprometimento moderado evoluíram com melhora neurológica. A função esfincteriana melhorou em 26 dos 46 pacientes com comprometimento, retornando ao normal em 11. 


\section{Tratamento Endovascular}

O objetivo do tratamento endovascular é a oclusão do nidus (intradural) e do início da veia de drenagem. Deve ser evitada a oclusão isolada da(s) artéria(s) proximal(is) ao nidus, com risco de que ocorra recanalização da lesão por anastomoses transdurais. Igualmente deve ser evitada a oclusão exagerada da veia de drenagem, com risco de ocasionar trombose das veias perimedulares (Niimi, 1997).

Inicialmente, o tratamento endovascular das FAD consistia na oclusão da lesão com partículas de polivinil álcool (PVA), mas este mostrou resultados desanimadores. A evolução mostrou que ocorria somente oclusão temporária da nutrição da lesão, havendo posterior recanalização da malformação em cerca de 80\% dos pacientes (Hall, 1989; Morgan, 1989). Morgan et al., em 1989, relataram os resultados do tratamento endovascular com partículas de PVA em 17 pacientes (Morgan, 1989). Foram tratados 14 pacientes através de 18 sessões de embolização. Três foram submetidos a cirurgia inicialmente. A recanalização foi constatada em 13 dos exames de controle angiográfico realizados após a embolização. Nichols et al., em 1992, trataram 14 pacientes com FAD através da embolização com partículas (Nichols, 1992). Observaram que inicialmente todos os pacientes apresentaram melhora dos sintomas, mas na evolução, 11 pacientes apresentaram piora neurológica. Destes, 9 apresentaram angiografia, mostrando recidiva da lesão. A ineficácia da embolização com partículas se deve a vários fatores. Pode ocorrer oclusão proximal à lesão, pois mesmo as menores partículas não conseguem atingir as fístulas microscópicas 
localizadas na dura-máter. Alem disso, a extensa rede de capilares colaterais pode facilitar a recidiva, pois o início da veia de drenagem não está ocluída. As partículas também podem ocasionar oclusão parcial da lesão, o que pode levar a estase sangüínea e trombose. Com a organização do trombo, poder haver reabsorção do mesmo com recanalização da lesão (Choi, 1992).

O tratamento endovascular com adesivos tissulares (colas) tem mostrado resultados satisfatórios. Consiste na cateterização superseletiva da artéria radicular e embolização da(s) fístula(s) com N-butil cianoacrilato (NBCA ou histoacryl囚) ou isobutil-2-cianoacrilato (IBCA). O desenvolvimento de cateteres cada vez menores e mais maleáveis tem permitido a evolução dessa abordagem terapêutica. Merland et al. trataram uma série de 45 pacientes através da embolização da FAD com IBCA. A oclusão foi bem sucedida em 31 pacientes e em 14 foi necessário o tratamento cirúrgico, pois a oclusão foi proximal. De 42 pacientes acompanhados no seguimento, 31 evoluíram com melhora neurológica. Niimi et al., em 1997, relataram os resultados da embolização de 49 pacientes com FAD (Niimi, 1997). Após o procedimento observaram uma taxa de oclusão da fístula em 39 (80\%) pacientes. No seguimento, 13 pacientes evoluíram com piora neurológica. Destes, em 6 a angiografia de controle mostrou recanalização da lesão. Esse achado era sugestivo de que o adesivo não havia penetrado adequadamente no nidus e no início da veia de drenagem, pois a fístula se opacificava por vasos colaterais. 


\subsection{MAVR tipo II}

\subsubsection{Aspectos Anatômicos}

As MAVR tipo II também são chamadas de malformações arteriovenosas intramedulares (MAI). Podem estar localizadas na superfície da medula, no interior (intramedulares), ou em ambas as situações (Connolly Jr, 1999). Costumam ter múltiplas nutrições arteriais, originárias das artérias espinhal anterior e/ou posteriores. A angioarquitetura da malformação pode incluir a presença de nidus, ou fístula(s), ou ambos. São lesões de alto fluxo sangüíneo e estão relacionadas à presença de aneurismas, arteriais ou venosos. A incidência de aneurismas associados a MAl é estimada entre 6 a 10\% (Herdt, 1971; Miyamoto, 1983; Pia, 1978a). Essa incidência é semelhante à encontrada entre aneurismas e malformações arteriovenosas encefálicas (Herdt, 1971; Suzuki 1979).

\subsubsection{Epidemiologia}

A sua freqüência é estimada entre 36 a 53\% das MAVR (Rosenblum, 1987; Berenstein e Lasjaunias, 1992). Não há predominância quanto ao sexo (Berenstein e Lasjaunias, 1992). Podem ocorrer em qualquer nível da medula, mas as localizadas na região tóraco-lombar parecem ser mais freqüentes. Berenstein e Lasjaunias, em 1992, relataram que as MAl localizadas na região tóraco-lombar foram encontradas em $63 \%$ dos pacientes e as cervicais, 
em $37 \%$ dos pacientes (Berenstein e Lasjaunias, 1992). A maioria ocorre em pacientes jovens, e em $50 \%$ dos pacientes os sintomas já estão presentes aos 16 anos de idade (Berenstein e Lasjaunias, 1992; Grote, 1999).

\subsubsection{Fisiopatologia}

A hemorragia costuma estar associada à presença de nidus e malformações de alto fluxo sangüíneo. É difícil estimar sua incidência e recorrência. As MAI podem ocasionar a formação de hematoma subdural, extradural, hemorragia subaracnóidea ou hematomielia. Geralmente é devastadora, levando à instalação súbita de déficit neurológico maciço. Outro sintoma freqüente é a dor, podendo ser localizada ou meningorradicular. Também podem causar rigidez nucal e opistótono. Mais raramente podem ocasionar hidrocefalia e hipertensão intracraniana (Djindjian M, 1978a). Dentre as MAVR, a associação com aneurismas é mais freqüente nas MAI (Stein, 1990). Miyamoto et al. relataram que a incidência de hemorragia pode ser maior na presença de aneurisma (Miyamoto, 1983). Rosenblum et al. relataram uma série de 54 pacientes, dentre os quais 24 apresentavam aneurismas arteriais ou venosos (Rosenblum, 1987). A incidência de hemorragia nos pacientes com aneurismas foi de 52\%, enquanto naqueles sem evidência de aneurisma foi de $50 \%$. Biondi et al., em 1992, trataram 14 pacientes com MAI ou MAVM e aneurisma associado através da embolização da MAVR (Biondi, 1992b). Observaram que os pacientes com MAI submetidos à embolização parcial ou total da MAVR 
apresentaram redução ou desaparecimento do aneurisma. Também observaram que nos casos de recanalização da MAVR com recidiva houve reaparecimento ou aumento do aneurisma.

O prognóstico costuma ser ruim, principalmente nas MAI localizadas na região cervical. A mortalidade é estimada em 18\% (Berenstein e Lasjaunias, 1992). Eventualmente, uma MAVR cervical pode manifestarse com hemorragia subaracnóidea encefálica, dificultando o seu diagnóstico.

A compressão medular pode ser causada por hemorragias, ou por aneurismas, em geral venosos, situados distalmente ao nidus. Extensas malformações arteriovenosas às vezes podem causar compressão medular. Os sintomas são variados, podendo haver dor e mielopatia progressiva.

Outro mecanismo é o "fenômeno de roubo", causado por hipofluxo e isquemia na periferia do nidus, e associado à mielopatia progressiva (Djindjian M, 1978b; Grote, 1999; Kaynar, 1999). Esse mecanismo foi extensamente analisado em três doenças: estenose da artéria subclávia proximal à origem da artéria vertebral, malformação arteriovenosa e coarctação da aorta. No entanto o "fenômeno de roubo" ainda é considerado um modelo teórico, que carece de comprovação científica (Taylor, 2002).

A gestação costuma estar associada à piora dos sintomas (Rosenblum, 1987). O mecanismo para que isso ocorra não está definido. 


\subsubsection{Anatomia Patológica}

As MAl consistem em um aglomerado de artérias e veias dismórficas que se comunicam diretamente, sem interposição de um leito capilar (Connolly Jr, 1999). As camadas dos vasos costumam estar espessadas e eventualmente podem ser encontrados trombos no seu interior (Hager, 1978; Jellinger, 1978). Embora as artérias que suprem a malformação possam estar dilatadas e as veias de drenagem estenderem-se ao longo da superfície medular, geralmente o nidus costuma ser compacto e a MAI está limitada a poucos segmentos espinhais.

\subsubsection{Sintomatologia}

Paresias costumam ser o sintoma inicial em um terço dos pacientes, mas na ocasião do diagnóstico podem estar presentes em até $90 \%$. Outros sintomas comuns na ocasião do diagnóstico são: alterações sensitivas (74\%), disfunções urinárias e intestinais (80\%), e impotência (42\%) (Berenstein e Lasjaunias, 1992).

\subsubsection{História Natural}

A maioria desses sintomas é devida à hemorragia. A apresentação com hemorragia subaracnóidea pode ser a manifestação inicial em $60 \%$ dos pacientes (Connolly, 1998). Quando a hemorragia é profusa, ou nas lesões 
cervicais, pode ocasionar cefaléia e alteração no nível de consciência, o que a torna indistinguível da hemorragia subaracnóidea intracraniana (Berenstein e Lasjaunias, 1992). Após a hemorragia subaracnóidea, pode ocorrer hidrocefalia (Djindjian M, 1978a). Uma manifestação rara pode ser através de hemorragia intraventricular (Barzó, 1997). A hemorragia pode estar presente em mais de $50 \%$ dos casos na ocasião do diagnóstico. A recorrência é maior que nas MAV cerebrais, ocorrendo em aproximadamente $10 \%$ no primeiro mês e $40 \%$ no primeiro ano após o sangramento inicial. A hemorragia está associada a uma mortalidade de 18\% (Berenstein e Lasjaunias, 1992). Esse mau prognóstico justifica uma terapia agressiva, principalmente nos pacientes jovens e com pouco déficit. As conseqüências neurológicas da hemorragia podem ser variáveis, podendo ser desde mínimas ou com déficit neurológico transitório, ou até sintomas de secção medular com déficit neurológico completo e são graves em mais da metade dos casos (Connolly, 1999).

Raramente, o paciente pode apresentar sintomas de mielopatia lentamente progressiva (Grote, 1999). Isso pode acontecer por fenômeno de roubo, isquemia, ou compressão. A presença de aneurismas arteriais é observada em até $44 \%$ dos pacientes, também podendo ser encontrados "aneurismas venosos" (Rosenblum, 1987; Niimi, 1999). 


\subsubsection{Diagnóstico por Imagem}

\section{Mielografia}

A mielografia, como já foi dito, apresenta sensibilidade elevada na detecção de MAVR. No entanto, não permite avaliar o tamanho, suprimento arterial, drenagem venosa da MAI, bem como avaliar a medula espinhal.

\section{Tomografia Computadorizada}

A TC também é pouco utilizada, mas pode ser útil para demonstrar a presença e a localização de sangramento. Caso o paciente apresente um nível sensitivo, o exame pode ser dirigido para aquela localização. Caso contrário, como se trata de um método seccional e a medula é extensa, a avaliação torna-se difícil. Com a administração de contraste podem ser realçadas imagens serpiginosas, sugestivas de vasos sangüíneos dilatados e tortuosos.

\section{Ressonância Magnética}

A RM é o exame de escolha para determinar a relação da MAI com a medula espinhal (Connolly, 1999). Também permite a determinação do tamanho do nidus, presença de aneurismas e varicosidades venosas (Di Chiro, 1985; Doppman, 1987). Nos pacientes com indicação cirúrgica, a RM pode permitir localizar se a MAl está situada anterior ou posteriormente na medula e determinar qual é a melhor abordagem cirúrgica (Joseph, 1999). 
Também permite detectar se o nidus está intra ou extramedular, além da presença de sangramento nas diversas fases de evolução, sua quantidade e localização (Dormont, 1987).

\section{Angiografia}

A angiografia digital na pesquisa de MAl deve seguir o mesmo protocolo de investigação de qualquer MAVR. Cateterismo seletivo, injeção do meio de contraste em ramos radículo-medulares das artérias vertebrais, costocervical, tirocervical, carótidas internas e externas, intercostais e lombares devem ser realizadas (Berenstein e Lasjaunias, 1992). Nas lesões torácicas inferiores e no cone medular, a artéria espinhal anterior geralmente está envolvida, o que justifica a identificação da artéria de Adamkiewicz (Joseph, 1999). O estudo angiográfico deve ser minucioso, procurando determinar se a lesão se opacifica por ramos diretos (vasos que suprem somente o nidus), ou por ramos indiretos (que opacificam o tecido nervoso normal e por recrutamento opacificam também a MAI). Esse aspecto é importante para o planejamento do tratamento endovascular, pois é motivo de insucesso desta terapia (Berenstein e Lasjaunias, 1992). Nessas situações, pode ser usado o recurso de magnificação da imagem para melhor definição da lesão (Shiozawa, 1978). Raramente a MAl pode ser múltipla, justificando assim a pesquisa de lesões em toda a raqui (Joseph, 1999). A identificação de aneurismas e fístulas intranidais é importante para o planejamento do tratamento. Eventualmente o aneurisma pode apresentar 
calcificações (Deeb, 1977). Esses componentes devem ser embolizados preferencialmente, pelo risco de hemorragia.

Ocasionalmente, pode ser difícil a diferenciação de um hemangioblastoma de uma MAI (Larsen, 1999).

Também pode ser realizada de maneira segura a angiografia intraoperatória nos casos de recidiva ou lesões complexas (Benes, 2003).

\subsubsection{Tratamento}

O tratamento dessas lesões ainda é controverso, dependendo de uma série de fatores: localização na medula, angioarquitetura, e tamanho. Pia, em 1978, avaliando os resultados a longo prazo dos tratamentos endovascular e cirúrgico, recomendou que essas lesões deveriam ser extirpadas cirurgicamente (Pia, 1978b). No entanto, o tratamento combinado, endovascular e cirúrgico, deve ser considerado. Na abordagem desses pacientes, é importante ressaltar que a sintomatologia está relacionada ao alto fluxo na lesão. A sua diminuição, através da embolização, pode levar ao abrandamento da ectasia e da congestão venosa, conseqüentemente acarretando melhora neurológica e minimizando o risco de sangramento na cirurgia (Detwiler, 1999). A completa exclusão da malformação, seja por via endovascular ou por microcirurgia, pode ter conseqüências desastrosas, por isso a monitorização do potencial evocado somato-sensitivo e motor é recomendada por alguns autores, qualquer que seja o método de tratamento empregado (Niimi, 1999). 


\section{Tratamento Cirúrgico}

O tratamento microcirúrgico isolado pode ser tecnicamente difícil, principalmente naquelas lesões intramedulares na região cervical, ou localizadas ventralmente na medula espinhal (Houdart, 1974). A embolização pré-cirúrgica reduz o fluxo sangüíneo na lesão, diminuindo o risco de sangramento intra-operatório. A simples ligadura das artérias nutridoras na cirurgia pode ser satisfatória. No entanto, pode levar à recanalização da lesão por ramos anastomóticos. Para se evitar isso, deve ser realizada a retirada do nidus (Doppman, 1971). Alguns princípios cirúrgicos que devem ser seguidos incluem: cuidado adicional para preservação da artéria espinhal anterior, evitar ressecções amplas e dissecção minuciosa do plano cirúrgico (Detwiler, 1999). Ohata et al., em 1999, relataram três casos que foram submetidos à coagulação dos vasos aferentes da MAI, sem retirada do nidus, com resultado satisfatório (Ohata, 1999). A ressecção completa da lesão pode ser conseguida em 53-59\% dos pacientes, podendo ocorrer deterioração em 14-22\% e óbito em 2-5\%. (Yaşargil, 1976; Rosemblum, 1987).

\section{Tratamento Endovascular}

O tratamento endovascular pode ser considerado como a primeira escolha nas MAVR tipo II, tanto para o alívio dos sintomas, como para diminuir o risco de sangramento intra-operatório. Existem duas estratégias para o tratamento dessas lesões: embolização com partículas (PVA), ou com adesivos líquidos (NBCA). 
A embolização com partículas tem como objetivo a diminuição do fluxo sangüíneo na malformação, reduzindo assim o fenômeno de roubo e risco de isquemia medular. O sistema venoso é aliviado, e reduz-se o risco de hemorragia. Em alguns pacientes, não se consegue atingir o nidus ou a fístula com o microcateter, e o risco de oclusão da artéria espinhal anterior torna-se maior. Liberando-se partículas, mesmo que à distância, por terem diâmetro inferior ao da artéria espinhal anterior e maior que as artérias comissurais, pode-se embolizar a malformação com relativa segurança (Riché, 1983a). Essa técnica não é aceita por todos. Hourton et al. preconizam a utilização de partículas com diâmetro maior que a artéria espinhal anterior. Para que isso ocorra, as artérias que suprem a MAI devem ser mais calibrosas que a artéria espinhal anterior (Horton, 1986). Como as partículas não desencadeiam reação inflamatória, é improvável que exista edema medular. A desvantagem é que a recanalização e revascularização da malformação são muito freqüentes (Casasco, 1999; Larsen, 1999). Por esse motivo, os pacientes submetidos a esse procedimento devem ser acompanhados continuamente, tanto do ponto de vista clínico, como radiológico. A estratégia consiste em controles angiográficos anuais, com reembolizações regulares. Biondi et al., em 1990, relataram os resultados a longo prazo de 35 pacientes submetidos a embolizações seriadas com PVA (Biondi, 1990). O período médio de seguimento pós-embolização foi de 6 anos e foram realizadas 158 sessões de embolização. Os resultados dessa abordagem mostram que $63 \%$ dos pacientes apresentaram melhora clínica em relação ao exame inicial e, em $8 \%$ das sessões de embolização, houve deterioração neurológica. 
A embolização com NBCA pode ser realizada quando se consegue progredir o cateter até o nidus, ou até a fístula. Através dessa técnica, a oclusão arterial é permanente, existindo maior chance de cura (Niimi, 1999). A desvantagem é a maior probabilidade de oclusão de vasos normais e a formação de edema medular (secundário ao processo inflamatório desencadeado pelo NBCA). Antes da injeção do material oclusivo pode ser feito um teste de oclusão com um microcateter com balão na extremidade (Kerber, 1978). Durante 10 minutos, este fica insuflado, sendo perfundido com contraste iodado. Caso o paciente não apresente sintomas neurológicos, pode ser injetado o adesivo. Essa técnica tem a desvantagem de ter que ser realizada com o paciente acordado, além de muitas vezes não ser possível o microcateter atingir a posição exata em que deve ser injetado o adesivo. Konan et al., em 1999, propuseram a embolização do aneurisma intranidal associado a MAI, visando à diminuição da taxa de ressangramento associada ao aneurisma (Konan, 1999).

A completa eliminação da lesão pôde ser conseguida em até $53 \%$ dos pacientes, e em $10 \%$ dos pacientes houve deterioração neurológica permanente e em 10\% transitória (Berenstein e Lasjaunias, 1992). O tratamento endovascular pode ser realizado com o paciente acordado, sob anestesia local. A vantagem desse método seria 0 monitoramento neurológico constante do paciente (Théron, 1986). Além disso, pode ser realizada a infusão de amobarbital sódico ou lidocaína no território a ser embolizado, para predizer o resultado funcional da embolização (Larsen, 1999). Nos pacientes submetidos a tratamento endovascular sob anestesia 
geral, essa informação pode ser obtida através do monitoramento do potencial evocado somato-sensitivo e do conhecimento detalhado da anatomia funcional (Berenstein, 1984). No entanto, o tratamento pode ser realizado sob anestesia geral e sem testes provocativos ou funcionais com segurança, desde que haja um bom conhecimento da anatomia funcional da medula e que o cateterismo seja superseletivo (Rodesch, 2003).

\subsection{MAVR tipo III}

\subsubsection{Aspectos Anatômicos}

As MAVR tipo III, também conhecidas como malformações arteriovenosas metaméricas (MAVM), são lesões extensas, e costumam comprometer a medula espinhal, a dura-máter, as estruturas ósseas, a musculatura paraespinhal, o tecido subcutâneo e a pele, no mesmo dermátomo (Hodes, 1999). Um exemplo dessas lesões é a síndrome de Cobb, descrita pelo mesmo em 1915 como uma malformação envolvendo pele, osso e medula espinhal (Cobb, 1915). Outras síndromes associadas às MAVM são a de Rendu-Osler-Weber e Klippel-Trenaunay-Weber (David, 1999). Costumam ser diagnosticadas na infância, através da identificação de uma malformação vascular cutânea (Krolak-Salmon, 1999).

As MAVM apresentam um nidus grande e entremeado ao parênquima da medula espinhal. Costumam se estender longitudinalmente pela raqui, 
envolvendo medula espinhal, pia-máter, estruturas extramedulares e até paraespinhais, como osso e tecidos moles (David, 1999).

O suprimento arterial dessas lesões é compartilhado pela medula espinhal e costuma ser originário por artérias de múltiplos níveis espinhais. Múltiplas e calibrosas artérias medulares, originárias das artérias espinhais anterior e posteriores, suprem essa malformação. Também podem ser supridas por artérias radiculares e durais.

A drenagem venosa é anterógrada, via plexo coronal, veias medulares e epidurais. São lesões constituídas por fístulas de alto fluxo, que geram turbilhonamento do sangue. A ausculta de sopro no nível da lesão pode ser audível (Rosenblum, 1987).

\subsubsection{Epidemiologia}

As MAVM podem ser consideradas com um subgrupo das MAI e são relativamente raras. Rosenblum et al. analisaram 43 pacientes com MAI e destes, 29 apresentavam MAVM (Rosenblum, 1987). Biondi et al., em 1992, analisaram 70 pacientes com MAI, dentre os quais 24 apresentavam MAVM (Biondi, 1992a). Essas séries provavelmente superestimaram a incidência dessas lesões, pois foram realizadas em centros de referência para tratamento de MAVR. Outros autores, como Ommaya et al., relataram um incidência de apenas 2 pacientes com MAVM numa série de 18 pacientes com MAVR (Ommaya, 1969). De maneira similar, Malis relatou ter encontrado somente 3 pacientes com MAVM numa série de 43 pacientes com MAVR (Malis, 1982). 
Essas lesões são sugestivas de serem congênitas e tendem a se apresentar em pacientes mais jovens que 30 anos. Rosenblum et al. relataram que a idade média dos pacientes era de 27 anos (Rosenblum, 1987).

Em contraste com as outras MAVR, as MAVM tendem a ser distribuídas de maneira uniforme ao longo da coluna vertebral (Rosenblum, 1987).

\subsubsection{Fisiopatologia}

Os mecanismos envolvidos na fisiopatologia dessas lesões são semelhantes aos das MAI. Podem apresentar sintomas relacionados à hemorragia, compressão ou "fenômeno de roubo", que estariam envolvidos no aparecimento da mielopatia progressiva, que é a apresentação mais freqüente (David, 1999).

\subsubsection{Sintomatologia}

Os pacientes com MAVM apresentam sintomas variados. Muitas vezes são semelhantes aos de um paciente com MAl. Esses sintomas costumam ser: dor, paresias, alterações sensitivas e distúrbios em esfíncteres. Eventualmente pode ser observada a presença de frêmito, sopro ou insuficiência cardíaca (Merland, 1979). 


\subsubsection{História Natural}

A hemorragia é uma apresentação freqüente nessas lesões, que também apresentam componente intramedular. Em 44\% dos pacientes com MAVR a hemorragia esteve correlacionada com a presença de aneurismas arteriais e varicosidades venosas, e mais freqüentemente naqueles com MAVM (Rosenblum, 1987).

A evolução mais comum nos pacientes com MAVM é a piora neurológica progressiva (Aminoff e Logue, 1974b). Pode estar relacionada a certas posturas e atividades, como tossir e realizar esforços físicos (David, 1999).

\subsubsection{Diagnóstico por Imagem}

\section{Mielografia}

Pouco utilizada na pesquisa dessas lesões, pela limitação na avaliação das estruturas intra e extramedulares, bem como paraespinhais.

\section{Tomografia Computadorizada}

Pouco utilizada também no diagnóstico das MAVM. Na janela óssea podem ser evidenciadas erosões no corpo vertebral (sugestiva de MAVR com componente extradural) ou alargamento do forame intervertebral (causado pela compressão por estrutural venosas dilatadas) (Berenstein e Lasjaunias, 1992). 


\section{Ressonância Magnética}

Os pacientes com suspeita de MAVM devem ser submetidos à RM. Esse exame tem elevada sensibilidade e especificidade para essas lesões. Permite avaliar a presença de sangramentos em diferentes estágios, vasos trombosados, "flow void", extensão extra-espinhal e localização precisa do nidus (David, 1999). A limitação restringe-se à avaliação do suprimento arterial e drenagem venosa.

\section{Angiografia}

A angiografia é o exame principal para definição da estratégia do tratamento dessas lesões. A investigação pode ser iniciada com uma aortografia não seletiva. Posteriormente, através de cateterismo seletivo, é realizado o estudo completo da malformação. É mandatória a visibilização das artérias espinhais anterior e posteriores. Esses vasos podem terminar no nidus da malformação ou somente passar através do mesmo e suprir a medula espinhal normal (David, 1999).

\subsubsection{Tratamento}

O tratamento dessas malformações usualmente é paliativo, pois sua ressecção total é muito difícil de ser atingida, podendo ocasionar morbidade elevada. O tratamento consiste de seriadas embolizações e ressecção cirúrgica parcial (Detwiler, 1999). Em pacientes intactos do ponto de vista neurológico, deve ser considerada a opção de acompanhamento clínico (Regan, 1991). 


\section{Tratamento Cirúrgico}

As MAVM têm sido consideradas irressecáveis, com resultados cirúrgicos devastadores. A experiência de Mallis com duas tentativas de remoção cirúrgica de MAVM, resultando em paraplegia e óbito, levou-o a afirmar que "o único aspecto favorável destas lesões é a sua raridade" (Malis, 1982). Conseqüentemente, tratamento dessas lesões passou a ser realizado através de ligaduras arteriais e embolizações seriadas de maneira paliativa, para controle da hemorragia e da deterioração neurológica. David et al. trataram de maneira bem sucedida 3 pacientes com MAVM através de múltiplas embolizações, inclusive intra-operatórias, ligaduras arteriais e ressecção cirúrgica (David, 1999). Outros relatos semelhantes foram encontrados na literatura (Spetzler, 1989, Touho, 1991; Martin, 1995, Alexander, 2002).

\section{Tratamento Endovascular}

Poucos relatos de tratamento somente com embolização de MAVM foram encontrados na literatura. Ommaya et al. relataram a melhora neurológica de um paciente submetido à embolização com partículas de aço da artéria principal que supria uma MAVM (Ommaya, 1969). Djindjian R, em 1975, relatou resultados semelhantes (Djindjian R, 1975). 


\subsection{MAVR tipo IV}

\subsubsection{Aspectos Anatômicos}

Também conhecidas como fístulas arteriovenosas perimedulares (FAVP). Foram descritas inicialmente por Djindjian M et al., em 1977, como uma fístula arteriovenosa entre a artéria espinhal anterior e uma veia perimedular (Djindjian M, 1977). Heros et al., em 1986, classificaram essas fístulas como MAVR tipo IV (Heros, 1986). Posteriormente Gueguen et al. dividiram essas lesões em 3 subtipos de acordo com o tamanho e o fluxo sangüíneo pela fístula (Gueguen, 1987). A classificação mais utilizada atualmente é a proposta por Anson e Spetzler, em 1992, que divide estas MAVR em tipos IV-A, IV-B e IV-C (Anson e Spetzler, 1992). São caracterizadas por uma fístula arteriovenosa entre a artéria espinhal anterior ou posterior, e veia do plexo coronal perimedular, não havendo nidus entre ambos. São intradurais, mas extramedulares e situam-se ventral ou lateralmente à medula (Grote, 1996). Essas malformações podem estar associadas a outras lesões vasculares como malformações arteriovenosas, aneurismas e ectasias venosas (Kaynar, 1999). O diâmetro das fístulas varia de 1 a 4 mm (Tomlinson, 1993).

As FAVP do subtipo A (FAVP-A) são fístulas arteriovenosas únicas, de pequeno calibre, geralmente localizadas entre a artéria espinhal anterior e uma veia perimedular que está moderadamente dilatada. Costumam estar localizadas na superfície ventral do cone medular e da cauda eqüina e são 
lesões que apresentam lento fluxo sangüíneo (Cawley, 1999). As do subtipo B (FAVP-B) apresentam tamanho e fluxo sangüíneo moderados. Essas lesões têm geralmente mais de um aporte vascular, incluindo uma dilatada artéria espinhal anterior e uma ou duas artérias espinhais posteriores. A comunicação entre a artéria e a veia é maior, permitindo que o fluxo, também maior, ocasione uma significativa dilatação nas veias de drenagem. As do subtipo C (FAVP-C) são fístulas gigantes, com múltiplos aportes arteriais. A artéria espinhal anterior recebe suprimento de várias outras artérias, mas é através desta que existe uma comunicação com o sistema drenagem, que está bastante dilatado. Essas lesões apresentam alto fluxo e alta pressão, que se transmite para as veias de drenagem.

\subsubsection{Epidemiologia}

A freqüência das FAVP é estimada entre 8 e $30 \%$ das MAVR (Rosenblum, 1987; Berenstein e Lasjaunias, 1992;). A faixa etária acometida é variável. Algumas séries relatam que pode variar de 1 a 55 anos (média de 25-45 anos) (Barrow, 1994; Cho, 2005). Mourier et al. relataram em 1993 os resultados de uma série de 35 pacientes com FAVP e observaram que a faixa etária acometida era mais baixa, variando de 2 a 42 anos (média de 25 anos) (Mourier, 1993). Esses achados talvez sejam um reflexo da incompreensão da etiologia dessas lesões. Muitos consideram que essas lesões sejam congênitas pela observação de vários casos na infância (Hurst, 1999). Entretanto, a hipótese de ser uma lesão adquirida tem sido reforçada 
pelos relatos de desenvolvimento de FAVP após a cirurgia de tumores raquimedulares (Gueguen, 1987; Barrow, 1994). Os subtipos mais freqüentes são os A e B (Cawley, 1999). A maioria dos relatos sugere não haver predominância quanto ao sexo (Gueguen, 1987, Mourier, 1993; Tomlinson, 1993; Cawley, 1999). A maioria das lesões acomete o cone medular e cauda eqüina, embora existam relatos de comprometimento nos níveis torácico e cervical (Heros, 1986; Gueguen, 1987).

\subsubsection{Fisiopatologia}

A hipertensão venosa está relacionada à presença de fístulas arteriovenosas e resulta em hipóxia e, tardiamente, em isquemia (Barrow, 1994). Geralmente ocasiona progressiva mielopatia de lenta evolução, ou mielomalácia e é caracterizada por déficit motor, sensitivo, distúrbios esfincterianos e espasticidade (Kaynar, 1999). Sem tratamento, a mielopatia progride para um déficit incapacitante e mielopatia transversa completa (Halbach, 1993). Também pode estar associada a dor localizada ou radicular. O "fenômeno de roubo" também pode estar associado (Cawley, 1999).

\subsubsection{Sintomatologia}

Os sintomas iniciais nos pacientes com FAVP costumam ser fraqueza nas pernas, alterações na sensibilidade, dor tóraco-lombar e alterações em esfíncteres (Heros, 1986; Tomlinson, 1993). A maioria dos pacientes se 
apresenta na ocasião do diagnóstico com fraqueza nas pernas, alterações na sensibilidade e nos esfíncteres (Kaynar, 1999). A duração dos sintomas pode variar de 2 a 25 anos (Tomlinson, 1993).

\subsubsection{História Natural}

Costumam cursar com sintomas de mielopatia progressiva, e às vezes com hemorragia ou dor. A mielopatia lentamente progressiva ocorre em 75 a 91\% dos pacientes e a hemorragia subaracnóidea em 20 a 50\% (Mourier, 1993; Barrow, 1994). Nos subtipos B e C é mais comum a evolução com hemorragia e compressão medular por ectasia venosa (Mourier, 1993). Os pacientes com mielopatia, se não tratados, podem evoluir para paraplegia em 5 a 7 anos (Cawley, 1999; Thompson, 2004).

\subsubsection{Diagnóstico por Imagem}

\section{Mielografia}

Historicamente, a mielografia foi o primeiro exame de imagem a demonstrar uma MAVR. Nas FAVP, essa lesão aparece como uma falha de enchimento de aspecto serpiginoso, na coluna de contraste. Não evidencia o local da fístula, nem a repercussão da lesão na medula espinhal (Cawley, 1999). 


\section{Tomografia Computadorizada}

A TC, tal como nas FAD, tem pouco valor no diagnóstico das FAVP. Com a administração de contraste podem ser identificadas imagens dilatadas e tortuosas, compatíveis com vasos sangüíneos. Porém a definição da fístula não é observada. Pode ser útil na detecção de hemorragias.

\section{Ressonância Magnética}

A RM não é um exame especifico para o diagnóstico das FAVP (Larsen, 1999). Em T2, é comum a imagem de "flow void" na superfície da medula espinhal, que é sugestiva de veia "arterializada". Artefatos de fluxo, causados pelo turbilhonamento do líquor, podem simular uma FAVP. Através da RM pode ser detectada a presença de sangramento nos diversos compartimentos raquimedulares, determinando inclusive, as diferentes épocas em que estes ocorreram (Osborn, 1999). Nas seqüências adquiridas em spin-eco, o sangramento antigo tem imagem com sinal hipointenso em T1 e em T2, correspondendo a depósitos de hemossiderina. O sangramento hiperagudo (24 a 48 horas) pode ser isointenso em T1 e T2, enquanto o subagudo (de 3 dias a meses) pode apresentar-se hiperintenso em T1 e T2, correspondendo a metahemoglobina extracelular. Também podem ser observadas alterações medulares como edema (secundário a hipertensão venosa), atrofia e presença de cavidade siringomiélica, o que tem valor prognóstico indiscutível. A imagem de edema medular pode apresentar-se com sinal hipointenso em T1 e hiperintenso em T2. Outros aspectos que podem ser encontrados são a trombose intravascular e aneurismas (Di Chiro, 1985). 


\section{Angiografia}

A angiografia seletiva é atualmente o exame indicado para o diagnóstico e para classificar o tipo de FAVP. Essa informação permite a escolha da abordagem terapêutica adequada. Durante a cateterização seletiva é importante a análise minuciosa das fases precoce, intermediária e tardia de opacificação da lesão. Na fase precoce é que será demonstrado o local da(s) fístula(s) e na tardia, a drenagem venosa da lesão (Cawley, 1999).

\subsubsection{Tratamento}

O tratamento dessas lesões é controverso e dependerá do subtipo de FAVP que o paciente apresenta. Na FAVP-A muitas vezes o tratamento preferido é o cirúrgico enquanto na FAV-C é o endovascular. Na FAV-B, ambas as abordagens podem ser utilizadas, de maneira isolada ou em conjunto (Detwiler, 1999; Larsen, 1999).

\section{Tratamento Cirúrgico}

Na FAVP-A, a cirurgia para coagulação ou clipagem da fístula, preservando a artéria espinhal, costuma ser a terapia mais efetiva e nesse caso a angiografia diagnóstica é fundamental para determinar o nível exato da transição arteriovenosa. Fístulas supridas pelas artérias espinhais posteriores podem ser abordadas através de laminectomia. Essa abordagem também pode ser útil para lesões lateralmente à medula espinhal, no cone e 
cauda eqüina. Uma abordagem póstero-lateral pode ser utilizada nas fístulas supridas pela artéria espinhal anterior, muitas vezes situada na superfície ventral da medula espinhal (Martin, 1995; Markert, 1996). A angiografia intraoperatória pode ser útil na identificação da fístula e na documentação da patência das artérias espinhais (Cawley, 1999).

As FAVP-B localizadas dorsalmente podem ser facilmente acessadas e eliminadas por cirurgia. O mesmo não pode ser dito nas situadas na face ventral da medula (Grote, 1996). Às vezes diminutas artérias podem suprir a FAVP e, quando não obliteradas, podem ocasionar fístula residual na evolução do paciente (Riché, 1983b).

Nas FAVP-C, fístulas gigantes são supridas por múltiplos pedículos arteriais. As veias de drenagem estão também dilatadas e tortuosas. O tratamento cirúrgico apresenta alto risco de hemorragia intra-operatória e infarto no território da artéria espinhal anterior (Detwiler, 1999).

\section{Tratamento Endovascular}

A FAVP-A é constituída de uma fístula perimedular única, de pequeno tamanho, e tanto a artéria espinhal envolvida, como a veia de drenagem, estão minimamente dilatadas. O fluxo pela fístula é lento, e o refluxo venoso também, refletindo pouca hipertensão venosa. Como as artérias nutridoras são as espinhais, o cateter para embolização deve ser locado no ponto fistular. Isso muitas vezes é difícil nesse subtipo, pois as artérias estão pouco calibrosas. A embolização com partículas pode ser uma alternativa naquelas localizadas ventralmente (Grote, 1996; Casasco, 1999). 
Na FAVP-B, as fístulas, e o fluxo através dela, são maiores, e tanto as artérias espinhais como a veias de drenagem estão mais dilatadas. Há ectasia e moderada hipertensão venosa. A dilatação das artérias nutridoras facilita o acesso endovascular ao ponto fistular. Mas a presença de múltiplos pedículos aferentes e fístulas dificulta a completa oclusão da malformação.

As FAVP-C são malformações que apresentam uma fístula grande, com acentuada dilatação tanto no sistema arterial, como no venoso, interligados a ela. O fluxo através dessa lesão é grande e rápido, causando maior hipertensão venosa, e sintomatologia exuberante. A oclusão seletiva da fístula com um agente embolizante que reduza o fluxo (molas ou balões) e posteriormente NBCA é o tratamento inicial para esses casos, sendo conseguida com sucesso em 68\% dos pacientes (Morgan, 1999). O tratamento conjunto, endovascular e cirúrgico, também pode ser realizado de maneira efetiva (Hallbach, 1993). A oclusão somente com balões também pode ser satisfatória (Riché, 1983b). 


\section{MÉTODOS}


Foi realizado o estudo prospectivo de 41 pacientes com MAVR encaminhados aos Serviços de Neurocirurgia do Hospital da Santa Casa de Misericórdia de São Paulo, de Radiologia Intervencionista dos Institutos do Coração (InCor) e de Radiologia (INRAD) do Hospital das Clínicas da Faculdade de Medicina da Universidade de São Paulo (FMUSP) para tratamento endovascular. O período do estudo esteve compreendido entre novembro de 1993 e dezembro de 2004.

O critério de inclusão foi:

- angiografia medular demonstrando MAVR.

Os critérios de exclusão foram:

- MAVR em que a artéria espinhal anterior e/ou posterior se opacificava após o nidus ou fístula raquimedular;

- opacificação da MAVR exclusivamente por artérias anastomóticas;

- pacientes com fístulas durais no forame magno com drenagem para o sistema venoso perimedular.

Os pacientes foram subdivididos por faixas etárias dos 0 aos 18 anos, dos 19 anos aos 35 anos e acima de 35 anos e correlacionados com os tipos de MAVR, segundo a classificação de Anson e Spetzler (1992). 
Com relação ao quadro clínico e neurológico, foram avaliados os seguintes parâmetros:

- dor;

- alterações na motricidade dos membros superiores e inferiores;

- marcha;

- alterações na sensibilidade dos membros superiores e inferiores;

- alterações vesicais e intestinais;

- impotência sexual;

- alterações cutâneas.

Com relação à dor, foi avaliada sua localização e a presença de irradiação radicular. A motricidade e a sensibilidade dos membros foram avaliadas se estavam normais ou alteradas. As alterações vesicais e intestinais, impotência sexual e alterações cutâneas foram avaliadas se estavam presentes ou não. A marcha foi avaliada segundo a classificação proposta por Aminoff e Logue, que quantificaram as alterações em (Aminoff e Logue, 1974c):

- Grau 1 - Fraqueza inicial nas pernas, postura ou caminhada anormal, sem restrição da atividade locomotora.

- Grau 2 - tolerância a limitados exercícios.

- Grau 3 - requer uma bengala ou algum tipo de suporte para caminhar.

- Grau 4 - requer duas bengalas ou muletas para caminhar.

- Grau 5 - incapaz de ficar em pé, restrito ao leito ou cadeira de rodas. 
A avaliação clínica e neurológica dos pacientes foi realizada antes e no mínimo 6 meses após o tratamento.

Os exames diagnósticos e procedimentos terapêuticos foram realizados no Serviço de Radiologia Intervencionista do InCor/INRAD da FMUSP, utilizando aparelhos de angiografia por subtração digital com arco para múltiplas incidências, matriz com resolução de 1024 X 1024, tubos de RX com alta resistência ao calor e fluoroscopia com sobreposição de imagem (recurso de "road-map"). Para estudo angiográfico diagnóstico foi utilizado um protocolo que consistia nas seguintes etapas:

- cateterismo seletivo das artérias intercostais, com obtenção de imagens em póstero-anterior (PA), orientado inicialmente para o nível sugerido pela RM;

- cateterismo seletivo das artérias lombares, com obtenção de imagens em PA;

- cateterismo seletivo das artérias sacrais, com obtenção de imagens em PA;

- cateterismo seletivo das artérias vertebrais, com obtenção de imagens em PA e perfil;

- cateterismo seletivo das artérias carótidas internas, com obtenção de imagens em PA e perfil;

- cateterismo seletivo das artérias carótidas externas, com obtenção de imagens em PA e perfil;

- cateterismo seletivo das artérias cervicais profundas, com obtenção de imagens em PA; 
- cateterismo seletivo das artérias cervicais ascendentes, com obtenção de imagens em PA;

- cateterismo seletivo das artérias subclávias, com obtenção de imagens em PA.

As angiografias foram realizadas utilizando-se seqüências rápidas de aquisição de imagens (mínimo de 4 aquisições/segundo) até a fase venosa tardia, algumas vezes até 30 segundos. O estudo angiográfico foi realizado utilizando-se contraste iodado não-iônico de baixa osmolaridade.

Foram monitorados o eletrocardiograma, a pressão arterial e a saturação de oxigênio por meios não-invasivos. Sob anestesia geral foi feita punção da artéria femoral comum e inserido pela técnica de Seldinger um introdutor com válvula hemostática de 5 French $(F)$ de calibre, para passagem do cateter para diagnóstico (Seldinger, 1953). Para o estudo seletivo das artérias intercostais e lombares, utilizou-se cateter Cobra, curva 2, com 4F de calibre. Nos casos com tortuosidades das artérias utilizou-se cateter Simmons, curva 1, com 4F de calibre. Para o estudo das artérias subclávias, cervicais, vertebrais, carótidas internas e externas utilizaram-se os cateteres Head Hunter com calibre 4F ou Simmons, curva 2, com calibre 5F. Foram utilizados fios guias de teflon e hidrofílico.

Por meio da angiografia foram divididas as MAVR segundo a classificação de Anson e Spetzler, de 1992, em tipos I (A e B), II, III e IV (A, B e C). O padrão hemodinâmico das MAVR foi avaliado e caracterizado de acordo com a velocidade do fluxo arteriovenoso, de maneira similar ao 
proposto por Brosnahan, em 1982, para as fístulas carotidocavernosas (Brosnahan, 1982):

- fluxo lento: opacificação lenta da drenagem venosa da MAVR, que ocorre após a opacificação das artérias espinhais;

- fluxo moderado: opacificação simultânea da drenagem venosa da lesão e das artérias espinhais;

- fluxo rápido: opacificação da drenagem venosa antes da opacificação das artérias espinhais.

Após a avaliação clínica e radiológica do paciente era proposto e explicado o tratamento. Ao final, era preenchido e assinado o termo de consentimento livre e esclarecido (Anexo 1).

O tratamento foi conduzido pelos médicos assistentes e estagiários dos Serviços de Radiologia Intervencionista dos Institutos do Coração e de Radiologia do Hospital das Clínicas da Faculdade de Medicina da Universidade de São Paulo, sempre com a participação do Chefe do Serviço, Professor Doutor José Guilherme Mendes Pereira Caldas, pois para tal procedimento é importante que seja conduzido pelo profissional com maior experiência, e a partir de fevereiro de 2001 com a participação direta do autor.

O tratamento endovascular era iniciado de maneira similar ao diagnóstico, com monitoramento do eletrocardiograma, pressão arterial e saturação de oxigênio por meios não-invasivos. Todos os pacientes foram submetidos à anestesia geral. Após a punção, os pacientes eram 
submetidos a heparinização sistêmica, utilizando-se a dose inicial de 110 UI/Kg/EV e manutenção com 20 UI/Kg/hora/EV.

Nas lesões torácicas e lombares foi utilizada a técnica de cateterismo co-axial com microcateterização por fluxo e/ou com o auxílio de microguia. Com o auxílio de um fio guia hidrofílico, progredia-se um cateter Cobra, curva 2, com calibre 5 French ou Simmons, curva 1, com calibre 5 French até o(s) vaso(s) que supria(m) a MAVR. Posteriormente, avançava-se no seu interior um microcateter de calibre variado, entre $2,3 \mathrm{~F}$ e $1,5 \mathrm{~F}$.

Nas lesões cervicais foi utilizada a mesma técnica, porém com uso de um cateter Envoy 5F, que era posicionado na artéria que opacificava a lesão. Posteriormente avançava-se um microcateter com as mesmas características citadas anteriormente.

Os materiais utilizados para a embolização foram:

- n-isobutil cianoacrilato (Histoacryl $\mathbb{R})$ :

É um material líquido, cujo efeito adesivo nos tecidos ocorre após entrar em contato com soluções iônicas, como o plasma sangüíneo, levando à polimerização e à solidificação do mesmo. Foi utilizado diluído com Lipiodol $\AA$, o que permitia sua visualização e retardamento do efeito de polimerização, proporcionado pelo contato do Histoacryl ${ }^{\circledR}$ com o plasma sangüíneo, permitido assim que a solução se espalhasse de maneira adequada no território vascular a ser embolizado e não causasse o aprisionamento do microcateter. 
- partículas de poli-vinil álcool (P.V.A.):

São constituídas de partículas esponjosas de PVA, de calibre controlado. Foram injetadas em uma solução de soro fisiológico $0,9 \%$ e contraste iodado não iônico de baixa osmolaridade (na proporção de 1:1). Essa diluição permitia o controle do fluxo das partículas através de fluoroscopia. As partículas utilizadas variavam de 150 a 600 micra de diâmetro.

- balões valvulados destacáveis:

São constituídos de látex e apresentam um marcador metálico para permitir a sua visualização através da radioscopia e uma válvula que impedia o seu esvaziamento. Os balões eram de duas dimensões: balões número 16 (GVB 16 Nycomed $\AA$ ), menores com diâmetro e comprimento máximo de 8 e $21 \mathrm{~mm}$, respectivamente, e balões número 12 (GVB 12 Nycomed $($ ) ), maiores, com diâmetro e comprimento máximo de 14 e 22,5 $\mathrm{mm}$, respectivamente. Esses balões foram utilizados e escolhidos conforme o calibre da fístula a ser ocluída. Para a utilização desses balões foi necessário o uso de cateteres guias com $9 \mathrm{~F}$ de calibre que permitissem a passagem dos microcateteres com calibre 2,3 F que levavam, fixos, os balões nas suas extremidades. Os balões foram posicionados nos pertuitos fistulares, e após confirmação da sua localização através de estudo angiográfico, os mesmos foram insuflados. Uma solução de contraste iodado não-iônico, isosmolar em relação ao plasma e respeitando as respectivas capacidades de insuflação dos balões foi utilizada em todos os casos. 
Nas FAD, o material de embolização utilizado preferencialmente foi o Histoacryl ${ }^{\circledR}$. Na impossibilidade técnica de microcateterização distal, prosseguia-se a embolização com partículas daquelas artérias que opacificavam a lesão, na tentativa de ocluir a fístula.

Nas MAI, o material de embolização utilizado preferencialmente também foi o Histoacryl $®$. Através de microcateterismo, descrito previamente, posicionou-se o microcateter nas artérias que opacificavam exclusivamente o nidus da malformação. Preferencialmente, o fluxo sangüíneo nessas artérias devia estar bloqueado pelo microcateter, permitindo a infusão de uma coluna de material de embolização no interior de todo o nidus. Se após o microcateterismo fosse constatada a opacificação de alguma artéria espinhal pelo mesmo pedículo arterial, cancelava-se a injeção do material oclusivo. Nos pedículos em que foram injetados a solução de Histoacryl $\circledast$ e Lipiodol ${ }^{\circledR}$, geralmente utilizou-se a proporção de 1:4. Nas MAl em que o fluxo era rápido utilizou-se a proporção de 1:1.

Nas MAVM, o material de embolização utilizado foi Histoacryl ${ }$. Ocluíram-se os principais pedículos arteriais com Histoacryl ${ }^{\circledR}$ de acordo com a técnica utilizada nas MAI. Foi necessário também o uso de balões destacáveis para oclusão temporária durante a injeção da cola, nas fístulas com alto fluxo sangüíneo. Essa técnica visou à diminuição do fluxo, permitindo que a cola não progredisse para a via de drenagem.

Nas MAFP, foi utilizado preferencialmente o Histoacryl囚. Através de microcateterismo foi atingido o posto fistular. Geralmente foi injetada a 
solução de Histoacryl ${ }^{\circledR}$ e Lipiodol ${ }^{\circledR}$, na proporção de 1:4. Nas FAVP em que o fluxo era rápido utilizou-se a proporção de 2:1. Na impossibilidade técnica de microcateterização do ponto fistular prosseguia-se a embolização com partículas daquelas artérias que opacificavam a lesão.

Ao final do procedimento, a heparinização era revertida com a administração endovenosa de $1 \mathrm{ml}$ de cloridrato de protamina para cada 1000 UI de heparina a ser revertida. Posteriormente era retirado o introdutor e o paciente encaminhado para a Unidade de Terapia Intensiva, onde ficava em observação por 24 horas. Caso não houvesse intercorrências, recebia alta da UTI e era encaminhado para a enfermaria, onde permanecia por cerca de 48 horas, quando então tinha alta hospitalar.

Os resultados do tratamento foram avaliados com relação ao quadro clínico e ao resultado angiográfico. Com relação ao quadro clínico, considerou-se o desaparecimento, melhora parcial, persistência ou piora dos sintomas. O resultado angiográfico foi avaliado considerando oclusão total e oclusão parcial e, neste caso, diminuição na velocidade do fluxo na lesão.

Analisou-se a embolização pelo resultado angiográfico e clínico. A evolução clínica foi comparada ao exame clínico inicial.

As complicações foram avaliadas segundo a piora do quadro neurológico ou complicações relativas à técnica. O déficit neurológico foi transitório ou definitivo.

Foi realizado acompanhamento em consultas periódicas por um período mínimo de 6 meses, nas quais se avaliou a evolução dos sintomas 
apresentados pelos pacientes e o eventual aparecimento de déficit neurológico.

O sucesso do tratamento foi dividido em sucesso técnico e clínico. O primeiro abordava dois aspectos: sucesso do procedimento e sucesso do tratamento.

O sucesso técnico do procedimento foi caracterizado como a oclusão total da MAVR evidenciada na angiografia após o procedimento. A recidiva implicava em insucesso do procedimento, mas não necessariamente do tratamento.

O sucesso técnico do tratamento foi caracterizado pela oclusão definitiva da MAVR, independentemente do número de procedimentos considerando a ausência de recidiva durante o período de acompanhamento até a alta.

O sucesso clínico do tratamento foi considerado como a melhora parcial ou total dos sintomas durante o período de pelo menos 6 meses de acompanhamento do paciente. O insucesso clínico foi considerado como a persistência ou piora dos sintomas apresentados pelo paciente por pelo menos 6 meses de tratamento.

A recidiva foi definida como o reaparecimento da MAVR, identificada na angiografia, após ter sido tratada com sucesso técnico por procedimento anterior, independentemente do quadro clínico apresentado. O diagnóstico de recidiva ou insucesso técnico de um procedimento implicou em novo tratamento. 


\section{Método Estatístico}

Inicialmente todas as variáveis foram analisadas descritivamente. Para as variáveis quantitativas, essa análise foi feita através da observação dos valores mínimos e máximos, e do cálculo de médias, desvios-padrão e medianas. Para as variáveis qualitativas foram calculadas freqüências absolutas e relativas.

Para se testar a hipótese de igualdade de médias dos três grupos de MAVR foi utilizado o teste não-paramétrico de Kruskal-Wallis, com as comparações dois a dois realizadas através de Dunn (Rosner, 1986). Para a comparação entre proporções foi utilizado o teste exato de Fisher (Rosner, 1986).

Para se avaliar a concordância das respostas pré e pós-tratamento, em cada tipo de MAVR, foi utilizado o índice de concordância Kappa (Rosner, 1986). Esse índice varia e 0 a 1, sendo que:

- Kappa $\leq 0,45$, temos concordância marginal

- $0,45<$ Kappa $<0,75$, temos boa concordância

- Kappa $\geq 0,75$, temos ótima concordância

O nível de significância utilizado para os testes foi de $5 \%$. 
5. RESULTADOS 
Quarenta e um pacientes foram encaminhados para tratamento endovascular da MAVR. Os pacientes foram classificados e subdivididos de acordo com o tipo de MAVR. Dessa maneira, foram admitidos 19 pacientes com FAD, 10 pacientes com MAI, 1 paciente com MAVM e 11 pacientes com FAVP. Foram excluídos da nossa casuística 2 pacientes com FAD e 4 pacientes com FAVP, totalizando 35 pacientes tratados, sendo 17 (48,6\%) pacientes com FAD, 10 pacientes $(28,5 \%)$ com MAI, 1 paciente $(2,9 \%)$ com MAVM e 7 pacientes $(20,0 \%)$ com FAVP.

TABELA 1: DISTRIBUIÇÃO DAS MAVR SEGUNDO A CLASSIFICAÇÃO DE ANSON E SPETZLER (1992)

\begin{tabular}{ccc}
\hline & N & $\%$ \\
\hline \hline FAD & 17 & 48,6 \\
MAl & 10 & 28,5 \\
MAVM & 1 & 2,9 \\
FAVP & 7 & 20,0 \\
\hline \hline Total & 35 & 100,0 \\
\hline
\end{tabular}

A média de idade dos pacientes com MAVR foi de 40,34 anos. Comparando com os diferentes tipos de MAVR, foi observado que eles diferem desta média (Teste não-paramétrico de Kruskal-Wallis $p<0,001$ ). 
Nos pacientes com FAD, a média de idade diferiu significamente quando comparados aos pacientes com MAI e FAVP (Teste de Dunn $p<0,05$ ). Com relação às MAVM, somente 1 paciente foi tratado, com idade de 47 anos. Após o tratamento os pacientes foram seguidos em consultas periódicas por um período médio de 27,5 meses ( $\pm 20,8$ meses).

TABELA 2: DISTRIBUIÇÃO POR IDADE DOS PACIENTES COM MAVR

\begin{tabular}{ccccccc}
\hline & N & Média & D.P & Mediana & Mínimo & Máximo \\
\hline \hline FAD & 17 & 57,23 & 13,16 & 58 & 33 & 81 \\
MAI & 10 & 26 & 9,06 & 25,5 & 16 & 41 \\
FAVP & 7 & 18,86 & 14,73 & 13 & 2 & 47 \\
\hline
\end{tabular}

Teste não-paramétrico de Kruskal-Wallis $p<0,001$ e Teste de Dunn $p<0,05$

Dos 19 pacientes com FAD, 2 foram excluídos da casuística. $\mathrm{O}$ primeiro porque a artéria espinhal anterior se originava do pedículo que opacificava a FAD, na artéria intercostal de T8 à esquerda. No segundo, a artéria de Adamkiewicz se originava dos dois pedículos, T10 e T11 à direita, que opacificavam a lesão. Ambos os pacientes foram encaminhados para tratamento cirúrgico.

Nos 17 pacientes com FAD houve predomínio do sexo masculino, sendo 13 homens $(76,5 \%)$ e 4 mulheres $(23,5 \%)$. Com relação à faixa etária, houve um predomínio significativo no grupo com mais de 35 anos de idade, sendo 15 pacientes $(88,2 \%)$ nesta faixa. 
GRÁFICO 1: DISTRIBUIÇÃO QUANTO AO SEXO DAS FAD

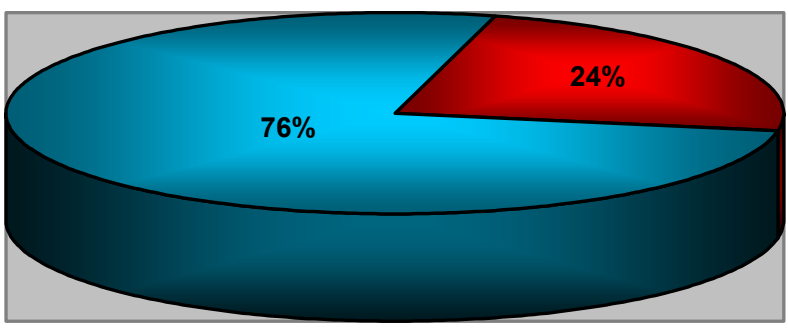

$\square$ Masculino

口Feminino

TABELA 3: DISTRIBUIÇÃO POR FAIXA ETÁRIA DAS FAD

\begin{tabular}{ccc}
\hline & $\mathbf{N}$ & $\%$ \\
\hline \hline $\mathbf{0 - 1 8}$ anos & - & 0 \\
$\mathbf{1 9 - 3 5}$ anos & 2 & 11,8 \\
Acima de 35 anos & 15 & 88,2 \\
\hline \hline Total & 17 & 100,0 \\
\hline
\end{tabular}

O sintoma inicial mais freqüente foi a fraqueza nos membros inferiores, presente em 11 pacientes (64,7\%), seguido da dor na região tóraco-lombar em 8 pacientes $(47,0 \%)$ e sensação de dormência em 4 pacientes $(23,5 \%)$. O tempo decorrido do sintoma inicial até o tratamento foi em média de 18,1 meses. Em 15 pacientes $(88,2 \%)$ a instalação dos sintomas aconteceu de maneira progressiva. 
TABELA 4: DISTRIBUIÇÃO DOS SINTOMAS INICIAIS NAS FAD

\begin{tabular}{ccc}
\hline & N & $\%$ \\
\hline \hline Déficit Motor & 11 & 64,7 \\
Dor & 8 & 47,0 \\
Déficit Sensitivo & 4 & 23,5 \\
Disfunção Vesical & - & 0 \\
Obstipação & - & 0 \\
Impotência Sexual & - & 0 \\
\hline
\end{tabular}

$\mathrm{Na}$ ocasião do tratamento, 16 pacientes $(94,1 \%)$ apresentavam fraqueza nos membros inferiores. A sensação de dormência estava presente em 13 pacientes $(76,5 \%)$ e alterações em esfíncter vesical em 13 pacientes (76,5\%). A obstipação foi relatada por 9 pacientes $(52,9 \%)$ e dor tóracolombar em 5 pacientes $(29,4 \%)$. Em 5 pacientes do sexo masculino foi referida impotência sexual $(38,5 \%)$. Um paciente $(5,9 \%)$ estava assintomático. A marcha estava alterada em 16 pacientes (94,1\%). Destes, 7 pacientes $(41,2 \%)$ estavam acamados e se locomoviam com o auxílio de cadeira de rodas, 4 pacientes $(23,5 \%)$ com muletas, 3 pacientes $(17,6 \%)$ com bengala e 2 pacientes $(11,8 \%)$ deambulavam sem apoio, mas com restrição aos esforços físicos. Um paciente $(5,9 \%)$ deambulava sem restrições. 
TABELA 5: DISTRIBUIÇÃO DOS SINTOMAS PRÉ-EMBOLIZAÇÃO NAS FAD

\begin{tabular}{ccc}
\hline & N & $\%$ \\
\hline \hline Déficit Motor & 16 & 94,1 \\
Déficit Sensitivo & 13 & 76,5 \\
Disfunção Vesical & 13 & 76,5 \\
Obstipação & 9 & 52,9 \\
Dor & 5 & 29,4 \\
Impotência Sexual & 5 & 29,4 \\
Assintomático & 1 & 5,9 \\
\hline
\end{tabular}

TABELA 6: DISTRIBUIÇÃO DA MARCHA PRÉ-EMBOLIZAÇÃO NAS FAD

\begin{tabular}{ccc}
\hline & N & $\%$ \\
\hline \hline Sem restrição & 1 & 5,9 \\
Restrição aos esforços & 2 & 11,8 \\
Bengala & 3 & 17,6 \\
Muleta & 4 & 23,5 \\
Acamado ou cadeira de rodas & 7 & 41,2 \\
\hline \hline Total & 17 & 100,0 \\
\hline
\end{tabular}


GRÁFICO 2: DISTRIBUIÇÃO DAS ALTERAÇÕES NA MARCHA PRÉEMBOLIZAÇÃO NAS FAD

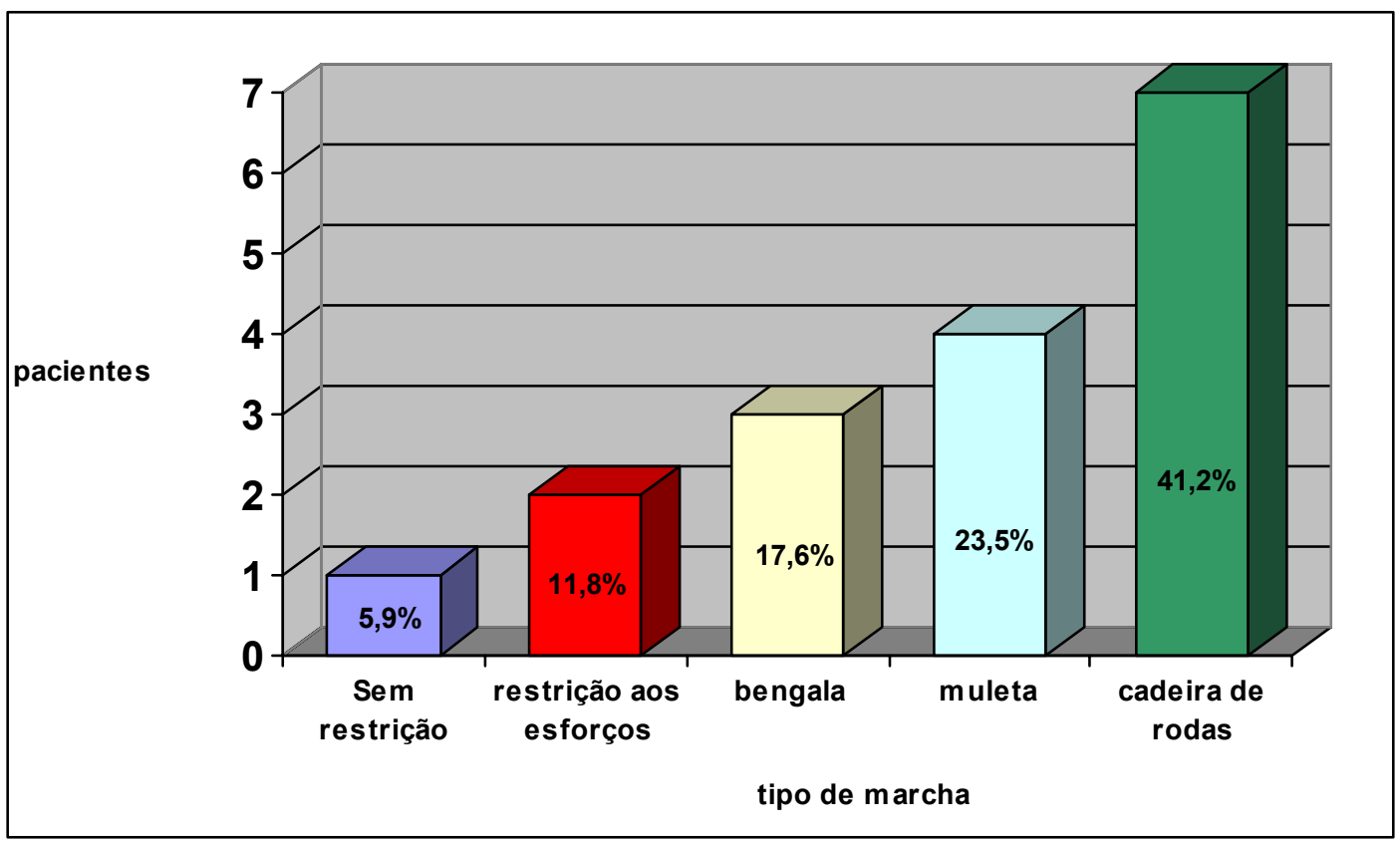

A localização mais freqüente da FAD na coluna foi na região torácica, observada em 12 pacientes (70,6\%). Os segmentos mais freqüentemente acometidos foram T10 e T7, com 3 pacientes $(17,6 \%)$ em cada um destes níveis, seguido de T10, com 2 pacientes (11,8\%). O acometimento na coluna lombar foi observado em 4 pacientes (23,5\%), sendo que em 2 pacientes $(11,8 \%)$ foi identificada em L2. Somente 1 paciente $(5,9 \%)$ apresentava FAD na coluna cervical.

O estudo angiográfico inicial demonstrou que 10 pacientes $(58,8 \%)$ apresentavam FAD-A e 7 pacientes (41,2\%) FAD-B. Nenhum dos pacientes apresentava aneurisma arterial ou venoso. O tratamento foi realizado com adesivo tissular em 9 pacientes (52,9\%), com partículas em 6 pacientes $(35,3 \%)$ e com ambos em 2 pacientes (11,8\%). Não observamos complicações durante ou após os procedimentos de embolização. 
Após a embolização, em 16 pacientes $(94,1 \%)$ foi constatada fraqueza nos membros inferiores. A sensação de dormência estava presente em 8 pacientes $(47,0 \%)$, as alterações em esfíncter vesical em 6 pacientes $(35,3 \%)$, a obstipação foi relatada por 4 pacientes $(23,5 \%)$ e a dor tóracolombar em 2 pacientes $(11,7 \%)$. Em 2 pacientes do sexo masculino foi referida a impotência sexual $(11,7 \%)$.

TABELA 7: DISTRIBUIÇÃO DOS SINTOMAS PÓS-EMBOLIZAÇÃO NAS FAD

\begin{tabular}{ccc}
\hline & N & $\%$ \\
\hline \hline Déficit Motor & 16 & 94,1 \\
Déficit Sensitivo & 8 & 47,0 \\
Disfunção Vesical & 6 & 35,3 \\
Obstipação & 4 & 23,5 \\
Dor & 2 & 11,8 \\
Impotência Sexual & 2 & 11,8 \\
Assintomático & 1 & 5,9 \\
\hline
\end{tabular}

A marcha estava alterada em 16 pacientes $(94,1 \%)$. Destes, 6 pacientes $(35,3 \%)$ deambulavam sem apoio, mas com restrição aos esforços físicos, 6 pacientes $(35,3 \%)$ com muletas, 2 pacientes $(11,8 \%)$ estavam acamados e se locomoviam com o auxílio de cadeira de rodas, 2 pacientes $(11,8 \%)$ com bengala e 1 paciente $(5,9 \%)$ deambulava sem restrições. Comparando os resultados do padrão da marcha no pré e pós-tratamento observamos que houve uma melhora 
significativa no padrão após a embolização (índice de concordância de Kappa $=0,341 ; p=0,006)$.

TABELA 8: DISTRIBUIÇÃO DA MARCHA PÓS-EMBOLIZAÇÃO NAS FAD

\begin{tabular}{ccc}
\hline & $\mathbf{N}$ & $\%$ \\
\hline \hline Sem restrição & 1 & 5,9 \\
Restrição aos esforços & 6 & 35,3 \\
Bengala & 1 & 5,9 \\
Muleta & 6 & 35,3 \\
Acamado ou cadeira de & & \\
rodas & 2 & 11,8 \\
\hline \hline Total & 17 & 100,0 \\
\hline
\end{tabular}

GRÁFICO 3: DISTRIBUIÇÃO DAS ALTERAÇÕES NA MARCHA PÓSEMBOLIZAÇÃO NAS FAD

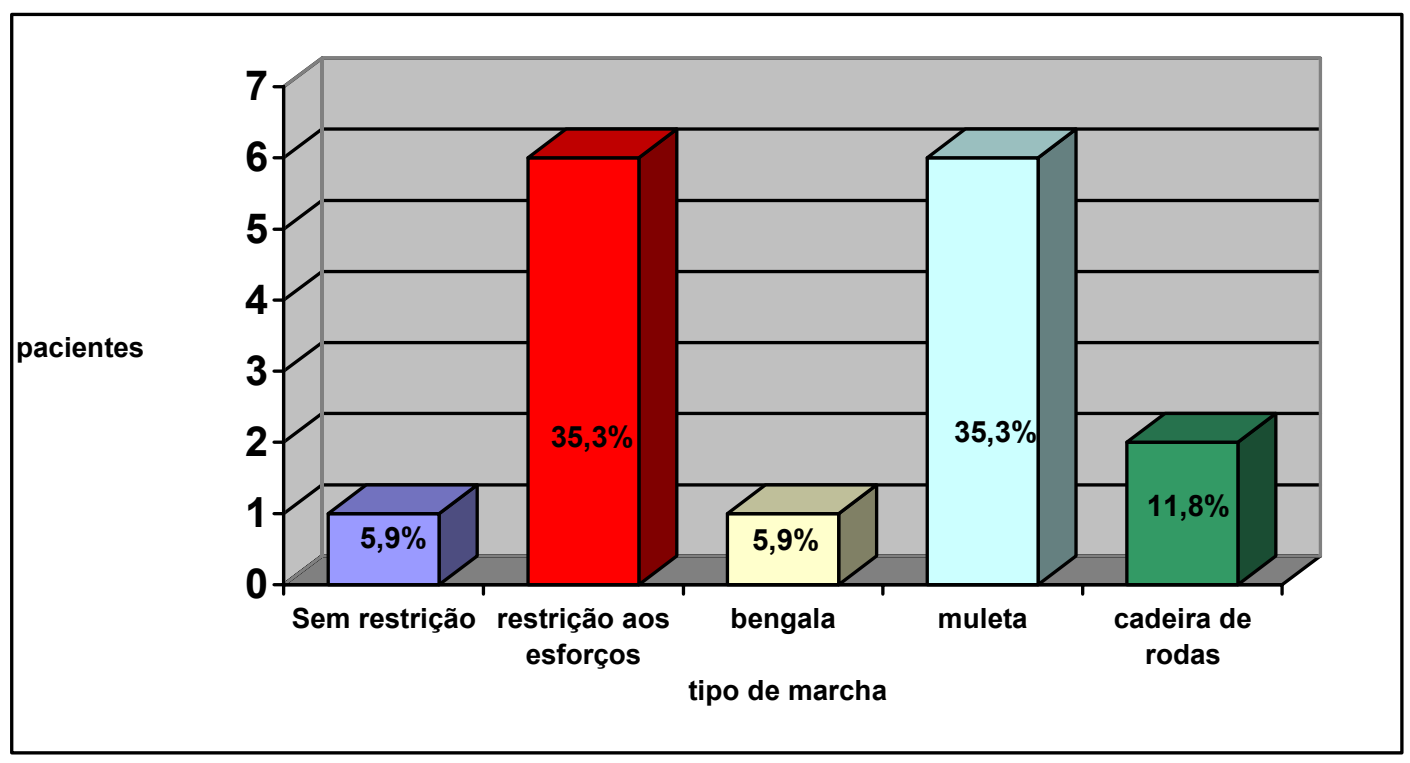


Na nossa casuística foram tratados 17 pacientes com FAD através de 30 sessões de embolização (média de 1,8 sessões/paciente). Ao final do procedimento o controle angiográfico demonstrou oclusão total da lesão em todos procedimentos, sugerindo que o sucesso do procedimento foi de 100\%. Houve recanalização da lesão em 17 procedimentos, demonstrando uma taxa de recidiva de $56,6 \%$. Nos pacientes submetidos à embolização com cola a recidiva foi de $11,1 \%$. Esse resultado foi significativamente menor que o observado nos pacientes tratados com partículas, ou com ambos. 0 sucesso do tratamento foi obtido em 13 pacientes $(76,4 \%)$, constatado através da cura angiográfica ou da evolução com melhora clínica. Dos que não evoluíram com cura, 3 foram tratados através de cirurgia e outro interrompeu o seguimento ambulatorial. A avaliação clínica mostrou que 11 pacientes $(64,7 \%)$ evoluíram com sucesso clínico deste método, ou seja, na evolução apresentaram melhora neurológica. Em 6 pacientes $(35,3 \%)$ houve insucesso, com $5(29,4 \%)$ pacientes evoluindo com quadro neurológico igual ao constatado antes do início do tratamento, e em 1 paciente $(5,9 \%)$ houve piora dos sintomas. Com relação ao sucesso clínico e do tratamento, não se observou diferença significativa entre as técnicas utilizadas.

Nos 6 pacientes submetidos à embolização com partículas, foram realizadas 15 sessões de embolização, perfazendo uma média de 2,5 sessões por paciente. Em 4 pacientes $(66,7 \%)$ a angiografia de controle demonstrou que houve recanalização da lesão. Em 3 pacientes (50\%) foi observada alguma melhora dos sintomas. Um paciente apresentou melhora da dor, um paciente apresentou melhora no controle dos esfíncteres e um paciente melhora na marcha. Este paciente, que se locomovia com o auxílio 
da cadeira de rodas, passou a deambular com o auxílio de bengala. Um paciente apresentou piora dos sintomas durante a evolução. Após a embolização, a marcha que era realizada sem apoio, mas com restrição aos esforços, passou a ser realizada com muletas.

Nos 9 pacientes que foram submetidos a tratamento endovascular com cola foram realizadas 9 sessões de embolização, perfazendo uma média de 1 sessão por paciente. Em 6 dos pacientes $(66,7 \%)$ foi observada alguma melhora dos sintomas. Cinco pacientes apresentaram melhora na marcha, 4 pacientes $(44,4 \%)$ apresentaram melhora da retenção urinária e 4 pacientes $(44,4 \%)$ da obstipação, 3 pacientes $(33,3 \%)$ apresentaram melhora da sensação de dormência, 2 pacientes $(22,2 \%)$ apresentaram diminuição da dor tóraco-lombar e um paciente $(11,1 \%)$ referiu regressão da impotência sexual. Em três dos pacientes $(33,3 \%)$ o quadro neurológico permaneceu estável, não sendo observada piora dos sintomas em nenhum paciente.

Dois pacientes $(11,8 \%)$ foram submetidos à embolização com partículas e cola. Um paciente foi submetido inicialmente à embolização com partículas e no seguimento evoluiu com recanalização da lesão, sendo posteriormente embolizado com cola. Evoluiu com melhora da sensação de dormência e a deambulação, que era feita com cadeira de rodas, passou a ser feita com o auxílio de bengala. $O$ outro paciente foi submetido a duas sessões de embolização com partículas e duas com cola. Apresentou recanalização por anastomoses, sendo encaminhado para tratamento cirúrgico. $\mathrm{Na}$ evolução apresentou melhora na deambulação, que inicialmente era feita com cadeira de rodas e passou a ser realizada com muletas. 
TABELA 9: DISTRIBUIÇÃO DOS RESULTADOS DO TRATAMENTO NAS FAD CONSIDERANDO OS DIFERENTES MÉTODOS E O SUCESSO OBTIDO

\begin{tabular}{l|rr|rr|rr|rr}
\hline & \multicolumn{2}{|c|}{ Total } & \multicolumn{2}{c|}{ Partículas } & \multicolumn{2}{c|}{ Cola } & \multicolumn{2}{c}{ Ambos } \\
\cline { 2 - 9 } & N & $\%$ & N & $\%$ & N & $\%$ & N & $\%$ \\
\hline \hline Sucesso do Procedimento & 30 & 100,0 & 15 & 100,0 & 9 & 100,0 & 6 & 100,0 \\
Recidiva (1) & 17 & 56,7 & 11 & 73,3 & 1 & 11,1 & 5 & 83,3 \\
Sucesso do Tratamento (2) & 13 & 76,4 & 4 & 66,7 & 8 & 88,9 & 1 & 50,0 \\
Sucesso Clínico (3) & 11 & 64,7 & 3 & 50,0 & 6 & 66,7 & 2 & 100,0 \\
\hline
\end{tabular}

Teste exato de Fisher (1) $p=0,005$, (2) $p=0,380$, (3) $p=0,644$

Nos 10 pacientes que apresentavam MAI houve um predomínio do sexo masculino, sendo 6 homens $(60,0 \%)$ e 4 mulheres $(40,0 \%)$. Com relação à faixa etária, houve um predomínio significativo no grupo com idade entre 19 e 35 anos de idade, sendo 5 pacientes (50,0\%) nesta faixa, seguido de $3(30,0 \%)$ pacientes com idade entre 0 e 18 anos e 2 pacientes $(20,0 \%)$ com mais de 35 anos.

GRÁFICO 4: DISTRIBUIÇÃO QUANTO AO SEXO DAS MAI

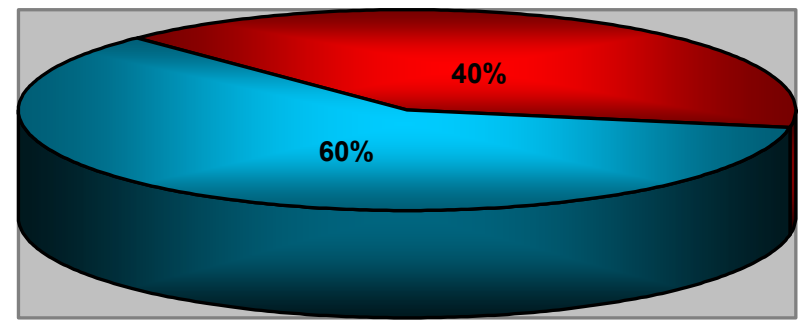


TABELA 10: DISTRIBUIÇÃO POR FAIXA ETÁRIA DAS MAI

\begin{tabular}{ccc}
\hline & $\mathbf{N}$ & $\%$ \\
\hline \hline 0-18 anos & 3 & 30,0 \\
19-35 anos & 5 & 50,0 \\
Acima de 35 anos & 2 & 20,0 \\
\hline \hline Total & 10 & 100,0 \\
\hline
\end{tabular}

O sintoma inicial mais freqüente foi a dor, presente em 9 pacientes (90,0\%), seguido da fraqueza nos membros em 4 pacientes $(40,0 \%)$. Em 1 paciente $(10,0 \%)$ foi referida a sensação de dormência e em outro paciente $(10,0 \%)$ retenção urinária. O tempo decorrido do sintoma inicial até tratamento foi em média de 47,3 meses. Em um paciente esse período foi de 14 anos e em outro, de 10 anos. Em 7 pacientes $(70,0 \%)$ a instalação dos sintomas se deu de maneira súbita e em 2 pacientes $(20,0 \%)$ de maneira progressiva. Em 1 paciente não foi possível caracterizar de maneira precisa esta informação.

TABELA 11: DISTRIBUIÇÃO DOS SINTOMAS INICIAIS NAS MAI

\begin{tabular}{ccc}
\hline & N & $\%$ \\
\hline \hline Dor & 9 & 90,0 \\
Déficit Motor & 4 & 40,0 \\
Déficit Sensitivo & 1 & 10,0 \\
Disfunção Vesical & 1 & 10,0 \\
Obstipação & - & 0 \\
Impotência Sexual & - & 0 \\
\hline
\end{tabular}


Na ocasião do tratamento o sintoma mais freqüente foi a fraqueza nos membros inferiores, presente em 7 pacientes $(70,0 \%)$. A sensação de dormência estava presente em 5 pacientes $(50,0 \%)$, alterações em esfíncter vesical em 3 pacientes $(30,0 \%)$, dor em 2 pacientes $(20,0 \%)$ e obstipação em 1 paciente (10,0\%). Nenhum paciente relatou impotência sexual. Três pacientes (30,0\%) estavam assintomáticos. A marcha estava alterada em 7 pacientes $(70,0 \%)$. Destes, 4 pacientes $(40,0 \%)$ deambulavam sem apoio, mas com restrição aos esforços físicos, 3 pacientes $(30,0 \%)$ estavam acamados e se locomoviam com o auxílio de cadeira de rodas, e 3 pacientes (30,0\%) deambulavam sem restrições.

TABELA 12: DISTRIBUIÇÃO DOS SINTOMAS PRÉ-EMBOLIZAÇÃO NAS MAI

\begin{tabular}{ccc}
\hline & N & $\%$ \\
\hline \hline Déficit Motor & 7 & 70,0 \\
Déficit Sensitivo & 5 & 50,0 \\
Disfunção Vesical & 3 & 30,0 \\
Dor & 2 & 20,0 \\
Obstipação & 1 & 10,0 \\
Impotência Sexual & - & 0 \\
Assintomático & 3 & 30,0 \\
\hline
\end{tabular}

TABELA 13: DISTRIBUIÇÃO DA MARCHA PRÉ-EMBOLIZAÇÃO NAS MAI

\begin{tabular}{ccc}
\hline & N & $\%$ \\
\hline \hline Sem restrição & 3 & 30,0 \\
Restrição aos esforços & 4 & 40,0 \\
Bengala & - & 0 \\
Muleta & - & 0 \\
Acamado ou cadeira de rodas & 3 & 30,0 \\
\hline \hline Total & 10 & 100,0 \\
\hline
\end{tabular}


GRÁFICO 5: DISTRIBUIÇÃO DAS ALTERAÇÕES NA MARCHA PRÉ-

EMBOLIZAÇÃO NAS MAI

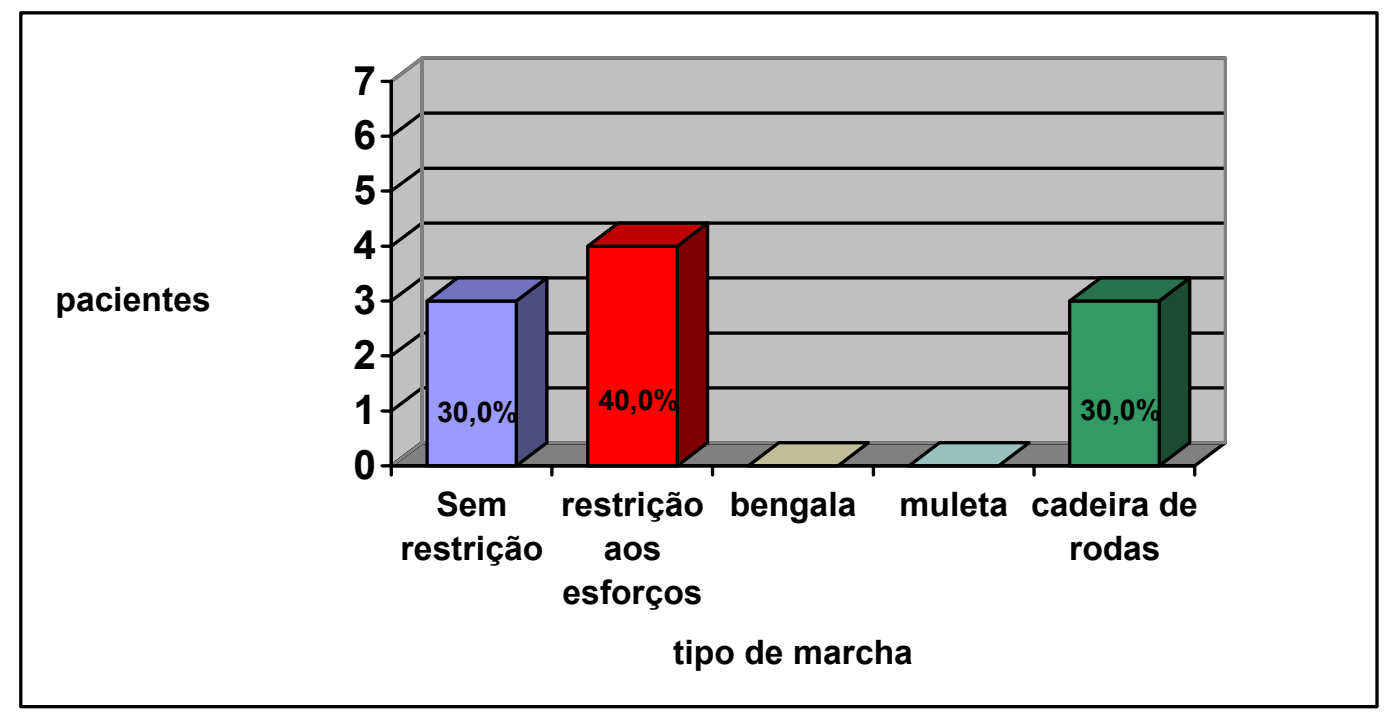

Na nossa casuística, as MAl se localizaram somente na região torácica e cervical, sendo na região cervical em 5 pacientes $(50,0 \%)$ e na torácica em 5 pacientes $(50,0 \%)$. Na região cervical o segmento mais freqüentemente acometido foi $\mathrm{C} 7$, com 3 pacientes. Não houve predomínio na região torácica.

O estudo angiográfico inicial demonstrou a presença de "aneurisma venoso" em 1 paciente $(10,0 \%)$.

O tratamento foi realizado com adesivo tissular em 8 pacientes $(80,0 \%)$ e com partículas em 2 pacientes (20,0\%). Observamos complicações durante a evolução de 4 pacientes $(40,0 \%)$ após os procedimentos de embolização, sendo que em 3 pacientes $(30,0 \%)$ essas complicações foram transitórias e em 1 paciente $(10,0 \%)$, permanente. Nos pacientes em que a piora foi transitória, observou-se diminuição na motricidade dos membros inferiores, que já apresentavam esse déficit. Dois pacientes foram por isquemia (pacientes 6 e 15) e outro por hemorragia durante a cateterização 
(paciente 28). Em 1 paciente houve aparecimento de hemiparesia ao final do procedimento, que evoluiu com regressão parcial (paciente 25). Atualmente o paciente apresenta discreta alteração na marcha, deambulando com restrição aos esforços físicos.

Após o tratamento, em 6 pacientes $(60,0 \%)$ foi constatada a presença de fraqueza nos membros. A sensação de dormência estava presente em 5 pacientes (50,0\%), alterações em esfíncter vesical em 3 pacientes $(30,0 \%)$ e obstipação em 1 paciente (10,0\%). Não foi relatada a presença de dor ou impotência sexual na evolução desses pacientes. Três pacientes $(30,0 \%)$ estavam assintomáticos.

TABELA 14: DISTRIBUIÇÃO DOS SINTOMAS PÓS-EMBOLIZAÇÃO NAS MAI

\begin{tabular}{ccc}
\hline & N & $\%$ \\
\hline \hline Déficit Motor & 6 & 60,0 \\
Déficit Sensitivo & 5 & 50,0 \\
Disfunção Vesical & 3 & 30,0 \\
Obstipação & 1 & 10,0 \\
Dor & - & 0 \\
Impotência Sexual & - & 0 \\
Assintomático & 3 & 30,0 \\
\hline
\end{tabular}

A marcha estava alterada em 6 pacientes $(60,0 \%)$. Três pacientes (30,0\%) deambulavam sem apoio, mas com restrição aos esforços físicos, 2 pacientes $(20,0 \%)$ estavam acamados e se locomoviam com o auxílio de 
cadeira de rodas e 1 paciente $(10,0 \%)$ deambulava com muletas. Quatro dos pacientes $(40,0 \%)$ deambulavam sem restrições. Comparando os resultados do padrão da marcha no pré e pós-tratamento, observamos que houve uma melhora significativa no padrão após a embolização (índice de concordância de Kappa=0,429; $p=0,049)$.

TABELA 15: DISTRIBUIÇÃO DA MARCHA PÓS-EMBOLIZAÇÃO NAS MAI

\begin{tabular}{ccc}
\hline & N & $\%$ \\
\hline \hline Sem restrição & 4 & 40,0 \\
Restrição aos esforços & 3 & 30,0 \\
Bengala & - & 0 \\
Muleta & 1 & 10,0 \\
Acamado ou cadeira de rodas & 2 & 20,0 \\
\hline \hline Total & 10 & 100,0 \\
\hline
\end{tabular}

GRÁFICO 6: DISTRIBUIÇÃO DAS ALTERAÇÕES NA MARCHA PÓS-

EMBOLIZAÇÃO NAS MAI

pacientes

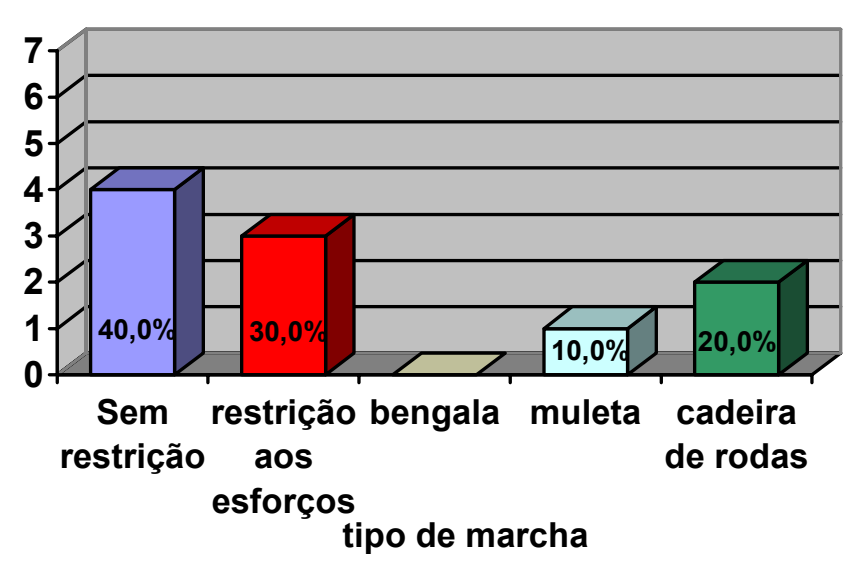


O tratamento endovascular das MAI foi realizado em 10 pacientes. Através desse método foram realizadas 15 sessões de embolização (média de 1,5 sessões/paciente). Ao final do procedimento o controle angiográfico demonstrou oclusão total da lesão em 8 procedimentos, resultando em sucesso de procedimento de 53,3\%. Em 7 dos procedimentos a embolização foi parcial (46,7\%). A recanalização aconteceu em somente 1 procedimento (paciente 15), demonstrando uma taxa de recidiva de $6,7 \%$. O sucesso do tratamento foi obtido em 8 pacientes $(80,0 \%)$, constatado através da cura angiográfica ou da evolução com melhora clínica. 0 paciente que evoluiu com recidiva foi tratado através de nova sessão da embolização. A avaliação clínica mostrou que 4 pacientes $(40,0 \%)$ evoluíram com sucesso clínico desse método, ou seja, na evolução apresentaram melhora neurológica. Nos outros 6 pacientes $(60,0 \%)$ houve insucesso, com quadro neurológico igual ao constatado antes do início do tratamento, porém nenhum evoluindo com piora dos sintomas. Com relação à recidiva, ao sucesso clínico e do tratamento, não se observou diferença significativa entre as técnicas utilizadas.

Nos 2 pacientes submetidos à embolização com partículas, foram realizadas 5 sessões de embolização, perfazendo uma média de 2,5 sessões por paciente. Em ambos os casos houve recanalização da lesão. Em ambos houve melhora dos sintomas. Um paciente apresentou melhora da dor e outro paciente apresentou melhora na marcha. Este paciente, que se locomovia com o auxílio da cadeira de rodas, passou a deambular com o auxílio de andador. 
Nos 8 pacientes que foram submetidos a tratamento endovascular com adesivo tissular foram realizadas 10 sessões de embolização, perfazendo uma média de 1,25 sessões por paciente. Em 3 pacientes $(37,5 \%)$ foi observada melhora dos sintomas. Dois pacientes $(25,0 \%)$ apresentaram diminuição da dor e um paciente $(12,5 \%)$ referiu melhora na marcha, que passou de restrita sem apoio para sem restrições. Em 5 pacientes $(62,5 \%)$ o quadro neurológico permaneceu estável, não sendo observada piora dos sintomas em nenhum paciente. A embolização foi total em 6 pacientes $(75,0 \%)$

TABELA 16: DISTRIBUIÇÃO DOS RESULTADOS DO TRATAMENTO NAS MAI CONSIDERANDO OS DIFERENTES MÉTODOS E O SUCESSO OBTIDO

\begin{tabular}{l|cc|cc|cc}
\hline & \multicolumn{2}{|c|}{ Total } & \multicolumn{2}{c|}{ Partículas } & \multicolumn{2}{c}{ Cola } \\
\cline { 2 - 7 } & $\mathbf{N}$ & $\%$ & $\mathbf{N}$ & $\%$ & $\mathbf{N}$ & $\%$ \\
\hline \hline Sucesso do Procedimento & 8 & 53,3 & 1 & 25,0 & 7 & 63,3 \\
Recidiva (1) & 1 & 6,7 & - & 0,0 & 1 & 9,1 \\
Sucesso do Tratamento (2) & 8 & 80,0 & 2 & 100,0 & 6 & 75,0 \\
Sucesso Clínico (3) & 4 & 40,0 & 2 & 100,0 & 2 & 25,0 \\
\hline
\end{tabular}

Teste exato de Fisher (1) $p=1,000,(2) p=1,000$ e (3) $p=0,133$

Em 4 pacientes observou-se opacificação do eixo espinal anterior pelo pedículo que supria a MAI. Em 2 pacientes optou-se pela embolização com partículas. Em 1 destes o paciente apresentou piora transitória da motricidade, mas ao final do tratamento apresentava melhora na deambulação, que inicialmente era feita com cadeira de rodas e passou a 
ser feita com andador. O outro paciente apresentou estabilização do quadro motor e melhora da sensação de queimação nos membros inferiores e melhor controle no esfíncter vesical. Em 2 pacientes o microcateterismo permitiu que fosse atingido o nidus da MAI, sem refluxo para o eixo espinhal anterior, permitindo a embolização com adesivo tissular. Um paciente evoluiu com piora transitória da motricidade nos membros inferiores (paciente 28) e outro apresentou melhora na marcha, que no início era realizada com restrição aos esforços e posteriormente evoluiu sem restrição.

Somente 1 paciente com MAVM foi encaminhado para tratamento endovascular. Era uma paciente do sexo feminino, sem lesões cutâneas e com histórico de mola hidatiforme. Apresentava antecedente de ter sido operada de um "hemangioma" na coluna torácica há 24 anos, quando apresentou quadro súbito de dor tóraco-lombar. Dois meses antes da admissão começou a apresentar quadro progressivo de dor tóraco-lombar e fraqueza nas pernas. Durante a internação apresentava dor tóraco-lombar, fraqueza nas pernas, acompanhada de sensação de dormência, retenção urinária e fecal. A marcha era realizada com auxílio de bengala. Os exames de imagem sugeriam neoplasia muito vascularizada. Foi submetida a procedimento cirúrgico e durante a laminectomia foi observada a presença de inúmeros vasos sangüíneos dilatados e tortuosos, tendo-se optado pela interrupção do procedimento. Posteriormente foi realizado estudo angiográfico que mostrou extensa malformação arteriovenosa com componentes intra e extra-raquianos, suprida pelas artérias brônquica esquerda, intercostais de T8, T9, T11 e T12 bilateralmente e T10 direita. 
A paciente foi submetida a tratamento endovascular na mesma internação. Foram embolizados os pedículos vasculares de T9 direito, T11 direito e T12 esquerdo com cola. No pedículo de T11 esquerdo havia uma fístula com fluxo sangüíneo muito alto, sendo então utilizado temporariamente um balão de látex. Após a insuflação do balão houve diminuição do fluxo, permitindo a injeção do adesivo tissular com segurança no pertuito fistular. A paciente evoluiu com melhora da dor e da marcha, que passou a ser realizada sem apoio, com restrição aos esforços.

Dos 11 pacientes com FAVP, 4 foram excluídos da casuística. Em 2 pacientes com FAVP-A, a artéria radículo medular nutridora da lesão apresentava calibre reduzido para atingir o ponto fistular, que se situava muito distalmente. Dois pacientes apresentavam fístulas localizadas no cone medular, uma FAV-B e outra FAV-C. Em ambas havia múltiplos pertuitos que convergiam para uma veia de drenagem dilatada, tornando o procedimento de maior risco pela possibilidade de trombose venosa e pela dificuldade técnica. Todos esses pacientes foram encaminhados para tratamento cirúrgico, já que o ponto fistular estava abaixo do cone medular.

Nos 7 pacientes submetidos a tratamento endovascular houve um predomínio do sexo masculino, sendo acometidos 4 homens $(57,1 \%)$ e 3 mulheres $(42,9 \%)$. Com relação à faixa etária, houve um predomínio significativo no grupo com menos de 18 anos de idade, sendo 5 pacientes $(71,4 \%)$ nesta faixa. 
GRÁFICO 7: DISTRIBUIÇÃO QUANTO AO SEXO DAS FAVP

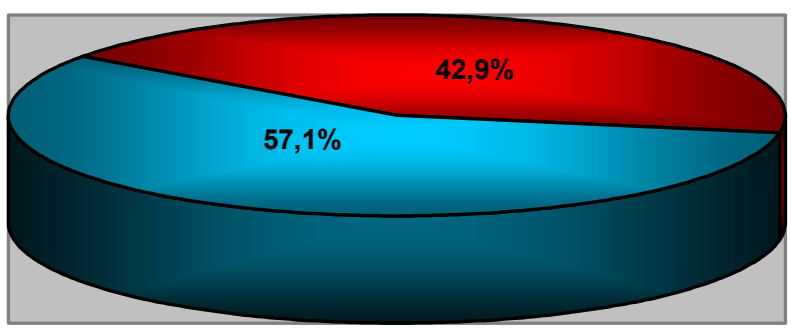

TABELA 17: DISTRIBUIÇÃO POR FAIXA ETÁRIA DAS FAVP

\begin{tabular}{ccc}
\hline & N & $\%$ \\
\hline \hline 0-18 anos & 5 & 71,4 \\
19-35 anos & 1 & 14,3 \\
Acima de 35 anos & 1 & 14,3 \\
\hline \hline Total & 7 & 100,0 \\
\hline
\end{tabular}

O sintoma inicial mais freqüente foi a fraqueza nos membros inferiores, observada em 6 pacientes (85,7\%), seguido da dor em 3 pacientes (42,9\%) e sensação de dormência em 1 paciente (14,3\%). O tempo decorrido do sintoma inicial até o tratamento foi em média de 24,5 meses. Em 5 pacientes $(71,4 \%)$ a instalação dos sintomas se deu de maneira súbita. Um paciente referiu piora dos sintomas com o esforço físico. 
TABELA 18: DISTRIBUIÇÃO DOS SINTOMAS INICIAIS NAS FAVP

\begin{tabular}{ccc}
\hline & N & $\%$ \\
\hline \hline Déficit Motor & 6 & 85,7 \\
Dor & 3 & 42,9 \\
Déficit Sensitivo & 1 & 14,3 \\
Disfunção Vesical & - & 0 \\
Obstipação & - & 0 \\
Impotência Sexual & - & 0 \\
\hline
\end{tabular}

Na ocasião do tratamento, 6 pacientes $(85,7 \%)$ apresentavam fraqueza nos membros, 5 pacientes alterações em esfíncter vesical (71,4\%), 3 pacientes dor $(42,9 \%), 2$ pacientes $(28,6 \%)$ sensação de dormência, e 2 pacientes obstipação (28,6\%). Em 1 paciente do sexo masculino foi referida impotência sexual $(25,0 \%)$. Um paciente $(14,3 \%)$ estava assintomático. A marcha estava alterada em 6 pacientes (85,7\%). Destes, 3 pacientes $(42,9 \%)$ deambulavam sem apoio, mas com restrição aos esforços físicos, 2 pacientes $(28,6 \%)$ estavam acamados e se locomoviam com o auxílio de cadeira de rodas e 1 paciente $(14,3 \%)$ deambulava com auxílio de muletas. Um paciente $(14,3 \%)$ deambulava sem restrições. 
TABELA 19: DISTRIBUIÇÃO DOS SINTOMAS PRÉ-EMBOLIZAÇÃO NAS FAVP

\begin{tabular}{ccc}
\hline & N & $\%$ \\
\hline \hline Déficit Motor & 6 & 85,7 \\
Disfunção Vesical & 5 & 71,4 \\
Dor & 3 & 42,9 \\
Obstipação & 2 & 28,6 \\
Déficit Sensitivo & 2 & 28,6 \\
Impotência Sexual & 1 & 14,3 \\
Assintomático & 1 & 14,3 \\
\hline
\end{tabular}

TABELA 20: DISTRIBUIÇÃO DAS ALTERAÇÕES NA MARCHA PRÉEMBOLIZAÇÃO NAS FAVP

\begin{tabular}{ccc}
\hline & N & $\%$ \\
\hline \hline Sem restrição & 1 & 14,3 \\
Restrição aos esforços & 3 & 42,9 \\
Bengala & - & 0 \\
Muleta & 1 & 14,3 \\
Acamado ou cadeira de rodas & 2 & 28,6 \\
\hline \hline Total & 7 & 100,0 \\
\hline
\end{tabular}

GRÁFICO 8: DISTRIBUIÇÃO DAS ALTERAÇÕES NA MARCHA PRÉ-

EMBOLIZAÇÃO NAS FAVP

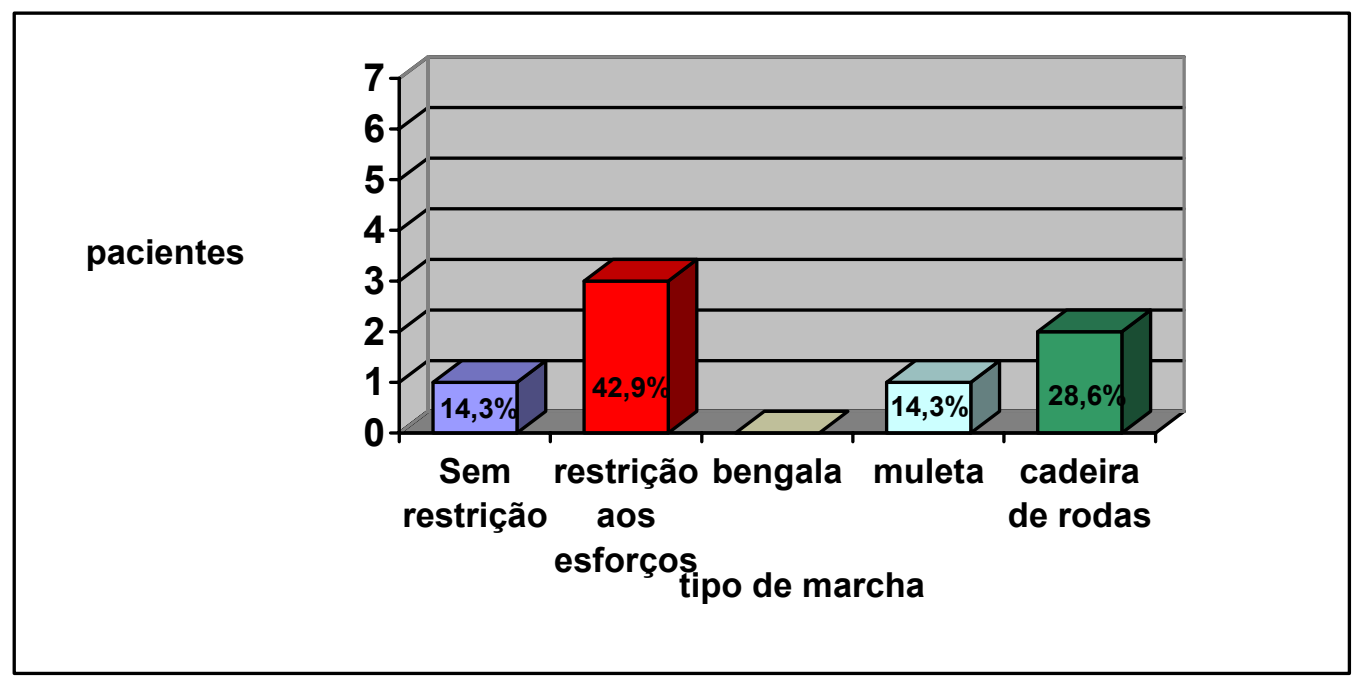


A localização mais freqüente da FAVP na coluna foi na transição tóraco-lombar, observada em 5 pacientes $(71,4 \%)$ seguida da região cervical, em 2 pacientes (28,6\%).

O estudo angiográfico inicial demonstrou que 4 pacientes $(57,1 \%)$ apresentavam FAVP-A, 1 paciente (14,3\%) FAV-B e 2 pacientes (28,6\%) FAV-C. Três dos pacientes apresentavam "aneurisma venoso". O tratamento foi realizado com adesivo tissular em 6 pacientes $(85,7 \%)$ e com partículas em 1 paciente (14,3\%). Observamos complicação em 1 paciente (14,3\%) após os procedimentos de embolização (paciente 1). Este paciente evoluiu com transitória espasticidade após a embolização com cola.

Após a embolização, em 6 pacientes $(85,7 \%)$ foi constatada fraqueza nos membros inferiores, 2 pacientes alterações em esfíncter vesical (28,6\%), 1 paciente dor (14,3\%) e 1 paciente obstipação (14,3\%). Em 1 paciente do sexo masculino foi referida impotência sexual $(25,0 \%)$. Um paciente $(14,3 \%)$ estava assintomático.

TABELA 21: DISTRIBUIÇÃO DOS SINTOMAS PÓS-EMBOLIZAÇÃO NAS FAVP

\begin{tabular}{ccc}
\hline & N & $\%$ \\
\hline \hline Déficit Motor & 6 & 85,7 \\
Disfunção Vesical & 2 & 28,6 \\
Dor & 1 & 14,3 \\
Obstipação & 1 & 14,3 \\
Impotência Sexual & 1 & 14,3 \\
Déficit Sensitivo & - & 0 \\
Assintomático & 1 & 14,3 \\
\hline
\end{tabular}


A marcha estava alterada em 6 pacientes (85,7\%). Destes, 4 pacientes $(57,1 \%)$ deambulavam sem apoio, mas com restrição aos esforços físicos, 1 paciente $(14,3 \%)$ estava acamado e se locomovia com o auxílio de cadeira de rodas e 1 paciente $(14,3 \%)$ deambulava com auxílio de muletas. Um paciente $(14,3 \%)$ deambulava sem restrições. Comparando os resultados do padrão da marcha no pré e pós-tratamento, observamos que a melhora no padrão após a embolização não foi significativa (índice de concordância de Kappa $=0,788 ; p=0,015)$.

TABELA 22: DISTRIBUIÇÃO DAS ALTERAÇÕES NA MARCHA PÓSEMBOLIZAÇÃO NAS FAVP

\begin{tabular}{ccc}
\hline & N & $\%$ \\
\hline \hline Sem restrição & 1 & 14,3 \\
Restrição aos esforços & 4 & 57,1 \\
Bengala & - & 0 \\
Muleta & 1 & 14,3 \\
Acamado ou cadeira de rodas & 1 & 14,3 \\
\hline \hline Total & 7 & 100,0
\end{tabular}

GRÁFICO 9: DISTRIBUIÇÃO DAS ALTERAÇÕES NA MARCHA PÓSEMBOLIZAÇÃO NAS FAVP

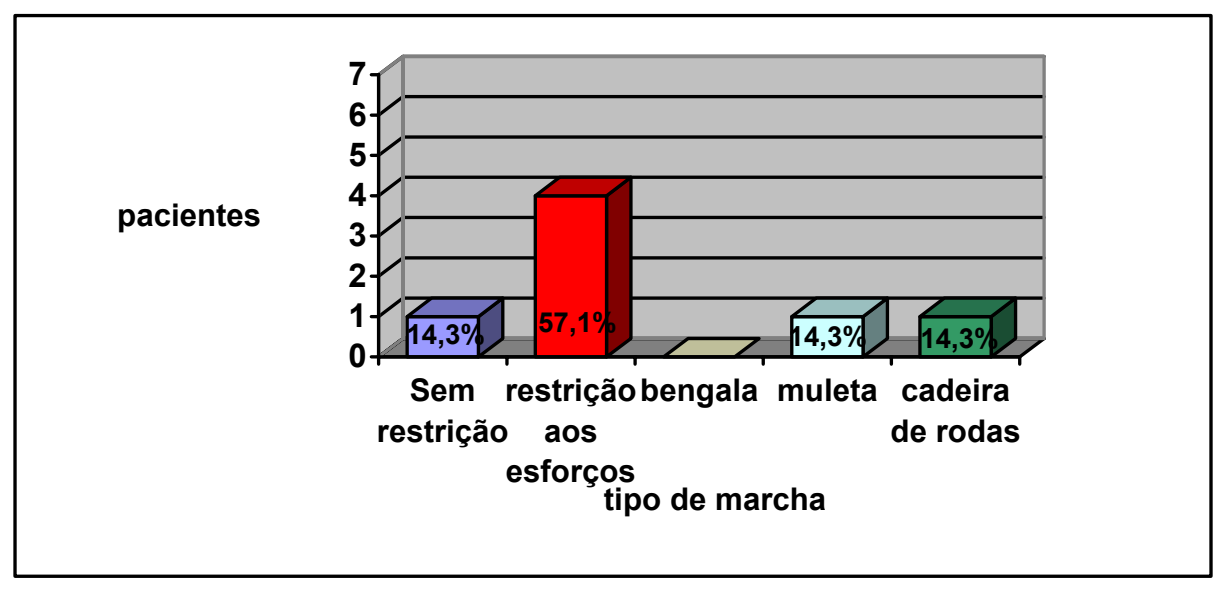


Sete pacientes com FAVP foram tratados com embolização. Foram realizados 9 procedimentos (média de 1,3 sessões/paciente). Ao final do procedimento o controle angiográfico demonstrou oclusão total da lesão em 6 procedimentos, resultando em sucesso de procedimento de $66,7 \%$. A embolização foi parcial em 2 procedimentos (22,2\%). A recanalização não aconteceu em nenhum procedimento, demonstrando ausência de recidiva. $O$ sucesso do tratamento foi obtido em 6 pacientes $(85,7 \%)$, constatado através da cura angiográfica ou da evolução com melhora clínica. A avaliação clínica mostrou que todos pacientes evoluíram com sucesso clínico deste método. Um desses pacientes apresentava-se assintomático antes do tratamento, e assim permaneceu após o procedimento. Com relação ao sucesso clínico e do tratamento, não se observou diferença significativa entre as técnicas utilizadas.

No paciente submetido à embolização com partículas foi realizada somente uma sessão de embolização. Foi observada melhora da dor nesse paciente.

Nos 6 pacientes que foram submetidos a tratamento endovascular com cola foram realizadas 8 sessões de embolização, perfazendo uma média de 1,3 sessão por paciente. Em 5 dos pacientes (83,3\%) foi observada melhora dos sintomas. Dois pacientes $(33,3 \%)$ evoluíram com melhora da dor, 2 pacientes (33,3\%) com melhora da retenção vesical e 1 paciente $(16,7 \%)$, da impotência sexual. Um paciente $(16,7 \%)$ estava traqueostomizado e com ventilação mecânica, e evoluiu com melhora do padrão ventilatório, tornando-se independente da ventilação assistida. Um paciente $(16,7 \%)$ 
apresentou melhora da deambulação, que inicialmente era feita com cadeira de rodas e passou a ser realizada com o auxílio de muletas. Em um paciente $(16,7 \%)$ o quadro neurológico permaneceu estável, não sendo observada piora dos sintomas em nenhum paciente.

TABELA 23: DISTRIBUIÇÃO DOS RESULTADOS DO TRATAMENTO NAS FAVP CONSIDERANDO OS DIFERENTES MÉTODOS E O SUCESSO OBTIDO

\begin{tabular}{l|cc|cc|cc}
\hline & \multicolumn{2}{|c|}{ Total } & \multicolumn{2}{c|}{ Partículas } & \multicolumn{2}{c}{ Cola } \\
\cline { 2 - 7 } & N & $\%$ & N & $\%$ & N & $\%$ \\
\hline \hline Sucesso do Procedimento & 6 & 66,7 & 0 & 0,0 & 6 & 100,0 \\
Recidiva & 0 & 0,0 & 0 & 0,0 & 0 & 0,0 \\
Sucesso do Tratamento (1) & 6 & 85,7 & 0 & 0,0 & 6 & 100,0 \\
Sucesso Clínico (2) & 7 & 100,0 & 1 & 100,0 & 6 & 100,0 \\
\hline
\end{tabular}

Teste exato de Fisher (1) $p=0,143$ e (2) $p=1,000$

Com relação às FAV-A, 4 pacientes foram tratados com embolização. Todos os pacientes $(100,0 \%)$ apresentaram melhora dos sintomas. Um paciente apresentou melhora da dor, 1 paciente que apresentava retenção urinária evoluiu com incontinência, um paciente que deambulava com cadeira de rodas passou a fazê-lo com muletas e um paciente que dependia de ventilação mecânica evoluiu com independência ventilatória.

Um paciente tratado foi classificado como FAV-B (paciente 1). Apresentava 2 pertuitos fistulares, um em T12 e outro em L2. Duas tentativas de embolização foram realizadas sem sucesso. O paciente foi encaminhado para tratamento cirúrgico, sendo ocluída a fístula em L2. Foi 
reavaliado do ponto de vista endovascular e optou-se por embolização do pertuito em T12, que foi realizada com sucesso. O paciente evoluiu com espasticidade transitória nos membros inferiores.

Na nossa casuística, somente 2 pacientes apresentavam FAVP-C. Uma paciente apresentava fístulas em T10 e T11 direitas e L2 bilateralmente (paciente 14). Foram embolizados com cola todos os pertuitos em uma única sessão. A paciente evoluiu com melhora do quadro álgico. Outro paciente apresentava fístulas em T10 e L1 esquerdas e L4 direita (paciente 12). Foi submetido à embolização através da artéria lombar de L4 à direita, com cola e em outra sessão através da embolização da artéria sacral mediana com cola. Evoluiu com melhora da dor, da sensação de dormência nas pernas e da retenção vesical. Porém ainda apresentava as fístulas em T10, que opacificavam o cone medular. Foi então encaminhado para cirurgia. Foram realizados 3 intervenções (média de 1,5 sessões/paciente). Ao final da embolização o controle angiográfico demonstrou oclusão total da lesão em uma intervenção, resultando em sucesso de procedimento de 33,3\%. Em 2 procedimentos a embolização foi parcial. A recanalização não aconteceu em nenhum procedimento, demonstrando ausência de recidiva. A avaliação clínica mostrou que todos os pacientes evoluíram com sucesso clínico deste método. Ambos evoluíram com melhora da dor e um deles também apresentou melhora da impotência sexual e controle dos esfíncteres. 
5.1 ILUSTRAÇÕES 

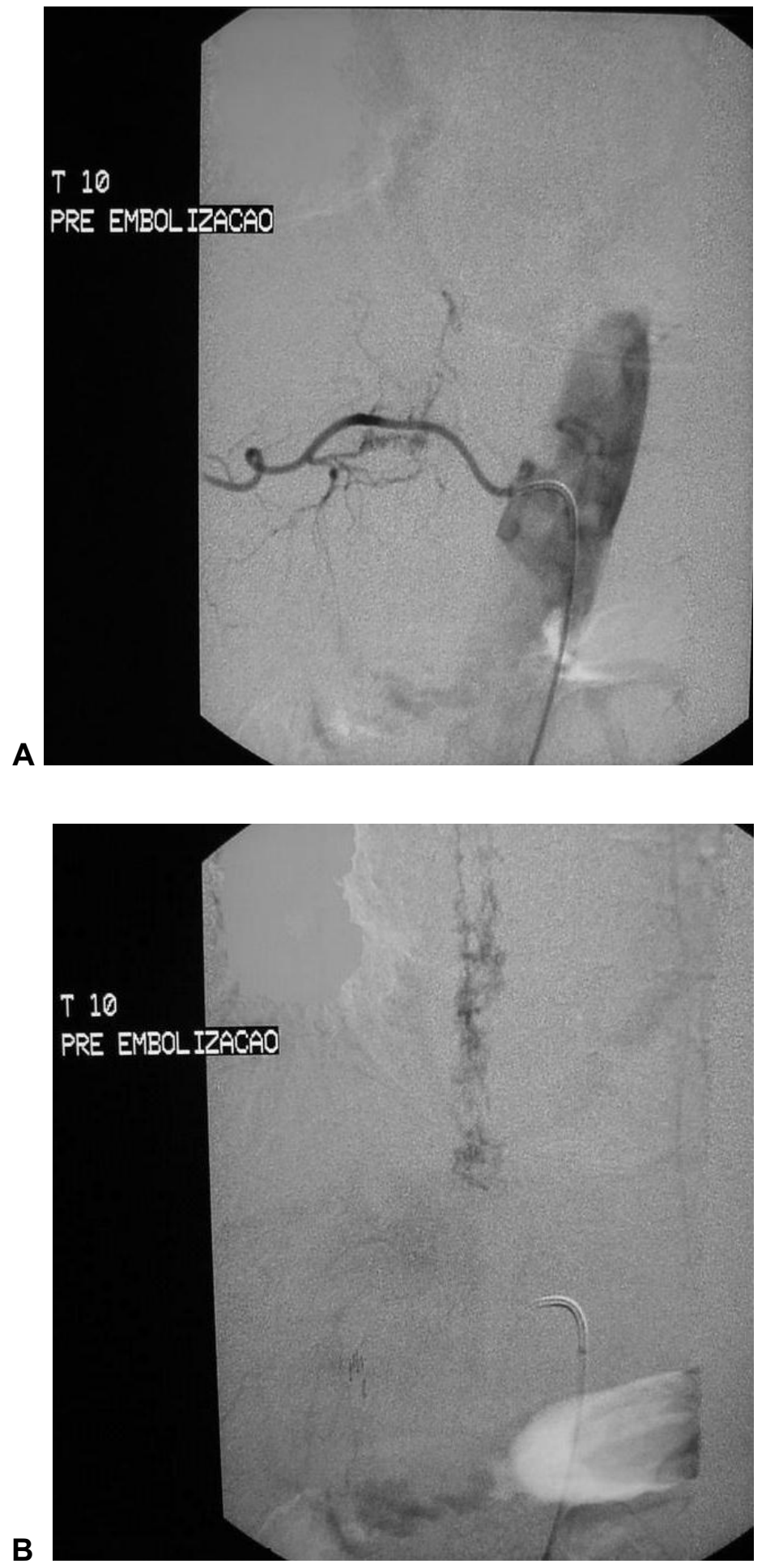

Figura 11: FAD-A que se opacifica pela artéria intercostal de T 10 direita (A e B). Paciente 8 

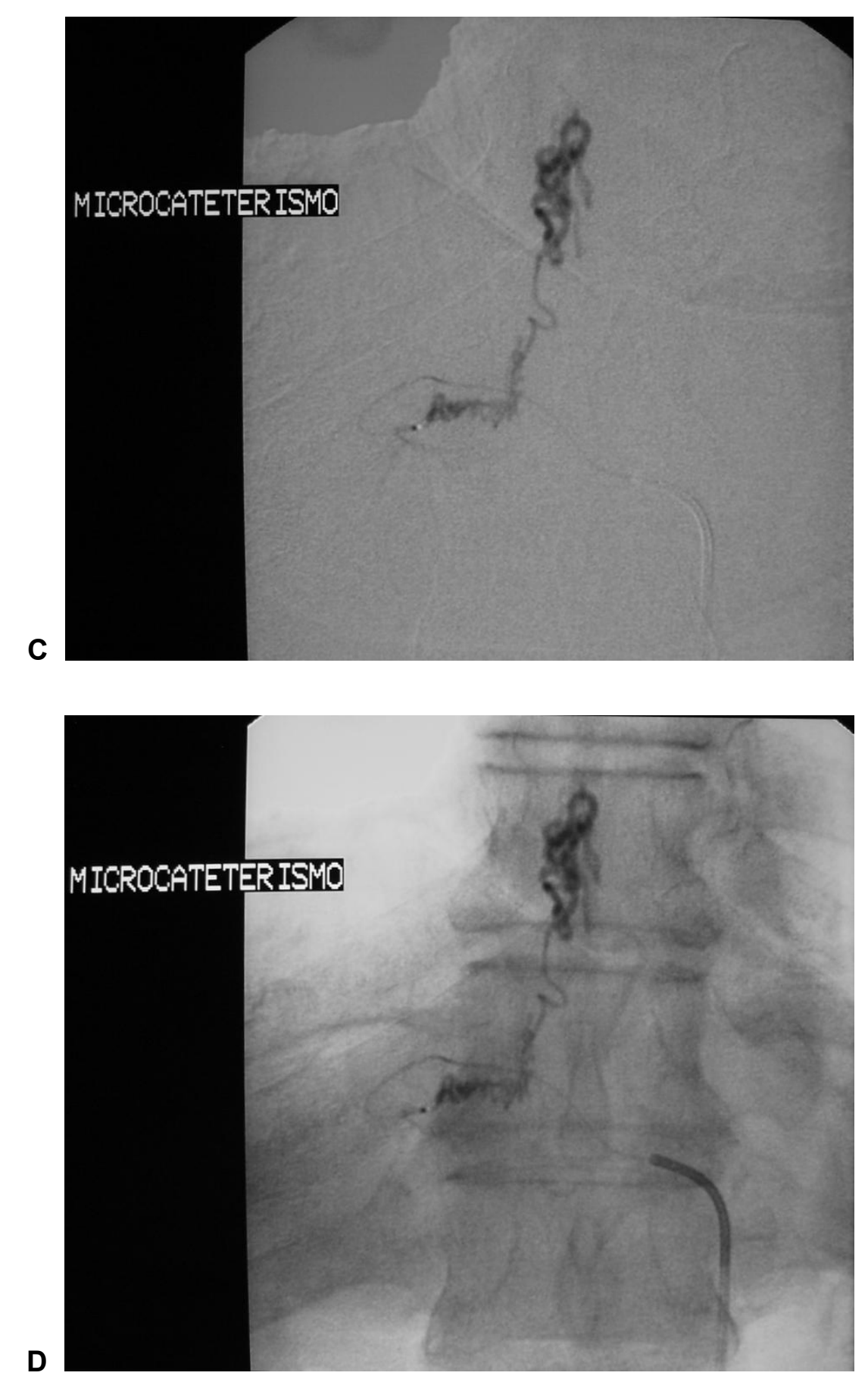

Figura 11: Microcateterismo da artéria radicular de T10 direita (C e D). Paciente 8 

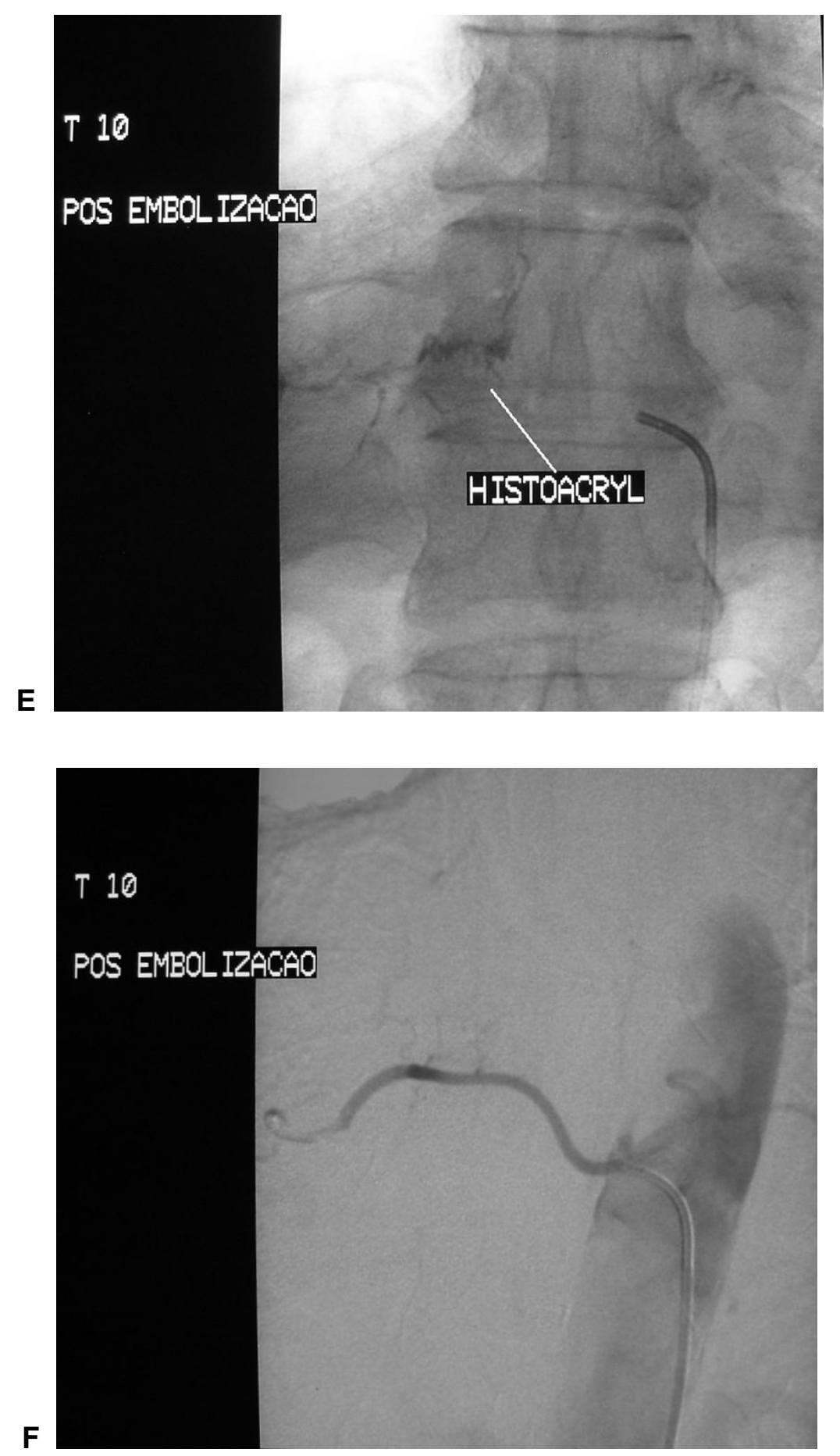

Figura 11: Injeção de Histoacryl $®$ e Lipiodol $®$ na FAD $(E)$. Controle final, mostrando ausência de opacificação da lesão $(F)$. Paciente 8 

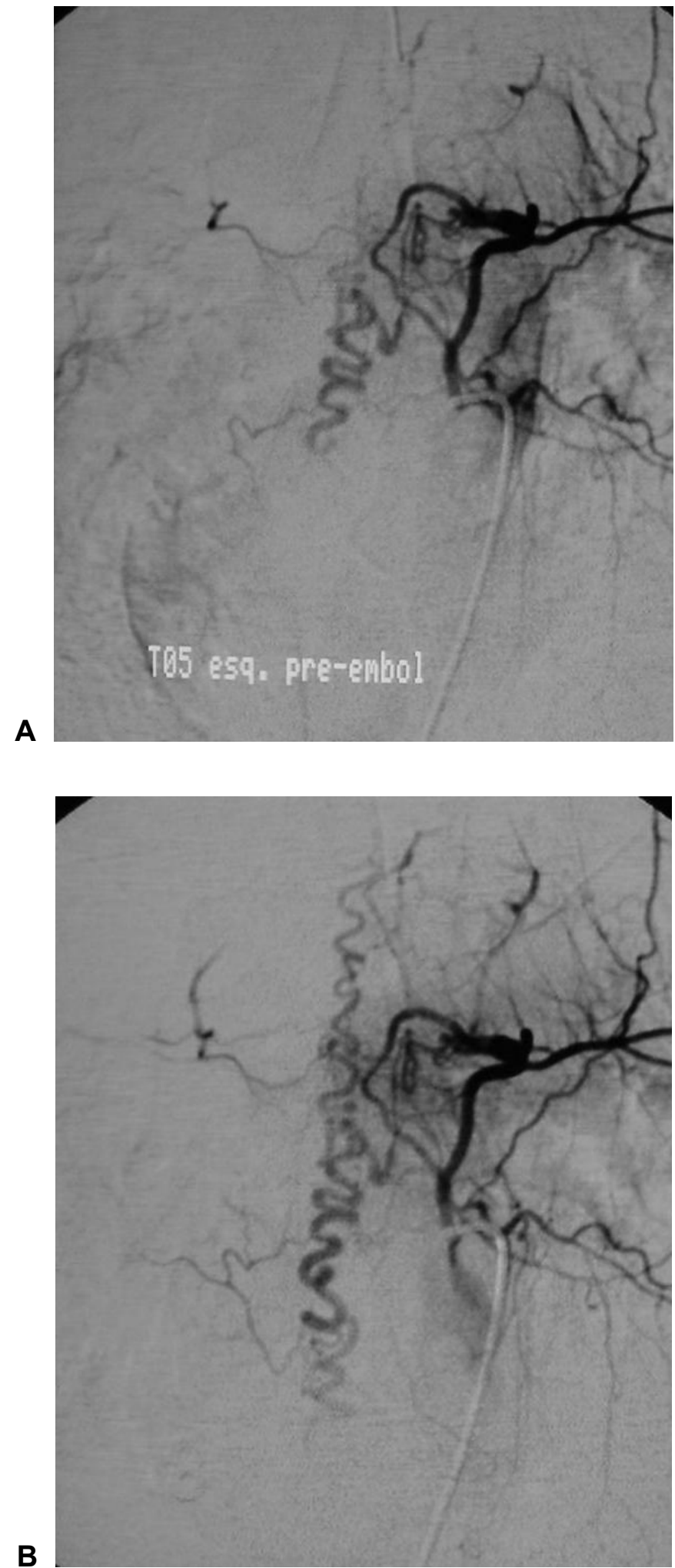

Figura 12: FAD-B que se opacifica pela artéria intercostal de $T 5$ esquerda ( $A$ e B). Paciente 2 

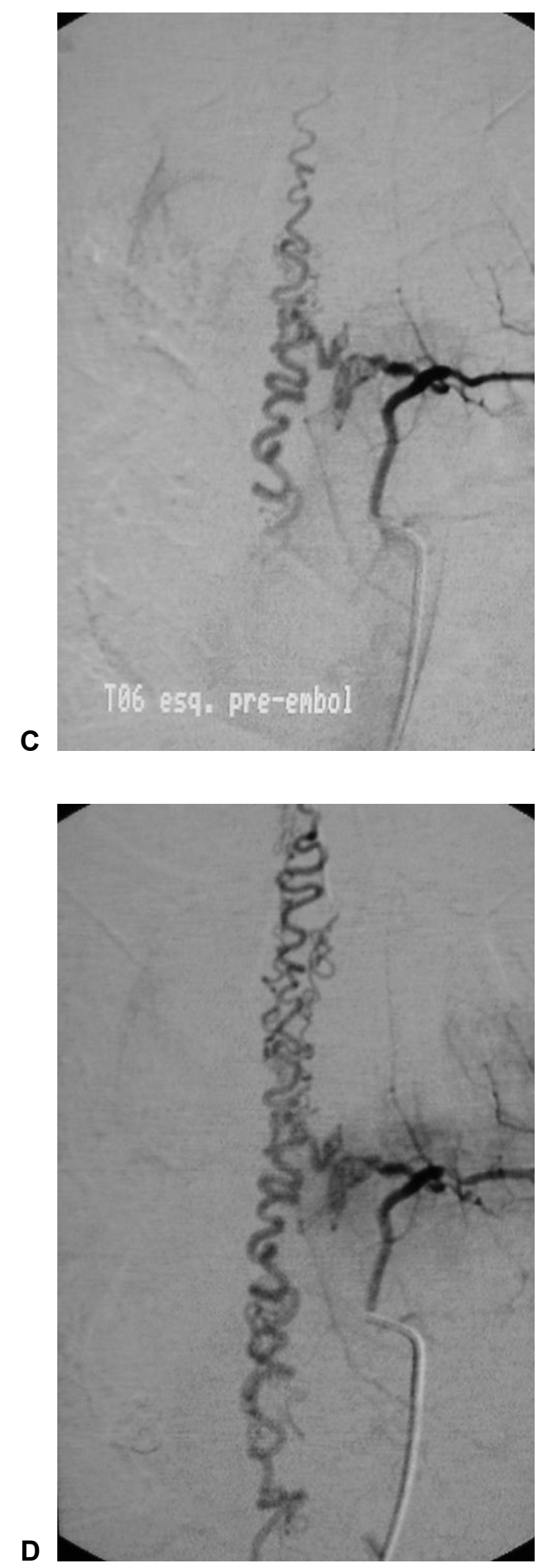

Figura 12: FAD-B que se opacifica pela artéria intercostal de T6 esquerda (C e D). Paciente 2 

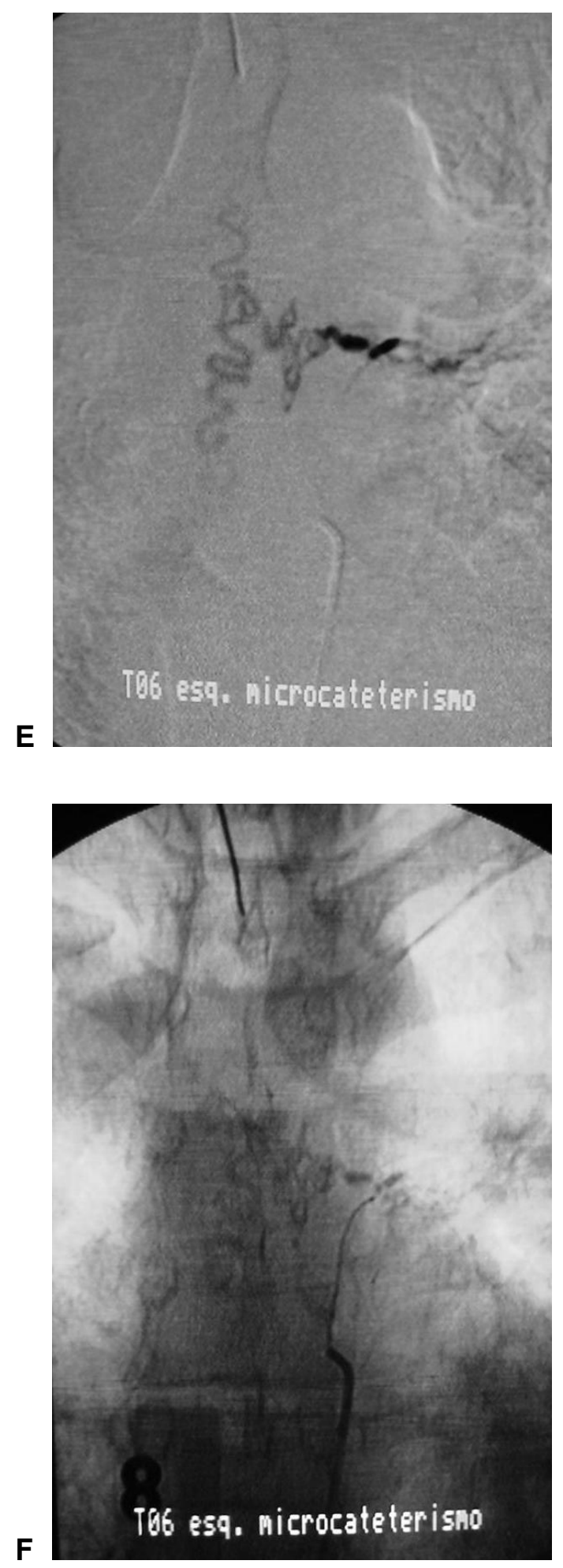

Figura 12: Realizado microcateterismo da artéria intercostal de T6 esquerda, com opacificação da lesão (E e F). Paciente 2 

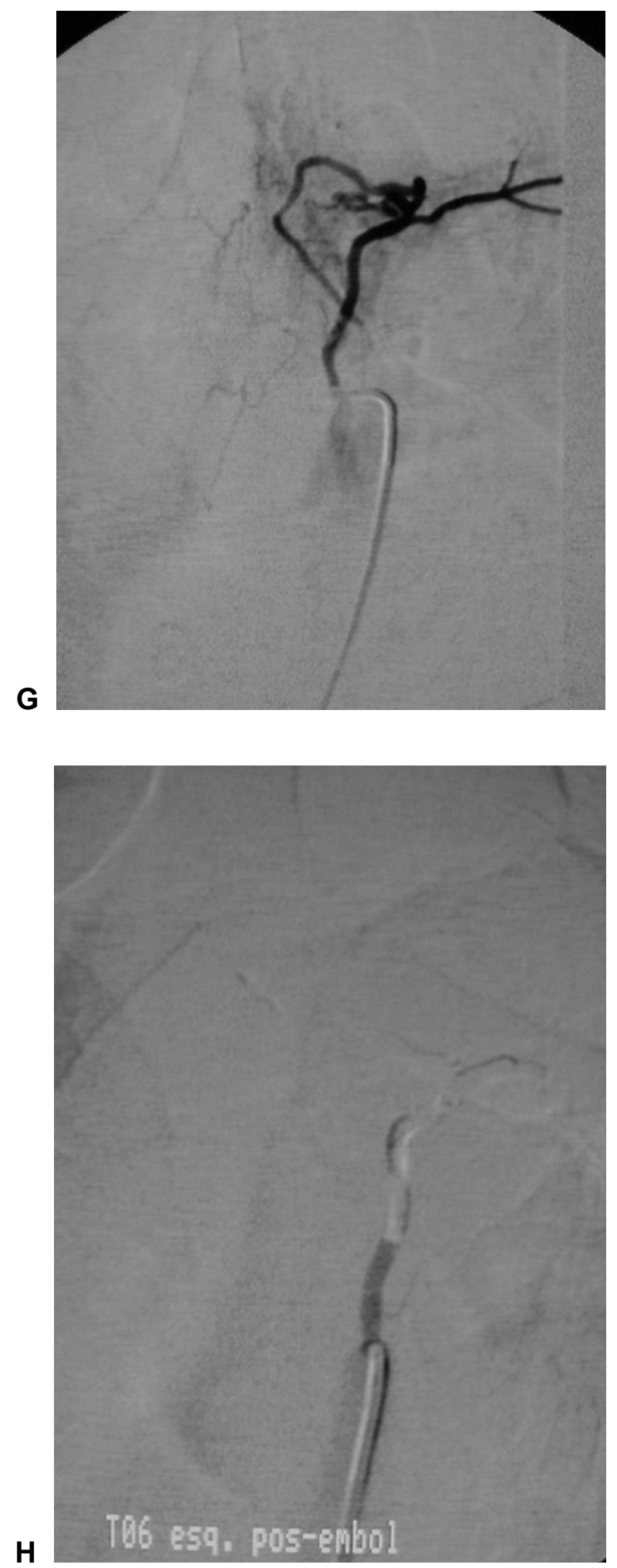

Figura 12: Controle angiográfico em T5 (G) e T6 (H), mostrando ausência de lesão residual. Paciente 2 


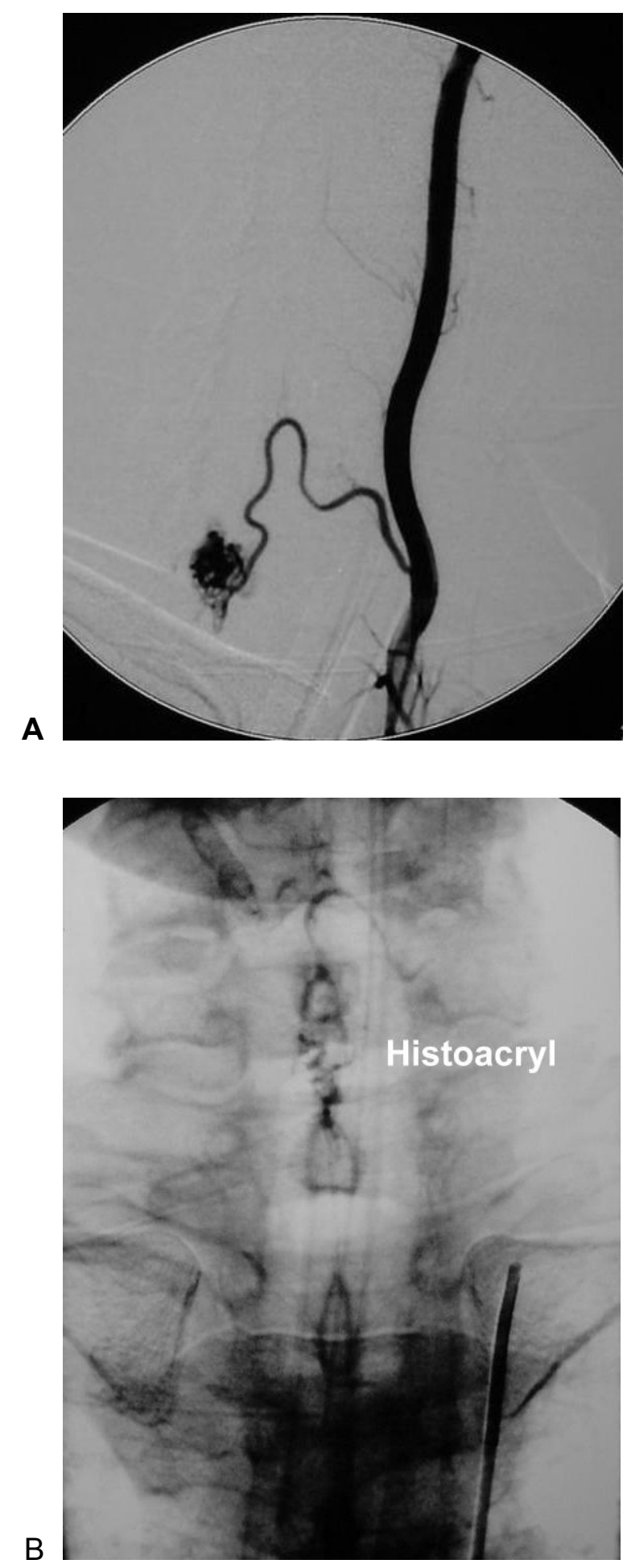

Figura 13: MAI que se opacifica por artéria radículo-medular, ramo da artéria vertebral esquerda (A). Controle mostrando aspecto final da injeção de Histoacryl ${ }^{\circledR}(B)$. Paciente 31 

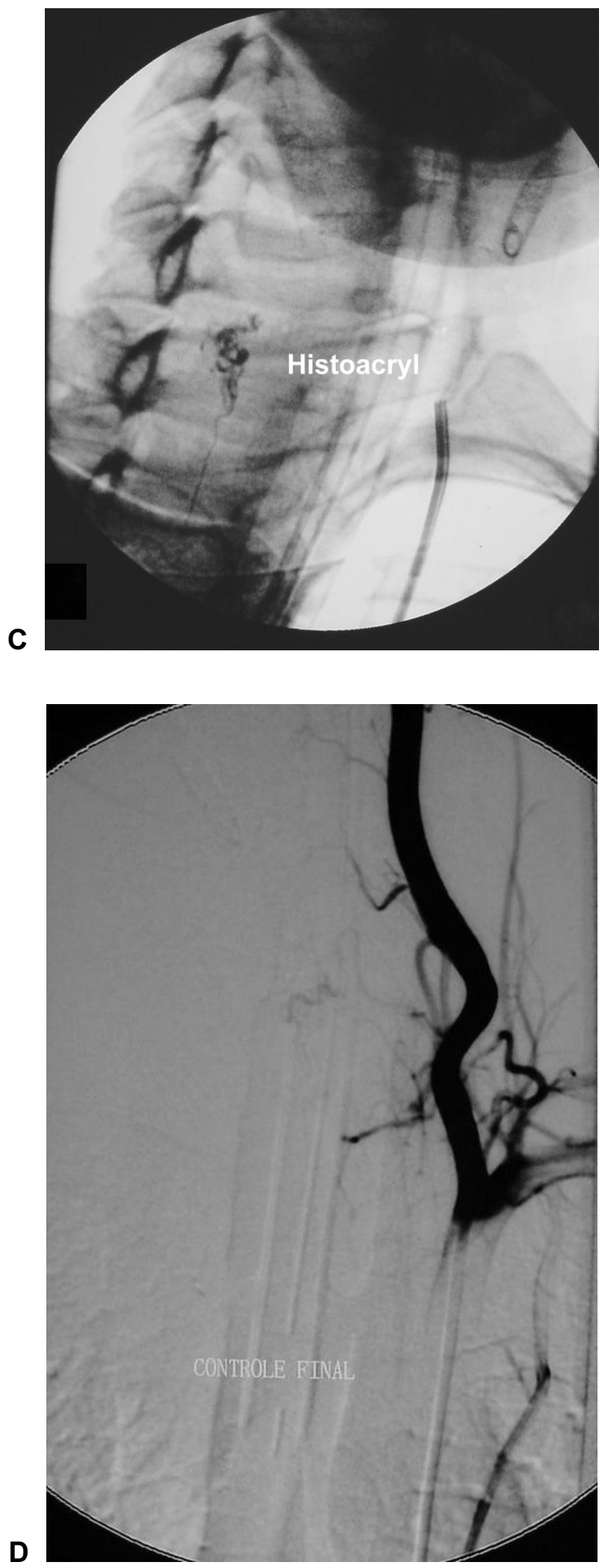

Figura 13: Controle final mostrando a localização do Histoacryl ${ }^{\circledR}$ (C). A injeção do meio de contraste na artéria vertebral esquerda, mostrando embolização total da lesão (D). Paciente 31 

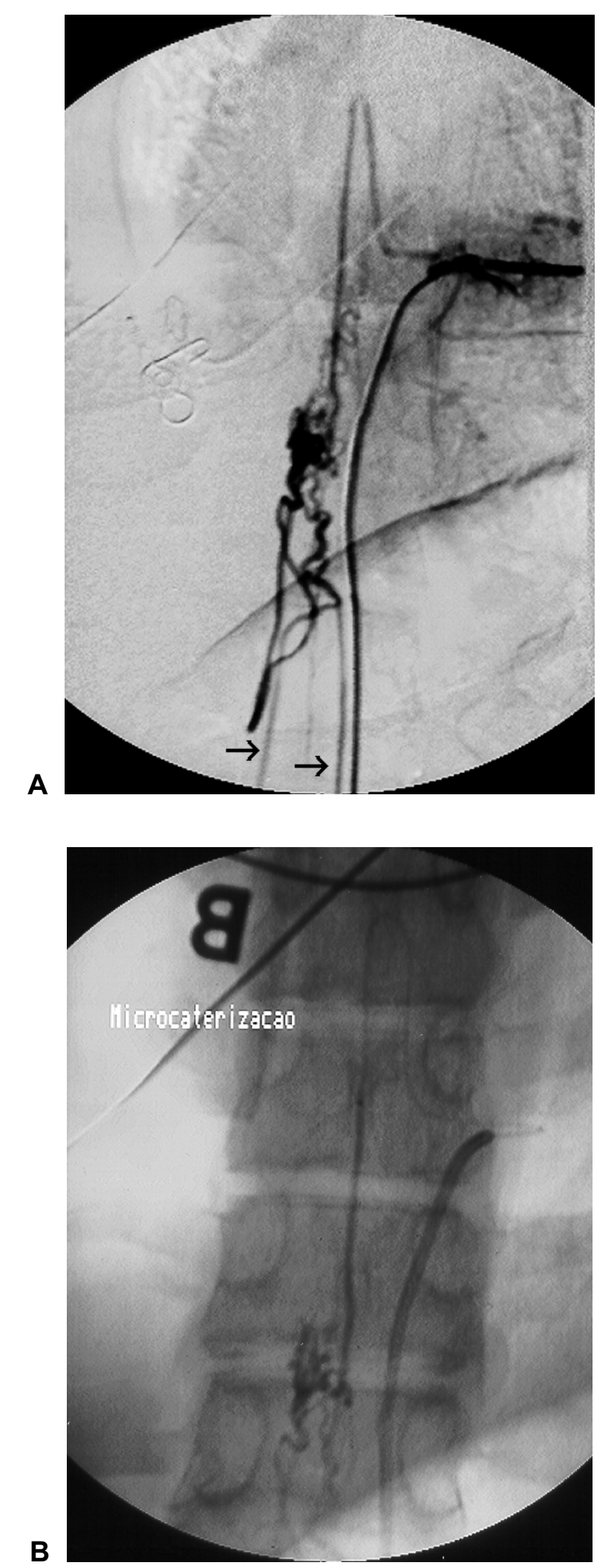

Figura 14: MAI que se opacifica pela artéria intercostal de T9 esquerda. Esta lesão é suprida por ramo da artéria de Adamkiewicz e com drenagem para 2 veias espinhais (setas) (A). Microcateterismo da MAI (B). Paciente 23 

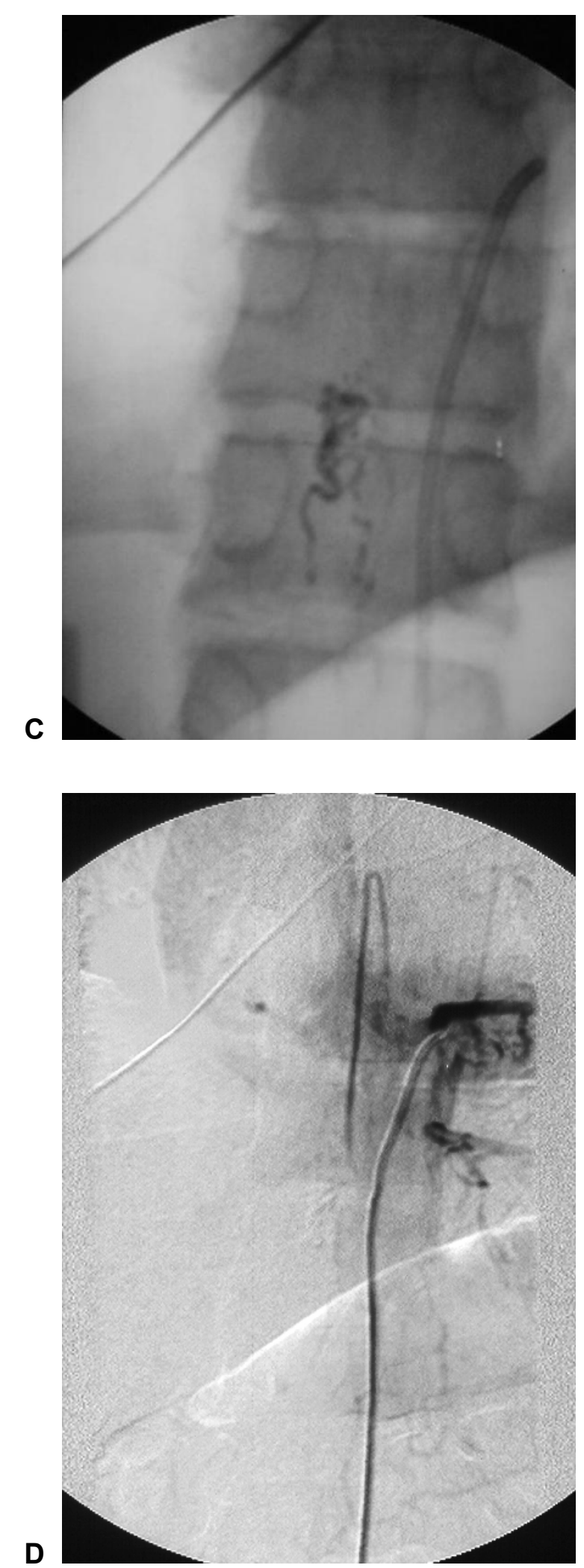

Figura 14: Controle final mostrando a localização do Histoacryl ${ }^{\circledR}(C)$. A injeção do meio de contraste na artéria intercostal de T9 esquerda, mostrando embolização total da lesão (D). Paciente 23 

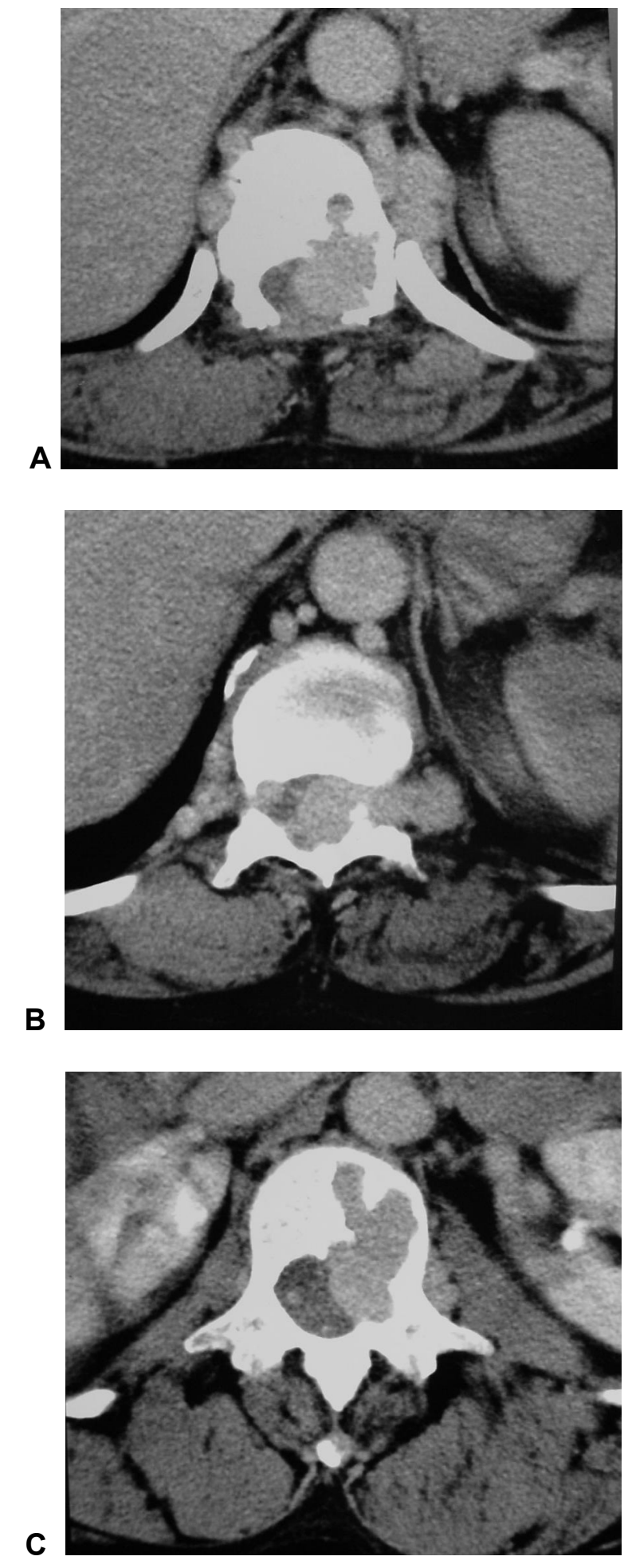

Figura 15: TC da coluna torácica mostrando extensa MAVM com componente extra e intraraquianos ( $A, B$ e $C)$. Paciente 33 

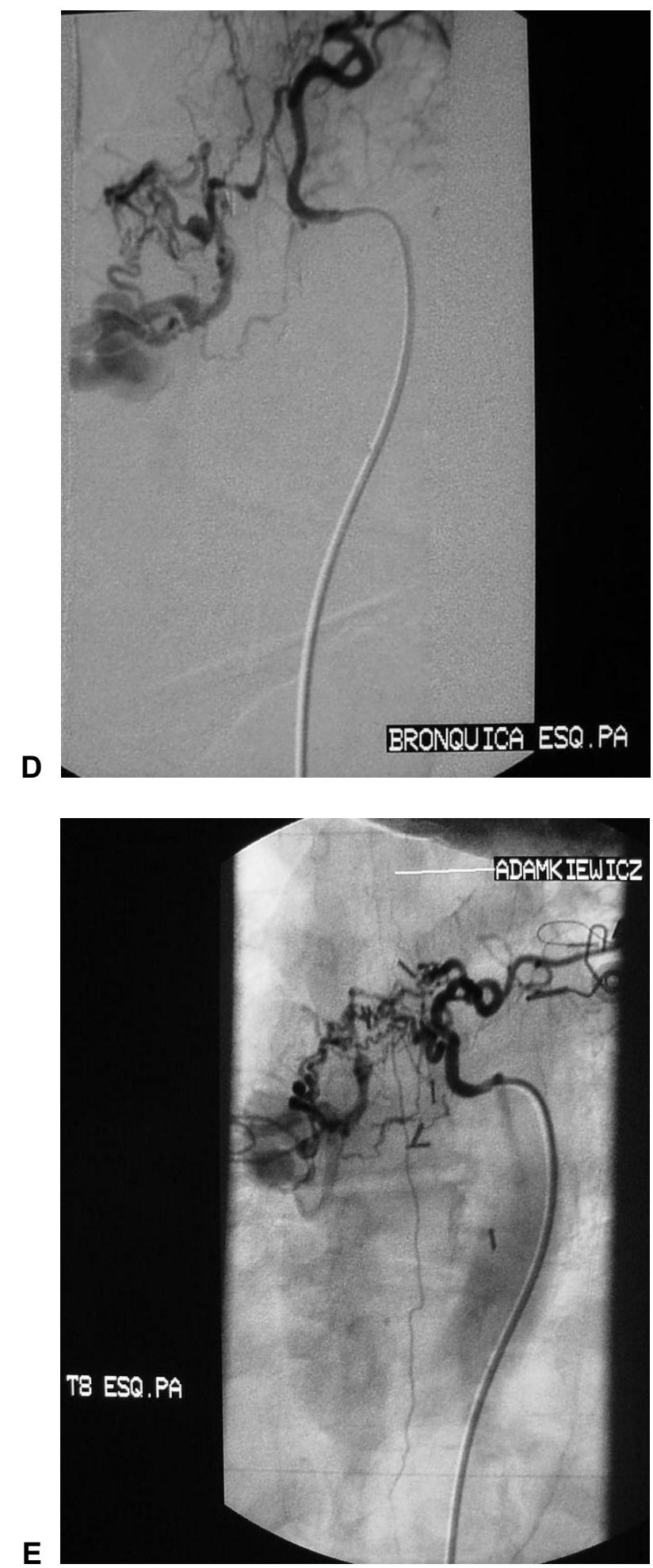

Figura 15: MAVM que se opacifica pela artéria brônquica esquerda (D) e pela intercostal de T8 esquerda (E). Observa-se a opacificação da artéria de Adamkiewicz. Paciente 33 

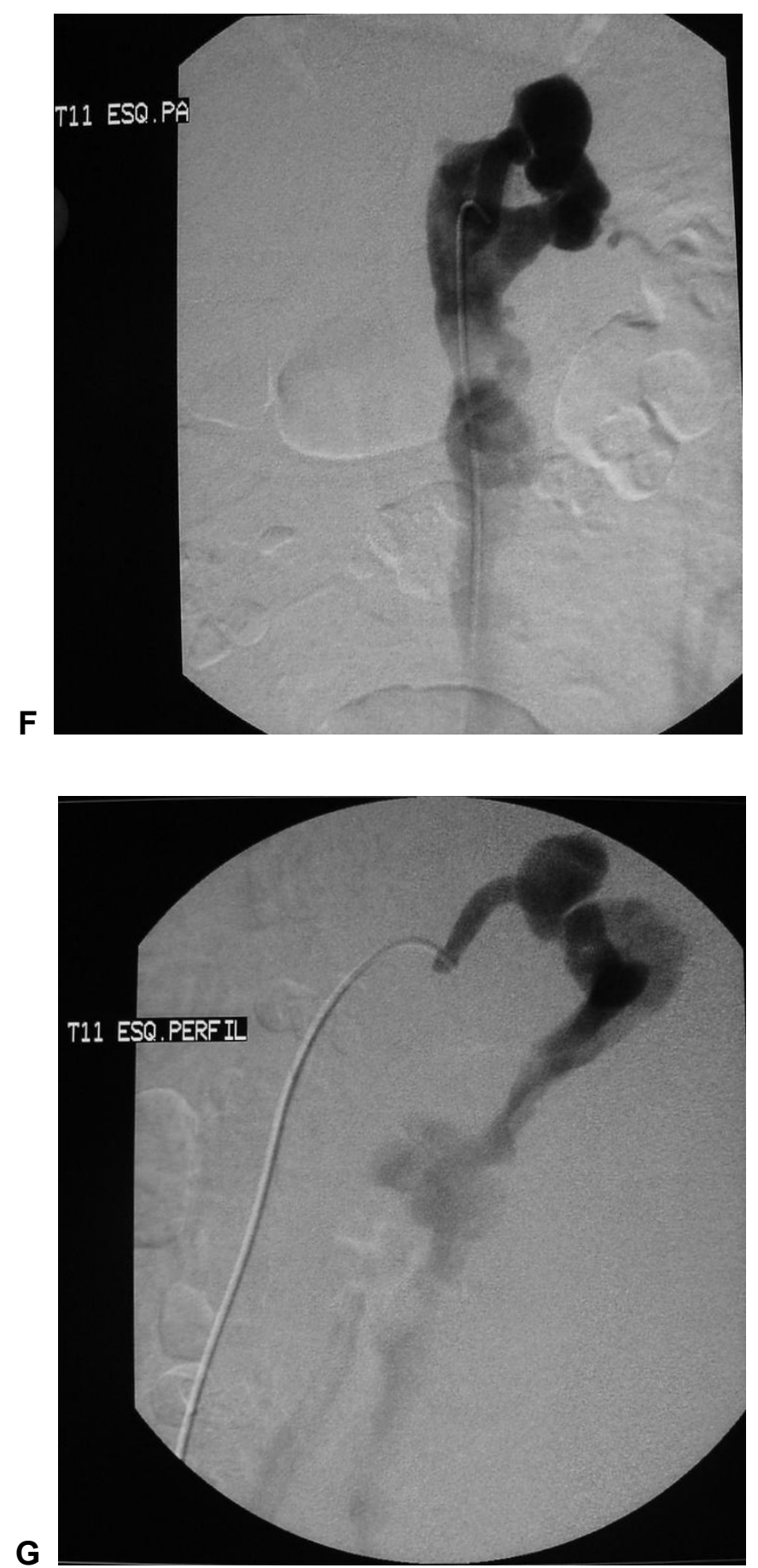

Figura 15: MAVM que se opacifica pela artéria intercostal de T11 esquerda, préembolização (F e G). Paciente 33 

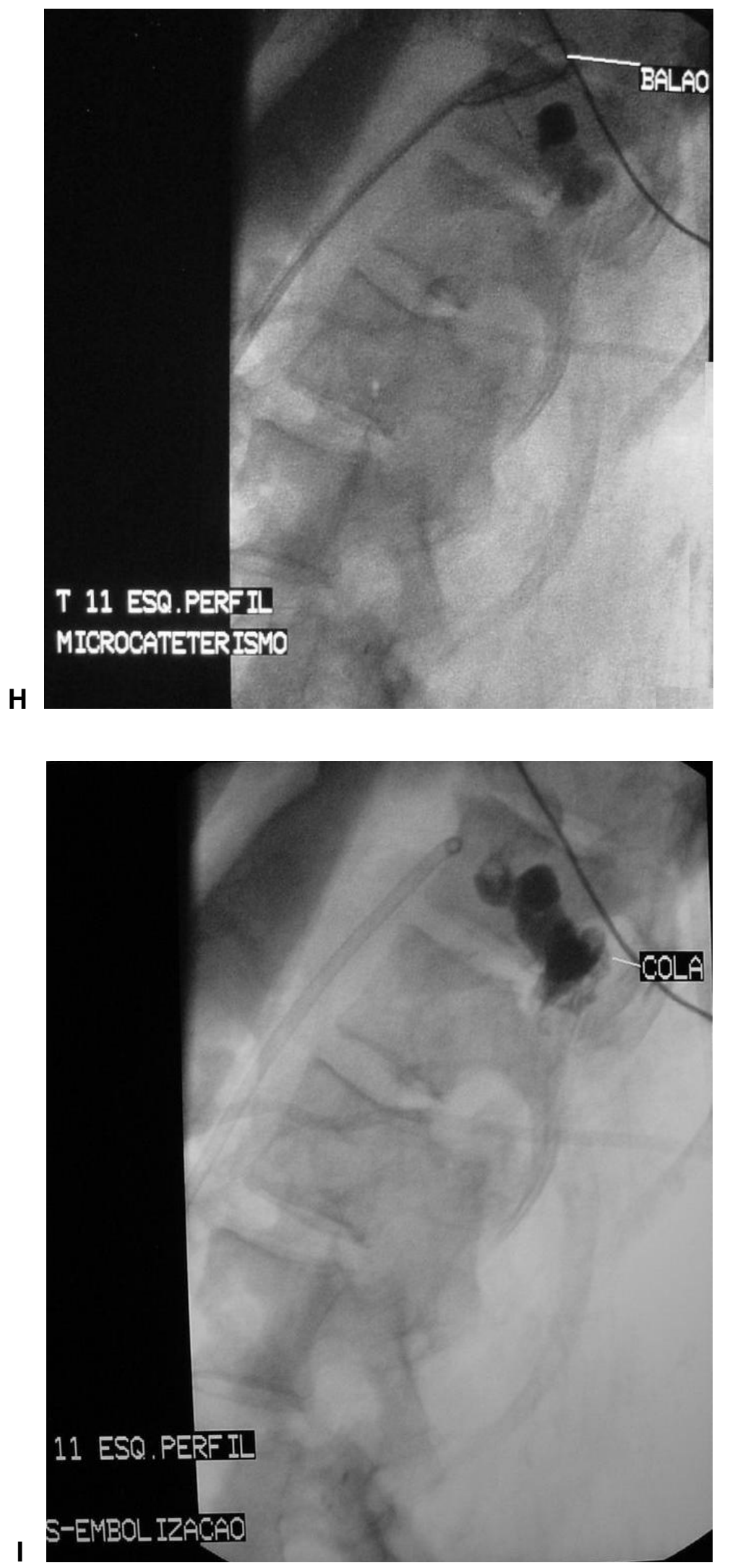

Figura 15: Microcateterismo da artéria intercostal de T11 esquerda com balão posicionado em fístula $(H)$. Aspecto final após a injeção de Histoacryl ${ }^{\circledR}(\mathrm{I})$. Paciente 33 

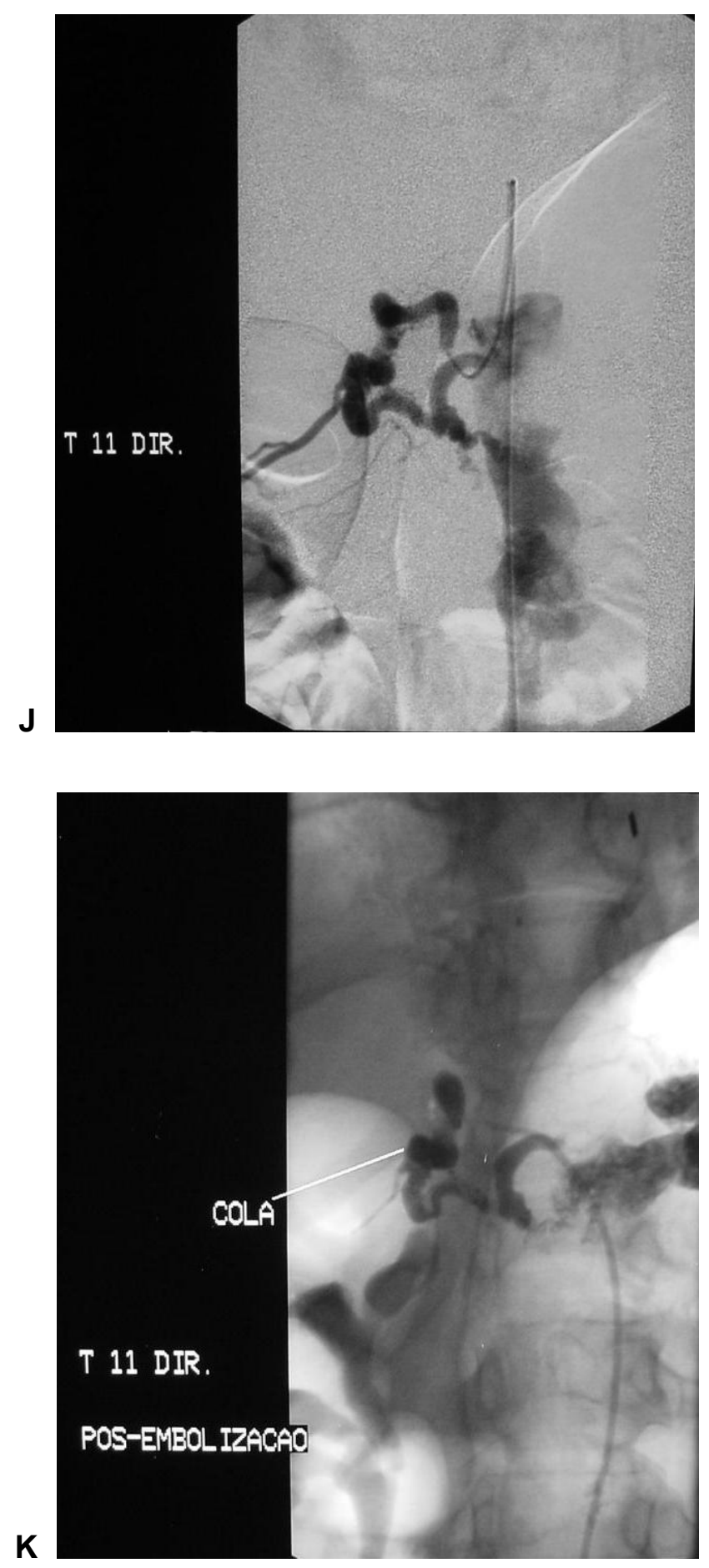

Figura 15: Microcateterismo da artéria intercostal de T11 (J). Aspecto final após a injeção de Histoacryl $₫(K)$. Paciente 33 

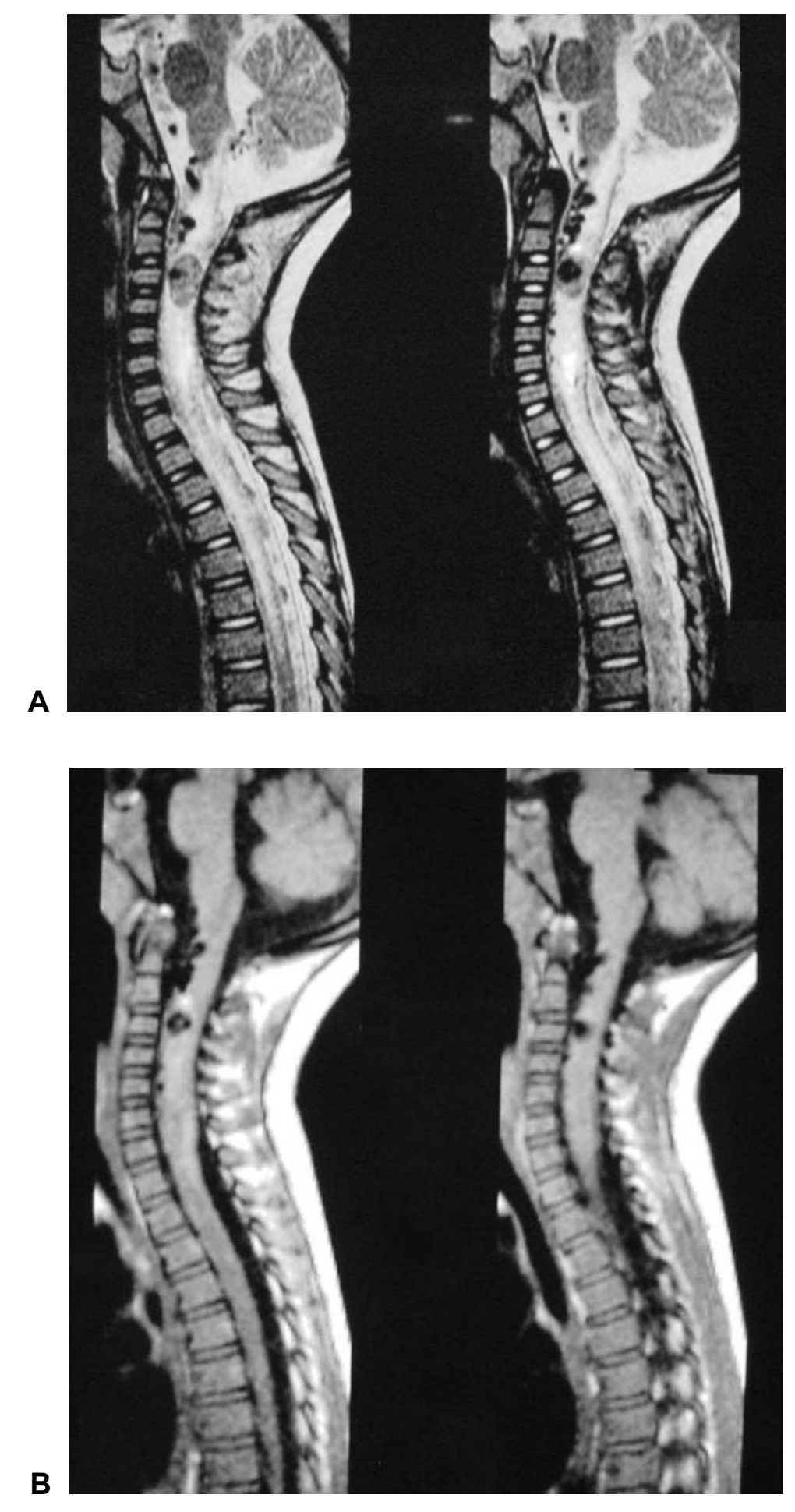

Figura 16: RM cervical mostrando imagens serpiginosas com ausência de sinal na superfície ventral da medula espinhal, compatível vasos dilatados (A e B) 

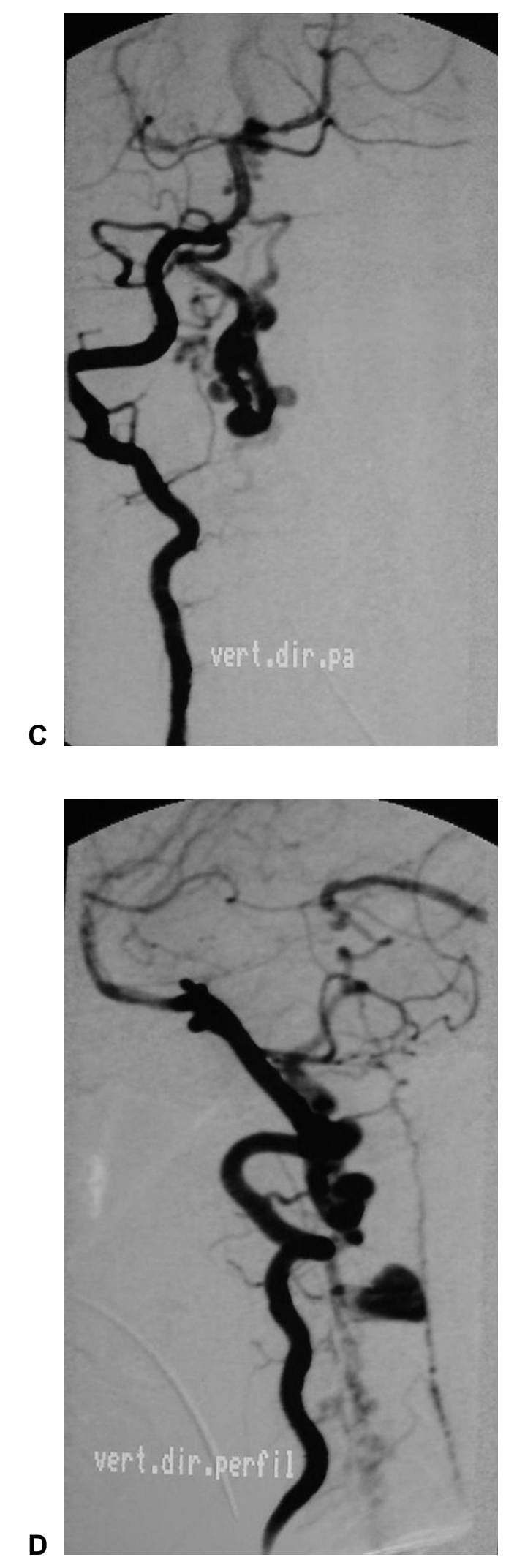

Figura 16: A injeção do meio de contraste na artéria vertebral direita mostra FAVP-A com "aneurisma venoso" associado (C e D). Paciente 17 

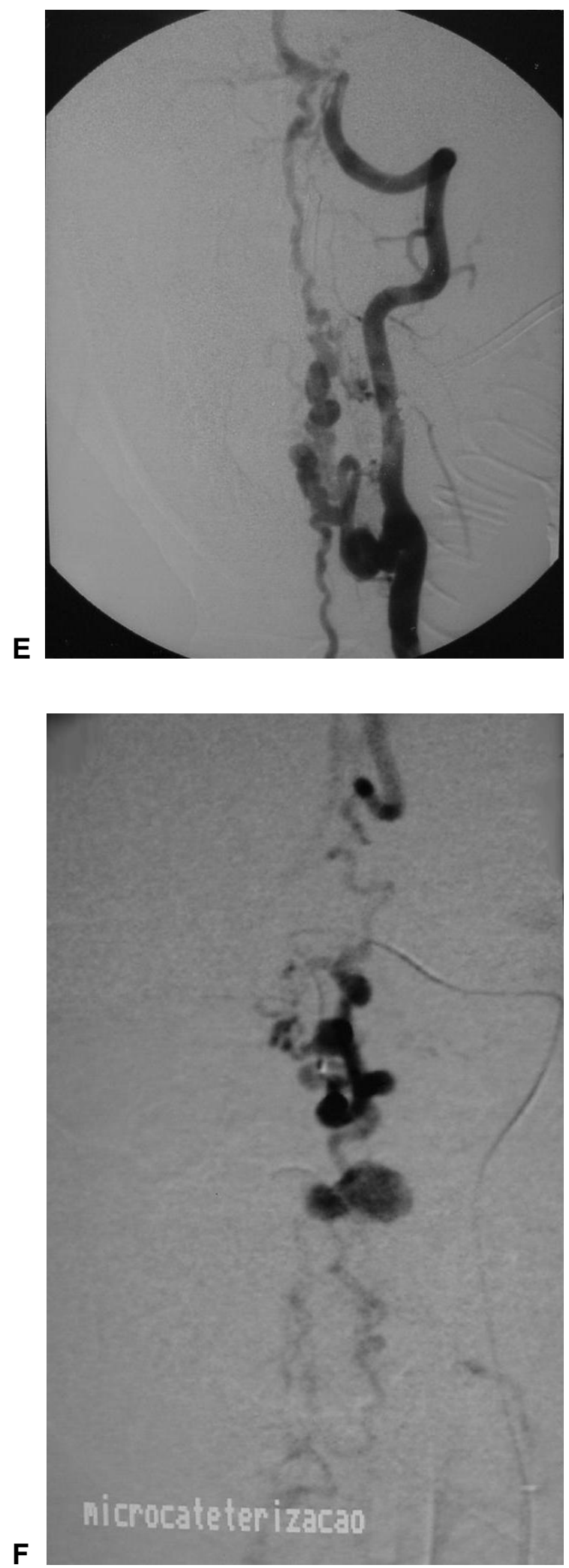

Figura 16: FAVP-A que se opacifica também pela artéria vertebral esquerda (E). Microcateterismo de artéria radículo-medular ao nível C6 à esquerda $(F)$. Paciente 17 

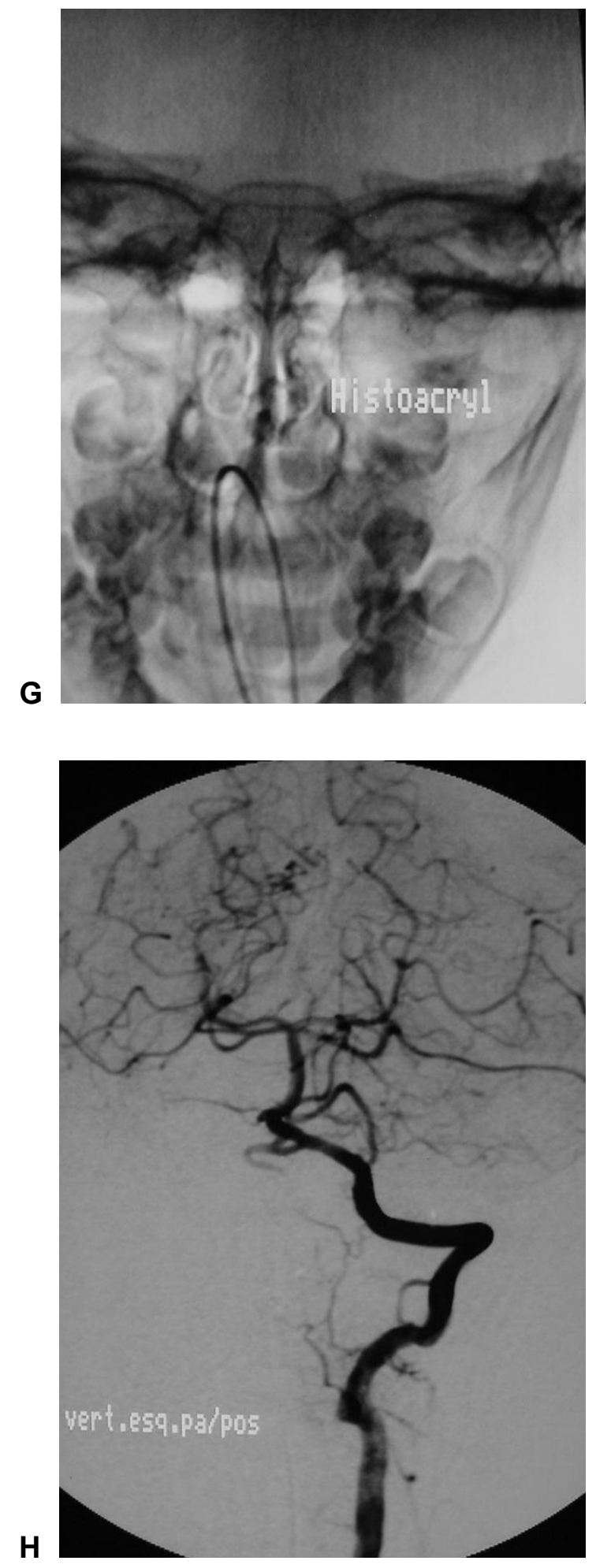

Figura 16: Controle final mostrando a localização do Histoacryl (G) e ausência de lesão residual $(\mathrm{H})$. Paciente 17 

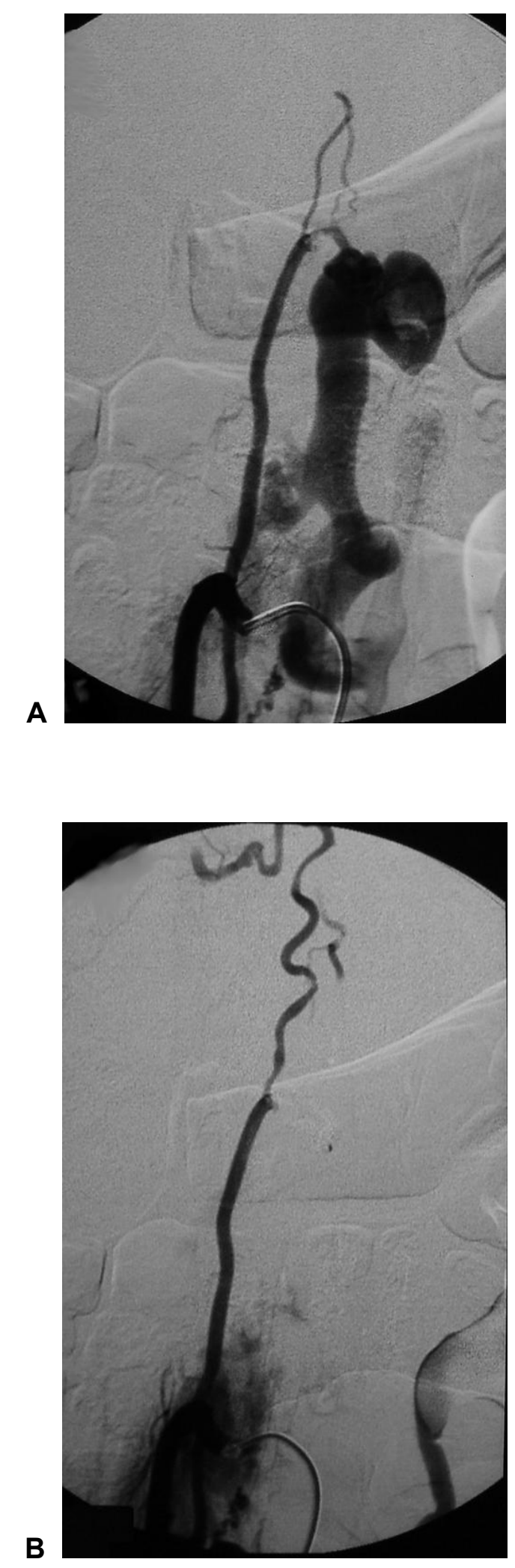

Figura 17: FAVP-C que se opacifica pela artéria lombar de $L 2$ direita, antes $(A)$ e depois $(B)$ da embolização com Histoacryl ${ }^{\circledR}$. Paciente 14 


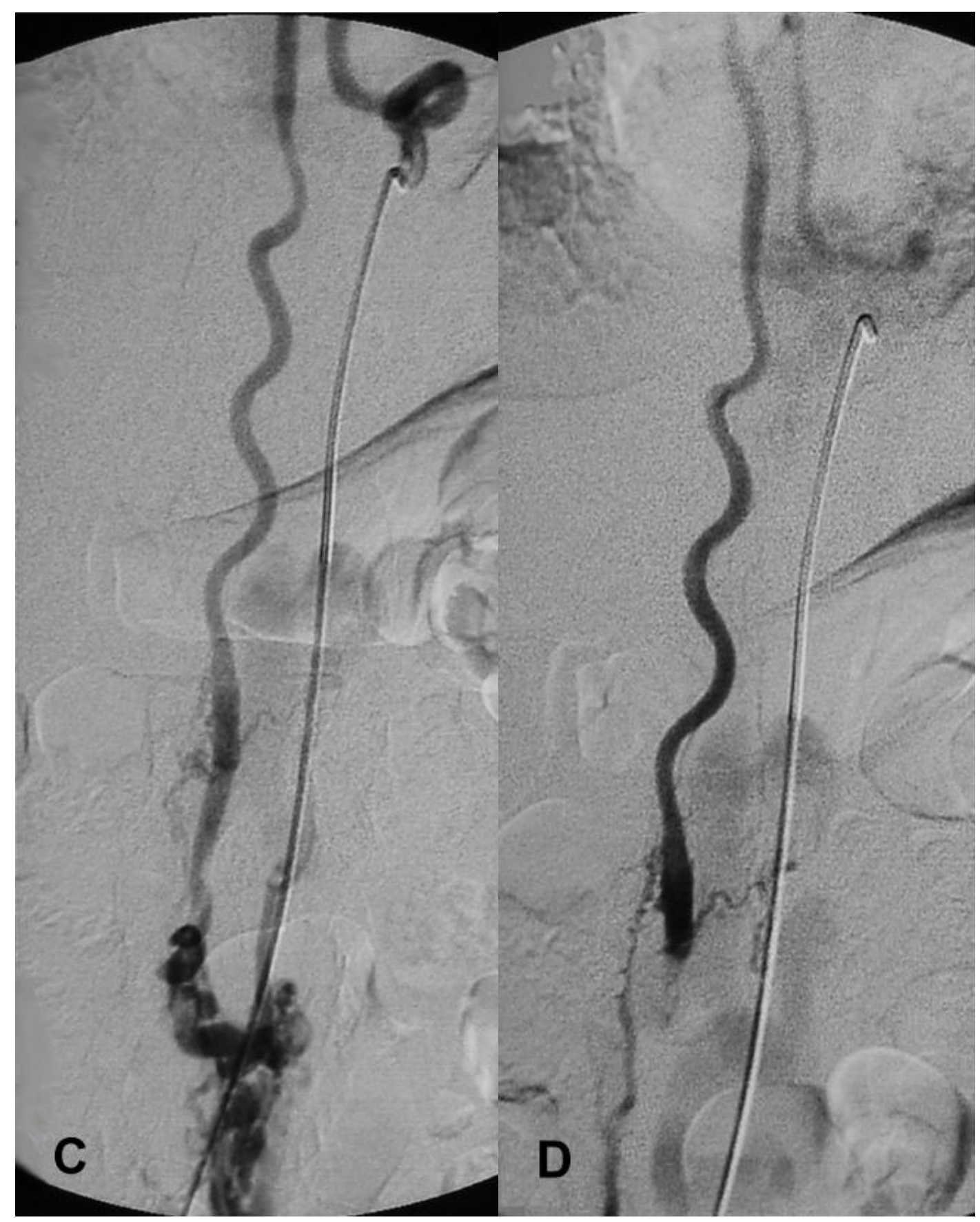

Figura 17: FAVP-C que se opacifica pela artéria radicular de T10 esquerda, antes (C) e depois (D) da embolização com Histoacryl ${ }^{\circledR}$. Paciente 14 


\section{DISCUSSÃO}


As MAVR são lesões que repercutem de maneira devastadora nos pacientes. Isso motiva uma abordagem rápida e multidisciplinar, evitando a progressão ou instalação de novos sintomas. A análise minuciosa da angiografia medular digital é fundamental para a compreensão da lesão, permitindo a identificação de fístula, nidus e vasos relacionados (angioarquitetura), propiciando a sua correta classificação e orientando o tratamento. A RM deve ser o exame inicial para determinar a presença ou não da MAVR e avaliar o comprometimento da medula. Além disso, a localização da MAVR pode ser determinante na indicação do tratamento o que aumenta a importância desse exame. Apesar de controverso, o tratamento evoluiu muito com o avanço da microcirurgia e terapia endovascular, e muitas vezes deve ser conjugado. O tratamento parcial da lesão pode evitar a progressão dos sintomas e melhorar o prognóstico. A revisão da literatura sugere diversos tipos de abordagens no tratamento das MAVR. No tipo I, tanto o tratamento endovascular, como o cirúrgico, apresentam resultados satisfatórios. No tipo II, o tratamento inicial costuma ser a embolização, seguida de cirurgia. O tratamento parcial da malformação também deve ser considerado, pois pode diminuir o risco de sangramento e a hipertensão venosa. No tipo III, a cura parece ser mais difícil de ser atingida. Devem ser consideradas embolizações seriadas ou cirurgias para 
ressecções parciais e alívio dos sintomas. No tipo IV, os melhores resultados por via endovascular parecem ser FACP-C, e os por cirurgia na FAVP-A. Na FAV-B, ambos podem apresentar resultados satisfatórios.

Os nossos resultados mostraram que o tratamento endovascular pode ser satisfatório nos diferentes tipos de MAVR e serão discutidos separadamente.

\subsection{MAVR Tipo I}

Dentre as MAVR, as do tipo I são as mais freqüentes. Na nossa casuística, que compreende somente os pacientes que necessitaram de tratamento endovascular, estas lesões foram encontradas em 17 (48,6\%) pacientes. Nosso achado está em concordância com a literatura, cuja freqüência destas lesões foi de 30-80\% das MAVR (Symon 1984, Rosenblum, 1987; Koenig, 1989; Berenstein e Lasjaunias, 1992).

Com relação à faixa etária, nesta casuística observamos um predomínio significativo no grupo com mais de 35 anos de idade, sendo 15 pacientes $(88,2 \%)$ nessa faixa, com uma idade média de 57,3 anos. Resultados semelhantes são encontrados na literatura, com um predomínio na quinta e na sexta décadas de vida (Rosenblum, 1987; Morgan, 1989; Van Dijk, 2002) e uma idade média de apresentação dos pacientes de 60 anos (Morgan, 1989; Song, 2001). Raros casos de FAD foram encontrados na infância (Cahan, 1987; Glasser, 1993). O paciente mais jovem deste estudo 
tinha 33 anos, não sendo observado nenhum paciente nas faixas etárias mais baixas. Com relação ao sexo, observamos um nítido predomínio do sexo masculino, com 13 homens (76,5\%). Na literatura esse achado também foi observado, numa freqüência de $80-90 \%$ (Berenstein e Lasjaunias, 1992; Watson, 1999; Van Dijk, 2002; Jellema, 2003; Steinmetz, 2004; Jellema, 2004). Nenhum dos pacientes avaliados referia história pregressa de trauma, o que está em desacordo com o observado por Osborn, em 1999, que relatou ser este fator observado em $40 \%$ dos pacientes (Osborn, 1999).

A localização mais freqüente foi na região torácica inferior e lombar. Rosenblum et al., em 1987, relataram que $85 \%$ dos pacientes com FAD apresentavam lesão abaixo de T6 e 100\% abaixo de T3 (Rosenblum, 1987). Na nossa casuística apenas 1 paciente apresentava lesão na região cervical.

O sintoma inicial mais freqüente observado na nossa casuística foi a fraqueza nos membros inferiores. Este sintoma foi observado em 11 pacientes $(64,7 \%)$. Em alguns relatos na literatura, esse sintoma foi o mais freqüente, sendo observado em $41 \%$ dos pacientes (Larsen e Hallbach, 1999).

Outro sintoma inicial muito freqüente encontrado no nosso estudo foi a dor, observada em 8 pacientes $(47,0 \%)$. Na literatura esse sintoma foi observado em 35-42\% dos pacientes (Aminoff e Logue, 1974b; Symon, 1984). A dor radicular isolada, como sintoma inicial, não foi observada na nossa série de pacientes. Esse achado está em concordância com a literatura, onde se observou somente um pequeno número de casos, cerca de 15\%, que se apresentou com dor radicular isolada (Rosenblum, 1987). $\mathrm{Na}$ ocasião do diagnóstico observamos que a dor estava presente em 5 
pacientes $(29,4 \%)$. Esse sintoma foi observado na literatura em $49-55 \%$ dos pacientes (Aminoff e Logue, 1974b; Larsen e Hallbach, 1999).

Outro sintoma inicial que observamos foram as alterações na sensibilidade, em 4 pacientes (23,5\%). Não observamos alterações em esfíncteres e impotência sexual como sintoma inicial na nossa série.

Muitas vezes os sintomas iniciais são pouco exuberantes ou inespecíficos, como no caso dos pacientes que apresentam somente dor. $\mathrm{O}$ diagnóstico diferencial das FAD inclui outras doenças, como espondilose lombar, doenças desmielinizantes e tumores raquimedulares (Kaynar, 1999). Raramente suspeita-se inicialmente de FAD e isso se reflete no longo tempo entre os sintomas iniciais e o tratamento. Este fato implica no aparecimento de novos sintomas e agravamento dos sintomas iniciais, acarretando em algumas situações déficits neurológicos irreversíveis.

A maioria dos pacientes na nossa casuística apresentou lenta piora dos sintomas. Em 15 pacientes $(88,2 \%)$ a instalação dos sintomas se deu de maneira progressiva. Somente 1 paciente $(5,9 \%)$ apresentou piora súbita dos sintomas. Na literatura observamos resultados semelhantes, com evolução aguda ou subaguda em cerca de 10-15\% dos pacientes (Criscuolo, 1989). O quadro de deterioração clínica rapidamente progressiva na ausência de hemorragia, sugestiva de síndrome de Foix-Alajouanine, não foi observado na nossa casuística.

O tempo decorrido do sintoma inicial até tratamento foi em média de 18,1 meses. Esse achado é importante do ponto de vista prognóstico, pois os pacientes com história longa de sintomas neurológicos tiveram resultado pior na evolução do tratamento. 
Observamos na nossa série que 2 pacientes apresentavam fatores de piora dos sintomas. Um paciente referiu piora da motricidade no final do dia, quando deambulava mais do que o habitual, e outro paciente referiu piora da marcha quando ficava muito tempo em pé. A piora dos sintomas associada aos exercícios físicos ou certas posturas também foi relatada na literatura (Rosenblum, 1987). Esse aspecto foi reforçado pelo estudo de Hassler et al., que analisaram os aspectos hemodinâmicos das FAD (Hassler, 1989). Foi medida a pressão na veia proximal, antes e após a desconexão cirúrgica da fístula em 25 pacientes. Antes da ligadura, a pressão era de aproximadamente 60 a $88 \%$ da pressão arterial média sistêmica. Após a desconexão, a pressão diminuía para 16 a $64 \%$ do valor inicial. Antes da ligadura, a pressão venosa oscilava simultaneamente com a pressão arterial média sistêmica, fato que não se observava após a ligadura. Vários outros fatores de piora foram associados às FAD foram relatados, como cirurgia (Criscuolo, 1989), punção liquórica lombar (Awad, 1990), gestação (Rosenblum, 1987) e menstruação (Kim, 1991).

A fraqueza nos membros inferiores também é o sintoma mais freqüente no momento do diagnóstico. Dentre os nossos pacientes, foi encontrada em todos os $16(94,1 \%)$. Na literatura esse achado também foi o mais observado, sendo encontrado em cerca de 95\% (Aminoff e Logue, 1974b; Larsen e Hallbach, 1999).

As alterações na sensibilidade são observadas freqüentemente na ocasião do diagnóstico. Na nossa casuística foram observadas em 13 pacientes $(76,5 \%)$. Na literatura, esse aspecto também foi muito freqüente, 
sendo observado em $87-100 \%$ dos pacientes (Aminoff e Logue, 1974b; Larsen e Hallbach, 1999).

O comprometimento vesical na ocasião do diagnóstico foi relatado por 13 pacientes (76,5\%). Esse resultado está em concordância com a literatura, onde este aspecto comprometia $83-93 \%$ dos pacientes (Aminoff e Logue, 1974b; Larsen e Hallbach, 1999).

A obstipação foi encontrada em 9 pacientes $(52,9 \%)$ e de maneira similar na literatura, sendo observada em $65-86 \%$ dos pacientes (Aminoff e Logue, 1974b; Larsen e Hallbach, 1999).

Outro sintoma observado na nossa casuística foi a impotência sexual, encontrada em 5 pacientes $(38,5 \%)$. Na literatura esta disfunção foi observada em 44\% dos pacientes (Larsen e Hallbach, 1999).

No estudo angiográfico inicial da nossa casuística, em 10 pacientes $(58,8 \%)$ as MAVR foram classificadas como FAD-A, ou seja, nutridas por um único ramo arterial (Figura 11). Em 7 pacientes $(41,2 \%)$, foram classificadas como FAD-B, ou seja, nutridas por múltiplos ramos arteriais (Figura 12). Não encontramos na literatura referências a esses dados, embora esses resultados sugiram relevante valor no prognóstico do tratamento endovascular. O fato de a FAD ser suprida por dois ou mais pedículos arteriais pode dificultar a oclusão do "pé da veia" e ocasionar insucesso no procedimento. É extremamente importante a identificação do eixo espinhal anterior acima e abaixo da lesão, pois isso será importante no planejamento cirúrgico ou endovascular. $\mathrm{Na}$ nossa casuística nenhum paciente apresentava opacificação da artéria espinhal anterior pelo pedículo arterial 
que supria a fístula, pois este era um critério de exclusão do tratamento. Está formalmente contra-indicada a embolização nessa situação pelo risco de déficit neurológico (Ommaya, 1969). Outros autores também indicam o tratamento cirúrgico se a artéria de Adamkiewicz e a FAD se opacificam pelo mesmo pedículo vascular (Afshar, 1995).

Nos pacientes tratados não observamos qualquer formação aneurismática no estudo angiográfico inicial. Biondi et al., em 1992, estudaram 72 pacientes com FAD e não encontraram nenhum paciente com formação aneurismática, o que é compatível com o fluxo lento desta lesão (Biondi, 1992a).

No seguimento após o tratamento, observamos melhora dos sintomas ou da marcha em 12 dos pacientes (70,6\%). A retenção urinária, que antes do tratamento foi encontrada em 13 pacientes $(76,5 \%)$, após o mesmo foi encontrada em 6 pacientes (35,3\%). A retenção fecal, que estava presente em 9 pacientes (52,9\%), continuou presente em 4 pacientes $(23,5 \%)$. Inicialmente, 5 pacientes $(29,4 \%)$ apresentavam dor e após o tratamento somente 2 pacientes $(11,8 \%)$ evoluíram com a persistência dos sintomas.

Melhora evidente também foi observada no padrão da marcha. Antes do procedimento, 7 pacientes $(41,2 \%)$ estavam acamados ou em cadeira de rodas, 4 pacientes $(23,5 \%)$ deambulavam com muletas, 3 pacientes $(17,6 \%)$ com bengala, 2 pacientes $(11,8 \%)$ deambulavam sem apoio, mas de maneira restrita e 1 paciente $(5,9 \%)$ deambulava sem restrição. Após a embolização observamos 2 pacientes $(11,8 \%)$ acamados ou em cadeira de rodas, 6 pacientes $(35,3 \%)$ deambulavam com muletas, 2 pacientes $(11,8 \%)$ 
com bengala, 6 pacientes $(35,3 \%)$ deambulavam sem apoio, mas de maneira restrita e 1 paciente $(5,9 \%)$ não apresentava restrição à deambulação. Comparando os resultados do padrão da marcha no pré e pós-tratamento, observamos que houve uma melhora significativa no padrão após a embolização. Não observamos piora transitória ou definitiva do quadro neurológico após o procedimento na nossa casuística.

Logue, em 1979, relatou o resultado cirúrgico de 24 pacientes com FAD. Na ocasião do diagnóstico, 12 pacientes $(50 \%)$ apresentavam comprometimento acentuado da marcha. Após o tratamento, observou que 15 pacientes (65\%) tiveram algum grau de melhora. A dor, que estava presente em 12 pacientes, apresentou remissão em 8 pacientes. A melhora dos sintomas urinários foi mais discreta, ocorrendo em somente 5 (22\%) dos 22 pacientes com esse comprometimento (Logue, 1979). Symon et al., em 1984, relataram os resultados do tratamento cirúrgico em 55 pacientes (Symon, 1984). Em 85\% dos pacientes houve estabilização da progressão da alteração na marcha, enquanto 10 dos 31 pacientes com comprometimento acentuado e 12 dos 15 pacientes com comprometimento moderado evoluíram com melhora neurológica. A função esfincteriana melhorou em 26 dos 46 pacientes que apresentavam comprometimento, retornando ao normal em 11. Anson e Spetzler, em 1994, mostraram os resultados do tratamento cirúrgico em FAD num período de 10 anos (Anson e Spetzler, 1994). Em 27 pacientes, 17 (71\%) apresentaram melhora, 6 (25\%) permaneceram inalterados e 1 (4\%) evoluiu com piora neurológica após a cirurgia. 
Na nossa casuística, foram tratados 17 pacientes com FAD através de 30 sessões de embolização (média de 1,8 sessões/paciente). Ao final da embolização o controle angiográfico demonstrou oclusão total da lesão em todas intervenções, sugerindo que o sucesso do procedimento foi de $100 \%$. Porém houve recanalização da lesão em 17 sessões de embolizações, demonstrando uma taxa de recidiva de $56,6 \%$. Nos pacientes submetidos à embolização com cola, a recidiva foi de $11,1 \%$. Esse resultado foi significativamente menor que o observado nos pacientes tratados com partículas ou com ambos, demonstrando que a embolização com cola tem resultados mais duradouros. O sucesso do tratamento foi obtido em 13 pacientes $(76,4 \%)$, constatado através da cura angiográfica ou da evolução com melhora clínica. Dos que não evoluíram com cura, 3 foram tratados através de cirurgia e outro interrompeu o seguimento ambulatorial. A avaliação clínica mostrou que 11 pacientes $(64,7 \%)$ evoluíram com sucesso clínico deste método, ou seja, na evolução apresentaram melhora neurológica. Em 6 pacientes (35,3\%) houve insucesso, com 5 (29,4\%) pacientes apresentando quadro neurológico igual ao constatado antes do início do tratamento, e 1 paciente (5,9\%) evoluindo com piora dos sintomas.

Avaliamos os resultados frente ao método de embolização utilizado, ou seja, partículas, adesivo tissular ou ambos.

Em 6 pacientes o tratamento utilizado foi através da embolização com partículas. Por meio deste método foram realizadas 15 sessões de embolização (média de 2,5 sessões/paciente). Ao final da embolização, o controle angiográfico demonstrou oclusão total da lesão em todos os casos, 
sugerindo que o sucesso do procedimento foi de 100\%. A evolução clínica, porém, mostrou que o resultado foi insatisfatório. Houve recanalização da lesão em 11 embolizações, demonstrando uma taxa de recidiva de 73,3\%. 0 sucesso do tratamento foi obtido em apenas 4 pacientes $(66,6 \%)$, constatado através da cura angiográfica ou da evolução com melhora clínica. Dos que não evoluíram com cura, 1 foi tratado através de cirurgia e outro interrompeu o seguimento ambulatorial. A avaliação clínica mostrou que 3 pacientes $(50,0 \%)$ evoluíram com sucesso clínico deste método, ou seja, na evolução apresentaram melhora neurológica. Em 3 pacientes $(50,0 \%)$ houve insucesso, com $2(33,3 \%)$ pacientes evoluindo com quadro neurológico igual ao constatado antes do início do tratamento, e 1 paciente $(16,7 \%)$ evoluindo com piora dos sintomas. Com relação ao sucesso clínico e do tratamento, não se observou diferença significativa entre as técnicas utilizadas.

O tratamento por meio da embolização com adesivo tissular foi realizado em 9 pacientes. Por esse método foram realizadas 9 sessões de embolização (média de 1,0 sessão/paciente). Ao final do procedimento o controle angiográfico demonstrou também a oclusão total da lesão em todos pacientes. A evolução clínica, mostrou que houve recidivas, mas em menor escala do que nos pacientes que foram embolizados com partículas. Houve recanalização da lesão em 1 procedimento, demonstrando uma taxa de recidiva de $11,1 \%$. O sucesso do tratamento foi obtido em 8 pacientes $(88,9 \%)$, constatado através da cura angiográfica ou da evolução com melhora clínica. O paciente que evoluiu com recidiva foi tratado por cirurgia. A avaliação clínica mostrou que 6 pacientes $(66,7 \%)$ evoluíram com sucesso 
clínico deste método, ou seja, na evolução apresentaram melhora neurológica. Em 3 pacientes (33,3\%) houve insucesso, todos apresentando quadro neurológico igual ao constatado antes do início do tratamento, nenhum evoluindo com piora dos sintomas.

O tratamento com partículas e cola foi realizado em 2 pacientes. Através deste método foram realizadas 6 sessões de embolização (média de 3,0 sessões/paciente). O controle angiográfico demonstrava a oclusão total da lesão em ambos os pacientes. A evolução clínica, mostrou que houve recidivas. Houve recanalização da lesão em 5 procedimentos, demonstrando uma taxa de recidiva de $83,3 \%$. Um paciente que evoluiu com recidiva foi tratado por cirurgia e o outro através de nova sessão da embolização. 0 sucesso do tratamento foi obtido em 1 paciente $(50,0 \%)$, constatado pela cura angiográfica. A avaliação clínica mostrou que ambos os pacientes evoluíram com sucesso clínico. Um paciente foi submetido inicialmente à embolização com partículas. Na evolução o controle angiográfico mostrou recidiva, sendo o paciente posteriormente submetido à embolização com cola e evoluindo com cura. Na evolução apresentou melhora no padrão da marcha. O outro paciente foi submetido a duas sessões de embolização com partículas e a duas com cola. O controle angiográfico mostrava recanalização da lesão por anastomoses. Apresentava melhora no padrão da marcha. Foi então encaminhado para tratamento cirúrgico.

Na nossa casuística 10 pacientes apresentavam FAD-A e 7 pacientes FAD-B. Nos pacientes com FAD-A foram realizadas 12 sessões de embolização (média de 1,2 sessões/paciente). O controle angiográfico 
demonstrou também a oclusão total da lesão em todos pacientes. A evolução clínica mostrou que houve recidivas. Houve recanalização da lesão em 3 procedimentos, demonstrando uma taxa de recidiva de $30,0 \%$. O sucesso do tratamento foi obtido em 8 pacientes $(80,0 \%)$, constatado pela cura angiográfica ou pela evolução com melhora clínica. O paciente que evoluiu com recidiva foi tratado por cirurgia. A avaliação clínica mostrou que 6 pacientes $(60,0 \%)$ evoluíram com sucesso clínico deste método. Em 4 pacientes $(40,0 \%)$ houve insucesso, sendo que 3 pacientes $(30,0 \%)$ apresentaram quadro neurológico igual ao constatado antes do início do tratamento e 1 evoluiu com piora dos sintomas.

Nos 7 pacientes com FAD-B foram realizadas 18 sessões de embolização (média de 2,6 sessões/paciente). O controle angiográfico demonstrou também a oclusão total da lesão em todos pacientes. A evolução clínica mostrou que houve recidivas. Houve recanalização da lesão em 14 procedimentos, demonstrando uma taxa de recidiva de $77,8 \%$. O sucesso do tratamento foi obtido em 3 pacientes $(42,9 \%)$, constatado através da cura angiográfica ou da evolução com melhora clínica. Dois pacientes que evoluíram com recidiva foram tratados por cirurgia. A avaliação clínica mostrou que 4 pacientes $(57,1 \%)$ evoluíram com sucesso clínico deste método. Em 3 pacientes (42,9\%) houve insucesso, sendo que todos pacientes apresentaram quadro neurológico igual ao constatado antes do início do tratamento e nenhum evoluiu com piora dos sintomas.

Esses resultados devem ser analisados com atenção. Apesar dos resultados dos pacientes com $F A D-A$ serem superiores àqueles 
apresentados por pacientes com FAD-B, deve-se ressaltar que dos 10 pacientes com FAD-A, $7(70,0 \%)$ foram tratados com cola, $2(20,0 \%)$ com partículas e $1(10,0 \%)$ com ambos. Dos 7 pacientes com FAD-B, 4 (57,1\%) foram tratados com partículas, $2(28,6 \%)$ com cola e $1(14,3 \%)$ com ambos.

Esses resultados sugerem que houve uma associação de dois fatores que foram favoráveis para o sucesso técnico e clínico, ou seja, a presença de pedículo único no suprimento arterial da fístula e o uso do adesivo tissular.

Não encontramos na literatura referências se esta subdivisão na classificação das FAD tem implicação no tratamento cirúrgico, porém podese supor que não tenha. Não implicará em mudança na abordagem cirúrgica e não adicionará comorbidades cirúrgicas, pois a exposição e desconexão da fístula pode ser conseguida de maneira similar.

Quando iniciamos o tratamento endovascular das FAD, este foi baseado na embolização com partículas. As artérias radiculares, que na maioria das vezes têm calibre reduzido, associadas ao baixo fluxo neste tipo de lesão, dificultavam a navegação com microcateteres guiados por fluxo. Também não estavam disponíveis microcateteres de calibre reduzido, hidrofílicos, que pudessem ser usados com o suporte de microguias. Esse foi com certeza um fator fundamental no insucesso do tratamento das FAD. O fato de não ser possível atingir com o microcateter o "pé da veia" impossibilitava a embolização com cola. O adesivo era injetado distante da lesão e não ocluía o início da veia, que continuava sendo opacificada por ramos anastomóticos das artérias radiculares acima, abaixo ou contralaterais. A opção era a injeção de partículas que na teoria poderiam ocluir um maior 
número de artérias na meninge que supriam a fístula. Na prática, essa técnica mostrou resultados desanimadores com recanalização na maioria dos pacientes.

Niimi et al. em 1997, relataram os resultados da embolização de 49 pacientes com FAD (Niimi, 1997). Após o procedimento observou-se uma taxa de oclusão da fístula em $39(80 \%)$ pacientes. No seguimento, 13 pacientes evoluíram com piora neurológica. Destes, em 6 a angiografia de controle mostrou recanalização da lesão. Esse achado era sugestivo de que o adesivo não havia penetrado adequadamente no nidus e no início da veia de drenagem, pois a fístula se opacificava por vasos colaterais.

Dois pacientes exemplificam bem essa dificuldade. $O$ primeiro apresentava fístula que se opacificava pela artéria radicular de T8 à direita (paciente 5). A primeira embolização foi realizada com partículas em outubro de 1995. Foram realizadas posteriormente 5 sessões de embolização com partículas, sendo a última em outubro de 1998. Foram embolizadas posteriormente pelas artérias radiculares de T7 direita e T9 direita, que não opacificava a fístula na ocasião do diagnóstico. No último exame de controle, realizado em novembro de 2000, não havia opacificação de fístula, mas o paciente apresentava ao exame paraplegia crural flácida, com certeza resultado do longo período de hipertensão venosa na medula espinhal. Outro paciente apresentava FAD que se opacificava pela artéria radicular de T7 direita e principalmente pela de T8 esquerda (paciente 27). A primeira embolização com cola de T8 esquerda mostrou persistências da lesão ao final do procedimento. Sucessivos controles e novas sessões de 
embolização foram realizadas num total de 4 embolizações. Ao final destas, tendo embolizadas as artérias radiculares de T7 e T8 bilateralmente, a fístula ainda se opacificava por anastomoses meníngeas. O paciente foi então encaminhado para cirurgia para tratamento da FAD.

\subsection{MAVR Tipo II}

Na nossa casuística de MAVR foram encontrados 10 pacientes $(28,5 \%)$ com MAI. Resultados semelhantes foram observados na literatura, com sua freqüência sendo estimada entre 36-53\% (Rosenblum, 1987; Berenstein e Lasjaunias, 1992). Com relação ao sexo, observamos um predomínio do sexo masculino, sendo acometidos 6 homens (60,0\%) e 4 mulheres (40,0\%). Na literatura não foi observada predominância quanto ao sexo (Berenstein e Lasjaunias, 1992).

As MAI podem ocorrer em qualquer nível da medula, mas as localizadas na região tóraco-lombares parecem ser mais freqüentes. Berenstein e Lasjaunias, em 1992, relataram que as localizadas na região tóraco-lombar foram encontradas em $63 \%$ dos pacientes e as cervicais em $37 \%$ dos pacientes (Berenstein e Lasjaunias, 1992). Na nossa casuística, em 5 pacientes $(50,0 \%)$ estavam localizada na coluna torácica, em 5 pacientes $(50,0 \%)$ na coluna cervical. Com relação à faixa etária, nesta casuística observamos um predomínio significativo no grupo dos 19 aos 35 anos. Na literatura observamos que cerca de $50 \%$ dos pacientes já apresentam sintomas aos 16 anos de idade (Berenstein e Lasjaunias, 1992; Grote, 1999). 
O aparecimento de déficit neurológico maciço de maneira súbita é sugestivo de transtorno de origem vascular, sendo muitas vezes devido a oclusão ou hemorragia. Nas MAl a apresentação com hemorragia é freqüente, podendo muitas vezes ser confirmada pela TC, ou através da RM. O estudo através deste último método apresenta vantagens em relação à TC. Através da RM pode ser avaliada a medula espinhal, presença de formações aneurismáticas, comprometimento extradural, além de permitir uma análise detalhada da hemorragia. A RM permite localizar com precisão a hemorragia e sua extensão, bem como se foi recente ou antiga.

A incidência de aneurismas associados a MAl é estimada entre 6 a 10\% (Herdt, 1971; Miyamoto, 1983; Pia, 1978a). Na nossa casuística, observamos a presença de "aneurisma venoso" no estudo angiográfico de 1 paciente $(10,0 \%)$ e, neste paciente, observamos presença súbita de dor cervical, sugestiva de hemorragia subaracnóidea, porém na ocasião do diagnóstico não foram realizados exames de imagem (RM ou TC) para confirmação. Miyamoto et al. relataram que a incidência de hemorragia pode ser maior na presença de aneurisma (Miyamoto, 1983). Rosenblum et al. relataram uma série de 54 pacientes, dos quais 24 apresentavam aneurismas arteriais ou venosos (Rosenblum, 1987). A incidência de hemorragia nos pacientes com aneurismas foi de $52 \%$, enquanto nos sem evidência de aneurisma foi de $50 \%$. Esses relatos demonstram que a correlação entre a presença de aneurismas e hemorragia associada ainda não está definida, dependendo de diversos fatores, como localização do 
aneurisma (arterial ou venoso), velocidade do fluxo na lesão e presença de estenoses nas veias de drenagem da MAVR.

O sintoma inicial mais freqüente nas MAI na nossa casuística foi a dor em 9 pacientes $(90,0 \%)$, seguida de fraqueza nos membros, em 4 pacientes (40\%), alterações sensitivas, encontradas em 1 paciente (10\%) e alterações vesicais, em 1 paciente (10,0\%). O tempo decorrido do sintoma inicial até tratamento foi em média de 47,3 meses. Como nas FAD, esse longo período pode ter contribuído para a piora dos sintomas.

Na ocasião do diagnóstico, os sintomas foram mais acentuados. O déficit motor foi observado em 7 pacientes $(70,0 \%)$. Na literatura, esses resultados foram os mais observados, com a presença de paresias em $90 \%$ dos pacientes (Berenstein e Lasjaunias, 1992). Também constatamos a presença de alterações na sensibilidade em 5 pacientes $(50,0 \%)$, distúrbios de esfíncter vesical em 4 pacientes (40,0\%) e obstipação em 1 paciente (10,0\%).

O estudo angiográfico na pesquisa de MAl deve seguir o mesmo protocolo de investigação de qualquer MAVR. Nas lesões torácicas inferiores e no cone medular, a artéria espinhal anterior geralmente está envolvida, o que justifica a identificação da artéria de Adamkiewicz (Joseph, 1999). O estudo angiográfico inicial deve ser minucioso, procurando determinar se a lesão se opacifica por ramos diretos (vasos que suprem somente o nidus), ou por ramos indiretos (que opacificam o tecido nervoso normal e por recrutamento opacificam também a MAI). Esse aspecto é importante para o planejamento do tratamento endovascular, pois é motivo de insucesso desta terapia (Berenstein e Lasjaunias, 1992). 
Na nossa casuística as MAI se opacificavam por 1 pedículo arterial em 6 pacientes $(60,0 \%)$, por 2 pedículos em 2 pacientes $(20,0 \%)$ e por 3 ou mais pedículos em 2 pacientes (20,0\%).

Raramente a MAl pode ser múltipla (Joseph, 1999). Na nossa casuística não observamos qualquer caso de MAI múltipla.

Após o tratamento, dos 7 pacientes $(70,0 \%)$ que inicialmente apresentavam fraqueza nos membros, 6 pacientes $(60,0 \%)$ persistiram com esse sintoma. A sensação de dormência, que no início foi encontrada em 5 pacientes $(50,0 \%)$, a retenção urinária, que foi encontrada em 3 pacientes (30,0\%), e a obstipação, em 1 paciente (10,0\%), não apresentaram variação no seguimento dos pacientes. A dor, que inicialmente estava presente em 2 pacientes $(20,0 \%)$, não foi observada no seguimento.

A melhora no padrão da marcha foi evidente. Antes do procedimento, 3 pacientes $(30,0 \%)$ estavam acamados ou em cadeira de rodas, 4 pacientes $(40,0 \%)$ deambulavam sem apoio, mas de maneira restrita, e 3 pacientes $(30,0 \%)$ deambulavam sem restrição. Após a embolização, observamos 2 pacientes $(20,0 \%)$ acamados ou em cadeira de rodas, 1 paciente deambulava com muletas, 3 pacientes $(30,0 \%)$ deambulavam sem apoio, mas de maneira restrita, e 4 pacientes (40,0\%) não apresentavam restrições à deambulação. Comparando os resultados do padrão da marcha no pré e pós-tratamento, observamos que houve uma melhora significativa no padrão após a embolização. Observamos complicações durante a evolução de 4 pacientes $(40,0 \%)$ após os procedimentos de embolização, sendo que em 3 pacientes $(30,0 \%)$ essas complicações foram transitórias e em 1 paciente 
$(10,0 \%)$, permanente. Nos pacientes em que a piora foi transitória, observouse diminuição na motricidade dos membros inferiores, que já apresentavam esse déficit. Dois pacientes foram por isquemia (pacientes 6 e 15) e outro por hemorragia durante a cateterização (paciente 28). Em 1 paciente houve aparecimento de hemiparesia ao final do procedimento, que evoluiu com regressão parcial (paciente 25). Aparentemente ocorreram tanto hemorragia (constatada pelo extravazamento do material de embolização), como isquemia (suposta pela obliteração do nidus e das artérias aferentes da lesão). O paciente evoluiu com progressiva melhora neurológica e atualmente apresenta discreta alteração na marcha, deambulando com leve restrição aos esforços físicos.

O tratamento endovascular das MAI foi realizado em 10 pacientes. Através desse método foram realizadas 15 sessões de embolização (média de 1,5 sessões/paciente). Ao final da embolização o controle angiográfico demonstrou oclusão total da lesão em 8 intervenções, resultando em sucesso do procedimento de 53,3\%. Em 7 das intervenções a embolização foi parcial $(46,7 \%)$. A recanalização aconteceu em somente 1 procedimento, demonstrando uma taxa de recidiva de $6,7 \%$. O sucesso do tratamento foi obtido em 8 pacientes $(80,0 \%)$, constatado através da cura angiográfica ou da evolução com melhora clínica. O paciente que evoluiu com recidiva foi tratado através de nova sessão da embolização. A avaliação clínica mostrou que 4 pacientes $(40,0 \%)$ evoluíram com sucesso clínico deste método, ou seja, na evolução apresentaram melhora neurológica. Nos outros 6 pacientes $(60,0 \%)$ houve insucesso, com todos apresentando quadro 
neurológico igual ao constatado antes do início do tratamento, e nenhum evoluindo com piora dos sintomas. Com relação à recidiva, ao sucesso clínico e do tratamento, não se observou diferença significativa entre as técnicas utilizadas.

O tratamento dessas lesões ainda é controverso, dependendo de uma série de fatores: localização na medula, angioarquitetura e tamanho. 0 tratamento combinado, endovascular e cirúrgico, deve ser considerado. $\mathrm{Na}$ abordagem desses pacientes, é importante ressaltar que a sintomatologia está relacionada ao alto fluxo na lesão. A diminuição deste pode levar ao abrandamento da ectasia e da congestão venosa, conseqüentemente acarretando melhora neurológica e minimizando o risco de sangramento na cirurgia (Detwiler, 1999). A completa exclusão da malformação, seja por via endovascular, seja por microcirurgia, pode ocasionar conseqüências desastrosas. No entanto, alguns relatos com resultados satisfatórios foram observados. A ressecção completa da lesão pode ser conseguida em 53$59 \%$ dos pacientes, podendo ocorrer deterioração em 14-22\% e óbito em 25\% (Yaşargil, 1976; Rosemblum, 1987). Esses resultados, mostrando as complicações do tratamento cirúrgico, refletem a dificuldade no tratamento cirúrgico neste tipo de MAVR.

O tratamento endovascular pode ser realizado com o paciente acordado, sob anestesia local. A vantagem desse método é o monitoramento neurológico constante do paciente. Além disso, pode ser realizada a infusão de amobarbital sódico ou lidocaína no território a ser embolizado, para predizer o resultado funcional da embolização (Larsen, 
1999). Nos pacientes submetidos a tratamento endovascular sob anestesia geral, essa informação pode ser obtida através do monitoramento do potencial evocado (Berenstein, 1984). Nossos pacientes foram submetidos a tratamento endovascular sob anestesia geral. $\mathrm{O}$ procedimento por muitas vezes pode ser demorado, estendendo-se por horas. Esse fato, associado à presença de dor, muito comum nessas lesões, acaba ocasionando incômodo e movimentação nos pacientes durante a intervenção. Além disso, a polimerização do adesivo tissular pode ser dolorosa, pelo discreto aquecimento da mistura. A movimentação do paciente nesse momento pode ocasionar deslocamento do microcateter e extravasamento do material de embolização, com conseqüências desastrosas. $O$ monitoramento neurológico durante o procedimento através do potencial evocado não foi realizado. Esse recurso, apesar de útil, não é disponível em muitos centros de referência para o tratamento dessas lesões. A injeção do material de embolização só era realizada quando havia certeza de injeção intranidal.

O tratamento endovascular pode ser considerado como a primeira escolha nas MAVR tipo II. Permite que ocorra o alívio dos sintomas e a diminuição do risco de sangramento intra-operatório. Dependendo da angioarquitetura, pode ser favorável para oclusão completa do nidus. A existência de somente um ou dois pedículos, a ausência de opacificação das artérias espinhais quando se injeta o contraste no pedículo da MAI e o não envolvimento da artéria de Adamkiewicz são aspectos importantes para que isso seja conseguido. Existem duas estratégias para o tratamento dessas lesões: embolização com partículas (PVA), ou com adesivos líquidos (NBCA). 
A embolização com partículas parece ter efeito transitório no tratamento destas lesões. A recanalização e revascularização dessas malformações são muito freqüentes (Casasco, 1999; Larsen, 1999). O objetivo da embolização com partículas é a diminuição do fluxo sangüíneo na malformação, e reduzindo assim o "fenômeno de roubo" e risco de isquemia medular. O sistema venoso é aliviado, e reduz-se o risco de hemorragia. Em alguns pacientes, não se consegue atingir o nidus com o microcateter, seja por calibre reduzido, seja por tortuosidade das artérias que suprem a MAI. Nessas situações o risco de oclusão da artéria espinhal anterior quando se injeta o NBCA é maior. Liberando-se partículas, mesmo que à distância, por terem diâmetro inferior ao da artéria espinhal anterior, e maior que as artérias comissurais, pode-se embolizar a malformação com relativa segurança. Além disso, não desencadeiam reação inflamatória, tornando improvável o desenvolvimento de edema medular, que pode ocasionar piora neurológica. Como o resultado costuma ser paliativo, os pacientes submetidos a esse procedimento devem ser acompanhados continuamente, tanto do ponto de vista clínico, como radiológico. Devem ser realizados controles angiográficos anuais, com novas sessões de embolização, quando necessário.

Biondi et al. relataram os resultados a longo prazo de 35 pacientes submetidos a embolizações seriadas com PVA (Biondi, 1990). O período médio de seguimento pós-embolização foi de 6 anos e foram realizadas 158 sessões de embolização. Os resultados dessa abordagem mostram que $63 \%$ dos pacientes apresentaram melhora clínica em relação ao exame inicial e em $8 \%$ das embolizações houve deterioração neurológica. 
A completa eliminação da lesão pode ser conseguida em até $53 \%$ dos pacientes; em $10 \%$ dos pacientes pode haver deterioração neurológica permanente e em 10\%, transitória (Berenstein e Lasjaunias, 1992).

O tratamento através da embolização com cola foi realizado em 8 pacientes. Através desse método foram realizadas 11 sessões de embolização (média de 1,4 sessões/paciente). Ao final da embolização o controle angiográfico demonstrou oclusão total da lesão em 7 intervenções, resultando em sucesso de procedimento de 63,6\%. Em 4 das intervenções a embolização foi parcial (36,4\%). A recanalização aconteceu em somente 1 procedimento, demonstrando uma taxa de recidiva de $9,1 \%$. O sucesso do tratamento foi obtido em 6 pacientes $(75,0 \%)$, constatado através da cura angiográfica ou da evolução com melhora clínica. O paciente que evoluiu com recidiva foi tratado através de nova sessão da embolização. A avaliação clínica mostrou que 2 pacientes $(25,0 \%)$ evoluíram com sucesso clínico desse método, ou seja, na evolução apresentaram melhora neurológica. Nos outros 6 pacientes $(75,0 \%)$ houve insucesso, todos apresentando quadro neurológico igual ao constatado antes do início do tratamento, nenhum evoluindo com piora dos sintomas.

O tratamento através da embolização com partículas foi realizado somente em 2 pacientes. Por meio desse método foram realizadas 4 sessões de embolização (média de 2,0 sessões/paciente). Ao final da embolização o controle angiográfico demonstrou oclusão total da lesão em uma intervenção, resultando em sucesso de procedimento de 25,0\%. Em 3 das intervenções a embolização foi parcial $(75,0 \%)$. A recanalização não foi 
constatada em nenhum paciente. O sucesso do tratamento foi obtido nos 2 pacientes (100,0\%), constatado através da cura angiográfica ou da evolução com melhora clínica. A avaliação clínica mostrou que os 2 pacientes $(100,0 \%)$ evoluíram com sucesso clínico deste método, ou seja, na evolução apresentaram melhora neurológica.

Na nossa casuística 2 pacientes foram tratados com embolização com partículas. Na ocasião que esses procedimentos foram realizados, ainda não eram disponíveis microcateteres com baixo perfil de calibre para navegação endovascular com o suporte de microguia. Estes são essenciais para a cateterização de lesões através de artérias de calibre reduzido, com baixo fluxo sangüíneo. A partir daquele momento foi possível tratar com cola lesões que eram consideradas inacessíveis por este método.

A embolização com NBCA tem resultados definitivos e pode ser realizada quando se consegue progredir o cateter até o nidus, ou até a fístula. Através dessa técnica, a oclusão arterial é permanente, existindo maior chance de cura. A desvantagem é a maior probabilidade de oclusão de vasos normais e a formação de edema medular (secundário ao processo inflamatório desencadeado pelo NBCA).

\subsection{MAVR Tipo III}

Na nossa casuística, as MAVR tipo III foram encontradas em apenas 1 paciente, do sexo feminino. Esse achado espelha a raridade dessas lesões, 
mesmo num centro de referência como é o nosso serviço. Rosenblum et al. analisaram 54 pacientes com MAI e, destes, 29 apresentavam MAVM (Rosenblum, 1987). Biondi et al., em 1992, analisando 70 pacientes com MAI, encontraram 24 que apresentavam MAVM (Biondi, 1992a). Essas séries provavelmente superestimaram a incidência destas lesões, pois foram realizadas em centros de referência para tratamento de MAVR. Outros autores, como Ommaya et al., relataram uma incidência de apenas 2 pacientes com MAVM numa série de 26 pacientes com MAVR (Ommaya, 1969). De maneira similar, Malis relatou ter encontrado somente 3 pacientes com MAVM numa série de 43 pacientes com MAVR (Malis, 1982).

Em contraste com as outras MAVR, as MAVM tendem a ser distribuídas de maneira uniforme ao longo da coluna vertebral (Rosenblum, 1987). Na nossa casuística, a lesão estava localizada na região torácica. Essas lesões são sugestivas de serem congênitas e tendem a se apresentar em pacientes mais jovens que 30 anos. Rosenblum et al. relataram que a idade média dos pacientes era de 27 anos (Rosenblum, 1987). Na nossa série a paciente tinha 47 anos, mas apresentava antecedente de cirurgia para exérese de "hemangioma" na mesma localização há 24 anos.

As MAVM são lesões extensas, e costumam comprometer a medula espinhal, a dura-máter, as estruturas ósseas, a musculatura paraespinhal, o tecido subcutâneo e a pele, no mesmo dermátomo (Hodes, 1999). São relacionadas a síndromes como de Cobb, descrita pelo mesmo em 1915 como uma malformação envolvendo pele, osso e medula espinhal (Cobb, 1915), e as síndromes de Rendu-Osler-Weber e de Klippel-Trenaunay- 
Weber (David, 1999). Costumam ser diagnosticadas na infância, através da identificação de uma malformação vascular cutânea. Na nossa casuística a paciente não apresentava comprometimento de outros órgãos ou sistemas, compatíveis com essas síndromes. Apresentava somente antecedente de mola hidatiforme.

O suprimento arterial dessas lesões é originário de artérias em múltiplos níveis espinhais. Múltiplas e calibrosas artérias medulares, originárias das artérias espinhais anterior e posteriores, suprem esta malformação. Também podem ser supridas por artérias radiculares e durais. Esses aspectos foram observados também na nossa casuística. A lesão se opacificava através da injeção do meio de contraste nas artérias intercostais de T8, T9, T11 e T12 bilateralmente, T10 direita, além da artéria brônquica esquerda.

Os pacientes com MAVM apresentam sintomas variados. Muitas vezes são semelhantes aos de um paciente com MAI. Na nossa casuística a paciente se apresentou com dor tóraco-lombar, fraqueza nas pernas, acompanhada de sensação de dormência, retenção urinária e fecal. A marcha era realizada com auxílio de bengala.

A hemorragia é um aspecto freqüente nessas lesões, que também apresentam componente intramedular. $\mathrm{Na}$ nossa série a paciente não se apresentou com quadro clínico sugestivo de hemorragia. Não foi constatada a presença de aneurismas arteriais ou venosos na nossa paciente. $\mathrm{Na}$ literatura observamos que em $44 \%$ dos pacientes com MAVR a hemorragia esteve correlacionada com a presença de aneurismas arteriais e varicosidades venosas (Rosenblum, 1987). 
A apresentação mais freqüente é o aparecimento da mielopatia progressiva e está associada ao "fenômeno de roubo". Essa evolução, com piora neurológica progressiva, também foi relatada por outros autores (Aminoff e Logue, 1974). Na nossa série essa evolução esteve presente. Na paciente observamos paraparesia crural progressiva com 2 meses de evolução, associada à espasticidade nos membros inferiores. Apresentava também retenção vesical e fecal. Essa evolução pode estar relacionada a certas posturas e atividades, como tossir e realizar esforços físicos (David, 1999). Esse tipo de apresentação não foi observada na nossa casuística.

A angiografia é o exame principal para definição da estratégia do tratamento dessas lesões. É mandatória a visibilização das artérias espinhais anterior e posteriores, pois esses vasos podem terminar no nidus da malformação ou somente passar através do mesmo e suprir a medula espinhal normal (David, 1999). Na nossa série observamos que a artéria espinhal anterior se opacificava pela artéria radicular de T8 esquerda, o que contra-indicou a embolização daquele pedículo, sendo tratadas somente as artérias radiculares de T9 direita, T12 esquerda e T11 bilateralmente que não apresentavam este tipo de padrão.

O tratamento dessas malformações é usualmente paliativo, pois sua ressecção total é muito difícil de ser atingida, podendo ocasionar morbidade elevada. O tratamento consiste de embolizações seriadas e ressecção cirúrgica parcial (Detwiler, 1999). Do ponto de vista cirúrgico, essas lesões muitas vezes foram consideradas irressecáveis, com resultados cirúrgicos devastadores, como foi relatado por Mallis, em 1982. O tratamento dessas 
lesões passou a ser realizado através de ligaduras arteriais e embolizações seriadas de maneira paliativa, para controle da hemorragia e de deterioração neurológica. Vários autores relataram o tratamento com sucesso das MAVM através de múltiplas embolizações, inclusive intra-operatórias, ligaduras arteriais e ressecção cirúrgica (Spetzler, 1989; Touho, 1991; Martin, 1995; David, 1999; Alexander, 2002).

Poucos relatos de somente embolização de MAVM foram encontrados na literatura. Ommaya et al. relataram a melhora neurológica de um paciente, submetido à embolização com partículas de aço da artéria principal que supria uma MAVM (Ommaya, 1969). Djindjian R, em 1975, relatou resultados semelhantes (Djindjian $R, 1975)$.

Na nossa casuística, tratamos somente uma paciente com MAVM. A embolização não tinha como intenção a cura, e sim o controle do quadro álgico e redução do fluxo sangüíneo na lesão, esperando com isso atenuar o "fenômeno de roubo" e o risco de hemorragia. Com base nisso, os resultados obtidos foram satisfatórios. A dor desapareceu na nossa paciente. No período acompanhado, a paciente não apresentou piora neurológica, sugerindo atenuação no "fenômeno de roubo" e ausência de hemorragias. A paciente apresentou melhora na motricidade dos membros inferiores e da marcha, que antes do procedimento era feita com bengala e na evolução tornou-se sem apoio e com restrição aos esforços. 


\subsection{MAVR Tipo IV}

As FAVP são caracterizadas por uma fístula arteriovenosa entre a artéria espinhal anterior ou posterior, e veia do plexo coronal perimedular, não havendo nidus entre ambos. São intradurais, mas extramedulares e situam-se ventral ou lateralmente à medula (Grote,1996).

A freqüência dessa malformação é estimada entre 8 e $30 \%$ (Rosenblum, 1987; Berenstein e Lasjaunias, 1992). Na nossa casuística, 7 pacientes $(20,0 \%)$ apresentavam FAVP. Destes, 4 pacientes $(57,1 \%)$ foram classificados como FAVP-A, 1 paciente (14,3\%) como FAVP-B e 2 pacientes $(28,6 \%)$ como FAVP-C. Na literatura observamos que a que a freqüência desses subtipos é variável. Cawley et al. relataram que os subtipos mais freqüentes são as FAVP-A e FAVP-B (Cawley, 1999). Mourier et al. estudaram 35 pacientes com FAVP (Mourier, 1993). Somente 4 pacientes (11\%) apresentavam FAVP-A, 9 pacientes (26\%) FAVP-B e 22 pacientes (63\%) FAVP-C. A faixa etária acometida é variável. Algumas séries relatam que esta pode variar de 1 a 55 anos (média de 25 a 45 anos) (Barrow, 1994; Cho, 2005). Mourier et al., na sua série de 35 pacientes com FAVP, observaram que a faixa etária acometida era mais baixa, variando de 2-42 anos (média de 25 anos) (Mourier, 1993). Na nossa casuística, observamos um predomínio significativo na faixa até os 18 anos, com 5 pacientes $(71,4 \%)$ e idade média de 18,8 anos. Esses achados talvez sejam um reflexo da incompreensão da etiologia dessas lesões. Muitos consideram que essas lesões sejam congênitas pela observação de vários casos na infância (Hurst, 
1999). Entretanto, a hipótese de ser uma lesão adquirida tem sido reforçada pelos relatos de desenvolvimento de FAVP após a cirurgia de tumores raquimedulares (Gueguen, 1987; Barrow, 1994). Na nossa casuística não observamos esse aspecto. A maioria dos relatos sugere não haver predominância quanto ao sexo (Gueguen, 1987, Mourier, 1993; Tomlinson, 1993; Cauley, 1999). Na nossa série observamos um predomínio do sexo masculino, sendo acometidos 4 homens $(57,1 \%)$ e 3 mulheres $(42,9 \%)$. Quanto à localização, a maioria dos pacientes apresentava fístula na transição tóraco-lombar, sendo observada em 5 pacientes $(71,4 \%)$ seguida da região cervical em 2 pacientes (28,6\%). Relatos semelhantes foram observados na literatura, com a maioria das lesões acometendo o cone medular e cauda eqüina, embora existam relatos de comprometimento nos níveis torácico e cervical (Heros, 1986; Gueguen, 1987).

Os sintomas iniciais costumam ser semelhantes aos apresentados na ocasião do diagnóstico, ou seja, fraqueza nas pernas, alterações na sensibilidade e esfíncteres (Kaynar, 1999). Na nossa casuística, observamos que o sintoma inicial mais freqüente foi a fraqueza nos membros em 6 pacientes $(85,7 \%)$, dor em 3 pacientes $(42,9 \%)$ e alterações na sensibilidade em 1 paciente (14,3\%). Não observamos alterações em esfíncteres. A duração dos sintomas até o tratamento foi em média de 24,5 meses. Na literatura esse intervalo variou de 2 a 25 anos (Tomlinson, 1993).

Os pacientes com FAVP costumam cursar com sintomas de mielopatia progressiva, e às vezes com hemorragia ou dor. A mielopatia lentamente progressiva ocorre em $75-91 \%$ dos pacientes e a hemorragia subaracnóidea em 20-50\% (Mourier, 1993; Barrow, 1994). Esses achados não foram 
observados na nossa casuística, com 2 pacientes $(28,6 \%)$ apresentando evolução lenta, compatível com mielopatia progressiva e 5 pacientes $(71,7 \%)$ com apresentação súbita de déficit motor, sugestiva de hemorragia. $\mathrm{Na}$ ocasião do diagnóstico, os sintomas foram mais acentuados. $\mathrm{O}$ déficit motor foi observado em 6 pacientes (85,7\%). Também observamos a presença de distúrbios de esfíncter vesical em 5 pacientes $(71,4 \%)$, dor em 3 pacientes $(42,9 \%)$, alterações na sensibilidade em 2 pacientes $(28,6 \%)$, obstipação em 2 pacientes $(28,6 \%)$ e impotência em 1 paciente (14,3\%). A marcha estava alterada em 6 pacientes $(85,7 \%)$. Destes, 3 pacientes (42,9\%) deambulavam sem apoio, mas com restrição aos esforços físicos, 2 pacientes $(28,6 \%)$ estavam acamados e se locomoviam com o auxílio de cadeira de rodas e 1 paciente $(14,3 \%)$ deambulava com auxílio de muletas. Um paciente $(14,3 \%)$ deambulava sem restrições.

A angiografia seletiva é atualmente o exame indicado para o diagnóstico e classificar o tipo de FAVP, além de permitir a escolha da abordagem terapêutica adequada. Durante a cateterização seletiva é importante a análise minuciosa das fases precoce, intermediária e tardia de opacificação da lesão. Na fase precoce é que será demonstrado o local da(s) fístula(s) e na tardia a drenagem venosa da lesão (Cawley, 1999). As fístulas podem estar localizadas em diversos níveis vertebrais, como observamos num dos pacientes da nossa casuística, que apresentava pertuitos fistulares em T10, L1 e L4.

Após o tratamento, em 6 pacientes $(85,7 \%)$ foi constatada a presença de fraqueza nos membros. Os distúrbios de esfíncter vesical estavam 
presentes em 2 pacientes (28,6\%), dor em 1 paciente $(14,3 \%)$, obstipação em 1 paciente $(14,3 \%)$ e impotência em 1 paciente $(14,3 \%)$.

A marcha estava alterada em 6 pacientes (85,7\%). Destes, 4 pacientes $(57,1 \%)$ deambulavam sem apoio, mas com restrição aos esforços físicos, 1 paciente $(14,3 \%)$ deambulava com auxílio de muletas e 1 paciente $(14,3 \%)$ estava acamado e se locomovia com o auxílio de cadeira de rodas. Um paciente $(14,3 \%)$ deambulava sem restrições. Comparando os resultados do padrão da marcha no pré e pós-tratamento observamos que a melhora no padrão após a embolização não foi significativa.

Sete pacientes com FAVP foram tratados com embolização. Foram realizados 9 intervenções (média de 1,3 sessões/paciente). Ao final da embolização o controle angiográfico demonstrou oclusão total da lesão em 6 intervenções, resultando em sucesso de procedimento de $66,7 \%$. A embolização foi parcial em duas intervenções (25,0\%). A recanalização não aconteceu em nenhum procedimento, demonstrando ausência de recidiva. $O$ sucesso do tratamento foi obtido em 6 pacientes $(85,7 \%)$, constatado através da cura angiográfica ou da evolução com melhora clínica. A avaliação clínica mostrou que todos pacientes evoluíram com sucesso clínico deste método. Um destes pacientes apresentava-se assintomático antes do tratamento, e assim permaneceu após o procedimento. Com relação ao sucesso clínico e do tratamento, não se observou diferença significativa entre as técnicas utilizadas.

O tratamento dessas lesões é controverso e dependerá do subtipo de FAVP que o paciente apresenta. Nas FAVP-A, muitas vezes o tratamento 
preferido é o cirúrgico, enquanto nas FAVP-C é o endovascular. Nas FAVP$\mathrm{B}$, ambas as abordagens podem ser utilizadas, de maneira isolada ou em conjunto (Detwiler, 1999; Larsen, 1999).

A FAVP-A é constituída de uma fístula perimedular única, de pequeno tamanho, e tanto a artéria espinhal envolvida, como a veia de drenagem, estão minimamente dilatadas. O fluxo pela fístula é lento, e o refluxo venoso também, refletindo pouca hipertensão venosa. A cirurgia para coagulação ou clipagem da fístula, preservando a artéria espinhal, pode ser uma terapia efetiva. A angiografia diagnóstica é fundamental para determinar o nível exato da transição arteriovenosa, bem como a angiografia intra-operatória, que pode ser útil na identificação da fístula e na documentação da patência das artérias espinhais (Cawley, 1999). Como as artérias nutridoras são as espinhais, o cateter para embolização deve ser locado no ponto fistular. Isso muitas vezes é difícil neste subtipo, pois as artérias estão pouco calibrosas. A embolização com partículas pode ser uma alternativa naquelas localizadas ventralmente (Grote, 1996; Casasco, 1999).

Quatro pacientes com FAVP-A foram tratados com embolização. Em 3 dos pacientes foi utilizado Histoacryl $\AA^{\circledR}$ e em 1 dos pacientes partículas. Foram realizados 4 procedimentos (média de 1,0 sessões/paciente). Ao final da embolização o controle angiográfico demonstrou oclusão total da lesão em todas intervenções, resultando em sucesso de procedimento de $100,0 \%$. Em nenhuma das intervenções a embolização foi parcial. A recanalização não aconteceu em nenhum procedimento, demonstrando ausência de recidiva. O sucesso do tratamento foi obtido em todos pacientes, constatado 
através da cura angiográfica ou da evolução com melhora clínica. A avaliação clínica mostrou que todos pacientes evoluíram com sucesso clínico deste método.

No subtipo $B$, as fístulas, e o fluxo através dela, são maiores, e tanto as artérias espinhais como a veias de drenagem estão mais dilatadas. Há ectasia e moderada hipertensão venosa. As localizadas na superfície dorsal da medula podem ser facilmente acessadas por cirurgia. O mesmo não pode ser dito nas situadas na face ventral da medula (Grote, 1996). As vezes diminutas artérias podem suprir a FAVP e quando não obliteradas podem ocasionar fístula residual na evolução do paciente (Riché, 1983b). A dilatação das artérias nutridoras facilita o acesso endovascular ao ponto fistular. Mas a presença de múltiplos pedículos aferentes e fístulas dificulta a completa oclusão da malformação.

Na nossa casuística, somente 1 paciente foi classificado como FAVP-B (paciente 1). O paciente apresentava 2 pertuitos fistulares, um em T12 e outro em L2. Inicialmente foi abordada cirurgicamente a fístula em L2 e posteriormente embolizada com cola a fístula em T12. Foi realizado somente 1 procedimento, no qual foi embolizada totalmente a lesão. Na evolução não apresentou recidiva. O paciente, que apresentava exame neurológico normal, evoluiu com espasticidade transitória nos membros inferiores.

Nas FAVP-C, fístulas gigantes são supridas por múltiplos pedículos arteriais. O fluxo através delas é grande e rápido, causando maior hipertensão venosa e sintomatologia exuberante. As veias de drenagem estão também dilatadas e tortuosas. O tratamento cirúrgico apresenta alto 
risco de hemorragia intra-operatória e infarto no território da artéria espinhal anterior (Detwiler, 1999). A oclusão seletiva da fístula com um agente embolizante que reduza o fluxo (molas ou balões) e posteriormente NBCA é o tratamento inicial para esses casos, sendo conseguida com sucesso em $68 \%$ dos pacientes (Morgan, 1999). A oclusão somente com balões também pode ser satisfatória (Riché, 1983b).

$\mathrm{Na}$ nossa casuística, somente 2 pacientes apresentavam FAVP-C. Uma paciente apresentava fístulas em T10 e T11 direitas e L2 bilateralmente (paciente 14). Foram embolizados com cola todos os pertuitos em uma única sessão. A paciente evoluiu com melhora do quadro álgico. Outro paciente apresentava fístulas em T10 e L1 esquerdas e L4 direita (paciente 12). Foi submetido à embolização através da artéria lombar de L4 à direita, com cola e em outra sessão através da embolização da artéria sacral mediana com cola. Evoluiu com melhora da dor, da sensação de dormência nas pernas e da retenção vesical. Porém ainda apresentava as fístulas em T10, que opacificavam o cone medular. Foi então encaminhado para cirurgia. Foram realizados 3 intervenções (média de 1,5 sessões/paciente). Ao final da embolização o controle angiográfico demonstrou oclusão total da lesão em uma intervenção, resultando em sucesso de procedimento de 33,3\%. Em 2 procedimentos a embolização foi parcial. A recanalização não aconteceu em nenhum procedimento, demonstrando ausência de recidiva. A avaliação clínica mostrou que todos os pacientes evoluíram com sucesso clínico deste método. Ambos evoluíram com melhora da dor e um deles também apresentou melhora da impotência sexual e controle dos esfíncteres. 
7. CONCLUSÕES 
Baseados na análise dos resultados encontrados, nas condições que este estudo foi realizado, podemos concluir que:

1. As MAVR mais freqüentes são a $\operatorname{FAD}(48,6 \%)$, seguidas das MAI $(28,6 \%)$, FAVP $(20,0 \%)$ e MAVM $(2,9 \%)$. Nas FAD, o subtipo A $(58,8 \%)$ é o mais freqüente, seguido do subtipo $B(41,2 \%)$. Nas FAVP, o subtipo A $(57,1 \%)$ é o mais freqüente, seguido dos subtipos C $(28,6 \%)$ e B $(14,3 \%)$.

2. Nas $F A D$, a faixa etária mais freqüente é no grupo com mais de 35 anos, enquanto nas MAl é dos 19 aos 35 anos e nas FAVP é abaixo dos 19 anos.

3. O tratamento endovascular das MAVR deve ser realizado preferencialmente com adesivos tissulares. Nos casos em que não for realizado o microcateterismo seletivo da lesão, uma alternativa é a embolização com partículas.

4. O tratamento endovascular das FAD mostrou que a recidiva é significativamente menor quando usado adesivo tissular $(11,1 \%)$, em comparação com as partículas (73,3\%). A melhora no padrão da marcha após a embolização foi significativa. 
5. No tratamento endovascular das MAI, a taxa de recidiva é igualmente baixa, tanto com a utilização de adesivo tissular, como com partículas. A melhora no padrão da marcha foi significativa após a embolização.

6. Nas MAVM, o tratamento objetivou a embolização parcial da lesão para alívio dos sintomas, resultado que foi obtido com sucesso.

7. O tratamento endovascular das FAVP mostrou ausência de recidiva. $O$ sucesso do tratamento foi de $85,7 \%$ e foi obtido o sucesso clínico em todos os pacientes.

8. O tratamento endovascular das MAVR é um método seguro, com baixos índices de complicações. 
8. ANEXOS 
Anexo 1- Termo de consentimento Livre e Esclarecido

$$
\begin{aligned}
& \text { HOSPITAL DAS CLÍNICAS } \\
& \text { DA }
\end{aligned}
$$

FACULDADE DE MEDICINA DA UNIVERSIDADE DE SÃO PAULO

TERMO DE CONSENTIMENTO LIVRE E ESCLARECIDO

I - DADOS DE IDENTIFICAÇÃO DO SUJEITO DA PESQUISA OU RESPONSÁVEL LEGAL

1. NOME DO PACIENTE ::

DOCUMENTO DE IDENTIDADE N': SEXO : M F

DATA NASCIMENTO:

l......

ENDEREÇO.

BAIRRO.

CEP:

\section{RESPONSÁVEL LEGAL}

NATUREZA (grau de parentesco, tutor, curador etc.).

DOCUMENTO DE IDENTIDADE :

DATA NASCIMENTO.:

ENDEREÇO:

BAIRRO:

CEP:

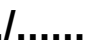

TELEFONE: DDD( TELEFONE: DDD(
APTO: CIDADE SEXO: $M \quad F$

II - DADOS SOBRE A PESQUISA CIENTÍFICA

1. TÍTULO DO PROTOCOLO DE PESQUISA: Tratamento endovascular das malformações arteriovenosas raquimedulares: resultados clínicos e angiográficos

PESQUISADOR: Mario Luiz Marques Conti

CARGO/FUNÇÃO: Médico/Pós Graduando

INSCRIÇÃO CONSELHO REGIONAL Nº 62.811

UNIDADE DO HCFMUSP: Radiologia

3. AVALIAÇÃO DO RISCO DA PESQUISA:

$\begin{array}{lll}\text { SEM RISCO } & \text { RISCO MÍNIMO } & \text { RISCO MÉDIO } \\ \text { RISCO BAIXO } X & \text { RISCO MAIOR }\end{array}$

(probabilidade de que 0 indivíduo sofra algum dano como conseqüência imediata ou tardia do estudo)

4.DURAÇÃO DA PESQUISA : 4 anos 
III - REGISTRO DAS EXPLICAÇÕES DO PESQUISADOR AO PACIENTE OU SEU REPRESENTANTE LEGAL SOBRE A PESQUISA CONSIGNANDO:

1. justificativa e os objetivos da pesquisa: É uma doença rara e o melhor tratamento ainda não está determinado (cirurgia ou endovascular)

2. procedimentos que serão utilizados e propósitos, incluindo a identificação dos procedimentos que são experimentais: Anestesia geral, introdução de cateter na artéria femoral, colocação de material (cola, partículas, balões ou molas) na malformação, para sua obstrução.

3. desconfortos e riscos esperados: Podem ocorrer mal estar, náuseas, vômitos, dor de cabeça, fraquezal dormência nos braços e pernas, dificuldade para urinar e evacuar. Dor.

4. benefícios que poderão ser obtidos: Melhora da fraqueza e da dormência em braços e pernas, do controle para urinar e evacuar, e da dor.

5. procedimentos alternativos que possam ser vantajosos para 0 indivíduo: Outras opções são cirurgia e fisioterapia

IV - ESCLARECIMENTOS DADOS PELO PESQUISADOR SOBRE GARANTIAS DO SUJEITO DA PESQUISA CONSIGNANDO:

1. acesso, a qualquer tempo, às informações sobre procedimentos, riscos e benefícios relacionados à pesquisa, inclusive para dirimir eventuais dúvidas.

2. liberdade de retirar seu consentimento a qualquer momento e de deixar de participar do estudo, sem que isto traga prejuízo à continuidade da assistência.

3. salvaguarda da confidencialidade, sigilo e privacidade.

4. disponibilidade de assistência no HCFMUSP, por eventuais danos à saúde, decorrentes da pesquisa.

5. viabilidade de indenização por eventuais danos à saúde decorrentes da pesquisa. 
V. INFORMAÇÕES DE NOMES, ENDEREÇOS E TELEFONES DOS RESPONSÁVEIS PELO ACOMPANHAMENTO DA PESQUISA, PARA CONTATO EM CASO DE INTERCORRÊNCIAS CLÍNICAS E REAÇÕES ADVERSAS.

Dr. Mario Luiz Marques Conti

Instituto de Radiologia do Hospital das Clínicas: Av. Dr. Enéas Carvalho de Aguiar 255.

Fone: $3069-7086$ ou $3069-6389$ ou $3069-5492$

VI. OBSERVAÇÕES COMPLEMENTARES:

$$
\text { VII - CONSENTIMENTO PÓS-ESCLARECIDO }
$$

Declaro que, após convenientemente esclarecido pelo pesquisador e ter entendido o que me foi explicado, consinto em participar do presente Protocolo de Pesquisa

São Paulo,

de

de

assinatura do sujeito da pesquisa ou responsável legal assinatura do pesquisador

(carimbo ou nome Legível) 
Anexo 2: Distribuição dos pacientes com MAVR submetidos a tratamento endovascular considerando-se sexo, idade, diagnóstico, instalação dos sintomas, dor, fraqueza muscular, dormência, retenção vesical e fecal, impotência sexual, fatores de melhora e piora.

\begin{tabular}{|c|c|c|c|c|c|c|c|c|c|c|c|c|}
\hline $\mathrm{N}^{\circ}$ & sexo & idade & diag & instal & dor & fraq & dorm & ret ves & ret fec & imp & melhora & piora \\
\hline $1 \mathrm{ADSL}$ & $\mathrm{m}$ & 13 & FAVP-B & 5a-súb & - & pernas & - & - & - & - & - & - \\
\hline 2 ARS & $\mathrm{m}$ & 33 & FAD-B & $4 m$-progr & - & pernas & - & - & - & - & - & - \\
\hline $3 \mathrm{AML}$ & $f$ & 27 & MAI & $6 m-?$ & cerv & perna d & - & - & - & - & - & - \\
\hline 4 AJC & $\mathrm{m}$ & 63 & FAD-A & $6 m$-progr & - & pernas & - & - & - & - & - & - \\
\hline $5 \mathrm{BP}$ & $\mathrm{m}$ & 58 & FAD-B & $2 m$-progr & - & pernas & - & - & - & - & - & - \\
\hline 6 CRR & $f$ & 17 & MAI & $10 \mathrm{~m}$-progr & pernas & pernas & - & + & - & - & - & - \\
\hline $7 \mathrm{CSG}$ & $f$ & 73 & FAD-B & 1a6m-progr & $\mathrm{t} / \mathrm{l}$ & - & - & - & - & - & - & - \\
\hline $8 \mathrm{CAF}$ & $\mathrm{m}$ & 81 & FAD-A & 45d-progr & $\mathrm{t} / \mathrm{l}$ & - & - & - & - & - & - & - \\
\hline $9 \mathrm{CV}$ & $\mathrm{m}$ & 38 & FAD-B & 2a-progr & $\mathrm{rad}$ & pernas & - & - & - & - & - & - \\
\hline $10 \mathrm{CDG}$ & $f$ & 27 & MAI & 10a-súb & cabeça & - & - & - & - & - & - & - \\
\hline $11 \mathrm{AJS}$ & $\mathrm{m}$ & 47 & FAVP-A & 2a-progr & - & perna d & - & - & - & - & - & - \\
\hline $12 \mathrm{DDS}$ & $\mathrm{m}$ & 13 & FAVP-C & 3a-súb & $1 / \mathrm{s}$ & & pernas & - & - & - & - & - \\
\hline $13 \mathrm{EW}$ & $\mathrm{m}$ & 55 & FAD-A & 3a-progr & $t / l$ & perna d & - & - & - & - & - & - \\
\hline $14 \mathrm{FH}$ & $f$ & 29 & FAVP-C & 4a-progr & $\mathrm{rad}$ & - & - & - & - & - & - & esforço \\
\hline 15 FMGF & $\mathrm{m}$ & 22 & MAI & $5 m$-súb & $t / l$ & pernas & - & - & - & - & - & - \\
\hline 16 FRB & $\mathrm{m}$ & 64 & FAD-A & 3a-progr & $\mathrm{rad}$ & - & - & - & - & - & - & - \\
\hline $17 \mathrm{JSM}$ & $\mathrm{m}$ & 2 & FAVP-A & $2 m$-súb & cerv & braço d & - & - & - & - & - & - \\
\hline $18 \mathrm{JMM}$ & $\mathrm{m}$ & 60 & FAD-A & $4 \mathrm{~m}$-progr & - & - & perna d & - & - & - & - & - \\
\hline $19 \mathrm{JCLS}$ & $\mathrm{m}$ & 57 & FAD-A & $1 \mathrm{~m}$-súb & cerv & - & - & - & - & - & - & - \\
\hline 20 LCP & $\mathrm{m}$ & 51 & FAD-A & 3a-progr & - & - & perna e & - & - & - & - & - \\
\hline 21 SPS & $\mathrm{m}$ & 74 & FAD-A & $2 m$-progr & - & pernas & - & - & - & - & - & - \\
\hline $22 \mathrm{FPN}$ & $\mathrm{m}$ & 66 & FAD-A & 7a-progr & - & pernas & - & - & - & - & - & - \\
\hline 23 LVSN & $\mathrm{m}$ & 17 & MAI & 1a-súb & - & - & perna d & - & - & - & - & - \\
\hline $24 \mathrm{MLA}$ & $f$ & 40 & FAD-A & 1a-progr & - & pernas & pernas & - & - & - & - & noturna \\
\hline 25 MRP & $\mathrm{m}$ & 16 & MAI & 2m-súb & cerv & - & - & - & - & - & - & - \\
\hline 26 MSA & $f$ & 48 & FAD-B & 1a6m-progr & $t / l$ & pernas & - & - & - & - & - & em pé \\
\hline 27 MVC & $\mathrm{m}$ & 48 & FAD-B & 1a-progr & lombar & - & perna e & - & - & - & - & - \\
\hline $28 \mathrm{NS}$ & $\mathrm{m}$ & 21 & MAI & 3d-súb & cerv & - & - & - & - & - & - & - \\
\hline $29 \mathrm{RL}$ & $\mathrm{m}$ & 64 & FAD-B & 1a-progr & - & pernas & - & - & - & - & - & - \\
\hline 30 RDO & $\mathrm{m}$ & 38 & MAI & 4a-progr & $\mathrm{rad}$ & - & - & - & - & - & - & - \\
\hline $31 \mathrm{ST}$ & $f$ & 41 & MAI & 4a-súb & - & 4 memb & - & - & - & - & - & - \\
\hline 32 VDMF & $f$ & 16 & FAVP-A & 1m-súb & - & pernas & - & - & - & - & - & - \\
\hline 33 VMGG & $f$ & 47 & MAVM & 24a-súb & $t / 1$ & pernas & - & - & - & - & - & - \\
\hline 34 SSA & $f$ & 12 & FAVP-A & 1sem-súb & - & $4 \mathrm{memb}$ & - & - & - & - & - & - \\
\hline 35 LSM & M & 34 & MAI & 14a-súb & cerv & - & - & - & - & - & - & - \\
\hline
\end{tabular}

$\mathrm{N}^{\circ}$ - número do paciente; $\mathrm{m}$ - masculino; f - feminino; diag - diagnóstico; instal - instalação; súb - súbita; progr progressiva; ? - interrogada; cerv - cervical; t/l - tóraco-lombar; I/s - lombo-sacra; rad - radicular; fraq - fraqueza muscular; dorm - dormência; memb - membros; d - direito; e - esquerdo; ret ves - retenção vesical; ret fec retenção fecal; imp - impotência sexual; melhora - fatores de melhora; piora - fatores de piora. 
Anexo 3: Distribuição dos pacientes com MAVR submetidos a tratamento endovascular considerando-se, diagnóstico, dor, fraqueza muscular, dormência, retenção vesical e fecal, impotência sexual e marcha na ocasião do diagnóstico.

\begin{tabular}{|c|c|c|c|c|c|c|c|c|}
\hline $\mathrm{N}^{\circ}$ & diag & dor & fraq & dorm & ret ves & ret fec & imp & marcha \\
\hline $1 \mathrm{ADSL}$ & FAVP-B & - & - & - & - & - & - & normal \\
\hline 2 ARS & FAD-B & - & pernas & + & + & - & + & beng \\
\hline $3 \mathrm{AML}$ & MAI & cerv & perna d & - & - & - & - & rest \\
\hline $4 \mathrm{AJC}$ & FAD-A & - & pernas & - & + & + & - & rest \\
\hline $5 \mathrm{BP}$ & FAD-B & - & pernas & T12 & + & + & + & acam \\
\hline $6 \mathrm{CRR}$ & MAI & - & pernas & $\mathrm{T} 4$ & - & - & - & acam \\
\hline $7 \mathrm{CSG}$ & FAD-B & $t / l$ & pernas & L2 & - & - & - & mul \\
\hline $8 \mathrm{CAF}$ & FAD-A & $t / l$ & pernas & $\mathrm{T} 10$ & + & + & - & acam \\
\hline $9 \mathrm{cV}$ & FAD-B & $\mathrm{rad}$ & pernas & - & + & - & - & mul \\
\hline $10 \mathrm{CDG}$ & MAI & - & perna d & perna e & + & - & - & rest \\
\hline 11 AJS & FAVP-A & - & perna d & - & + & - & + & rest \\
\hline 12 DDS & FAVP-C & $1 / \mathrm{s}$ & pernas & L4/L5 & + & incont & - & rest \\
\hline $13 \mathrm{EW}$ & FAD-A & - & pernas & T9 & + & - & - & acam \\
\hline $14 \mathrm{FH}$ & FAVP-C & $\mathrm{rad}$ & pernas & - & + & + & - & mul \\
\hline 15 FMGF & MAI & - & pernas & T9 & + & + & - & acam \\
\hline $16 \mathrm{FRB}$ & FAD-A & $\mathrm{rad}$ & pernas & pernas & + & + & + & beng \\
\hline $17 \mathrm{JSM}$ & FAVP-A & - & 4 memb & - & - & - & - & acam \\
\hline $18 \mathrm{JMM}$ & FAD-A & - & pernas & pernas & - & - & - & acam \\
\hline $19 \mathrm{JCLS}$ & FAD-A & - & - & - & - & - & - & normal \\
\hline 20 LCP & FAD-A & - & pernas & pernas & - & - & - & acam \\
\hline 21 SPS & FAD-A & - & pernas & pernas & + & + & - & acam \\
\hline 22 FPN & FAD-A & - & pernas & $\mathrm{T} 10$ & + & + & + & rest \\
\hline 23 LVSN & MAI & & pernas & - & - & - & - & rest \\
\hline 24 MLA & FAD-A & - & pernas & T9 & + & + & - & beng \\
\hline 25 MRP & MAI & - & - & - & - & - & - & normal \\
\hline $26 \mathrm{MSA}$ & FAD-B & - & pernas & - & + & + & - & rest \\
\hline 27 MVC & FAD-B & lombar & pernas & pernas & - & - & - & acam \\
\hline $28 \mathrm{NS}$ & MAI & - & - & - & - & - & - & normal \\
\hline $29 \mathrm{RL}$ & FAD-B & - & pernas & T10 & + & + & + & mul \\
\hline 30 RDO & MAI & $\mathrm{rad}$ & pernas & T6 & + & - & - & rest \\
\hline $31 \mathrm{ST}$ & MAI & - & - & - & - & - & - & normal \\
\hline 32 VDMF & FAVP-A & $\mathrm{rad}$ & pernas & pernas & + & - & - & rest \\
\hline 33 VMGG & MAVM & $t / 1$ & pernas & pernas & + & + & - & beng \\
\hline 34 SSA & FAVP-A & - & 4 memb & - & + & - & - & acam \\
\hline 35 LSM & MAI & - & 4 memb & pernas & + & - & - & acam \\
\hline
\end{tabular}

$\mathrm{N}^{\circ}$ - número do paciente; diag - diagnóstico; cerv - cervical; $\mathrm{t} / \mathrm{l}$ - tóraco-lombar; I/s - lombo-sacra; rad - radicular; fraq - fraqueza muscular; dorm - dormência; memb - membros; d - direito; e - esquerdo; ret ves - retenção vesical; ret fec - retenção fecal; incont - incontinência; imp - impotência sexual; beng - bengala; rest - restrição aos esforços; mul - muletas; acam - acamado ou cadeira de rodas. 
Anexo 4: Distribuição dos pacientes com MAVR submetidos a tratamento endovascular considerando-se, diagnóstico, dor, fraqueza muscular, dormência, retenção vesical e fecal, impotência sexual e marcha após a embolização.

\begin{tabular}{|c|c|c|c|c|c|c|c|c|c|}
\hline $\mathrm{N}^{\circ}$ & diag & dor & fraq & dorm & ret ves & ret fec & imp & marcha & seguimento \\
\hline $1 \mathrm{ADSL}$ & FAVP-B & - & - & - & - & - & - & normal & $4 a$ e $1 m$ \\
\hline 2 ARS & FAD-B & - & pernas & - & - & - & - & rest & 1a e $1 \mathrm{~m}$ \\
\hline $3 \mathrm{AML}$ & MAI & - & perna d & - & - & - & - & rest & $3 a$ e $4 m$ \\
\hline $4 \mathrm{AJC}$ & FAD-A & - & pernas & - & + & + & - & rest & $6 \mathrm{~m}$ \\
\hline $5 \mathrm{BP}$ & FAD-B & - & pernas & T8 & + & + & - & acam & $5 a$ e $1 \mathrm{~m}$ \\
\hline $6 \mathrm{CRR}$ & MAI & - & pernas & $\mathrm{T} 8$ & - & - & - & $\mathrm{mul}$ & $3 a$ e $3 m$ \\
\hline $7 \mathrm{CSG}$ & FAD-B & $\mathrm{t} / \mathrm{l}$ & pernas & T8 & - & - & - & mul & $6 \mathrm{~m}$ \\
\hline $8 \mathrm{CAF}$ & FAD-A & - & pernas & - & + & - & - & rest & 1a e $4 m$ \\
\hline $9 \mathrm{CV}$ & FAD-B & - & pernas & - & - & - & - & mul & $6 a$ e $8 m$ \\
\hline $10 \mathrm{CDG}$ & MAI & - & perna d & perna e & - & - & - & rest & $6 \mathrm{~m}$ \\
\hline 11 AJS & FAVP-A & - & perna d & - & incont & - & + & rest & $4 a$ e $5 m$ \\
\hline $12 \mathrm{DDS}$ & FAVP-C & - & pernas & - & - & - & - & rest & $3 a$ e $1 \mathrm{~m}$ \\
\hline $13 \mathrm{EW}$ & FAD-A & - & pernas & - & - & - & - & acam & $2 \mathrm{a}$ e $1 \mathrm{~m}$ \\
\hline $14 \mathrm{FH}$ & FAVP-C & - & pernas & - & + & + & - & mul & $6 \mathrm{~m}$ \\
\hline 15 FMGF & MAI & - & pernas & T9 & + & + & - & acam & $6 \mathrm{~m}$ \\
\hline $16 \mathrm{FRB}$ & FAD-A & - & pernas & - & - & - & - & rest & $1 \mathrm{a}$ e $3 \mathrm{~m}$ \\
\hline $17 \mathrm{JSM}$ & FAVP-A & - & pernas & - & - & - & - & rest & $2 \mathrm{a}$ e $10 \mathrm{~m}$ \\
\hline $18 \mathrm{JMM}$ & FAD-A & - & pernas & - & - & - & - & beng & $1 \mathrm{a} e \mathrm{~m}$ \\
\hline $19 \mathrm{JCLS}$ & FAD-A & - & - & - & - & - & - & normal & $3 a$ e $11 \mathrm{~m}$ \\
\hline $20 \mathrm{LCP}$ & FAD-A & - & pernas & pernas & - & - & - & bengala & $2 a$ e $4 m$ \\
\hline $21 \mathrm{SPS}$ & FAD-A & - & pernas & - & - & - & - & mul & $1 \mathrm{a}$ e $11 \mathrm{~m}$ \\
\hline $22 \mathrm{FPN}$ & FAD-A & - & pernas & $\mathrm{T} 10$ & + & + & + & mul & $3 a$ e $8 m$ \\
\hline 23 LVSN & MAI & - & - & - & - & - & - & normal & $6 m$ \\
\hline $24 \mathrm{MLA}$ & FAD-A & - & pernas & T9 & - & - & - & rest & $1 \mathrm{a} e \mathrm{~m}$ \\
\hline $25 \mathrm{MRP}$ & MAI & - & perna e, braço e & - & - & - & - & rest & $3 a$ e $4 m$ \\
\hline $26 \mathrm{MSA}$ & FAD-B & - & pernas & - & - & - & - & rest & $6 a$ e $4 m$ \\
\hline $27 \mathrm{MVC}$ & FAD-B & - & pernas & pernas & - & - & - & rest & $2 a$ \\
\hline $28 \mathrm{NS}$ & MAI & - & - & - & - & - & - & normal & $2 a$ e $6 m$ \\
\hline $29 \mathrm{RL}$ & FAD-B & - & pernas & $\mathrm{T} 10$ & + & + & + & mul & $4 a$ e $5 m$ \\
\hline $30 \mathrm{RDO}$ & MAI & - & - & - & + & - & - & normal & $1 \mathrm{a}$ e $6 \mathrm{~m}$ \\
\hline $31 \mathrm{ST}$ & MAI & - & - & - & - & - & - & normal & $6 \mathrm{~m}$ \\
\hline 32 VDMF & FAVP-A & - & pernas & - & - & - & - & rest & $6 \mathrm{~m}$ \\
\hline 33 VMGG & MAVM & - & pernas & pernas & - & - & - & rest & $2 a$ e $8 m$ \\
\hline $34 \mathrm{SSA}$ & FAVP-A & - & 4 membros & - & - & - & - & acam & $1 \mathrm{a}$ e $1 \mathrm{~m}$ \\
\hline 35 LSM & MAI & - & 4 membros & pernas & + & - & - & acam & $7 \mathrm{~m}$ \\
\hline
\end{tabular}

$\mathrm{N}^{\circ}$ - número do paciente; diag - diagnóstico; instal - instalação; súb - súbita; progr - progressiva; cerv - cervical; t/l - tóraco-lombar; l/s - lombo-sacra; rad - radicular; memb - membros; d - direito; e - esquerdo; ret ves - retenção vesical; ret fec - retenção fecal; incont - incontinência; imp - impotência sexual; beng - bengala; rest - restrição aos esforços; mul - muletas; acam - acamado ou cadeira de rodas. 
Anexo 5: Distribuição dos pacientes com MAVR submetidos a tratamento endovascular considerando-se, data da primeira embolização, pedículos arteriais da MAVR, localização dos pertuitos fistulares, aneurismas, pedículos embolizados, material utilizado na embolização, resultado, recanalização, número de sessões de embolização, complicações e observações.

\begin{tabular}{|c|c|c|c|c|c|c|c|c|c|c|c|c|}
\hline $\mathrm{N}^{\circ}$ & diag & $1^{\mathrm{a}} \mathrm{emb}$ & ped & pert & aneur & ped emb & mat & result & recanal & $\begin{array}{c}\mathrm{n}^{\circ} \\
\text { sess }\end{array}$ & complic & obs \\
\hline $1 \mathrm{ADSL}$ & FAVP-B & 21.10 .96 & $\begin{array}{c}\text { T9e, T11e, } \\
\text { L2d }\end{array}$ & T12, L2 & ven & T11e & cola & total & - & 1 & espasticidade & cir \\
\hline 2 ARS & FAD-B & 10.11 .03 & T5e, T6e & T6e & - & T6e & cola & total & - & 1 & - & - \\
\hline $3 \mathrm{AML}$ & MAI & 28.8 .01 & $\begin{array}{c}\text { tirocerv bil, } \\
\text { costbr d }\end{array}$ & $\mathrm{C} 7, \mathrm{~T} 1$ & ven & $\begin{array}{c}\text { tirocerv bil, } \\
\text { costbr d }\end{array}$ & cola & total & - & 1 & - & - \\
\hline $4 \mathrm{AJC}$ & FAD-A & 31.5 .95 & T10d & T10 & - & $10 \mathrm{~d}$ & cola & total & - & 1 & - & - \\
\hline $5 \mathrm{BP}$ & FAD-B & 18.10 .95 & $\begin{array}{c}\text { T7d, T8d, } \\
\text { T9d }\end{array}$ & T8 & - & $\begin{array}{c}\text { T7d, T8d, } \\
\text { T9d }\end{array}$ & part & total & + & 6 & - & - \\
\hline $6 \mathrm{CRR}$ & MAI & 30.12 .97 & $\begin{array}{l}\text { costbr d, } \\
\text { bronq d, } \\
\text { T7d, T8e }\end{array}$ & $\mathrm{T} 7, \mathrm{~T} 8$ & - & $\begin{array}{l}\text { costbr d, } \\
\text { bronq d, } \\
\text { T7d, T8e }\end{array}$ & part & parcial & - & 3 & $\begin{array}{l}\text { piora trans da } \\
\text { paraparesia }\end{array}$ & - \\
\hline $7 \mathrm{CSG}$ & FAD-B & 16.5 .00 & $\mathrm{~T} 4, \mathrm{~T} 5$ & T5 & - & T5 & part & total & - & 1 & - & - \\
\hline $8 \mathrm{CAF}$ & FAD-A & 3.7 .03 & T10d & T10d & - & T10d & cola & total & - & 1 & - & - \\
\hline $9 \mathrm{CV}$ & FAD-B & 23.11 .93 & L2d, L3d & L3d & - & L2d, L3d & part & total & + & 4 & - & - \\
\hline $10 \mathrm{CDG}$ & MAI & 4.7 .00 & T10d & T10d & - & T10d & part & total & + & 2 & - & - \\
\hline 11 AJS & FAVP-A & 29.6.04 & T10d & $\mathrm{T} 12$ & - & T10d & cola & total & - & 1 & - & - \\
\hline 12 DDS & FAVP-C & 16.9 .98 & $\begin{array}{l}\text { T10e, L1e, } \\
\text { L2 bil, L3e, } \\
\text { L4d, sacral }\end{array}$ & $\begin{array}{l}\text { T10e, L1e, } \\
\text { L4d }\end{array}$ & - & L4d, sacral & cola & parcial & - & 2 & - & cir \\
\hline $13 \mathrm{EW}$ & FAD-A & 26.11.01 & $\mathrm{T} 7 \mathrm{e}$ & $\mathrm{T7}$ & - & T7e & cola & total & - & 1 & - & - \\
\hline $14 \mathrm{FH}$ & FAVP-C & 7.11 .02 & $\begin{array}{c}\text { T10e, } \\
\text { T11d, L2 bil }\end{array}$ & T12, L1 & - & $\begin{array}{c}\text { T10e, T11d, } \\
\text { L2 bil }\end{array}$ & cola & parcial & - & 1 & - & - \\
\hline 15 FMGF & MAI & 27.8 .98 & T12e & $\mathrm{T} 12$ & - & $\mathrm{T} 12 \mathrm{e}$ & cola & total & + & 2 & $\begin{array}{c}\text { piora trans do } \\
\text { déficit }\end{array}$ & - \\
\hline $16 \mathrm{FRB}$ & FAD-A & 25.9 .03 & $T 7 d$ & T7d & - & T7d & cola & total & - & 1 & - & - \\
\hline $17 \mathrm{JSM}$ & FAVP-A & 9.4 .01 & vert bil & $\mathrm{C} 2$ & ven & $\begin{array}{l}\text { espinhal } \\
\text { anterior }\end{array}$ & cola & total & - & 1 & - & - \\
\hline $18 \mathrm{JMM}$ & FAD-A & 2.6 .00 & T10e & T10e & - & T10e & part/cola & total & + & 2 & - & - \\
\hline $19 \mathrm{JCLS}$ & FAD-A & 2.01 .01 & vert $d$ & $\mathrm{C} 2$ & - & vert $d$ & cola & total & - & 1 & - & - \\
\hline 20 LCP & FAD-A & 31.10 .00 & T7e & T7e & - & $\mathrm{T} 7 \mathrm{e}$ & part & total & + & 1 & - & cir \\
\hline 21 SPS & FAD-A & 18.1 .03 & L2e & L2e & - & L2e & cola & total & - & 1 & - & - \\
\hline 22 FPN & FAD-A & 19.4.01 & L1e & L1e & - & L1e & part & total & + & 2 & - & - \\
\hline 23 LVSN & MAI & 14.5 .99 & T9e & T9e & - & T9e & cola & total & - & 1 & - & - \\
\hline $24 \mathrm{MLA}$ & FAD-A & 23.8 .96 & $\mathrm{~T} 12 \mathrm{~d}$ & $\mathrm{~T} 12 \mathrm{~d}$ & - & T12d & cola & total & - & 1 & - & - \\
\hline 25 MRP & MAI & 16.8 .01 & vert e & $\mathrm{C} 4 \mathrm{e}$ & ven & vert e & cola & total & - & 1 & hemip e & - \\
\hline $26 \mathrm{MSA}$ & FAD-B & 2.8 .95 & T6e, T7e & T6e & - & T6e & part & total & + & 2 & - & - \\
\hline $27 \mathrm{MVC}$ & FAD-B & 17.9 .01 & $\mathrm{~T} 7 \mathrm{~d}, \mathrm{~T} 8 \mathrm{e}$ & T8e & - & T7 bil, T8 bil & cola/part & parcial & + & 4 & - & cir \\
\hline $28 \mathrm{NS}$ & MAI & 18.4 .95 & vert $d$ & $\mathrm{C} 1, \mathrm{C} 2$ & - & vert d & cola & parcial & - & 3 & $\begin{array}{c}\text { paraparesia } \\
\text { trans }\end{array}$ & - \\
\hline $29 \mathrm{RL}$ & FAD-B & 18.7 .00 & L2 bil & L2 & - & L2e & cola & total & + & 1 & - & cir \\
\hline $30 \mathrm{RDO}$ & MAI & 8.2 .99 & T8e & T8e & - & T8e & cola & total & - & 1 & - & - \\
\hline $31 \mathrm{ST}$ & MAI & 5.12 .01 & $\mathrm{C} 7 \mathrm{e}$ & $\mathrm{C} 7$ & - & $\mathrm{C} 7 \mathrm{e}$ & cola & total & - & 1 & - & - \\
\hline 32 VDMF & FAVP-A & 27.6 .96 & T12e, L2d & T12 & & $\mathrm{T} 12 \mathrm{e}, \mathrm{L} 2 \mathrm{~d}$ & part & total & - & 1 & - & - \\
\hline 33 VMGG & MAVM & 18.11.01 & $\begin{array}{c}\text { bronq e, T8 } \\
\text { bil,T9 bil, } \\
\text { T10d, T11 } \\
\text { bil, T12 bil }\end{array}$ & $\begin{array}{c}\text { T9, } \\
\text { T11,T12 }\end{array}$ & - & $\begin{array}{l}\text { T9d, T11 bil, } \\
\text { T12e }\end{array}$ & cola/balão & parcial & - & 1 & - & - \\
\hline $34 \mathrm{SSA}$ & FAVP-A & 12.3 .00 & $\mathrm{C} 6 \mathrm{e}$ & $\mathrm{C} 6$ & ven & $\mathrm{C} 6 \mathrm{e}$ & cola & total & - & 1 & - & - \\
\hline 35 LSM & MAI & 10.5 .04 & vert bil & $\mathrm{C} 7$ & - & vert e & cola & parcial & - & 1 & - & - \\
\hline
\end{tabular}

$\mathrm{N}^{\circ}$ - número do paciente; diag - diagnóstico; $1^{\mathrm{a}}$ emb - data da primeira embolização; ped - pedículos arteriais que opacificam a MAVR; tirocerv - tirocervical; costbr - costobrônquico; bronq - brônquica; vert - vertebral; bil bilateral; d - direito; e - esquerdo; pert - localização do pertuito fistular da MAVR; ped emb - pedículos arteriais embolizados; mat - materiais utilizados para embolização; part - partículas; result - resultado final da embolização; recanal - recanalização; $n^{\circ}$ sess - número de sessões para embolização da MAVR; complic - complicações; trans - transitória; hemip - hemiparesia; obs - observações; cir - cirurgia. 
9. REFERÊNCIAS 
Afshar JKB, Doppman JL, Oldfield EH. Surgical interruption of intradural draining vein as curative treatment of spinal dural arteriovenous fistulas. $J$ Neurosurg. 1995; 82:196-200.

Agnoli AL, Laun A, Pia HW, Vogelsang H. Radiologic findings in spinal angiomas - plain x-rays, myelography, and spinal phlebography. In: Pia HW, Djindjian R, editors. Spinal angiomas: advances in diagnosis and therapy. New York: Springer-Verlag; 1978, p.84-97.

Alexander MJ, Grossi PM, Spetzler RF, McDougall CG. Extradural thoracic arteriovenous malformation in a patient with Klippel-Trenaunay-Weber syndrome: case report. Neurosurgery. 2002; 51:1275-9.

Alleyne Jr CH, Barrow DL, Joseph G. Surgical management of angiographically occult spinal dural arteriovenous fistulae (type I spinal arteriovenous malformations): three technical case reports. Neurosurgery. 1999; 44:891-5.

Aminoff MJ, Barnard RO, Logue V. The pathophysiology of spinal vascular malformations. J Neurol Sci. 1974a; 23:255-63.

Aminoff MJ, Logue V. Clinical features of spinal vascular malformations. Brain. 1974b; 97:197-210.

Aminoff MJ, Logue $\mathrm{V}$. The prognosis of patients with spinal vascular malformations. Brain. 1974c; 97:211-8. 
Anson JA, Spetzler RF. Classification of spinal arteriovenous malformations and implications for treatment. Barrow Neurol Institute Quarterly. 1992; 8:2-8.

Awad IA, Barnett GH. Neurological deterioration in a patient with a spinal arteriovenous malformation following lumbar puncture. J Neurosurg. 1990; 72:650-3.

Bailey WL, Sperl MP. Angiomas of the cervical spinal cord. J Neurosurg. 1969; 30:560-8.

Baker HL, Love LG, Layton DD. Angiographic and surgical aspects of spinal cord anomalies. Radiology. 1967; 88:1078-85.

Bao YH, Ling F. Classification and therapeutic modalities of spinal vascular malformations in 80 patients. Neurosurgery. 1997; 40:75-81.

Barrow DL, Colohan ART, Dawson R. Intradural perimedullary arteriovenous fistulas (Type IV spinal cord arteriovenous malformations). J Neurosurg. 1994; 81:221-9.

Barzó P, Vörös E, Bodosi M. Intraventricular hemorrhage as a false localizing sign of a thoracolumbar arteriovenous malformation: case report. Surg Neurol. 1997; 51:430-4.

Benes L, Wakat JP, Sure U, Bien S, Bertalanffy H. Intraoperative spinal digital subtraction angiography: technique and results. Neurosurgery. 2003; 52:603-9.

Benhaiem N, Poirier J, Hurth M. Arteriovenous fistulae in the meninges draining into the spinal veins. A histological study of 28 cases. Acta Neuropathol (Berl). 1983; 62:103-11. 
Berenstein A, Young W, Ransohoff J, Benjamin V, Merkin H. Somatosensory evoked potentials during spinal angiography and therapeutic transvascular embolization. J Neurosurg. 1984; 60:777-85.

Berenstein A, Lasjaunias P. Spine and spinal cord vascular lesions. In: Berenstein A, Lasjaunias P, editors. Surgical Neuroangiography. Berlin: Springer-Verlag; 1992, v. 5, p.1-109.

Biondi A, Merland JJ, Hodes JE, Reizine D, Aymard A, Hodes JE, Lecoz P, Rey, A. Embolization with particles in thoracic intramedullary arteriovenous malformations: long-term angiographic and clinical results. Radiology. 1990; 177:651-8.

Biondi A, Merland JJ, Hodes JE, Pruvo JP, Reizine D. Aneurysms of spinal arteries associated with intramedullary arteriovenous malformations. I. Angiographic and clinical aspects. AJNR Am J Neuroradiol. 1992a; 13:913-22.

Biondi A, Merland JJ, Hodes JE, Aymard A, Reizine D. Aneurysms of spinal arteries associated with intramedullary arteriovenous malformations. II. Results of AVM endovascular treatment and hemodynamic considerations. AJNR Am J Neuroradiol. 1992b, 13:923-31.

Bowen BC, Fraser K, Kochan JP, Pattany BA, Green BA, Quencer RM. Spinal dural arteriovenous fistulas: evaluation with $\mathrm{mr}$ angiography. AJNR Am J Neuroradiol. 1995; 16:2029-43.

Cahan LD, Higashida RT, Halbach VV, Hieshima GB. Variants of radiculomeningeal vascular malformations of the spine. J Neurosurg. 1987; 66:333-7.

Caragine LP, Halbach VV, Ng PP, Dowd CF. Vascular myelopathies vascular malformations of the spinal cord: presentation and endovascular surgical management. Semin Neurol. 2002; 22:123-31. 
Casasco AE, Houdart E, Jhaveri HS, Aymard A, Herbreteau D, Guichard JP, Reizine D, Mourier KL, Merland JJ. Embolization of spinal vascular malformations. In: Connors III JJ, Wojak JC, editors. Interventional neuroradiology: strategies and practical techniques. Philadelphia: W. B. Saunders; 1999, p.186-98.

Cawley CM, Barrow DL. Intradural perimedullary spinal cord arteriovenous fistulas. In: Barrow DL, Awad IA, editors. Spinal vascular malformations. Park Ridge: American Association of Neurological Surgeons; 1999, p.147-60.

Chiras J, Merland JJ. Lumbosacral spinal angiography. Technical note. J Neuroradiol. 1978; 5:303-10.

Cho KT, Lee DY, Chung CK, Han MH, Kim HJ. Treatment of spinal cord perimedullary arteriovenous fistula: embolization versus surgery. Neurosurgery. 2005; 56:232-241.

Choi IS. Spinal dural arteriovenous fistula: the role of PVA embolization. AJNR Am J Neuroradiol. 1992; 13:941-2.

Cobb S. Haemangioma of the spinal cord associated with skin naevi of the same metamere. Ann Surg. 1915; 62:641-9.

Connolly Jr ES, Bertrand GP, McCormick PC, Stein BM. The posterior approach to a series of glomus (Type II) intramedullary spinal cord arteriovenous malformations. Neurosurgery. 1998; 42:774-86.

Connolly Jr ES, McCormick PC. Intramedullary vascular malformations: type II glomus arteriovenous malformations and cavernous malformations. In: Barrow DL, Awad IA, editors. Spinal vascular malformations. Park Ridge: American Association of Neurological Surgeons; 1999, p.135-45. 
Conti MLM, Costa Filho A, Caldas JGMP, Veiga JCE. Malformações arteriovenosas raquimedulares. In: Tedeschi $\mathrm{H}$, Pereira $\mathrm{CU}$, editores. Doenças cerebrovasculares. Diagnóstico e tratamento. Rio de Janeiro: Revinter; 2004, p.187-95.

Costa Filho A. Correlação anátomo-radiológica da vascularização arterial da medula espinhal [dissertação]. São Paulo: Faculdade de Medicina, Universidade de São Paulo; 1984.

Criscuolo GR, Oldfield EH, Doppman JL. Reversible acute and subacute myelopathy in patients with dural arteriovenous fistulas. Foix-Alajouanine syndrome reconsidered. J Neurosurg. 1989; 70:354-9.

Cushing H, Bayley, P. Tumors arising from the blood vessels of the brain. Angiomatous malformations and hemangioblastomas. London: Bailliére, Tindall \& Cox; 1928.

David CA, Vishteh AG, Zabramski JM. Juvenile and diffuse spine arteriovenous malformations. In: Barrow DL, Awad IA, editors. Spinal vascular malformations. Park Ridge: American Association of Neurological Surgeons; 1999, p.161-7.

Deeb ZL, Rosenbaum AE, Benssy JJ, Scarff TB. Calcified intramedullary aneurysm in spinal angioma. Neuroradiology. 1977; 14:1-3.

Detwiler PW, Porter RW, Spetzler RF. Spinal arteriovenous malformations. Neurosurg Clin N Am. 1999; 10:89-100.

Di Chiro G, Doppman J, Ommaya AK. Selective arteriography of arteriovenous aneurysms of spinal cord. Radiology. 1967; 88:1065-77. 
Di Chiro G, Doppman JL, Dwyer AJ, Patronas NJ, Knop RH, Bairamian D, Vermess $\mathrm{M}$, Oldfield $\mathrm{EH}$. Tumors and arteriovenous malformations of the spinal cord: assessment using MR. Radiology. 1985; 156:689-97.

Djindjian M. Les malformations arterio-veineuses de la moelle épiniére et leur traitement. A propos de 150 cas [these]. Paris: Faculte de Medecine PitieSalpetriere, Universite de Paris VI; 1976.

Djindjian $M$, Djindjian $R$, Rey A, Hurth $M$, Houdart R. Intradural extramedullary spinal arterio-venous malformations fed by the anterior spinal artery. Surg Neurol. 1977; 8:85-93.

Djindjian M. Clinical symptomatology and natural history of arteriovenous malformations of the spinal cord - a study of the clinical aspects and prognosis, based on 150 cases. In: Pia HW, Djindjian R, editors. Spinal angiomas: advances in diagnosis and therapy. New York: Springer-Verlag; 1978a, p.75-83.

Djindjian M, Djindjian R, Hurth M, Houdart R, Rey A. Steal phenomena in spinal arteriovenous malformations. J Neuroradiol. 1978b ; 5:187-201.

Djindjian $R$, Dumesnil $M$, Fauré $C$, Lefebre $J$, Levèque $B$. Étude angiographique d'un angiome intra-rachidien. Rev Neurol (Paris). 1962; 106:278-85.

Djindjian R, Hurth $M$, Houdart R. Intérêt diagnostique et thérapeutique de l'artériographie médullaire dans les angiomes spinaux. Société Médicale des Hôpitaux de Paris. 1967; 118:415-9.

Djindjian R. Summary of the anatomy of the blood supply to the spinal cord. In: Djindjian R, Hurth M, Houdart R, Laborit G, Julian H, Mamo $\mathrm{H}$, editors. Angiography of the spinal cord. Paris: Masson; 1970. p.1-26. 
Djindjian R. Embolization of angiomas of the spinal cord. Surg Neurol. 1975; 4:411-20.

Djindjian R. Angiography in angiomas of the spinal cord. In: Pia HW, Djindjian R, editors. Spinal Angiomas: Advances in Diagnosis and Therapy. New York: Springer-Verlag; 1978a, p.98-136.

Djindjian R, Merland JJ, Djindjian M, Houdart R. Place de l'embolisation dans le traitement des malformations artério-veineuses médullaires à propos de 38 cas. Neuroradiology. 1978b; 16:428-9.

Doppman J, Di Chiro G. Subtraction-angiography of spinal cord malformations. J Neurosurg. 1965, 23:440-3.

Doppman J, Di Chiro G, Ommaya G. Obliteration of spinal cord arteriovenous malformations by percutaneous embolization [letter]. Lancet. 1968; 1:477.

Doppman JL. The nidus concept of spinal cord arteriovenous malformations. A surgical recommendation based upon angiographic observations. $\mathrm{Br} J$ Radiol. 1971; 44:758-63.

Doppman JL, Di Chiro G, Dwyer AJ, Frank JL, Oldfield EH. Magnetic resonance imaging of spinal arteriovenous malformations. J Neurosurg. 1987; 66:830-4.

Dormont D, Assouline E, Gelbert F, Helias A, Halimi P, Chiras J, Bories J, Doyon D, Merland JJ. MRI study of spinal arteriovenous malformations. $J$ Neuroradiol. 1987; 14:351-64.

Figueirêdo D, Figueirêdo D, Leitão F, Leitão Filho F, Fuentes AF. Novos conceitos na classificação e tratamento das malformações arteriovenosas medulares. J Bras Neurocirurg. 1999; 10:55-8. 
Foix C, Alajouanine T. La myélite nécrotique subaigüe: myélite centrale angéio-hypertrophique à évolution progressive. Paraplégie amyotrophique lentement ascendante, d'abord spasmodique, puis flasque, s'accompangnant de dissociation, albumino-cytologique. Rev Neurol. 1926; 2:1-42.

Gariépy JL, Houdart E, Boukobza M, Chapot R, Cambra R, Merland JJ. Spine and spinal cord vascular malformations: pictorial essay. Can Assoc Radiol J. 1999; 50:397-406.

Gilbertson J, Miler G, Goldman M, Marsh WR. Spinal dural arteriovenous fistulas: MR and myelographic findings. AJNR Am J Neuroradiol; 1995; 16:2049-57.

Gillilan LA. Veins of the spinal cord. Anatomic details; suggested clinical applications. Neurology. 1970; 20:860-8.

Glasser R, Masson R, Mickle JP, Peters KR. Embolization of a dural arteriovenous fistula of the ventral cervical spinal canal in a nine-year-old boy. Neurosurgery. 1993; 33:1089-94.

Grote $\mathrm{EH}$, Bien S. Arteriovenous malformations of the spinal cord. In: Youmans JR, editor. Neurological surgery, $4^{\text {th }}$ ed. Philadelphia: W. B. Saunders; 1996. p.1511-30.

Grote EH, Voigt K. Clinical syndromes, natural history, and pathophysiology of vascular lesions of the spinal cord. Neurosurg Clin N Am. 1999; 1:17-45.

Gueguen B, Merland JJ, Riche MC, Rey, A. Vascular malformations of the spinal cord: intrathecal perimedullary arteriovenous fistulas fed by medullary arteries. Neurology. 1987; 37:969-79. 
Hager $\mathrm{H}$. Operative findings in spinal angiomas. In: Pia HW, Djindjian R, editors. Spinal angiomas: advances in diagnosis and therapy. New York: Springer-Verlag; 1978. p.45-8.

Halbach VV, Higashida RT, Dowd CF, Fraser KW, Edwards MS, Barnwell SL. Treatment of giant intradural (perimedullary) arteriovenous fistulas. Neurosurgery. 1993; 33:972-80.

Hall WA, Oldfield EH, Doppman JL. Recanalization of spinal arteriovenous malformations following embolization. J Neurosurg. 1989; 70:714-20.

Han PP, Theodore N, Porter RW, Detwiler PW, Lawton MT, Spetzler RF. Subdural hematoma from a Type I spinal arteriovenous malformation. Case report. J Neurosurg (spine 2). 1999; 90:255-7.

Hassler W, Thron A, Grote EH. Hemodynamics of spinal dural arteriovenous fistulas. An intraoperative study. J Neurosurg. 1989; 70:360-70.

Henson RA, Croft PB. Spontaneous spinal subarachnoid hemorrhage. Quart J Med. 1956; 25:53-66.

Herdt JR, Di Chiro G, Doppman JL. Combined arterial and arteriovenous aneurysms of the spinal cord. Radiology. 1971; 99:.589-93.

Heros RC, Debrun Gm, Ojemann RG. Direct spinal arteriovenous fistula: a new type of spinal AVM. Case report. J Neurosurg. 1986; 64:134-9.

Hodes JE, Merland JJ, Casasco A, Houdart E, Reizine D. Spinal vascular malformations: endovascular therapy. Neurosurg Clin N Am. 1999; 10:139-52. 
Horton JA, Latchaw RE, Gold LHA, Pang D. Embolization of intramedullary arteriovenous malformations of the spinal cord. AJNR Am J Neuroradiol. 1986; 7:113-8.

Houdart R, Djindjian R, Hurth M. Vascular malformations of the spinal cord. The anatomic and therapeutic significance of arteriography. $J$ Neurosurg. 1966; 24:583-94.

Houdart R, Djindjian R, Hurth M, Rey A. Treatment of angiomas of the spinal cord. Surg Neurol. 1974; 2:186-94.

Hurst RW, Kenion LC, Lavi E, Raps EC, Marcotte P. Spinal dural arteriovenous fistula: the pathology of venous hypertensive myelopathy. Neurology. 1995; 45:1309-13.

Hurst RW, Bagley LJ, Marcotte P, Schut L, Flamm ES. Spinal cord arteriovenous fistulas involving the conus medullaris: presentation, management, and embryologic considerations. Surg Neurol. 1999; 52:95-9.

Jellema K, Canta LR, Tijssen CC, Van Rooij WJ, Koudstaal PJ, Van Gijn J. Spinal dural arteriovenous fistulas: clinical features in 80 patients. J Neurol Neurosurg Psychiatry. 2003; 74:1438-40.

Jellema K, Tijssen CC, Van Rooij WJJ, Sluzewski M, Koudstaal PJ, Algra A, Van Gijn J. Spinal dural arteriovenous fistulas: long-term follow-up of 44 treated patients. Neurology. 2004; 62:1839-41.

Jellinger K. Pathology of spinal vascular malformations and vascular tumors. In: Pia HW, Djindjian R, editors. Spinal angiomas: advances in diagnosis and therapy. Berlin: Springer-Verlag; 1978. p.8-44.

Joseph GJ, Lock Jr J. Diagnostic evaliation of spinal cord arteriovenous malformations. In: Barrow DL, Awad IA, editors. Spinal vascular 
malformations. Park Ridge, American Association of Neurological Surgeons; 1999. p.57-83.

Kataoka H, Miyamoto S, Nagata I, Ueba T, Hashimoto N. Venous congestion is a major cause of neurological deterioration in spinal arteriovenous malformations. Neurosurgery. 2001; 48:1224-30.

Kaynar MY, Wecht DA, Awad IA. Clinical spectrum and natural history of spinal vascular malformations. In: Barrow DL, Awad IA, editors. Spinal vascular malformations. Park Ridge: American Association of Neurological Surgeons; 1999. p.45-55.

Kendal BE, Logue V. Spinal epidural angiomatous malformations draining into intrathecal veins. Neuroradiology. 1977; 13:181-9.

Kerber CW, Cromwell LD, Sheptak PE. Intraarterial cyanoacrylate: an adjunct in the treatment of spinal/paraspinal arteriovenous malformations. AJR Am J Roentgenol. 1978; 103:99-103.

Kim DI, Choi IS, Berenstein A. A sacral dural arteriovenous fistula presenting with an intermittent myelopathy aggravated by menstruation. Case report. $J$ Neurosurg. 1991; 75:947-9.

Koenig E, Thron A, Schrader V, Dichgans, J. Spinal arteriovenous malformations and fistulae: clinical, neuroradiological and neurophisiological findings. J Neurol. 1989; 236:260-6.

Konan AV, Raymond J, Roy D. Transarterial embolization of aneurysms associated with spinal cord arteriovenous malformations. J Neurosurg (Spine 1). 1999; 90:148-4.

Krauss WE. Vascular anatomy of the spinal cord. Neurosurg Clin NAm. 1999; 10:9-15. 
Krayenbühl H, Yaşargil MG, McClintock HG. Treatment of spinal cord vascular malformations by surgical excision. J Neurosurg. 1969; 30:427-35.

Krolak-Salmon P, Moreau T, Bouhour F, Bascoulergues Y, Secchi T, Confavreux C. Simultaneous medullar and cutaneous revelation of a cutaneomeningospinal angiomatosis. Eur Neurol. 1999; 41:170-1.

Kunk Z, Bret J. Diagnosis and treatment of vascular malformations of the spinal cord. J Neurosurg. 1969; 30:436-45.

Larsen DW, Halbach VV, Teitelbaum GP, McDougall CG, Higashida RT, Dowd CF, Hieshima GB. Spinal dural arteriovenous fistulas supplied by branches of the internal iliac arteries. Surg Neurol. 1995; 43:35-41.

Larsen DW, Halbach VV. Endovascular therapy: indications and general principles. In: Barrow DL, Awad IA, editors. Spinal vascular malformations. Park Ridge: American Association of Neurological Surgeons; 1999. p.85-101.

Lazorthes G, Poulhes H, Bastide G, Roulleau J, Chancholle AR. La vascularisation artérielle de la moelle. Recherches anatomiques et applications à la pathologie médullaire et à pathologie aortique. Neurochirurgie. 1958; 4:3-19.

Lazorthes G. Blood supply and vascular pathology of the spinal cord. In: Pia HW, Djindjian R editors. Spinal angiomas: advances in diagnosis and therapy. New York: Springer-Verlag; 1978. p.1-17.

Lee TM, Gromelski EB, Bowen BC, Green BA. Diagnostic and surgical management of spinal dural arteriovenous fistulas. Neurosurgery. 1998; 43:242-6. 
Lhermitte J, Fridbourg-Blanc A, Kyriaco N. La gliose angéio-hypertrophique de la moelle épinière (myélite nécrotique de Foix-Alajouanine). Rev Neurol. $1931 ; 2: 37-53$.

Logue V. Angiomas of the spinal cord: review of the pathogenesis, clinical features and results of surgery. J Neurol Neurosurg Psychiatry. 1979; 42:1-11.

Luessenhop AJ, Cruz TD. The surgical excision of spinal intradural vascular malformations. J Neurosurg. 1969; 30:552-9.

Malis L. Arteriovenous malformations of the spinal cord. In: Youmans J, editor. Neurological surgery. A comprehensive reference guide to the diagnosis and management of neurological problems. $2^{\text {nd }}$ ed. Philadelphia: WB Saunders; 1982. p.1850-74.

Markert JM, Chandler WF, Deveikis JP, Ross DP. Posterolateral cervical or thoracic approach in the surgical treatment of an intradural ventral cervical spinal cord vascular malformation: technical case report. Neurosurgery. 1996; 38:412-5.

Marsh WR. Vascular lesions of the spinal cord: history and classification. Neurosurg Clin N Am. 1999; 10:1-8.

Martin NA, Khanna RK, Batzorf U. Postero lateral cervical or thoracic approach with spinal cord rotation for vascular malformations or tumors of the ventrolateral spinal cord. J Neurosurg. 1995; 83:254-61.

McCormick, WF. The pathology of vascular ("arteriovenous") malformations. J Neurosurg. 1966; 24:807-16. 
McCutcheon IE, Doppman JL, Oldfield EH. Microvascular anatomy of dural arteriovenous abnormalities of the spine: a microangiographic study. $J$ Neurosurg. 1996; 84:215-20.

Meder JF, Devaux B, Merland JJ, Frédy D. Spontaneous disappearance of a spinal dural arteriovenous fistula. AJNR Am J Neuroradiol. 1995; 16:2058-62.

Merland JJ, Chiras J, Riché MC. Arteriovenous malformations of the posterior wall of the thorax and abdomen. J Neuroradiol. 1979; 6:221-9.

Miyamoto S, Kikuchi H, Karasawa J, Ikota T, Nagata I. Spinal cord arteriovenous malformations associated with spinal aneurysms. Neurosurgery. 1983; 13:577-80.

Morgan MK, Marsh WR. Management of spinal dural malformations. $J$ Neurosurg. 1989; 70:832-6.

Morgan MK. Outcome from treatment for spinal arteriovenous malformation. Neurosurg Clin N Am. 1999; 10:113-9.

Moseley IF, Tress BM. Extravasation of contrast medium during spinal angiography: a cause of paraplegia. Neuroradiology. 1977; 13:55-57.

Mourier KL, Gobin YP, George B, Lot G, Merland JJ. Intradural perimedullary arteriovenous fistulae: results of surgical and endovascular treatment in a series of 35 cases. Neurosurgery1993; 32:885-91.

Nichols DA, Rufenacht DA, Jack Jr CR, Forbes GS. Embolization of spinal dural arteriovenous fistula with polyvinyl alcohol particles: experience in 14 patients. AJNR Am J Neuroradiol. 1992; 13:933-40.

Niimi Y, Berenstein A, Setton A, Neophytides A. Embolization of spinal dural arteriovenous fistulae: results and follow up. Neurosurgery. 1997; 40:675-83. 
Niimi $Y$, Berenstein A. Endovascular treatment of spinal vascular malformations. Neurosurg Clin N Am. 1999, 10:47-71.

Ohata K, Takami, T, El-Naggar A, Morino M, Nishio A, Inoue Y, Hakuba A. Posterior approach for cervical intramedullary arteriovenous malformation with diffuse-type nidus. Case report. J Neurosurg (Spine 1). 1999; 91:105-11.

Oldfield EH, Di Chiro G, Quindlen EA, Rieth KG, Doppman JL. Successful treatment of a group of spinal cord arteriovenous malformations by interruption of dural fistula. J Neurosurg. 1983; 59:1019-30.

Oldfield EH, Doppman JL. Spinal arteriovenous malformations. Clin Neurosurg. 1988; 34:161-83.

Ommaya AK, Di Chiro G, Doppman J. Legation of arterial supply in the treatment of spinal cord arteriovenous malformations. J Neurosurg. 1969; 30:679-92.

Osborn AG: Distúrbios não neoplásicos da coluna vertebral e da medula. In: Osborn AG, editor. Diagnóstico Neurorradiológico. Rio de Janeiro: Revinter; 1999. p.820-75.

Pia HW. Symptomatology of spinal angiomas. In: Pia HW, Djindjian R, editors. Spinal angiomas: advances in diagnosis and therapy. New York: Springer-Verlag; 1978a. p.48-74.

Pia HW. Operative treatment of spinal angiomas. In: Pia HW, Djindjian R editors. Spinal angiomas: advances in diagnosis and therapy. New York: Springer-Verlag; 1978b. p.137-60.

Regan EQ, Spencer D, Levy JM, Russel EJ. Spinal arteriovenous malformations. Case report. J Spinal Disord. 1991; 4:238-41. 
Renowden SA, Molineux AJ. Case report: spontaneous thrombosis of a spinal dural AVM (Foix-Alajouanine syndrome) - magnetic resonance appearance. Clin Radiol. 1993 ; 47 :134-6.

Riché MC, Melki JP, Merland JJ. Embolization of spinal cord vascular malformations via the anterior spinal artery. AJNR Am J Neuroradiol. 1983a; 4:378-81.

Riché MC, Scialfa G, Gueguen B, Merland JJ. Giant extramedullary fistula supplied by the anterior spinal artery: treatment by detachable balloons. AJNR Am J Neuroradiol. 1983b; 4:391-4.

Rodesch G, Hurth M, Alvarez H, Tadié M, Lasjaunias P. Classification of spinal cord arteriovenous shunts: proposal for a reappraisal - the Bicêtre experience with 155 consecutive patients treated between 1981 and 1999. Neurosurgery. 2002; 52:374-80.

Rodesch G, Hurth M, Ducot B, Alvarez H, David P, Tadié M, Lasjaunias P. Embolization of spinal cord arteriovenous shunts: morphological and clinical follow-up and results - review of 69 consecutive cases. Neurosurgery. 2003; 53:40-50.

Rogano LAC. Dor crônica decorrente de mielopatias: aspectos clínicos e terapêuticos [tese]. São Paulo: Universidade Federal de São Paulo, Escola Paulista de Medicina; 2001.

Rosenblum B, Oldfield EH, Doppman JL, Di Chiro G. Spinal arteriovenous malformations: a comparison of dural arteriovenous fistulas and intradural AVMs in 81 patients. J Neurosurg. 1987; 67:795-802.

Rosenwasser RH, Armonda R. Spinal vascular malformations: normal anatomy, diagnostic angiography and angiographic classification. In: Barrow 
DL, Awad IA, editors. Spinal vascular malformations. Park Ridge: American Association of Neurological Surgeons; 1999. p.23-35.

Rosner B. Fundamentals of Biostatistics. $2^{\text {nd }}$ ed. Boston: PWS Publishers; 1986.

Russel DS, Rubinstein LJ. Pathology of tumors of the nervous system. $5^{\text {th }}$ ed. Baltimore: Williams \& Wilkins; 1989.

Sargent P. Haemangeioma of the pia matter causing compression paraplegia. Brain. 1925; 48:259-67.

Seldinger S.I. Catheter replacement of the needle in percutaneous arteriography. A new technique. Acta Radiol. 1953; 39:368-76.

Shiozawa Z, Tanaka Y, Makino N, Sugita K. Spinal cord angiography using 4X magnification. Radiology. 1978; 127:181-4.

Song JK, Viñuela F, Gobin YP, Duckwiller GR, Murayama Y, Kureshi I, Frazee JG, Martin NA. Surgical and endovascular treatment of spinal dural arteriovenous fistulas: long-term disability assessment and prognosis. $J$ Neurosurg (Spine 2). 2001; 94:199-204.

Spetzler RF, Zabramski JM, Flom RA. Management of juvenile spinal AVM's by the embolization and operative excision. Case report. J Neurosurg. 1989; 70:628-32.

Spetzler RF, Detwiler PW, Riina HA, Porter RW. Modified classification of spinal cord vascular lesions. J Neurosurg (Spine 2). 2002; 96:145-56.

Stein B, Solomon RA. Arteriovenous malformations of the spinal cord. In: Youmans J, editor. Neurological surgery. A comprehensive reference guide to the diagnosis and management of neurological problems. $3^{\text {rd }}$ ed. Philadelphia: WB Saunders; 1990. p.1918-33. 
Steinmetz MP, Chow MM, Krishnaney AA, Andrews-Hinders D, Benzel EC, Masaryk TJ, Mayberg MR, Rasmussen PA. Outcome after the treatment of spinal dural arteriovenous fistulae: a contemporary single-institution series and meta-analyses. Neurosurgery. 2004; 55:77-88.

Stiver SI, Ogilvy CS. Spinal dural arteriovenous fistulas. In: Barrow DL, Awad IA editors. Spinal vascular malformations. Park Ridge: American Association of Neurological Surgeons; 1999. p.115-33.

Suzuki J, Onuma T. Intracranial aneurysms associated with arteriovenous malformations. J Neurosurg. 1979; 42:742-6.

Symon L, Kuyama H, Kendall B. Dural arteriovenous malformations of the spine. Clinical features and surgical results in 55 cases. J Neurosurg. 1984; 60:812-7.

Taylor CL, Selman WR, Ratcheson RA. Steal affecting the central nervous system. Neurosurgery. 2002; 50:679-89.

Théron J, Cosgrove R, Melanson D, Ethier R. Spinal arteriovenous malformations: advances in therapeutic embolization. Radiology. 1986; 158:163-9.

Thompson BG, Oldfield EH. Spinal arteriovenous malformations. In: Youmans J R, editor. Neurological surgery. A comprehensive reference guide to the diagnosis and management of neurological problems. $5^{\text {th }} \mathrm{ed}$. Philadelphia: WB Saunders; 2004. p.2375-420.

Tomlinson FH, Rüfenacht DA, Sundt TM, Nichols DA, Fode NC. Arteriovenous fistulas of the brain and the spinal cord. J Neurosurg. 1993; 79:16-27. 
Toole JF. Afecções dos vasos da medula espinhal. In: Toole JF, editor. Distúrbios cerebrais de origem vascular. São Paulo: Livraria Santos Editora; 2002. p.507-19.

Touho H, Karasawa J, Shishido H, Yamada K, Shibamoto K. Successful excision of a juvenile-type spinal arteriovenous malformation following intraoperative embolization. Case report. J Neurosurg. 1991; 75:647-51.

Turner OA, Kernohan JW. Vascular malformations and vascular tumors involving the spinal cord. A pathologic study of forty six cases. Arch Neurol Psychiatry (Chicago). 1941; 46:444-63.

Van Dijk JMC, TerBrugge KG, Willinsky RA, Farb RI, Wallace MC. Multidisciplinary management of spinal dural arteriovenous fistulas. Clinical presentation and long-term follow-up in 49 patients. Stroke. 2002; 33:1578-83.

Watson JC, Oldfield EH. The surgical management of spinal dural vascular malformations. Neurosurg Clin N Am. 1999; 10:73-87.

Willinsky R, terBrugge K, Montanera W, Wallace MC, Gentili F. Spinal epidural arteriovenous fistulas: arterial and venous approaches to embolization. AJNR Am J Neuroradiol. 1993; 14:812-7.

Willinsky $R$, terBrugge $\mathrm{K}$, Montanera W, Mikulis D, Wallace MC. Posttreatment MR findings in spinal dural arteriovenous malformations. AJNR Am J Neuroradiol. 1995 ; 16 :2063-71.

Wirth FP Jr, Post KD, Di Chiro G, Doppman JL, Ommaya AK. FoixAlajouanine disease. Spontaneous thrombosis of spinal cord arteriovenous malformation: a case report. Neurology. 1970; 20:1114-8. 
Wong JH, Kim JH, Awad, IA. Pathological features of spinal vascular malformations. In: Barrow DL, Awad IA, editors. Spinal vascular malformations. Park Ridge: American Association of Neurological Surgeons; 1999. p.9-21.

Yaşargil MG. Intradural spinal arteriovenous malformations. In: Vinken PJ, Bruyn GW editors. Handbook of clinical neurology. Stutgard: George Thieme Verlag; 1976. p. 481-523.

Zülch KJ. Brain tumors. Their biology and pathology. $3^{\text {rd }}$ ed. Berlin: SpringerVerlag; 1986. 
10. APÊNDICE 


\section{HOSPITAL DAS CLINICAS}

FACULDADE DE MEUICINA DA UNIVERSIDADE DE SĀO PAULO

CAIXA POSTAL, 3671

SÃO PAULO - BRASIL.

\section{DIRETORIA CLÍNICA}

\section{Comissão de Ética para Análise de Projetos de Pesquisa}

\section{APROVAÇÃO}

A Comissão de Ética para Análise de Projetos de Pesquisa - CAPPesq da Diretoria Clínica do Hospital das Clínicas e da Faculdade de Medicina da Universidade de S̆̈s Paulo, em sessão de 08.05.02, APROVOU o Protocolo de Pesquisa $n^{\circ}$ 048/02, intitulado: "Tratamento endovascular das malformações arteriovenosas raquimedulares: Resultados clínicos $e$ angiográficos", do Departamento de RADIOLOGIA, bem como o Termo de Consentimento Livre e Esclarecido.

Pesquisador(a) Responsável: DR. JOSÉ GUILHERME MENDES PEREIRA CALDAS

Pesquisador(a) Executante: DR. MARIO LUIZ MARQUES CONTI

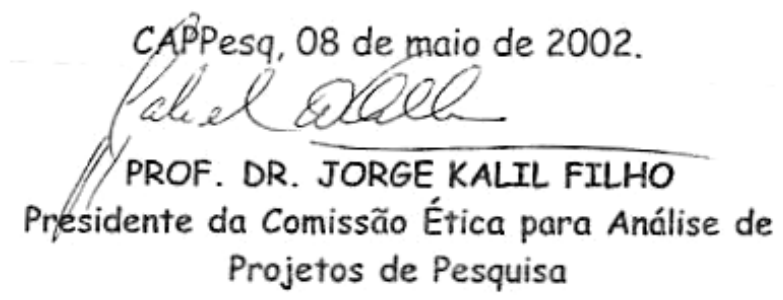

OBSERVAÇÃO: Cabe ao pesquisador elaborar e apresentar à CAPPesq, os relatórios parciais e final sobre a pesquisa (Resoluçẫo do Conselho Nacional de Saúde $n^{\circ} 196$, de 10.10.1996, inciso IX.2, letra "c"). 